\title{
Team level locus of control and competitive team behavior : an experimental study
}

Citation for published version (APA):

van Olffen, W. (1999). Team level locus of control and competitive team behavior : an experimental study. [Doctoral Thesis, Maastricht University]. Datawyse / Universitaire Pers Maastricht. https://doi.org/10.26481/dis.19990226wo

Document status and date:

Published: 01/01/1999

DOI:

10.26481/dis.19990226wo

Document Version:

Publisher's PDF, also known as Version of record

\section{Please check the document version of this publication:}

- A submitted manuscript is the version of the article upon submission and before peer-review. There can be important differences between the submitted version and the official published version of record. People interested in the research are advised to contact the author for the final version of the publication, or visit the DOI to the publisher's website.

- The final author version and the galley proof are versions of the publication after peer review.

- The final published version features the final layout of the paper including the volume, issue and page numbers.

Link to publication

\footnotetext{
General rights rights.

- You may freely distribute the URL identifying the publication in the public portal. please follow below link for the End User Agreement:

www.umlib.nl/taverne-license

Take down policy

If you believe that this document breaches copyright please contact us at:

repository@maastrichtuniversity.nl

providing details and we will investigate your claim.
}

Copyright and moral rights for the publications made accessible in the public portal are retained by the authors and/or other copyright owners and it is a condition of accessing publications that users recognise and abide by the legal requirements associated with these

- Users may download and print one copy of any publication from the public portal for the purpose of private study or research.

- You may not further distribute the material or use it for any profit-making activity or commercial gain

If the publication is distributed under the terms of Article $25 \mathrm{fa}$ of the Dutch Copyright Act, indicated by the "Taverne" license above, 


\title{
TEAM LEVEL LOCUS OF CONTROL AND COMPETITIVE TEAM BEHAVIOR
}

\author{
An experimental study
}


(C) W. van Olffen, Maastricht 1999

ISBN 9052782458

Druk: Datawyse/Universitaire Pers Maastricht 


\title{
TEAM LEVEL LOCUS OF CONTROL AND COMIPETITIVE TEAM BEHAVIOR
}

\author{
An experimental study
}

\section{PROEFSCHRIFT}

ter verkrijging van de graad van doctor aan de Universiteit Maastricht, op gezag van de Rector Magnificus, Prof. Dr. A.C. Nieuwenhuijzen Kruseman, volgens het besluit van het College van Decanen in het openbaar te verdedigen op vrijdag 26 februari 1999 om 14.00 uur

door

Woody van Olffen

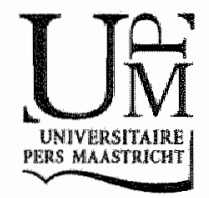




\section{Promotor:}

Prof. Dr. C. Boone

\section{Beoordelingscommissie:}

Prof. Dr. C.G. Koedijk (voorzitter)

Prof. Dr. B. De Brabander (Universiteit van Antwerpen, België)

Prof. Dr. H. Schreuder 
Wat leefbaar is op tekentafels, zet aan tor waanzim in her echt. In zijn vak was dat ook zo. Natuurlijk was [hij] gebaat bij een econometrisch model. Maar in de werkelijk besiaande economie leverde dat geen precieze instmmenten op. In het beste geval kon je de zichtbare geldstromen in kaart brengen. Nooit de ondersiromen, laat siaan de wissen erin."

Tom Lanoye - Her Goddelijke monster, p. 119. 



\section{Dankwoord}

Promoveren doe je in 'geleide eenzaamheid', zoekend naar de juiste balans tussen enerzijds eigen initiatief en spontaniteit en anderzijds leiding en doordachtheid. Daar heb ik nogal mee geworsteld in de afgelopen viereneenhalf jaar. Dat alles toch nog goed kwam is mede te danken aan de volgende mensen.

Allereerst mijn promotor, Christophe Boone, die mij doordrong van de idee dat economie een gedragswetenschap is, en als zodanig beoefend dient te worden. Zijn nauwgezette en kritische houding was soms pijnlijk maar altijd oprecht en leerzaam. Ik hoop op een lange en vruchtbare voortzetting van onze samenwerking. Op het persoonlijke vlak delen we een voorliefde voor tamelijk basale humor en het café. Door onze omgang betrap ik mijzelf regelmatig op Vlaamse intonaties en zinswendingen die aan zijn 'Aantwarreps geklap' ontleend zijn. Hoe dan ook, 'wat misschien begon als opportunisme is geëindigd in vriendschap': bedankt Charley!

Arjen van Witteloostuijn was degene die bijna zes jaar geleden zijn vertrouwen in mij uitte door me een baan als toegevoegd docent in afwachting van een AIO-project aan te bieden. Hij deed hetzelfde door het aanbod van een post doc baan nog vóór duidelijk was of ik de promotie-eindstreep wel zou halen. Bovendien leverde hij in de eerste anderhalf jaar een belangrijke bijdrage aan het tot stand komen van dit promotie-onderzoek. Arjen, bedankt voor de begeleiding en het vertrouwen. Moge de as Mastricht-Groningen waarlijk fortuinlijk blijken!

Dit onderzoek had niet op deze wijze uitgevoerd kunnen worden zonder de beschikking over betrouwbaar datamateriaal. $\mathrm{kk}$ ben zeer dankbaar dat MCC International b.v. in Amsterdam zo vriendelijk was om dit te leveren. In het bijzonder wil ik Ir. Jack Koster, één van de pioniers van het spel, bedanken voor de hartelijke en bereidwillige hulp. uitleg en ondersteuning, zélfs buiten kantoortijd. De ballen-gehakt-met-jus-op-brood in jullie bedrijfsrestaurant zal ik niet snel vergeten...

De dieptes in het AIO-bestaan werden vaak draaglijk gemaakt door de atmosfeer onder mijn collega's van de Sectie Organisatie. Gelukkig bezitten velen van hen (ik noem geen namen) een gezonde dosis humor en relativeringsvermogen: twee eigenschappen die onder wetenschappers helaas niet vanzelfsprekend zijn. Allen bedankt hiervoor. Ik will twee ex-collega's in het bijzonder dankzeggen. Ciska Bosman was gedurende ruim vier jaar mijn kamer- en lotgenote. Ze werd (mede) daardoor een vriendin wier professionele en emotionele steun wezenlijk voor mij en voor dit proefschrift was. Mijn andere belangrijke ex-collega is Robert van Well. Niet voor niets stond zijn paranimfschap al vier jaar vast. Gedurende onze gezamenlijke tijd als toegevoegd docent is onze vriendschap gegroeid tussen pinda's, 'kaboutertjes', Carrera, Supaplex en Deathmatches. O ja, en het onderwijs natuurlijk! Bedankt voor je stimulering, interesse en vriendschap. 
viii

Dank ook aan mijn familie en wrienden 'uit' Apeldoorn, Bristol, Delft, Den Bosch, Drunen, Eindhoven, Krimpen a/d Lek, Maastricht, Nice, Nuenen, Rijnsburg, Rotterdam, Steenwijk en Weert voor het feit dat mijn herhaaldelijk afslaan van jullie initiatieven en uitnodigingen vanwege dit boekje ons niet van elkaar heeft verwijderd (hoop ik...). Piety van der Nagel en Lennaert Stuy bedankt voor het leveren van belangrijke secretariële en grafische ondersteuning.

I $\mathrm{k}$ wil mijn ouders bedanken omdat zij een lastig, dwars en/of eigenwijs kind zodanig hebben weten op te voeden dat deze eigenschappen weliswaar niet verdwenen zijn (zo is mij verzekerd) maar wel in productieve banen werden geleid. Met het voorliggende resultaat.

En dan Selma: zij is met voorsprong mijn belangrijkste ontdekking van de afgelopen jaren. Een ontdekking, bovendien, die geen resultaat was van gericht zoeken maar van onvervalste serendipiteit. Z Zij geeft het begrip 'teamwork' een onvermoed diepe zin. To you, love!

Woody van Olffen

Maastricht, december 1998

' Dit is de kunst van het vinden waar je niet bewust naar op zoek bent. 


\section{Contents}

\section{Introduction}

1 General Introduction......................................................................... 3

2 Purpose of the Current Study............................................................. 4

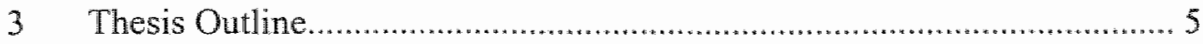

2 Top Management Team Composition: a Theoretical and Empirical Review

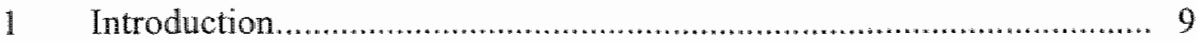

2 Theoretical Background................................................................ 9

2.1 Origins and Development of the Upper Echelons Model............. 9

2.2 TMT Variables and the Multiple Effects of Variety.................... II

2.3 The Model Refined............................................................... 14

3 Empirical TMT Composition Research.............................................. 15

3.1 Average Experiences............................................................ 15

3.2 Experience Variety ................................................................ 22

3.3 Summary of Average and Variety Effects..................................... 27

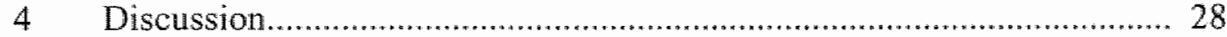

4.1 Limitations and Possible Extensions of Past Research.................. 29

$5 \quad$ Conclusion: the Model Completed..................................................... 32

\section{Locus of Control: Theoretical Background and Behavioral Implications}

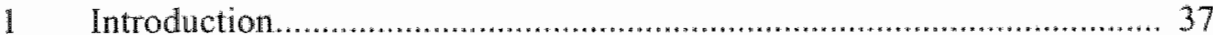

2 Theoretical Background................................................................ 38

2.1 The Importance of Perceived Control........................................... 38

2.2 Rotter's Social Learning Theory ............................................... 40

3 Behavioral Implications of Internal and External Control Perceptions.... 44

3.1 Locus of Control and Self-directed Behavior................................. 44

3.1.1 Learning How the World Works: Attention, Information Search and Information Assimilation............................... 45

3.1.2 Taking Concerted Action: Motivation and Persistence.... 47

3.1.3 Adaptation: Changing Behavior When Necessary........... 49

3.1.4 Achievement........................................................... 51

3.2 Locus of Control in a Social Context......................................... 52

3.3 Some Concluding Remarks on the Nature of Control Perceptions. 54

4 Summary and Outlook: Locus of Control in Management Studies.......... 55 


\section{Methodology and Data Description}

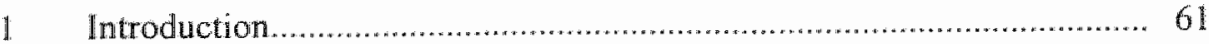

2 Research Setting............................................................................. 61

2.1 General Description and Motivation.......................................6. 61

2.2 Game Functioning and Organization......................................... 63

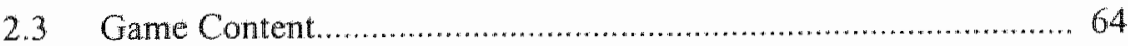

3 Data Collection and Sample Characteristics........................................... 66

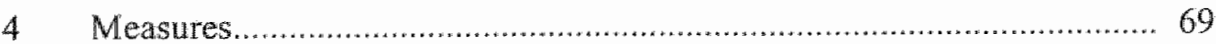

4.1 Tearn Level Control Perceptions................................................. 69

4.2 Environmental Dynamisn .................................................... 70

$5 \quad$ Some Technical Remarks................................................................ 71

5 Achievement: Team Locus of Control Composition and Economic

\section{Performance}

1 Introduction................................................................................ 75

2 Locus of Control and Managerial Effectiveness: Theory and Hypotheses 75

3 Results and Discussion................................................................ 79

3.1 Between Subject Analyses........................................................ 79

3.2 Within Subject Analyses........................................................ 84

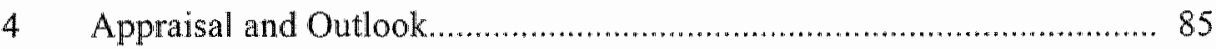

\section{Strategic Preferences}

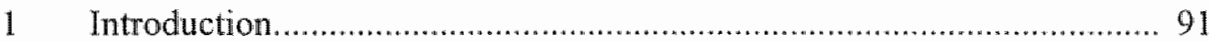

2 Teams' Strategic Preferences and the Locus of Control Trait................ 91

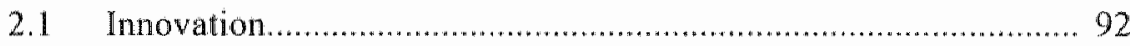

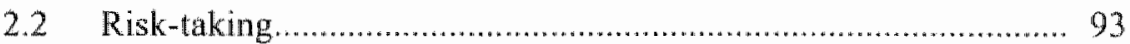

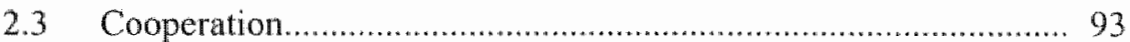

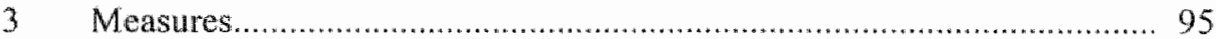

3.1 Innovative Activity: Product Quality Levels Through R\&D Investment .................................................................................. 95

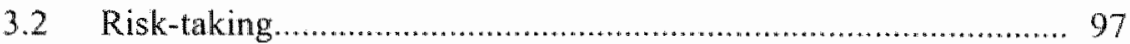

3.3 Cooperative Activity: R\&D Deals ............................................. 98

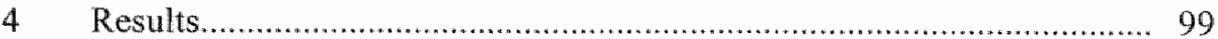

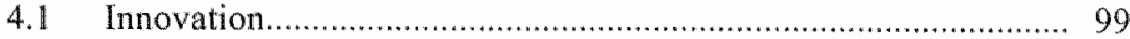

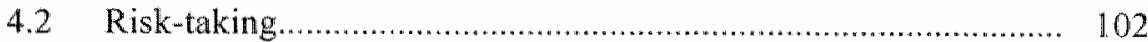

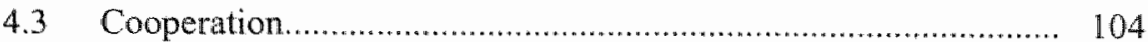

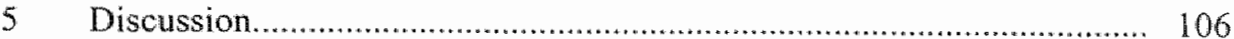


7 Strategy Making I: Informed, Planned and Consistent Action

1 Introduction .................................................................................... 115

2 Information search and Informed Action.......................................... 117

2.1 Theory and Hypotheses........................................................... 117

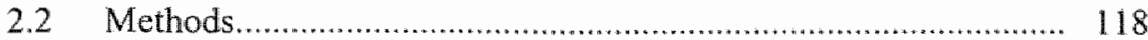

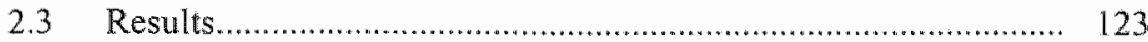

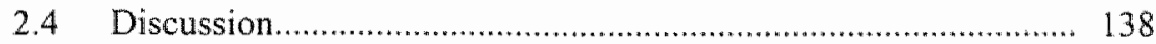

3 Planned Action................................................................................. 139

3.1 Theory and Hypotheses.............................................................. 139

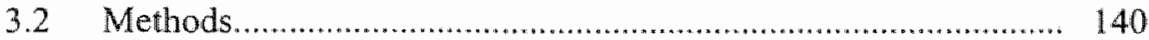

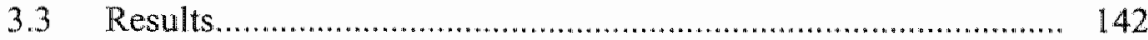

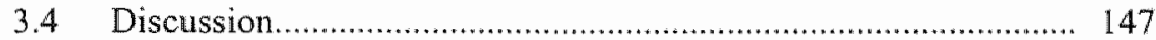

$4 \quad$ Consistent Action............................................................................... 147

4.1 Theory and Hypotheses............................................................ 147

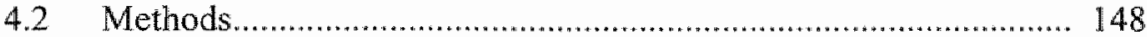

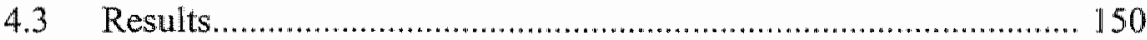

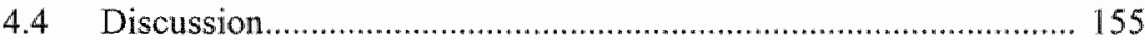

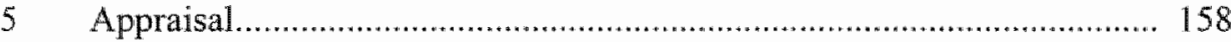

\section{Strategy Making II: Adaptive Action}

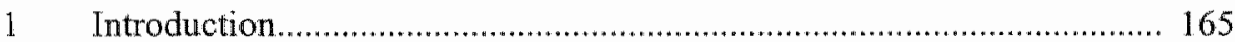

2 Theory and Hypotheses........................................................................ 166

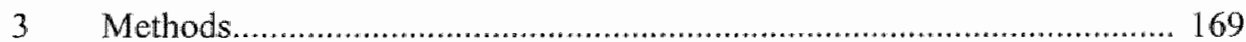

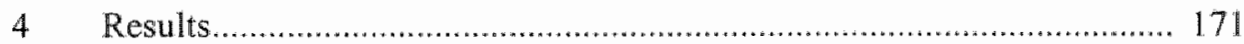

5 Discussion ......................................................................................... 181

\section{Summary, Conclusions and Outlook}

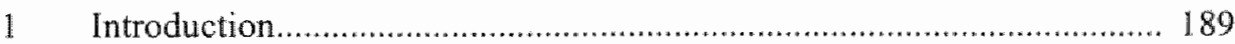

2 Summary of Study Setup and Findings ................................................ 189

3 Main Scientific Contributions............................................................ 192

$4 \quad$ Limitations and Future Research........................................................ 195

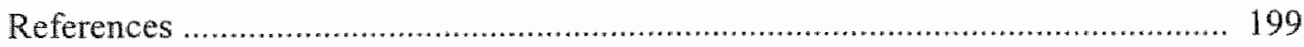

Summary in Dutch (Nederlandse samenvatting) …............................................. 209

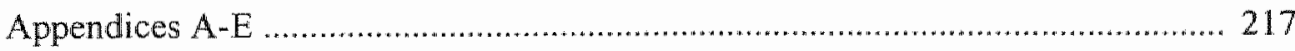

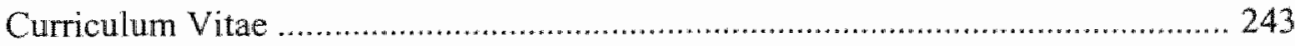



Introduction 

The interest in teams as a vehicle to improve the functioning of organizations has increased importantly in the last two decades. Indeed, this interest is mirrored not only in academic publications but in the more popular business press as well. Many books on teams and team functioning were and are still being published for a management readership dealing, with issues like team organization, team effectiveness and team management. A crude bibliometric analysis of the frequency of the team lemma in approximately 1000 international periodicals covering business and management indicates a sharp increase of interest in team related issues. In the 6-year period 1986-1991 the average annual count is about 1400 publications. The average annual counts in the biannual periods 1992-1993,1994-1995 and 1996-mid. 1998 are 2700,3400 and 5300, respectively. It is unclear what exactly inspired this sudden and overwhelmingly risen interest in teamwork in recent years. Popular business handbooks (e.g., Tjosvold, 1991) explain it by referring to intensifying (global) competition and the associated increase in environmental dynamism and uncertainty in business life. The need for fast and concerted organizational responses necessitates the integration of various parts of the organization into units that have far reaching autonomous decision power. As such the teamwork-trend can be linked to other business developments like de-layering, participative management and quality circles. As Tjosvold (1991: 1) puts it: "[M]echanical, bureaucratic, impersonal ways of working are giving way to lean, entrepreneurial ones. Teamwork is needed to make these new ways of managing and organizing effective". Still, it is probably fair to say that the entire current wave of popular teamwork literature does not add much to our understanding of teams and team functioning. Theoretically, it largely represents old wine in new bottles and mainly draws upon a decades-old research tradition of (working) groups in social and industrial psychology. For instance, the studies by the Tavistock Institute in the late 40s (Trist and Bamforth, 1951) were among the first to demonstrate that following sheer Tayloristic principles of labor division may in fact go against workers' productivity by disrupting social and psychological ties among people. Thus, the attention was drawn first to the importance of workgroups at the shop floor. Coupled to the steady rise of group dynamics (Lewin, 1948) a firm basis was laid during the " 50 s for studying the impact of groups, group functioning and group composition in organizations. The results of these efforts are now an integral part of organization theory. A final important step in the development of team studies was the recognition of the importance of a specific group in organizations: its top group of administrators, who importantly influence the course and eventual fate of the organization (Child, 1972, 1974).

Economists stepped into the picture only after economic theories of organization were developed. Alchian and Demsetz (1972), for example, analyzed teamwork from an agency perspective in which team production is only justified when members of the team are able to yield an output larger than the sum of each individual contributor. The

\footnotetext{
'The source of this analys is is the ABU/NFORM database of management literature from 1986 until mid 1998.
} 
economic problem associated with team work thus centers around the difficulty of objectively assessing marginal inputs and outputs of individual team members (Ciborra, 1993). It is conceived as a problem of effective and efficient monitoring and rewarding of agents by principals. In these economic theories of the firm, and particularly in industrial organization (Tirole, 1988; Van Witteloostuijn, 1995), the firm has basically been viewed as a profit-maximizing production function. The emphasis has been on modeling competitive conditions in explaining organizational performance. Ten years ago, after a representative exposition on industrial organization's view of the firm, Tirole (1988: 50) argued that "this author feels and hopes that many of the conclusions of the theory of industrial organization will remain valid (at least at a descriptive level) when the profit-maximizing postulate is abandoned for a full-fetched model of internal organization". In addition, he plead for cross-fertilizing organization theory and industrial organization in order to advance our knowledge on the functioning of firms (Tirole, 1988: 4). The last decade, a vast and growing body of economic literature has emerged in which issues of internal organization are analyzed and the intersection between industrial organization and organization theory is explored (Holmstrom and Tirole, 1989). Although these economic models abandoned the concept of the firm as a black box, an effort advocated by many scholars (Tirole, 1988), they still treat decision makers as abstract depersonalized profit-maximizers, assuming that different decision makers behave exactly the same when confronted with the same decision situation.

\section{Purpose of the current study}

In this thesis we examine a key aspect of the internal organization - the features of a firm's top management team - in relationship to the team's actions and performance in a competitive context. As such, this inquiry is also an attempt to take up the challenge of merging external environment and internal organization arguments in the study of organizational performance. However, it departs from the standard economic assumption of homogeneity among decision makers by focusing on the effects of human varialion on economic outcomes. It is here that psychology has much to offer. In the context of this thesis, the argument is that the psychological make-up of a firm's dominant coalition - its top management team - may well be a key determinant of organizational actions and outcomes. We hope that the combination of this psychological driver of firm behavior with the economic theory of market competition will ultimately produce an economic-psychological theory of the firm that associates organizational performance with a two-edged explanation: the psychological make-up of (the top management team of) the firm and the economic forces from the competitive environment. We therefore examine, both theoretically and empirically, whether - and how - the psychological make-up of a firm's top management team can explain its market performance. By doing so, we hope to contribute to the development of an economic psychology of the firm. That is, firm behavior and performance are assumed to be determined by both economic and psychological forces - being primarily located outside and inside the firm, respectively. 
In focusing on the composition of top management teams we follow the surging interest in these issues in the management literature of the 1980s and 1990s. This literature has produced a significant number of studies dealing with the top management team - organizational action or performance relationship. However, this literature concentrates primarily on the performance consequences of the non-psychological features of top management team members, albeit with reference to the social psychology of group dynamics. In effect, in so far as psychological attributes are included, the focus has been on a single top manager - a firm's Chief Executive Officer (CEO).

Thesis outline

The thesis consists of two parts. The first part (Chapters 1-3) is theoretical in nature. The second part (Chapters 4-8) reports our empirical results. In Chapter 2 we will present a review of studies that deal with the impact of top management team composition on teams' functioning, choices and performance in business settings. From this we identify several limitations that characterizes research thus far. In particular, we will argue that too few attention thas been paid to the psychological features of top management teams. One such characteristic, managers' locus of control (Rotter, 1966) already has a longstanding and proven status in the study of individual businessmen and therefore seems a prime candidate for research at the team level. To illustrate the validity of this personality trait in management studies, it will be elaborately introduced in Chapter 3. By the end of Chapter 3 we will give a research model for studying the effects of management team composition with regard to its members' locus of control. This will be the guiding model for the rest of the thesis as it highlights the different aspects of tean choices and actions that may emanate from various team compositions. This concludes our theoretical section. The second part of the thesis is empirical in nature. First, in Chapter 4, we introduce our research setting, which is an international management game played by young managers throughout Europe in 1994. We will describe the game and its participants in detail. Chapters 5 to 8 represent the empirical core of the thesis. In Chapter 5 we focus on the team composition - performance rellationship to see whether differently composed teams show predictably different market performances. The purpose of the following three chapters is on explaining in more detail the mechanism that causes team performance differences to occur. Chapter 6 focuses on the possibility of differing content of strategies that varyingly composed teams may have, i.e., do different teams prefer to follow different strategies? Chapter 7 and 8 take a different stance, as they analyze whether team performance differences are rooted in the processes of making strategies, i.e., quite apart from their content. Specifically, in Chapter 7 we ask ourselves whether teams differ in dealing with information to support decisions, in the quality of planning efforts or in the consistency of their action repertoires. A final aspect of strategy making will be explored in Chapter 8 , when we look at differences in adaptive behavior between teams. Here, we explore whether teams show differences in reorientation in function of environmental developments and feedback on their own results. Finally, Chapter 9 concludes the study by drawing conclusions and sketching future research possibilities. 
Top management team composition:

A theoretical and empirical review 

The purpose of the present chapter is to provide a theoretical and empirical review of top management team (TMT) composition research. This research is theoretically inspired by the old tradition of group dynamics research (e.g., Lewin, 1948; 1951) and later insights into the effects managers have in shaping the course and fates of organizations (e.g., Child, 1972). Throughout this chapter we will develop a conceptual model linking team composition, behavior and results. This model will provide the basis for our empirical analyses in subsequent chapters. The current chapter is structured as follows. First, in section 2, we introduce the theoretical background of present TMT composition studies and their theoretical antecedents in the decision-making insights of the Carnegie School, strategic choice theory and group dynamics. A model is presented that underlies socalled upper echelons research into the effect of TMT composition on organizational outcomes. We will describe the kinds of variables typically used in upper echelons studies to characterize a team: team averages and team variety. A major theoretical debate will then be introduced on the different effects of member variety in a team. Based on this discussion we will make a first refinement to the original upper echelons model. Next, in section 3, we give a summary of empirical research into team composition variables that have received most attention in TMT studies so far, such as averages and spreads in age, tenure and educational or functional background. Section 4 provides a critical discussion of the empirical findings in relation to the model and identifies some theoretical and empirical shortcomings in the research carried out so far. From this discussion a final analytical model is derived for studying TMT composition, strategic choices, processes and results. This model will serve as a basis for the rest of this thesis.

\section{Theoretical background}

\subsection{Origins and development of the upper echelons model}

Although group dynamics research has a long history in social psychology, the systematic linking of characteristics of a group of top managers to organizational results was only started in the first half of the 1980s. In their seminal paper, Hambrick and Mason (1984: 193) argued for "a new emphasis in macro-organizational research: an emphasis on the dominant coalition of the organization, in particular its top managers". Their call was followed by a large number of TMT studies. However, the claim that studying the role of the dominant organizational coalition would be a worthwhile undertaking was by no means new.

Based upon the theorists of the Carnegie School (Cyert and March, 1963; March and Simon, 1958), it had long been acknowledged that decisions in organizations are taken by boundedly rational people. The bounds on people's rationality, according to the Carnegie theorists, are brought about by the limited ability of individuals to process all information relevant for taking decisions in complex environments. Therefore, in order to cope with complexity, managers process only part of the relevant stimuli and filter information according to their own cognitive base. This base is composed of assumptions 
about future events, knowledge of alternatives and the consequences of alternatives (March and Simon, 1958). A person's cognitive base is formed by individual life experiences, including formal training and work history. Therefore, it is argued that a manager's specific perception of and response to environmental stimuli will partly depend upon the experiences (s)he has had during her/his life - that is, on her/his personal demography. The Carnegie School thus largely demystified the manager as a rational actor in the traditional sense of an objective optimizer but instead linked the decision maker"s individual constitution to the choices (s)he makes. The connection between managerial choices and outcomes was made in the early $70 \mathrm{~s}$, when strategic choice theorists (Child, 1972; 1974) developed and successfully tested the idea that company performance is not completely externally determined by market influences. Rather, managerial choices and strategies can play an important role in explaining differences in performance between organizations in comparable contexts.

The important contribution of Hambrick and Mason (1984) was to point at the potency of - and to stimulate systematic empirical research into - demographic variables like age, gender, and functional, educational and socio-economic backgrounds of the executive team in directly explaining a variety of organizational outcomes. Specifically, they provided an agenda to research the effects of these top management characteristics on organizational attributes such as types of strategies, extent and type of diversification, innovativeness and ultimately growth and variability in profit. Moreover, they underlined the relevance of existing social-psychological research into group heterogeneity or diversity for the study of top management teams. In this way, they linked the research tradition of group dynamics with that of strategic choice in the context of a specific type of groups: top management teams. This viewing of organizational strategic choices and performance levels as determined by managerial background characteristics was coined the upper echelons perspective.

In Hambrick and Mason's model (1984), shown in figure 2.1 below, two classes of managerial characteristics are distinguished: one observable, including personal and group demographic variables, and one psychological, including the individual's cognitive base and values. Combined, they influence the strategic choices TMTs make.

\section{Figure 2.1: The original upper echelons model}

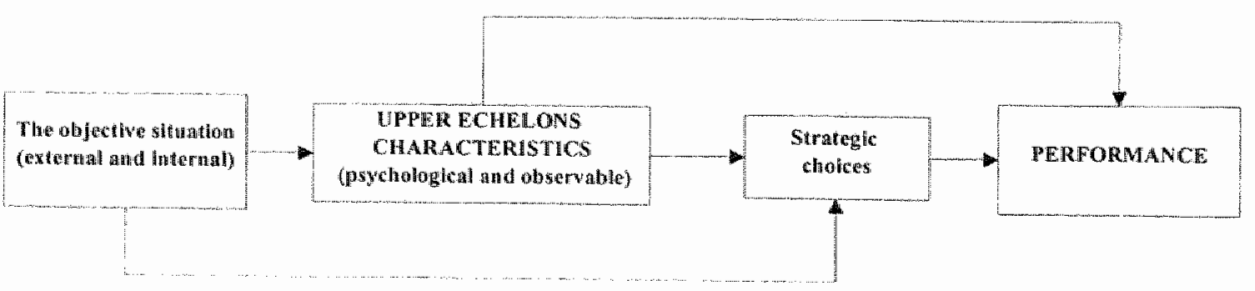


These choices range from acquisition and product innovation decisions to issues of administrative structure and hierarchical authority. In tum, these choices produce organizational performance in terms of profit (variability), growth and survival. Hambrick and Mason (1984) argue that the TMT's influence on performance nuight come in two ways: direct and indirect. Two hypothetical examples will ilustrate these effects. As for the direct effect, longer tenured teams may have so much industry experience that their response time to an arising strategic problem is condensed compared to that of a shorter tenured team which needs prolonged time to process information and sort things out. Therefore, although their ultimate strategic choice may be the same, the quicker response of the experienced team may contribute more to organizational performance than the relatively inexperienced team's lagged reaction. Note that with these direct effects it is not the particular choice but aspects of team processing and functioning that influence performance. Indirect effects arise when different team characteristics lead to different strategic choices and, consequently, different outcomes. Teams composed largely of people with economic business training may react differently to increased foreign competition compared with a team of technocrats. The former may be inclined to counter by cutting prices, whereas the latter may prefer to react by changing product designs to deliver higher perceived value.

Another important aspect of Hambrick and Mason"s model is that the objective external and internal situation is included as well. Three reasons can be given for this. First, the objective situation co-determines which people rise to the top. Internal political processes and external industry norms place restrictions on people's upward mobility in organizations (Pfeffer, 1983). For example, technical industries, such as chemicals, tend to be dominated by managers holding technical degrees. Second, the nature and structure of an industry have a direct impact on strategic choices regarding such issues as acquisition, capital intensity and integration (Porter, 1980). Third, external and internal situational factors may impose important restrictions upon the maneuvering space of managers as to their strategic choices. Societal pressure groups, legislation, market evolution, powerful boards of directors and/or company councils may severely limit the degrees of freedom upper echelons have in deciding on critical matters. This maneuvering space is generally referred to as managerial discretion (Hambrick and Finkelstein, 1987). It is an important interaction variable in the general model by determining whether the effects of TMT characteristics on organizational outcomes will materialize. So, to sum up, in the upper echelons model psychological and observable characteristics of the TMT determine performance directly via team processes and indirectly via the strategic choices they lead to. The objective situation, both internal and external, also bears a direct infuence on the characteristics of the TMT and on the strategic choices made. The team aspects that are of particular interest in TMT studies are discussed in the next paragraph.

\subsection{TMT variables and the multiple effects of variety}

Upper echelons studies employ a number of variables measuring aspects of the TMT that can be classified under two headings. First, we can look at the average or level of specific attributes of the team members, an example being average tenure. We may then 
theorize on how teams with different average tenures may differ in their behavior and performance. These team-level hypotheses then, are merely extrapolations of what is expected and/or known at the individual level. For instance, as long-tenured employees tend to develop rigid behavioral patterns and frames of reference, the same is expected of teams with long average tenure (Wiersema and Bantel, 1992). Second, we can focus on the spread or distribution of specific team members" attributes - for example in case we are interested in how age differences in teams affect processes and results of team interactions. Teams, then, can be either homogeneous (low spread) or heterogeneous (high spread) with regard to such characteristics. When it comes to the spread or variety of attributes (age, tenure, education) hypothesis generation is much more complex than it was in case of the averages where extrapolation to the team level sufficed. The reason is, that in case of variety, groups encounter specific problems in dealing with their inequality per se, that is, independent of the specific attribute on which they differ. Therefore, we will have a closer look at the effect homogeneity or heterogeneity of teams has on their functioning and performance. Two theoretical perspectives on this issue can be distinguished. The first will be llabeled the process facilitation perspective, which underscores the importance of homogeneity; the second is the resource diversity perspective, advocating heterogeneity. Both perspectives are discernable and recurrent throughout all hypothesizing on variety effects in the upper echelons studies we will encounter in the empirical section. We will treat the effects subsequently below.

\section{The process facilitation perspective}

Homogeneity at the group level means that group members are alike with regard to important attitudes and values. This similarity may be caused by the members being of roughly the same cohorts (Pfeffer, 1983). This implies that members in homogeneous groups share important dates (Ryder, 1965) and, consequently, life experiences. They were, for example, raised in the same era, studied in comparable school systems, entered the labor market under similar circumstances and have comparable careers. Moreover, at any point in time they probably share similar life stage experiences such as marrying, raising children, losing parents, et cetera. In fact, empirical studies in social psychology have demonstrated that people who are alike in attitude and socio-economic status tend to be attracted more to each other and exchange a larger number of positive reinforcements (Byrne, Clore and Worchel, 1966) than people who are different in these respects. When those relatively similar people form a group, they are therefore expected to show greater social integration and cohesion because they share important frames of reference, attitudes and values (McCain, O'Reilly and Pfeffer, 1983; Wagner, Pfeffer and O'Reilly, 1984). In effect, a positive association between homogeneity and cohesion was shown in several group studies including top management teams (Katz, 1982; O'Reilly, Caldwell and Barnett, 1989). Similar frames of reference among team nembers facilitate communication frequency and effectiveness (Wagner, Pfeffer and O'Reilly, 1984; Zenger and Lawrence, 1989), which is, in turn, thought to produce superior team social integration and, ultimately, organizational performance (Smith et al., 1994).

There is, however, a dark side to homogeneity. It was already noted that homogeneity generally enhances cohesion and social integration. Moreover, cohesive groups 
reveal greater conformity (Lott and Lott, 1961). This may imply that social acceptability is maintained at the cost of lower criticism towards other group members and their contributions and also a decreased ability to critically evaluate (strategic) alternatives and environmental developments. The group becomes less open to absorbing information (Whitney \& Smith, 1983) and discussing novel behavioral patterns. This set of group pathologies is well documented under the name of groupthink (Janis, 1972), involving a general decrease in mental efficiency by which the desire for consensus and group unity in cohesive groups overrides the realistic appraisal of altemative courses of action. In their fear of 'rocking the boat", victims of groupthink tend to conform to the communis opinio within the group even if privately they have serious doubts about its correctness. This may lead to escalating commitment to existing choices and strategies (Brockner, 1992), especially when these were successful in the past (Hambrick, Geletkanycz and Frederickson, 1993).

\section{The resounce diversity perspective}

If a group faces a complex decision environment, team performance may benefit from having a wide range of viewpoints that can be discussed and evaluated critically. In order to cope with the multi-faceted issues that arise in a complex environment, solutions must be ingenious. Team heterogeneity is likely to facilitate the 'production' of such a wide spectrum of perspectives. As people are the carriers of cognitive capacities and as there are limits to the cognitive complexity an individual can handle (Cyert and March, 1963), every team member can provide only part of the diversity needed to solve the problem. The cognitive resources must therefore be pooled to solve complex dilemmas: teams should be diverse to accomplish this. Empirical research indeed reveals that in solving complex and non-routine problems groups are more effective when composed of members with a variety of skills, knowledge, abilities and perspectives (Filley, House and Kerr, 1976; Shaw, 1981; Wanous and Youtz, 1986). Especially innovation seems to be enhanced by heterogeneity of team members (Bantel and Jackson, 1989; Katz, 1982; Murray, 1989). Diversity with regard to psychological types is also advocated (Belbin, 1981; Blaylock, 1983; Hurst, Rush and White, 1989).

Nonetheless, heterogeneity has important drawbacks in relation to group processes. As team members have diverging frames of reference, attitudes and values, communication is hampered (McCain, O'Reilly and Pfeffer, 1983; Zenger and Lawrence, 1989). This, in turn, enhances the chances of conflicts, turnover (Wagner, Pfeffer and O'Reilly, 1984) and power struggles to occur (Pfeffer, 1983), attracting attention away from the immediate tasks of the group. According to group dynamics theorists, there is a tradeoff between group-maintenance and task-oriented behavior (Shaw, 1981). This means that the operational efficiency of the heterogeneous team in performing its tasks is threatened because much time and energy are required to overcome communication barriers and power games.

\section{A balance}

Relative homogeneity and heterogeneity endow the team with different strengths and weaknesses. On the positive side, homogeneity lowers communication barriers and eases 
member interactions, whereas heterogeneity provides creativity and innovativeness in problem solving. On the negative side, homogeneity can lead to apathy, non-responsiveness and a lack of critical spirit, while heterogeneity hinders effective communication and wastes resources (especially time) in power struggles. However, organizations and teams operate in different environments in which the pros and cons of team composition may have a diverging impact on organizational functioning and effectiveness. A.n important moderator is environmental turbulence. High turbulence in the organization's environment requires the organization to be creative in adapting to changing environmental demands. "This would call for a heterogeneous team regarding functional speciality, educational background andior personality. Conversely, a stable environment may require the task-orientedness of a homogeneous team. In addition, low turbulence decreases the necessity to be creative and imnovative. So, under specific environmental contingencies different team compositions may be waranted to arrive at a balance between homo- and heterogeneity effects that facilitate team performance most. A review of three decades of literature concerning the effects of diversity in different environments (Maznevski, 1994) suggests, that member diversity will only realize its potential and improve performance if members can understand each other and combine and build on each others' ideas, that is, if integration is achieved among the diverse members. For instance, a study by Abrahamson (1992) revealed that the companies most successful in entering a new market were those headed by TMTs high on both diversity and integration.

\subsection{The model refined}

Now that we have assessed the importance of the above processes in determining outcomes in teams, we are ready to incorporate them more formally in our own stylized model. See figure 2.2 .

Figure 2.2: Stylized model of composition effects

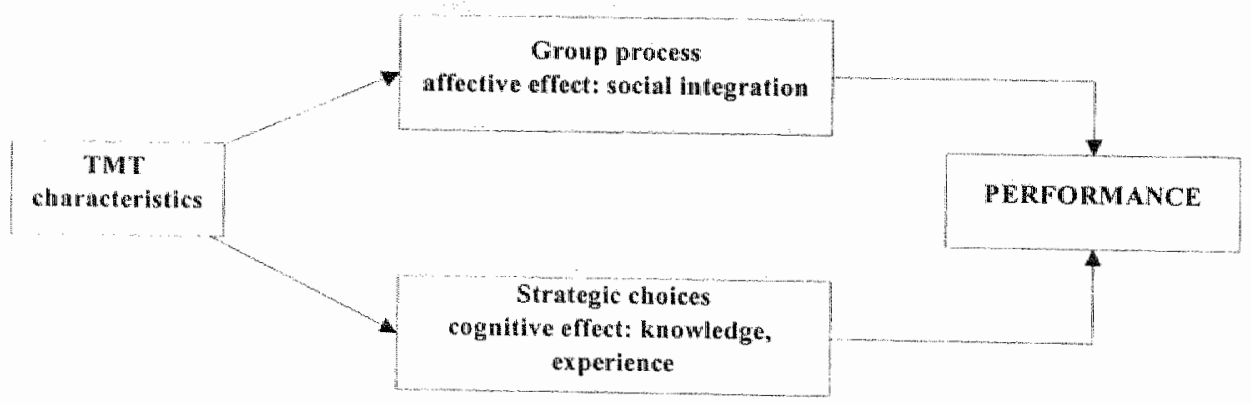

The direct path of Hambrick and Mason has now been replaced by the influence of team composition on the processes within the team. In accordance with the two perspectives above, team composition can have an affective effect (social integration) and a cognitive 
effect (breadth of perspective and creativity). Both effects will influence performance. For instance, poor communication in heterogeneous groups may delay decision making so as to miss opportunities; groups dominated by seniors may take more conservative strategic choices than juniors-dominated teams. From the present model, it should already be evident that many variables interact in determining the ultimate impact of group composition on performance. In the next section we will present the evidence on this matter.

\section{Empirical TMT composition research}

In the present section we will summarize the empirical research on TMT composition within the upper echelons framework. Thus, although we rely on a broader tradition of group (diversity) research to form our expectations, we will confront these with existing empirical findings in TMT settings. This means that in this review we will not deal with aspects of organizational diversity that, to our knowledge, have not yet been studied at the level of TMTs, like for instance race or ethnic background, nationality, gender and personality (see also Milliken and Martins, 1996). Instead we will report on the effects of compositional variables like age, tenure and functional experience that have attracted most attention so far. These compositional variables all touch in some way or the other on the amount (average) and diversity (heterogeneity) of experience the TMT contains by way of its members. Experiences can be diverse in nature. They may be life experiences (as in chronological age), team experiences (as in TMT tenure), organizational experiences (as in organizational tenure), industry experiences (as in industry tenure), functional experiences (as in member's functional backgrounds) and educational experiences (as in professional/educational background).

In the next two sections we will ask ourselves what effects may be expected of the average amounts (3.1) and variety (3.2) of experiences in TMTs and what the empirical evidence looks like. Section 3.3 summarizes the results.

\subsection{Average experiences}

Intuitively, high average experience in a team will improve its performance. This would be a simple human capital way of looking at it: the more experience people have in a certain area, the better they will be ablle to interpret their situation and the more effective they will be in dealing with the problems they confront. However, this way of reasoning tends to hold overly optimistic assumptions about people's memories and flexibility in interpreting and applying knowledge. In fact, experience tends to form frames of reference that may lead to habitual routines in interpreting and acting upon problems (Pfeffer, 1983; Finkelstein and Hambrick, 1990). If so, teams highly experienced in certain areas may have difficulty in handling the new and unexpected that occupy no place (yet) in the industrial, organizational or functional paradigm on which they act. In fact, they may not even notice it. Thus, high experience can both enhance and hinder performance partly depending on the flexibility needed. 
Team members' average age is likely to affect the functioning of teams for a number of reasons. First, when comparing teams of high versus low average age ${ }^{i}$ it is important to note that young teams were raised and educated in another epoch than old teams. Depending on the specific socio-economic situations that prevailed during their way to the top they will probably hold different values, outlooks and practices concerning their work. Thus, their behavior and results are likely to reflect their age. Assessing the impact. of these differing views on team results is however very difficult. To the present author's knowledge no empirical study has yet been undertaken to see what age-related differences in viewpoint between teams affect strategies and performance. Second, ageing seems to have a detrimental effect on cognitive faculties like learning ability, reasoning and memory (Botwinick, 1977; Burke and Light, 1981). This may generally have a negative bearing on executives' functioning as they get older. Third, younger managers were empirically found to have more favorable attitudes towards risk taking (Vroom and Pahl, 1971). Moreover, managerial youth is thought to be associated with much risky experimenting due to relative lack of experience. Thus, higher risk taking among younger managers, is a combined result of their risk taking attitude and the way they necessarily go about in learning the rules of the game. Older teams then, are thought to be characterized by a certain conservatism which, according to Hambrick and Mason (1984) is due to physical and mental limitations (Child, 1974), greater psychological commitment to the status quo (Stevens, Beyer and Trice, 1978) or financial and career security considerations (Carlssion and Karlsson, 1970).

These theoretical and empirical results have prompted researchers to hypothesize mainly on two issues in relation to the average age of team members (Hambrick and Mason, 1984). First, youth was expected to lead to the pursuit of risky strategies involving innovation and diversification ${ }^{2}$. This hypothesis was already backed by evidence mentioned above on younger managers' riskier attitude. Second, as successful innovation and diversification strategies will lead to expansion, companies experiencing above industry average rates of growth and profit are expected to be led by teams with relatively low average ages. Previous research does indeed suggest managerial youth to be associated with corporate growth (Child, 1974; Hart and Mellons, 1970), although the direction of causality in these models remains unclear.

Few recent empirical studies into the effects of average TMT member age exist. The research by Wiersema and Bantel (1992) (see Appendix A) lends support to the hypothesis that older teams lead companies experiencing less strategic change. However, in Bantel and Jackson's (1989) study the hypothesized direct association between average

\footnotetext{
'As a matter of convenience, a rather sharp distinction is made here berween "old" and "young" teams as measured by the in average chronological age. As with al "average effects" theory is largely an extrapolation of what is known at the individul level. Therefore, in describing the "pure" effects of thigh versus low age in teams, we lave to inplicitly assume spread to be low, This is a frequent but seldom acknowledged assumption in mosi studies.

2 Of course, the entrepreneurial type of diversification is meant here, as the kind of diversification inspired by portfolio
considerations is intended only to reduce risk.
} 
TMT age and innovativeness did not materialize. Instead, a negative spurious correlation existed: bigger companies both employed relatively young management teams and were more innovative. Generally, then, it appears that older teams are more hesitant in taking diversification risks, but not in taking innovation risks. A possible explanation may be that diversification is perceived strategically riskier because it leads the organization further from its established safe core domains than does innovation.

\section{Average tenure on the team}

The influence on performance of the time a certain (relatively) fixed group of people has worked together, is usually measured by taking the members' average team tenure. As people work together for a longer period of time, several related social processes begin to affect group behavior and especially communication. Katz (1982) suspected these tendencies in communication to play an important mediating role in the typical curvilinear relationship between average team tenure and project group performance that was found in previous research (Pelz \& Andrews, 1966; Smith, 1970): at first, average team tenure seems to enhance team performance, but after a certain (optimal) point, it depresses performance. Four processes are thought to occur as teams work together for a longer time. First, as groups start to structure their work, they will eventually develop standard work patterns or routines (Weick, 1979), that are predictable and comfortable to them. Groups will thus exhibit increasing behavioral stability over time. Moreover, with increasing group longevity, group members will tend to increasingly close off towards information that threatens to disrupt their comfortable and predictable practices and patterns of behavior (Staw, 1976). Second, long-standing membership leads to a phenomenon called selective exposure (Rogers and Shoemaker, 1971). This is a tendency for group members to communicate only with those whose ideas and viewpoints are in accord with their own interests and current perspectives. Outside messages and information conflicting with their established practices and dispositions are more likely to be avoided. Third, a relatively long history of shared experiences and socialization is likely to bind the group together by providing similar frames of references. Therefore, as team members continue to interact over time, the set of understandings about the group and its environment will become more homogeneous (Salancik and Pfeffer, 1978). Burke and Bennis (1961) showed, that consensus with one another increased among team members interacting over a longer period of time. All this has a positive influence on the group's sense of identity, but it will also demarcate the group more sharply from other groups in the organization. Consequently, the quantity and quality of inter group communication is likely to decrease with team longevity. Fourth, as team members work together for a long time, the tasks they have to perform are likely to be accomplished using a division of labor or role differentiation that is increasingly well tuned to members' individual strengths and weaknesses. Each member knows what to expect from others, and what is expected of him. This lowers the immediate necessity of task-related talk and interaction among team members (Porter, Lawler and Hackman, 1975). Taken together, over time interactions among team members and with members of other teams, are expected to decrease. 
In an important study among 50 R\&D project groups, Katz (1982) tested the above predictions concerning the effect of group longevity on cornmunication and performance. He found empirical support for the increased "closing off" of longer tenured teams from key information sources both within and outside their groups. Communication appeared to be significantly less in high-tenured teams as opposed to shorttenured tearns. In fact, with regard to contacts outside the project group, a curvilinear association was detected, indicating an initial increase and subsequent decrease in outside communications with increasing team tenure. More importantly, Katz did find these communication patterns to mediate the relationship between team age and team performance. Specifically, performance was curvilinearly related to team age because communication rose and fell with increasing team tenure. In explaining the form of this relationship, it is argued that in low tenure regions team building and learning promote performance as team members contribute fresh ideas and get to know each other's strengths better. After a certain amount of time, however, (about 2,5 years in Katz study) high longevity teams tend to "settle down", rely on routines and decrease overall communication. As a result performance deteriorates. In other words: his study demonstrates "the important role group longevity and its underlying social processes can play in influencing the information processing behaviors of project group members which, in turn, affect project performance" (Katz, 1982: 98).

From the empirical overview (see Appendix $\mathrm{A}$ ), it is clear that few researchers had a close look at TMT longevity as an influencing variable on performance. The positive effect team tenure has on strategic change was not expected by Wiersema and Bantel (1992). Instead, they drew on Katz (1982) in hypothesizing lower communication levels and consequently higher resistance to change in longer tenured teams. Possibly, they speculate, team longevity fosters social integration and more effective communication which in turn promotes performance. The positive effect on group dynamies and change seems to taper off, however, at higher levels of team tenure, indicating that, over time, teams in frequent interaction develop towards the "optimal" smooth group dynamics that ease strategic change. Eisenhardt and Schoonhoven (1990) discovered a strong positive effect of the joint prior work experience of founders on the success of new ventures. Again referral is made to heightened familiarity, cohesiveness and communication quality among groups having experience in working together. Finally, Smith et al. (1994) did not find any of the expected effects of team age.

On balance, then, results on TMTs are not very clear. Two studies do find a positive effect of average team tenure on performance-related variables while another does not. However, these results may very well hide the curvilinear relationship established so often in other group research. Regrettably, this relationship is not explicitly tested in any of the TMT studies. Moreover, authors are often unclear about the units of measurement and ranges of their average measures, making it difficult to compare results

\footnotetext{
3 In quoting empirical TMT research unto this relationship, authors (e.g., Smith et al., 1994) sometimes erroneously refer to studies that do not as a matter of fact deal with team tenure, but rather with the awerage organizational tenure of members within the team. In on empirical overview (see Appendix A) we only mentioned studies that explicilly dealt with the average tenure of members on the rem.
} 
of studies. Still, this drawback seems to characterize TMT research in general.

\section{Average tenure in the organization}

Long organizational tenures may be seen as the outcome of a self-selection process by which those adhering to the organizations" norms and perspectives are willing or allowed to stay in the firm (Pfeffer, 1983). Longer tenured managers are therefore more committed to the organizations' ways (Wanous, 1980), show higher commitment to the status quo (Alutto and Hrebiniak, 1975) and to the values of the firm (Schmidt and Posner, 1983). With organizational tenure, managers" rigidity and commitment to established policies and practices increases (Katz, 1982; Hambrick, Geletkanycz and Frederickson, 1993) as an action repertoire is built up over time that promotes behavioral stability (Finkelstein and Hambrick, 1990). Ever more reliance is put on experience instead of on new stimuli (Katz, 1982) and resistance to change and risk-aversion may become politically or emotionally motivated because of vested interests (Salancik, 1977; Miller and Friesen, 1980). Generally, then, some kind of conservatism in strategies and policies is expected.

Empirical team results (see Appendix A) demonstrate this conservatism of long tenured TMTs. Finkelstein and Hambrick (1990) found that higher average organizational tenures led firms to be more persistent and inflexible in their strategies. Moreover, these firms appeared to follow "middle of the road" strategies closely resembling those of competitors, resulting in performance levels close to industry averages. Similarly, Wiersema and Bantel (1992) find the amount of corporate strategic change to be related to low average organizational tenure. This apparent conservatism, however, is not necessarily reflected in lower levels of innovation (Bantel and Jackson, 1989) or in lower performance. In a matched sample of surviving and failing firms Hambrick and D'Aveni (1992) found that bankrupts' TMTs had lower and declining average organizational tenures during the years preceding their failure than their surviving counterparts, reflecting the higher turnover rate in this period. However, bankrupts" organizational tenures were already significantly lower five years before failure and it is doubtful whether this signals lower managing qualities of short tenured teams. More probably, it simply reffects the turmoil (scapegoating, replacements or voluntary departures) that is a wellknown tendency in troubled organizations (Hambrick and D'Aveni, 1992). Michel and Hambrick (1992) find a tendency for longer tenured TMTs to lead companies with a high degree of interdependence in business unit diversification. This result was expected as the integration, coordination and (especially) communication skills needed to manage interdependencies across business units would be fostered by more cohesive groups, allegedly TMTs with high organizational tenures. However, nor TMT organizational tenure, nor its interaction with the degree of interdependence appeared to affect performance. We may conclude that high organizational tenure TMTs tend to be rather conservative with regard to strategic choice and flexibility, leading to quite average organizational performance. 
Just like high organizational tenure, long tenures in a certain industry built shared interpretations and policy preferences that form a kind of 'industry wisdom". Several studies have shown the existence of these kinds of 'industry recipes' to managing a company within the industry (Spender, 1989; Hambrick, Geletkanycz and Frederickson 1993). As their industry tenure rises, managers show an increasing psychological adherence to these industry specific frames of reference. Therefore, they take on an increasingly prominent position in managers views on current problems. Despite the potential value of this in-depth industry familiarity (Gupta, 1984), too much industry experience may, just like organizational experience, restrict managers" awareness of alternatives and lead to 'conservative' policies close to industry standards. This point was clearly demonstrated in a study by Hambrick, Geletkanycz and Frederickson (1993) who did indeed find a strong association between industry tenure and top executives' commitment to the status quo concerning their organizations' future policies and leadership. Interestingly, the effect of industry tenure on commitment to the status quo appeared stronger than and independent of that of organizational tenure, suggesting a distinctive impact of industry experiences on conservatism. Unfortunately, the authors only report a small and insignificant positive simple correlation between CEO industry tenure and performance. Their call for team level research in this area has not yet been followed; consequently there is no empirical material to report on. Based on the foregoing, it does however make sense to expect average industry tenure to have similar effects as organizational tenure.

\section{Average educational level}

An individual's level of education reflects its cognitive abilities and skills. As such, it was shown to be positively associated with tolerance for ambiguity and information processing capacity (Schroder, Driver and Streufert, 1967; Dollinger, 1984). Because of this, higher educated people may be expected to "generate (and implement) creative solutions to complex problems" (Bantel and Jackson, 1989: 110) and indeed higher managerial education level appears consistently associated with the receptivity to innovation (Becker, 1970; Rogers and Shoemaker, 1971; Kimberly and Evanisko, 1981). These findings have inspired team researchers as well (see Appendix A). Bantel and Jackson (1989) found innovation to be greater in banks headed by more educated TMTs. Similarly, the mean educational level of a team appeared to be the strongest demographic predictor of strategic change in an heterogeneous sample of US manufacturing companies (Wiersema and Bantel, 1992). It may be speculated from this, that higher average educational levels on a team make it more prone to undertake highly consequential strategic decisions that help ensure survival in the long run. A (direct) connection between educational level and performance, however, was not researched.

\section{Main functional expertise}

Although a categorical variable like functional experience cannot be averaged (just like, 
for instance, race or nationality), teams can be rated according to the relative dominance of certain functional expertise represented in a team. Various studies in the strategy literature have shown that different strategies may require different functional skills for successful implementation (Hitt, Ireland and Palia, 1982; Snow and Hrebiniak, 1980). For instance, Gupta and Govindarajan (1984) reasoned that "build" strategies, required a managerial competence at monitoring and analyzing external industry characteristics like consumer needs and competitor strategies“ of managers with functional experience in marketing and sales. "Harvest" strategies on the other hand require skills to improve internal efficiency. Thus, the hypothesis was formulated that general managers with experience in marketing and sales would be more successful in implementing "build" rather than "harvest" strategies. This was indeed the case; moreover, implementation of harvest strategies even appeared to be hampered by managers' marketing or sales backgrounds. A relationship between individual managers' functional expertise and the required strategic expertise was also found by Song (1982) and Chaganti and Sambharya (1987). In the former study, CEOs of companies diversifying through internal growth had mainly followed marketing and operations careers, whereas the CEOs of acquisitive diversifiers tended to have finance, accounting and law backgrounds. Chaganti and Sambharya (1987) analyzed the functional orientations of high ranking managers of a prospector, analyzer and defender firm in the US tobacco industry over a period of 25 years.. As expected, the prospector firm had a higher percentage of executives with $R \& D$ and marketing backgrounds than the analyzer and defender firm; the defender firm employed the highest percentage of finance-oriented executives.

Turning from dominant functional backgrounds of individuals to core functions represented in managing teams, to date, only two studies exist. Michel and Hambrick (1992) expect teams managing more interdependent business units to need a higher proportion of top managers that understand the substantive rather than the strietly financial or administrative implications of their decisions. This understanding, they expect, is brought by core operational areas like marketing, operations and $R \& D$. The results of their analysis supports the contention that more interdependent businesses were led by teams with more core functional expertise. However, contrary to expectation, this match produced worse instead of better results, something the authors have difficulty in explaining. Hambrick and D'Aveni (1992) take a related point of departure. They stress the general importance of so-called 'core functional area's' like design, production and marketing in the survival of firms. Experience in these areas, it is argued, ensures executives with "hands-on" competencies that staff fields like accounting; finance, law and personnel do not provide (Hayes and Abernathy, 1980; Hambrick and D'Aveni, 1992). As compared to survivors, bankrupts did indeed have lower and declining levels of core functional expertise in their teams as they approached failure. It appears, then, that given the specific tasks of a TMT team, certain core expertise may prove critical in handing situations appropriately. 


\subsection{Experience variety}

As discussed in section 2.2, two opposing viewpoints exist as to the normative effects of team diversity. On the one hand diversity offers more diverse resources to confront complex problems. On the other hand it wastes resources: dissimilar people have more difficulty in working together because they lack common ground. An important moderator in determining the performance impact of diversity is the state of the environment. In complex and changing circumstances, diversity may have a premium, whereas in stable conditions homogeneity seems preferable. These main and moderated effects will be recurrent in the empirical experience variety studies below.

\section{Age variety}

People's outlook on the world is greatly determined by the historic events and societal values during their formative years (Eisenstadt, 1956). People from similar age cohorts are therefore likely to share important frames of reference inherited from their past, but present experiences are also likely to be similar. For instance, employees of the same age share the experience of important historical events (e.g., wars, crises, social developments), and are now probably raising children of the same age or tend to have other similar events occurring in their family lives. Shared biographies produce a shared language, including a common vocabulary and interpretation of events concerning a wide range of non work-related issues (Ryder, 1965). Because of these language compatibilities, people who share demographic attributes (in this case age) communicate more frequently (Byrne, 1969; Pfeffer, 1983; Zenger and Lawrence, 1989). They feel attracted to each other more and form more cohesive groups (Lott and Lott, 1965; Good and Nelson, 1971) which will generally lead to enhanced team performance (Shaw, 1981; Mullen and Copper, 1994; Smith et al., 1994). Teams of dissimilar age lack these integrating forces and are likely to run into communication problems that may result in power struggles, conflict (Pfeffer, 1983) and, ultimately, turnover. O'Reilly, Caldwell and Barnett (1989) even report a direct positive effect of group age heterogeneity on turnover: the relationship was not mediated by worsened social integration. ${ }^{5}$

In empirical TMT research (see Appendix A), two studies were concerned with these turnover effects. Wagner, Pfeffer and O'Reilly (1984) find a negative influence of individual age distances on the likelihood of individuals to stay in the team, a result that is in line with theory in that age similarity fosters interpersonal attraction and thus the likelihood of staying. The stimulating effect of TMT age heterogeneity on turnover was particularly strong in a sample of Japanese TMTs (Wiersema and Bird, 1993) allegedly because of Japanese' higher (cultural) sensitivity to interpersonal differences. Interestingly, in the TMT literature, age heterogeneity is also expected to provide the variety of

\footnotetext{
"This will only hold if the group's norms are set to high performance; otherwise even the opposite may occur
(Shaw, 1981). surprisingly, individual distance in age to other tean members lowered individual turnover, that is: more distant
members were less likely to tum over. This finding remaans ill understood.
} 
perspectives that may enhance inmovation and strategic change. However, neither of the two studies on this issue (Bantel and Jackson, 1989; Wiersema and Bantel, 1992) could detect these expected effects.

We conclude that age heterogeneity promotes turnover both at the individual and at the team level. A positive effect on strategic change and innovation was not found. No study directly examined the effect on organizational performance. However, as TMT tumover tends to precede (and follow) bad organizational performance (Hambrick and D'Aveni, 1992), it may be speculated that age heterogeneity is ultimately associated with low performance through its effect on turnover.

\section{Team tenure variety}

Homogeneity of tenures on the team suggests a shared socialization and group experiences that reinforce cohort effects (Wiersema and Bantel, 1992) including heightened cohesiveness and lower turnover. O'Reilly, Caldwell and Bamett (1989), for instance, show that team tenure homogeneity of work groups increases group level social integration, which in turn, restricts turnover in the team.

TMT studies (see Appendix A) were mostly concemed with these positive effects of team tenure diversity on tumover. Although the effect did not materialize in a US context study (Wiersema and Bantel, 1993) a study among Japanese TMTs (Wiersema and Bird, 1993) did show a strong positive impact of team tenure diversity on team tumover. According to Wiersema and Bird (1993) this is caused by a greater attention and sensitivity to differences among Japanese TMTs because they are substantially more homogeneous than US TMTs. What is more, Japanese' collectivist cultural values are likely to encourage conformity and heighten sensitivity to own and others' differences. Only Wiersema and Bantel (1992) formulated and tested an alternative expectation favoring heterogeneity of team tenures. They hypothesized that team tenure homogeneity leads firms to undertake less corporate strategic change, as it provides a group with less variety of information sources and outlooks to act upon. However, no support for this hypothesis was found. We can conclude that team tenure homogeneity tends to increase social integration and lower member turnover. Variety of team tenures does not seem to enhance strategic change.

\section{Organizational tenure variety}

Just like people of the same age colhort share life experiences, people of the same organizational cohort share many organizational experiences that over time lead to the development of similar beliefs and perspectives on the firm and how it operates (Pfeffer, 1983 ; Tushman and Romanelli, 1985; Wagner, Pfeffer and O'Reilly, 1984) This set of perspectives can be thought of as an organizational paradigm that is more congruent within groups of similar dates of entry. This congruence among organizational members on a team enhances interpersonal communication (Zenger and Lawrence, 1989) and cohesion (Lott and Lott, 1961; Katz, 1982). However, too much homogeneity may ultimately lead to groupthink (Janis, 1972): an urge to maintain good intragroup relations at the cost of 
realistic and critical appraisal of alternatives. This critical spirit is more likely to be maintained in a somewhat heterogeneous team, pooling long and short tenured people to provide more diverse opinions. Moreover, members who joined the organization at different times often have different technical skills and views on the organization. The diverse pool of these inputs may in fact improve the probability that a group will generate diverse and innovative solutions (Ancona and Caldwell, 1992) that lead to higher quality decisions (Wanous and Youtz, 1986). Thus, organizational tenure diversity is likely to influence group processes and outcomes in different ways.

In fact, this compositional variable is among the most popular ones studied in empirical TMT research (see Appendix A). Michel and Hambrick (1992) expect homogeneous TMTs to head firms having strongly interdependent business unit diversification postures. Homogeneity of tenures is thought to promote cohesion and high quality of ingroup communication that are in turn deemed necessary to manage interdependencies. In contrast to this hypothesis, they find that organizational tenure heterogeneity is associated with high interdependence. This unexpected result is attributed to a higher need for team continuation in high interdependence firms. This would be facilitated by staggered team membership around a high team tenure mean. In their own words, this would "[e]nhance stability and provide opportunities for the mentoring and grooming of heirs. The team recreates itself slowly, gradually engendering commitment to a core business, shared perspectives and perpetuation of a given strategy" (Michel and Hambrick, 1992: 30). We feel this is a rather far-fetched explanation where a much simpler alternative exists: managing high interdependence calls for the more varied repertoire of experiences in a heterogeneously tenured team. Anyway, the direct relationships with performance of firms, nor the interactions between interdependency and heterogeneity were significant.

As to the expected higher turnover among teams with heterogeneous organizational tenures, two studies are of interest. Wagner, Pfeffer and O'Reilly (1984) do indeed find the expected result in a US sample of TMTs. However, in the Japanese firms study by Wiersema and Bird (1993) organizational tenure heterogeneity is in fact the only temporal heterogeneity measure that does not have a (direct) effect on team turnover. The lack of significance for organizational tenure heterogeneity was caused probably by its association with a control variable, mean team age, which had a strong negative impact on turnover in Japanese firms. The latter is counter intuitive from a Western point of view and possibly reflects good job switching opportunities for young Japanese employees and/or a relluctance of incumbent dominant coalitions to share power by promoting young managers.

The idea that diverse tenures may promote creativity is reflected in two studies searching for a link with innovation (Bantel and Jackson, 1989) or strategic change (Wiersema and Bantel, 1992). However, neither study found heterogeneous organizational tenures to predict more innovation or corporate strategic change, possibly because organizational tenure heterogeneity does not adequately capture the underlying construct of creativity and information diversity. Finally, three studies linked organization tenure heterogeneity to corporate performance. Hambrick and D'Aveni (1992) found no difference in organizational tenure heterogeneity between survivors and bankrupts in the five years preceding failure, suggesting that this kind of heterogeneity is not associated with 
organizational decline nor with its successful management. Smith et al. (1994) did find a negative direct effect of TMT experience heterogeneity ${ }^{6}$, on the return of investment of high-technology firms, possibly indicating distracting and time-consuming conflict in these teams. New support was also found for the negative relationship between tenure heterogeneity and the amount of informal communication within the team. The third study, by Haleblian and Finkelstein (1993) ${ }^{7}$ again revealed a negative association between organizational tenure heterogeneity and a composite measure of firm performance. As can be expected, the relationship was most pronounced in the high discretion (computer) industry.

To summarize the above, heterogeneity of organizational tenures affects the team process mainly through more difficult communication, integration and (at least in Western countries) increased turnover. As to the eventual organizational outcomes, however, evidence is mixed. The influence this type of TMT variety on performance is at best neutral: it ranges from zero in case of survival chances to negative in case of financial econonic measures. In addition, no association between organizational tenure heterogeneity and strategic decisions like change and innovation seems to exist.

\section{Industrial tenure variety}

As discussed in the section on average industry tenure effects, experiences within an industry also tend to mould one's views on how (all) companies within it should be managed; consequently industrial paradigms may develop. As with the other variety effects, heterogeneity of industry tenures and experiences may lead to different interpretations and conflict whereas homogeneity fosters interpersonal understanding and cohesion. Industries in a rut, may however benefit from frame-breaking insights typically developed by more heterogeneous teams within the industry. However, these kinds of hypotheses on industrial tenure heterogeneity were never empirically tested in TMT settings.

\section{Educational background variety}

In contrast to the preceding variables, educational tracks measure cognition more directly because of a self-reinforcing choice and training process. Educational choices people make reflect their personalities, attitudes and cognitive styles (Holland, 1985). In turn, the chosen curriculum further shapes perspectives and outlooks in line with the professional profile it seeks to produce. Thus, whereas in case of age or tenure we have to infer a lot as to what attitudes it produces, educational tracks and their content are known and people graduating will be fairly homogeneous in the professional attitudes and outlooks

\footnotetext{
'In fact, Smith et al. (1994) used a composite measure of industry and organizational tenure heterogeneity, called experience heterogeneity.

7n this study, organizational tenure heterogeneity is included only as a control wariable "[t]o control for team effects and to ensure that the power distribution and team size variables were not confounded" (Haleblian and Finkelstein, 1993: 854). As to its effect on performance no expectation is stated.
} 
they were taught (which is a lot more difficult to say from life or organizational experiences). A TMT with diverse educational backgrounds (e.g., arts, sciences, business, engineering, etcetera) may be expected to benefit from these varying perspectives taken by its members, but it should again be mindfiul of the strains that the integration of various perspectives is likely to produce on the group process (Pfeffer, 1983). However, in a TMT study by Wiersema and Bantel (1993) the expected negative effect of educational diversity on turnover did not materialize. Other empirical TMT research (see Appendix A) has generally been rather mixed. The expected positive influence of educational heterogeneity on dynamic strategic choices was found for strategic change (Wiersema and Bantel, 1992), but not in case of innovativeness (Bantel and Jackson, 1989). As to performance, Smith et al. (1994) find a positive direct effect of the heterogeneity in TMT years of education on both ROI and sales growth and (again) no relation with process variables (communication and integration). This result supports the creativity argument that may be expected to be particularly influential in dynamic industries. However, note that these authors are actually measuring some kind of educational tenure heterogeneity, which does not necessarily imply a broad scope of different educationall tracks ${ }^{8}$. We should therefore treat this result cautiously and can only conclude that educational differences do not particularly hamper group processes and may have direct positive effects on performance and the propensity to strategic change.

\section{Functional background variety}

In a similar way as educational tracks, time spent in a particular department or function is likely to lead to the development of a viewpoint consistent with the activities and goals of that department or particular function. As a result, the usual problems and benefits of diversity would arise in varyingly composed groups. Empirical evidence on the effects hereof on performance, however, is mixed. Ancona and Caldwell (1992) found functionally diverse new product teans to perform worse, possibly because of social integration or communication difficulties that relate to function-specific frames of reference. To test their existence, Dearborn and Simon (1958) presented managers with a complex business case and found that "each executive will perceive those aspects of a situation that relate specifically to the activities and goals of his department" (op. cit.: 142). So selective perception in the identification of company problems arises. However, in an extended conceptual replication of Dearborn and Simon's study by Walsh (1988) the former's results are severely doubted as managers do not appear to suffer from "impoverished world views or parochial information use" (op. cit.: 887) that reflect their functional area of management. Instead, the average manager appeared very capable to identify problems and use information across five functional domains. Based on these results then, we would not expect functional TMT homogeneity to lead to one-sided team views on problems. Nor would heterogeneous functional teams have substantial problems in integrating, communicating and performing, as Ancona and Caldwell (1992) suggested.

\footnotetext{
Whersema and Bantel even report a negative simple correlation between educational curriculum heterogeneity and their control variable firm performance.
} 
In short, we would not expect any particular effect from functional diversity. Nevertheless, empirical TMT studies (see Appendix A) keep basing their hypotheses on presumed integration difficulties, although without much success. Smith et al. (1994) find no effect at all of functional TMT diversity on team processes or firm performance. A marginal negative effect is found by Haleblian and Finkelstein (1993) but only in those contexts where managerial discretion is high. Michel and Hambrick (1992) also found no effect of functional diversity on the performance of diversified firms. Summarizing this TMT research then, we conclude that functional diversity does not influence performance much.

\section{Temporal and background variety}

One empirical study by Murray (1989: see Appendix A) is discussed separately as it combines several spread variables in two heterogeneity indexes, called temporal heterogeneity (age, team and organizational tenure) and background heterogeneity (functional and educational experience). As hypothesized, temporal heterogeneity is positively related to (adaptability-based) long-run performance, but no significant negative association was found with (efficiency-based) short-run performance. Apparently, short-run performance is very hard to predict from demographic data. This may be supportive of previous findings (Weiner and Mahoney, 1981) that management contributions to shortrun performance tend to be dominated by external circumstances. Moreover, the effects only materialize in the oil business and not in the food business sub sample, probably because success criteria in the latter are more determined by the marketing department than by the TMT. Contrary to temporal heterogeneity, background heterogeneity was no significant predictor of either long or short-run performance.

\subsection{Summary of average and variety effects}

Averages and spreads of various demographic variables in teans have been used to predict several organizational phenomena ranging from tumover in the team itself to innovation, strategic change and performance. However, the results are far from consistent and very often fail to reach significance. Table 2.1 summarizes the number of studies and hypotheses regarding the demographic variables encountered, the percentages confirmed effects, no effects and counter hypothesized effects. As can be seen, the record is not very impressive as results are ridden with non-findings and even counter hypothesized findings. Average experience appears most promising in the area of organizational, educational and functional experience. In particular, low organizational experience and high education levels tend to be associated with organizational change and innovativeness, whereas core functional expertise seems to be of general importance. Average age and team tenure are generally weak predictors of organizational phenomena.

In the realm of variety effects, the record is even worse. Findings are inconsistent (for instance regarding the effect on team turnover) and difficult to relate to each other. Even for the most frequently studied organizational tenure variety variable, only 4 out of 
TABLE 2.1

Overview of TMT studies on hypothesis level

\begin{tabular}{|c|c|c|c|c|c|}
\hline Team characteristic & $\begin{array}{l}\text { 梠 TMT stud- } \\
\text { ies }\end{array}$ & $\begin{array}{l}\text { Wypothe- } \\
\text { ses }\end{array}$ & $\begin{array}{l}\% \text { con- } \\
\text { firmed }\end{array}$ & $\begin{array}{l}\% \text { no re- } \\
\text { sult }\end{array}$ & $\begin{array}{l}\% \text { counter } \\
\text { hypothesis }\end{array}$ \\
\hline Average... & & & & & \\
\hline Age & 2 & 2 & 50 & 50 & 0 \\
\hline Team tenure & 3 & 6 & 17 & 67 & 17 \\
\hline $\begin{array}{l}\text { Organizational } \\
\text { tenure }\end{array}$ & 5 & 8 & 75 & 25 & 0 \\
\hline Educational level & 2 & 2 & 100 & 0 & 0 \\
\hline $\begin{array}{l}\text { Functional } \\
\text { orientation }\end{array}$ & 2 & 3 & 67 & 0 & 33 \\
\hline Wariety of $\ldots$ & & & & & \\
\hline Age & 4 & 4 & 50 & 50 & 0 \\
\hline Team tenure & 3 & 3 & 33 & 67 & 0 \\
\hline $\begin{array}{l}\text { Organizational } \\
\text { tenure }\end{array}$ & 8 & 13 & 31 & 62 & 8 \\
\hline Education & 4 & 8 & 37 & 63 & 0 \\
\hline Function ${ }^{1}$ & 2 & 5 & $a$ & 80 & 20 \\
\hline Total & 12 & 54 & 41 & 52 & 7 \\
\hline
\end{tabular}

Study by Haleblian and Finkelstein (1993) was left out as the characteristic is entered only as a control variable for which no hypothesized effect is stated.

13 hypothesized relationships could be confirmed. Overall, it is fair to conclude that although many serious attempts have been undertaken to relate team demography to team outcomes and individual studies are sometimes successful in finding one or two significant relationships, the results lack coherence between and often even within studies. In the next section we will try to explain what features of research thus far may be responsible for this bad record and we set forth possible remedies and extensions in future research.

\section{Diseussion}

The present section will discuss the empirical TMT research to date in relation to the upper echelons model of figure 2. In doing so, several limitations of current research will] be identified along with possible extensions. The limitations we detect are of theoretical and empirical nature and we will deal with them consecutively. Concerning theory and theory development, we will argue that research has been rather fragmented when 
viewed from the original upper echelons model. It has focused on short causal links and has insufficiently dealt with the competing hypotheses theory sometimes gives rise to. Furthermore, there are interesting aspects of the model that have hardly been researched. These include psychological team composition and the development or adjustment of team strategic choices over time. On the empirical side, a problem exists in the way means and spreads of variables have traditionally been treated and in the often inadequate control of confounding variables. We will modify our model to meet several of these limitations and extensions.

\subsection{Limitations and possible extensions of past research}

\section{Theory (development)}

From the perspective of the upper echelons model as a whole, the first thing that clearly characterizes empirical research to date is fragmentation. Different authors tend to deal with different parts of the upper echelons model, linking averages and spreads of TMT characteristics to various strategic choices, processes and performance measures. The result, as stated above, is a rather confusing set of (mostly unique) TMT research findings in various parts of the model, that are difficult to integrate in one clear and coherent picture.

A second, related point is the length of the causal chain explored. The upper echelons model clearly specifies a three-step chain from team characteristics, through choices and/or processes to performance. Most TMT research however only links inputs to outputs based on an inferred intermediate (choice) process that is not actually mea sured. Little is known consequently, of how the effects are produced. In the studies reviewed here only the one by Smith et al. (1994) captures the entire causal chain by including three process variables. The model thus formed explains 56 and 44 percent of total variance in $\mathrm{ROI}$ and sales growth, respectively. To the present author's knowledge, no empirical study yet exists that includes the entire model including strategic choices.

Third, in team studies competing theoretical expectations may exist as to the effect of certain variables (Hambrick and D'Aveni, 1992) especially when it comes to the impact of team variety. Few authors (e.g., Murray, 1989; Finkelstein and Hambrick, 1990) however handle this issue properly by either specifying alternative hypotheses, specifying curvilinear relationships (e.g., Katz, 1982) or by including moderator variables to account for different effects under different circumstances. Because of this, many non-findings remain unexplained that may in fact be due to imprecise specification of relationships or circumstances under which effects should or should not materialize. For instance, variety on a team potentially provides many perspectives on solving new problems with which the team has no experience yet. On the other hand, it hinders communication and social integration as different people tend to hold different frames of reference and people generally prefer dealing with likes. It now depends on the group's task or the circumstances under which it is to perform its task, which of these effects will take most prominent effect. In stable environments with routine problems, heterogeneity on a team is less warranted and its destabilizing role on social functioning is likely to 
dominate and undermine performance. In more dynamic environments with non-routine problems to be solved, heterogeneity may provide the breadth of perspective needed to arrive at an innovative solution. Inter-individual differences are less damaging as they are interpreted and used productively to the task. In a similar way, time pressure can prompt a team to acknowledge the need to set aside personal dislike and mistrust and turn heterogeneity from a negative to a positive influence on team performance. Inclusion of interaction variables like, for instance, task characteristics, environmental dynamism or time pressure does more justice to the situational specificity of demography effects and may heighten the explained amount of variance in the dependent variables.

A fourth important limitation of existing studies is their crude treatment of the individual choice process by using demographic variables. In essence, people with certain demographic characteristics are supposed to be rather homogeneous in holding certain attitudes, traits and values that presumably lead to a particular behavior. These attitudes and values are, however, seldom measured and neither are their relationships with demographics. This obscures the exact mechanism by which demographics influence behavior, leading to rather speculative conclusions when expected results do not show up. We will illustrate our point with an example by Hambrick and Mason (1984: 201). The authors quote research suggesting that managers from lower socio-economic origins tend to pursue more diversification and acquisition. They do this "presumably in order to achieve recognition and esteem" (op. cit., p. 201; emphasis added). However, when Hambrick and Mason translate this finding to TMTs they stick to the simple association between background and diversification. Whether high needs for esteem do indeed lead to diversification thus remains unclear. Similarly, whether managers' social class backgrounds are indeed related to need for esteem in a particular sample remains unknown". Instead, a more distant (assumed) proxy of need for esteem (i.e., socio-economic background) is used. In addition, or even worse, the inferred behavioral implications of many demographic variables can be very diverse, each having distinct and sometimes conflicting performance implications. For instance, higher average age is often taken to represent more experience. It might, however, equally well signal conservatism or even physiological (especially memory) deterioration that hinders performance and it has indeed been used in that sense. We suspect that many non-findings in upper echelons studies are at least partly caused by this use of rather distal proxies (demographics). A research field that is so fragmented and ridden with non-findings ( $52 \%$ in the reviewed literature) may therefore benefit from going one step back in the causal chain by measuring managers' (pre)dispositions, for instance their personality, more directly and linking these to their behaviors, choices and, ultimately, performance in a team. Thus, a focus on more fundamental behavioral tendencies rooted in personality seems warranted because these are more directly linked to behavior and provide a more valid measurement of values and attitudes than do demographic variables. In fact, this is a

\footnotetext{
9his is important from an normative point of view. In sereening candidates for an important acquisition function; should an applicant be intenvewed and tested to gange his need for esteem or simply asked to state his father"s
income?
} 
crucial point that Hambrick and Mason (1984) readily acknowledged. When they presented the model and called for empirical research they made it very clear that "[i]t is doubtful that this research stream can progress far without greater attention to relevant literature in related fields, especially psychology and social psychology" (Hambrick and Mason, 1984: 203). Their emphasis on 'observable' characteristics to start with, was inspired by rather practical reasons like data availability and measurability. However, the growing need to use more psychological variables in upper echelons research is repeatedly stressed by researchers in the field. For instance, Hambrick, Geletkanycz and Frederickson (1993: 402) state that "[e]ven though psychological factors (...) are of central significance to upper echelons theory, such phenomena are rarelly studied or measured directly in empirical inquiries of top executives"10. Indeed, we know of no empirical upper echelons study to date that has explicitly looked at the psychological composition of the team using validated personality inventories. In fact this seems to be a void even in the broader field of organizational diversity (Milliken and Martins, 1996).

A final limitation of the upper echelons model is its simplicity in dealing with the strategy concept itself. One aspect of this problem was already mentioned above: the importance of interaction variables on the causal links in the model is too seldom acknowledged. Moreover, the eagerness to predict specific strategic choices from demographics causes a complete lack of attention to the importance of strategy making and implementation. That is: to the process of configuring repertorres of actions, to the consistency of strategies both internally and over time and to the proper implementation of these strategies. Finally, the dynamic processes of strategic adjustments and reactions over time have been completely overlooked. In many industries the capacity to change or stick to a strategic course is vital, so a proper model that links choices to performance should include this element as well.

\section{Empirical issues}

Three limitations of empirical nature will be discussed. First, there is a problem in untangling the different effects of the average and variety of variables. Two teams that have the same spread (variety) in age, for instance, may have widely differing means. It is likely that relatively young diverse teams deal with this diversity differently than relatively (experienced) old teams. Conversely, two teams of equal average age can differ widely on the spread in those ages. Consequently, if one hypothesizes on the impact of high or low average age (for instance on innovativeness) one is implicitly assuming (but not ensuring!) low spreads around those means; otherwise the effect is likely to be 'diluted" by the more extreme team members. This problem of means and spreads is hardly acknowledged in the reviewed literature, where mean and diversity effects are simply treated separately. Anyway, if a methodology is applied that does not properly deal with this problem, results are essentially uninterpretable as one compares

\footnotetext{
10 The man reasons for this are rather practical in mature: top managers are often reluctant to submit to batteries of psychological tests and research has to bridge considetable tine to 'await' the effects of psychological diversity (Finkelstein and Hambrick, 1996).
} 
apples and oranges.

A second and related problem concerns the right measurement of variety in a team. Most authors refer to the classic overview of inequality measures by Allison (1978) when they choose the coefficient of variation (COV, i.e., standard deviation divided by the mean) to measure spread in a team. The main reason they do this is the socalled scale-invariant character of this measure, which means that it is not sensitive to multiplication of each members" score with a constant. This property of a spread measure is useful when we want to compare, for instance, an income distribution expressed in yen with one in dollars. Note that only relative positions are of interest when the COV is used, absolute positions are not. It is our contention that past team researchers have too easily gone along with the stress on scale invariant measures by (mainly) sociologists, without thinking too much about its relevance or applicability in their own field of study. As it happens, in our type of research absolute differences often do matter. This can be easilly shown if we take two teams of four persons with the following tenure distribu-

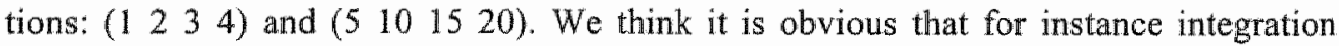
problems because of different dates of entry are highest in the second team as they differ most in this respect. Still, both teams have the same COV (.45), so they would (incorrectly) be treated as equally diverse when this measure is used.

A third issue of empirical nature is the use of very heterogeneous samples in team research. In fact, many studies are cross sections of the Fortune 500: samples that vary widely in size, industry structure, market conditions, governance structures and other confounding variables for which adequate controls are seldom included. It is for this reason, that Hambrick and Mason (1984) stressed the need either to use single industry samples or matched pair designs. In order to gain more control over confounding variables, another strategy is offered by Wiersema and Bantel (1992: 115) when they propose to "[r]ely on more in-depth analysis, such as case studies and experimental research".

\section{Conclusion: the model completed}

Although much research has already been done to test various propositions of the upper echelons theory, no clear coherent picture emerges. This is mainly due to limitations in the way upper echelons research has been approached so far. In the present thesis, we will conduct a basic test of the upper echelons model in which we try to go beyond the limitations mentioned in a number of ways. Concerning theoretical issues, first, we will follow the call of several authors by studying the effects of the psychological composition of teams with regard to their so-called locus of control (Rotter, 1966). This particular trait was selected, because of its proven validity and relevance in past research in business settings (Boone, de Brabander and van Witteloostuijn, 1996; Finkelstein and Hambrick, 1996), as will be shown throughout this thesis. Second, the effects of varying psychological team composition on performance will be analyzed both directly and indirectly through the strategic choices different teams make (see figure 2.3). In dealing with the indirect strategic choice path, we will look at both (static) strategic preferences as well as the way strategic choices are made and, possibly, changed. Although direct measures of 
intra-group processes (i.e., the upper path) were not part of our study, the possible effects of mixing different traits on performance can and will be examined in an indirect way. Third, we will include an important moderator variable, market dynamism, to allow effect sizes to vary between market circumstances. The final model is presented in figure 2.3 .

\section{Figure 2.3: The model completed}

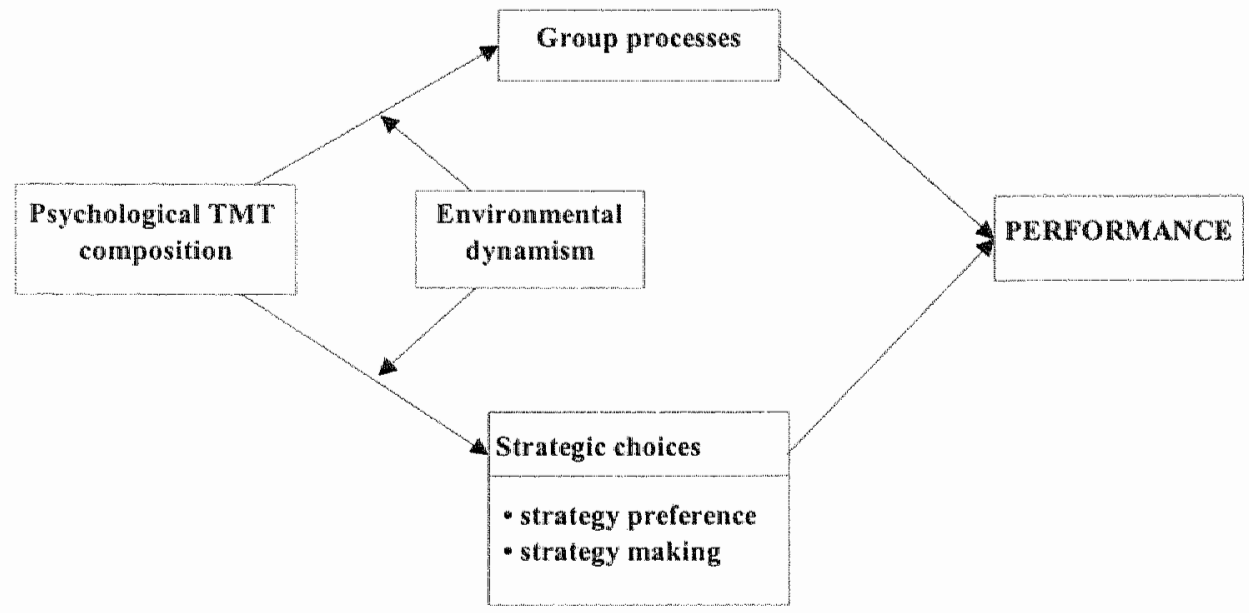

Concerning the empirical issues, Chapter 4 explains our methods in detail and will show how we tried to overcome the problems with spread-and level-effects and the use of the COV. The problem of heterogeneous samples and confounding variables was dealt with by following the advice of Wiersema and Bantel (1992): we conducted an experimental study that allowed in-depth analysis of competitive behavior in a relatively controlled environment.

In the next chapter we will describe the locus of control personality trait. Locus of control is a general expectation people hold about whether they can or cannot personally control the things that happen to them. It will be shown that this variable is particularly useful in an upper echelons model for at least two reasons. First, at an individual level it has been shown to predict involved, motivated and goal-directed behavior that is necessary to develop, implement and monitor business strategies. Indeed a lot of business research has successfully used the locus of control trait in predicting managerial behavior. Second, locus of control is associated with better learning and conscious behavior adaptation, which fits our purpose to study strategic adjustment. By the end of the next chapter we will provide a chapter plan for studying the various effects in the model. 
3 Locus of control -

Theoretical background and behavioral implications 

In the previous chapter it was shown that the composition of a top management team can have important consequences for its functioning and its results. At the end we concluded that the investigation of personality characteristics at the team level, although explicitly called for, has hardly been addressed yet. In order to fill this gap in team research, we chose to study the locus of control personality characteristic because of its proven validity in the study of individual managers (e.g., Brockhaus, 1975; Miller, Kets de Vries and Toulouse, 1982; Miller, 1983; Miller and Toulouse, 1986a; 1986b; Boone, De Brabander and Van Witteloostuijn, 1996). In the present chapter we will introduce this personality trait by giving a broad overview of the related theoretical and empirical research in the psychological literature. The chapter is divided into two main parts. In the first part we will describe the theoretical origins and background of the locus of control research. In the second part we will deal with the impact of different control expectations on the behavior of individuals. There is in fact a lot of material to be covered in the current chapter. We will therefore first sketch our general line of argument below.

Psychological experiments in the 50 s and 60 s showed that people behave differently on tasks when the level of control they perceived to have over the outcomes was manipulated. For instance, they are more motivated at completing a task if they are led to believe that success at the task depends on skills instead of sheer luck. We will discuss these early developments and their implications in section 2.1. In section 2.2 we will introduce the important work by Julian Rotter $(1954 ; 1966)$, who incorporated these experimental findings in his social learning theory. In short, Rotter insisted that during (early) life we are continuously involved in situations in which our expectations as to what controls the outcomes of our efforts, are either fulfilled or disappointed. The expectations fulfilled most often, tend to form a more general expectation as to what controls life events, in other words: we learn what to expect. Once learned, these expectations continue to influence the way we approach situations in life and they become a distinctive feature of our personality, which Rotter termed our locus of control. This concept therefore refers to individual differences in the (learned) expectations about who or what controls the occurrence of life events. These expectations can take an external and an internal form. People holding extemal perceptions of control (so-called externals) perceive low personal control over what happens to them. Instead, they feel their fate is determined by uncontrollable external factors like for instance luck, fate and powerful people or institutions. On the other hand, people with an internal perception of control (i.e., internals) do perceive a link between their own actions and what befalls them: they feel masters of their own fate. Once this theoretical 'groundwork' is laid, we will move on to section 3 where we will introduce the behavioral implications of these different control expectations. The implications will be divided in implications for self-directed behavior (section 3.1) and implications for social behavior (section 3.2). Concerning self-directed behavior, we will maintain that control perceptions importantly influence three interconnected behaviors which collectively determine an individual's achievement. These behaviors are: the way individuals establish their position in the environment (section 3.1.1), how they take directed action (section 3.1.2) and how they change or adapt their behavior if necessary (section 3.1.3). Taken together these 
behaviors co-determine the individual's level of achievement (section 3.1.4). In section 3.2 we will discuss the implications of control perceptions on the individual's interaction with others, i.e. on his social behavior. We end our treatment on behavioral implications in section 3.3 with some concluding remarks on the fundamental nature and origins of control perceptions. Finally, section 5 provides a summary and conclusion. It ties up the current to the previous chapter by providing a general research model and an agenda for the rest of the thesis.

\section{Theoretical background}

\subsection{The importance of perceived control}

The important role of control perceptions in task performance, is nicely illustrated by a number of experimental studies. For instance, Glass, Singer and Friedman (1969), studied the effects of severely distracting and randomly occurring noise on subjects' accuracy in carrying out two tasks that required persistence and attention to details. In the first task, ten spelling and grammatical errors had to be discovered in a seven-page essay during 15 minutes. The second task involved copying the lines of four designs provided, under the restrictions that the pencil was not to be lifted from the paper and that no line was to be traced more than once. The latter task was frustrating in nature as two of the designs were in fact insoluble. Four experimental groups of subjects were formed depending on the intensity of the noise (low: $56 \mathrm{db}$ versus high: $110 \mathrm{db}$ ) and its predictability (low: 9 seconds every minute versus high: random length at random time intervals). Results revealed that task performance was lower when the noise was louder and unpredictable. The effect of unpredictability, however, was much stronger than the "loudness-effect". The former effect is explained by referring to the differing amounts of control subjects perceive over the effects of the noise in the two conditions. If regularity is perceived, the distracting effects of the noise can be anticipated which raises the perception of being able to deal with it in some way. Thus, as regularity enhances perceived control over the aversive effect of noise, performance on the task suffers less. Note that, although the notion of control in this experiment is plausible, it remains rather implicit. Therefore, Glass and his colleagues conducted a second experiment in which the possibility to exercise control was brought in more explicitly. In this experiment two groups of subjects were exposed to a regime of loud and unpredictable noise while working on similar proofreading and insoluble puzzle tasks. However, half the sample was given a button that, if pressed, would stop the noise if it became really unbearable. Even if no subject made actual use of the button, it turned out that subjects having access to the off-switch attempted to solve the insoluble puzzles almost five times as often and did significantly better on the proofreading task. Thus, the sheer knowledge that control can, ultimately, be exerted lowers the effect of the distracting stimulus and enhances task performance. This general finding was replicated in many studies since, using a variety of aversive stimuli, tasks and even species. For example, Sherrod (1974) found that the aversive effects of crowding on cognitive functioning were lower if subjects believed they had the opportunity to leave the crowd than in case they thought they did not. Here also, subjects rarely actually used their 'off-switch', i.e., left the 
crowd. Similar studies in animals show comparable results. In an early study, Mowrer and Viek (1948) demonstrated that rats show less fear of an aversive stimulus when they can terminate it. Twenty food-deprived rats were paired in experimental cages and offered food on 15 consecutive days. Ten seconds after food was taken, an electrical shock was administered through the floor grid of the cage, which was terminated when one of the rats jumped into the air. The other rat received the shock for as long as the other rat did not jump. Thus, the first rat had control over shock duration (by jumping), whereas the other had not. The failure of rats to take the food because of the shocks was seen as an inhibition response. In the 15 days the experiment lasted, the 10 shock-controlling rats showed only 16 inhibitions, whereas the "helpless" rats produced 85 inhibitions. The results are taken to indicate, that when an aversive stimulus is perceived to be under control, it has less potency of inducing withdrawal behavior that runs counter to self-interest (i.e., not eating). The helpless rats were so fear-frozen by their lack of control that they were unable to eat despite their hunger. Moreover, this experiment clearly shows that predictions from the straightforward stimulus-response model of behavior can be improved considerably if the perception of control over negative reinforcements (shocks) is taken into account. We will return to this issue in discussing social learning theory later. For now, we conclude that reactions to stimuli are shaped by our perceptions of these stimuli and the perception of our ability to cope with them (Lefcourt, 1982).

In the cited research so far, control was either implicit (as in the predictability of aversive stimuli) or rather explicit (as in the off-switch examples). In other experiments, however, control expectations of subjects were manipulated by instructing subjects on what determined their success at a task. Specifically, success was presented beforehand as being dependent either on skills (an internal control factor) or on chance (an external control factor). The interest, then, was in how performance on tasks differed between skillinstructed and chance-instructed subjects. Phares (1957) presented subjects with a colourmatching and a line length matching task, in which they were to judge whether a particular colour or line presented to them was identical to a colour or line on a board at some distance from them. To complicate the task further, the standard colour was set against different backgrounds and the lines were presented under different angles. Consequently, this task was so ambiguous that it was almost impossible for subjects to determine whether they were right or wrong in their judgements. Half the subjects were told that the task was so difficult that success was a matter of luck, whereas the other half was instructed that success was a matter of skill and that some people were very good at it. After each judgement, subjects were asked to bet a number of chips on the probability of being correct in the subsequent trial, and all subjects received the same fixed sequence of 'right" or "wrong' reinforcements after judging. As expected, Phares found that skill-instructed subjects in response to success and failure respectively raised and lowered their bets significantly more than chanceinstructed subjects. Success apparently strengthened skill-instructed subjects' confidence in their 'skills', whereas a failure made them more cautious: they had momentarily 'lost it'. On the other hand, chance-instructed subjects showed more unusual shifts in bets, typical of the 'gamblers' fallacy'. That is, after failure their bets went up, whereas after success they bet lower, as if the odds of being successful decline after a success. This betting pattern was called superstitious learning by Skinner and is typical of a believer in luck. James and Rotter 
(1958) and Rotter, Liverant and Crowne (1961) were able to replicate Phares' results and furthermore showed that subjects" reactions to continued (experimenter controlled) failure after a series of more or less successful trials also depended strongly on their beliefs of control over the situation (skill versus chance). For example, when subjects had been successful more than $75 \%$ of the time, then, after the success rate was set continuously below $30 \%$, it took longer for skill-instructed subjects to permanently adjust their success expectations downward than it did for chance-instructed subjects. The difference is supposedly caused by the way the extinction of reinforcements (i.e., the continuance of "failures") is construed by different subjects. Skill-instructed subjects are more likely to perceive their increased failure-rate as an indication that they have, probably temporarily, "lost touch". They will, however, tend to persist believing in their chances of success as skills do not simply disappear overnight. In other words: their past experience with applying their skills has considerable relevance for their current expectations of success. It will therefore take them longer to accept that apparently their skills are not sufficient in being successful. Chance-instructed subjects, on the other hand, will interpret the continued failures as a change of the experimental situation (as controlled by the experimenter) or as an indication that the odds have shifted against them. In either case they will adjust their success expectations faster than skill-instructed subjects.

What these experiments demonstrate is that the beliefs people hold as to what determines their success at tasks importantly affects their confidence and persistence at completing it. If a task is perceived as skill dependent, subjects make greater efforts (i.e., persist longer) at 'learning' to do the right things and failures are interpreted as a lack of skill that is to be built by experience. On the other hand, when a task is perceived as chance dependent, nothing is expected to be learned from experience and subjects are likely to engage in gambling behavior. In the words of Rotter (1966:8):"[W] hen a subject perceives the task as controlled by the experimenter, chance or random conditions, experience is relied upon less. Consequently, it may be said that he learns less (...)"'. Perhaps the most important implication of these studies is the fact that people's potential to learn from reinforcements in a certain context is importanty affected by their beliefs or expectations about what determines these reinforcements to occur.

Thus far we have been looking at specific individual situations in which people's control beliefs were manipulated to see their impact on behavior. However, in life we continuously encounter situations in which our beliefs and expectations are confirmed and disconfirmed. As a result of gaining experience in a range of such situations, people develop more general and stable expectations as to what controls their fate as well. These expectations then begin to form a distinctive personality trait that typifies the individual. How this works is explained in Rotter's social learning theory, to which we will turn now.

\subsection{Rotter's social learning theory}

Social learning theory as developed by Rotter (Rotter, 1954; Rotter, Chance and Phares,

${ }^{1}$ Rotter (1966) adds to this that the perception of tasks as skill or task-dependent may be culturally detemined. 
1972; Rotter, 1982) is a theory of behavior that seeks to integrate stimulus-response theories and cognitive or field theories (Rotter, 1966). Thus, behavior is not seen as deriving solely from the seeking of positive and/or avoiding of negative reinforcements. Instead, it explicitly brings in the personal expectations and values subjects have regarding stimuli and reinforcements as major determinants of whether behavior in a certain situation is likely to occur. In this way a personal element is brought in. So people are seen to behave in response to certain reinforcements, but how and to what extent they will react is largely determined by personal factors. These include the value they place on a reinforcement and the expectancies regarding the relation between their own behavior and the reinforcement. Another factor determining behavior potential of a reinforcer, is the psychological sinuation (Rotter, Chance and Phares, 1972). Depending on the situation in which the subject finds itself, expectations and values attached to the reinforcer may differ and so may their behavior potential. For instance, if we want to predict a specific behavior it may be important to know which alternative reinforcements in this particular situation exist that may compete in reinforcement value with the focal reinforcement (Rotter, 1975). To sum up the preceding in a more formal way, the SLT's main argument can be stated as follows:

$$
\mathrm{BP}_{x, S I, R a}=\mathrm{f}\left(\mathrm{E}_{x, R a, S !} \& \mathrm{RV}_{a, s i}\right)
$$

with $\mathrm{BP}=$ the potential of behavior $x$ to occur in situation $1(S 1)$ in relation to reinforcenent $a(R a), \mathrm{E}=$ the expectancy of the occurrence of reinforcement $a$ following behavior $x$ in situation $1, \mathrm{RV}=$ the value of reinforcement $a$ in situation $S 1$. An example may illuminate the working of the theory. Suppose we want to predict the amount of time (BP) a student will spend in preparing for an exam in an elective course. Clearly, this will depend on the expectations the student has as to what her chances of passing ( $\mathrm{E}_{\mathrm{x}, \mathbb{R}}$ ) are. It will also depend on the value she places on passing the exam $\left(R_{\mathrm{a}}\right)$. Finally, the situation $(\mathrm{S} I)$ is important in predicting behavior potential for studying: perhaps there are other reinforcements (for example enjoying a night out with friends) whose reinforcement values compete with that of passing the exam. All these considerations combine to predict how much effort the student will invest in studying for the exam.

According to social learning theory, the expectations subjects hold are formed and shaped over time as we experience reinforcements in situations that are alike. When confronted with the same situation once again, we will base our expectations on experience in previous occasions in which we had the same problem of choosing our response. This type of expectation is called a specific expectation $\left(\mathrm{E}_{\mathrm{s}}\right)$. However, when a different situation occurs that is perceived to be similar to the known situation, the expectations in the known situation tend to generalize to the more unfamiliar situation. Thus, expectancies developed for a certain reinforcement or indeed a class of reinforcements will generalize from one situation to another, especially when a subject has not yet had much experience with the situation at hand. In these instances he will tend to rely more on the generalized expectancies derived from different, but perceptually similar situations. As Rotter (1975: 57) puts it: "[E] xpectancies in each situation are determined not only by specific experiences in that situation but also, to some varying extent, by experiences in other situations that the individual perceives as similar". The varying extent to which generalized expectancies are 
used to complement specific expectancies depends on the newness of the situation. Fomally:

$$
\mathrm{E}_{\mathrm{s},}=\mathrm{f}\left(\mathrm{E}_{\mathrm{si}}^{\mathrm{Q}} \& \mathrm{GE} / \mathrm{N}_{\mathrm{si}}\right)
$$

The resultant expectancy $\left(\mathbb{E}_{S i}\right)$ in a situation $S 1$ depends on the specific expectancy $\left(\mathbb{E}_{S \mathrm{~S}}^{\prime}\right)$ in that situation and on the generalized expectancy (GE) derived from perceptually similar situations, divided by the amount of experience $\left(\mathrm{N}_{\mathrm{si}}\right)$ the individual has had in the specific situation S1. Consequently, as experience with the situation goes up, the explaining power of generalized expectancies on behavior declines, and the individual will draw more on its specific expectancies that it has learned by experience. So, if the student in our example is studying for her first university exam, she is likely to base her expectations of success on her expectancy of being successful at taking tests, derived from her high school experiences. That is, she generalizes old experiences to the new situation. However, after the student has taken several university exams, she can arrive at more accurate expectations by using her newly developed experiences in the university situation and she will be influenced less by the generalized expectancy for success from her high school years. Note that this has an important implication, namely, that the relative importance of a generalized expectancy goes up as the situation is more novel or ambiguous and goes down as the individual builds up experience in the situation (Rotter, 1975).

Two kinds of generalized expectancies can be discerned (Rotter, Chance and Phares, 1972): (i) generalized expectancies for particular kinds of reinforcements (GER) and (ii) generalized problem solving expectancies (GPS). Generalized expectancies for reinforcement refer to an expectancy regarding the probability of occurrence of a particular kind of reinforcement, based upon past experience. These kinds of reinforcement include for instance achievement or social approval for which we have learned to estimate the chances of occurrence. The student in our example may have developed a generalized expectancy of being able to pass exams based on her past passing or failing experiences. It will provide her with a rather 'stable estimate' of her chances of passing exams (Lefcourt, 1982)'. Generalized problem solving expectancies on the other hand, do not depend on the particular reinforcement. Rather, they represent concepts or views people have developed over time and that have appeared effective in attaining reinforcements of various kinds. Such problem solving expectancies include for instance the expectation that looking for alternative solutions or the trusting of people are potentially fruitful in arriving at a solution to the problem at hand (i.e., attaining the reinforcement). Another example of such a generalized problem solving expectancy is the expectation as to whether the accurrence of reinforcements is within or outside the personal realm of influence. This GPS came to be referred to as the locus of control and was introduced and defined by Rotter (1966:1) as follows: "[W] When a reinforcement is perceived by the subject as following some action of his own but not being entirely contingent upon his action, then, in our culture, it is typically

\footnotetext{
"In fact, wher this estimate is further generalized to capture a broad array of situations, we arrive at what Rotter called the individuals' freedon of movement, defined as "the mean subjective probability that a group of related behaviors will
lewd to a particular set of goals" (Phares, 1991 , emphasis added)
} 
perceived as the result of luck, chance, fate, as under the control of powerful others, or as unpredictable because of the great complexity of the factors surrounding him. When the event is interpreted in this way by an individual, we have labelled this a belief in external control. If the person perceives that the event is contingent upon his own behavior or his own relatively permanent characteristics, we have termed this a belief in internal control". The student in our example may have the general impression that her success at the exam is under her own control and that it is her effort and perseverance that determines her grade. This would constitute an internal perception of control. On the other hand, she may think that her efforts are futile and her grade will depend on uncontrollable factors outside herself. This is called an external perception of control.

We will use an example by Lefcourt (1982) to illustrate that the two types of generalized expectancies (GER and GPS) do not necessarily go hand in hand. Take a man who has been rather consistently successful in attracting the attention and appreciation of the opposite sex. Thus, his expectations for successful interactions of this kind (GER) will be increased. There is, however, no certainty that he will attribute his success to his personal characteristics; he may actually be rather puzzled as to what causes underlie his success, and attribute it to luck or women's indifference (GPS). This, in turn, may determine his view on and treatment of women. However, the simple registering and building of expectations of success and failure as in GER is not enough to determine behavior. In addition, the interpretation (GPS) of whether outcomes are under internal (i.e., personal) or under external control provides an independent contribution to behavior potential. Similarly, the student in our example is more likely to study hard for her exam when she perceives the outcomes to depend on her own ('internal') characteristics and efforts than in case she assumes to have no influence in determining the outcome at all.

So, to sum up this section's argument, social learning theory states that expectations along with values and the characteristics of the situation determine how we will act on reinforcements. Expectations are learned through our continuous involvement and reinforcement in different situations, and we tend to generalize them across situations that are perceived to be similar. Moreover, the impact of generalized expectancies on behavior potential will be strongest in novel or ambiguous situations in which we can not yet rely on expectations that are specific to this new situation. Two types of generalized expectancies are distinguished: generalized expectancies for reinforcements (GER) and generalized problem solving reinforcements (GPS). The difference between the two is, that the former pertains to the probability of occurrence of reinforcements, whereas the latter deals with expectations as to how reinforcements are brought about. An important example of the latter category is the generalized expectancy of reinforcement control, commonly referred to as the locus of control (Rotter, 1966). This expectation can range from a belief in personal control of reinforcements, called an internal perception or locus of control, to a belief in control that is located completely outside the personal realm of influence: an external perception or locus of control. Figure 3.1 schematically highlights the main elements of social learning theory.

In order to get a more profound picture of the exact role the locus of control plays in determining behavior, we will examine its implications for several aspects of self-directed and social behavior. 


\section{Figure 3.1: Schematic representation of social learning theory}

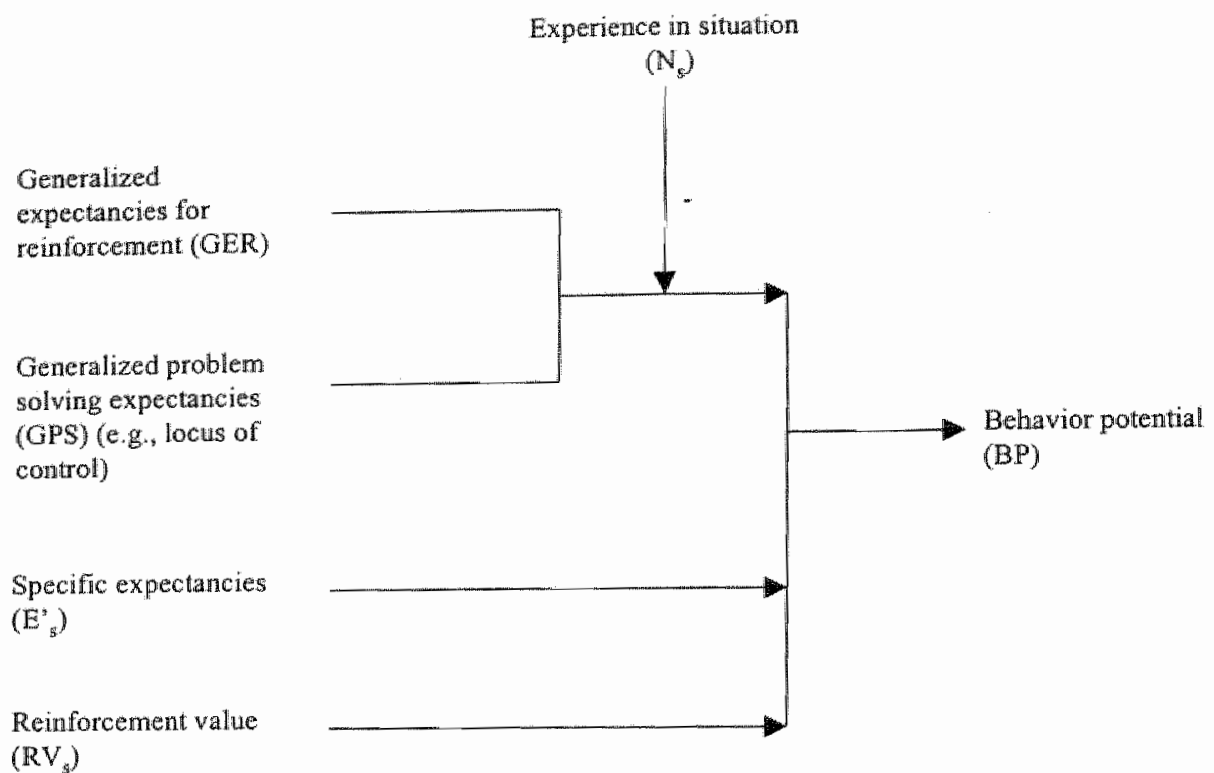

3 Behavioral implications of internal and external control perceptions

\subsection{Locus of control and self-directed behavior}

In the late $50 \mathrm{~s}$ and early 60 s, Phares, James and Rotter developed paper-and-pencil tests to measure individuals' locus of control. The most widely used and validated test is known as the Rotter scale and consists of 23 pairs of statements ${ }^{3}$. Each pair has an internal and an external alternative from which a forced choice has to be made. The final score is obtained by adding the number of external alternatives chosen. Since the introduction of the concept and especially after the personality inventory was available, research into the effects of internal versus external perceptions of control on various behavioral variables developed very rapidly (Lefcourt, 1982). In the current section we will deal with the self-directed behavior of internal and external individuals toward their goals. As will become clear in the fourth subsection (3.1.4), internals perform better than externals in several achievementrelated domains. Achieving goals is only possible when at least the following three conditions are met. First, an individual has to understand how his surrounding world works by paying attention to and making sense of the overwhelming number of stimuli which he encounters. Second, he must be willing to make persistent efforts to be successful, even when confronted with setbacks. Thus, the things that are learned must be translated in goaldirected behavior. Third, he has to be flexible enough to adapt behavior to the requirements of the (changing) situation when necessary. That is: the choice of certain goal-directed

\footnotetext{
The Rotter scale is included in Appendix D. See Chapter 4, section 4.1 for a detailed deseription.
} 
behavior has to be revised continuously. As will be discussed below, internals tend to be superior in each of these domains, resulting in the effect that internals will generally be more effective in achieving valued goals then externals. Figure 3.2 provides an overview of the issues we will deal with consecutively in this section.

\section{Figure 3.2: Section overview}

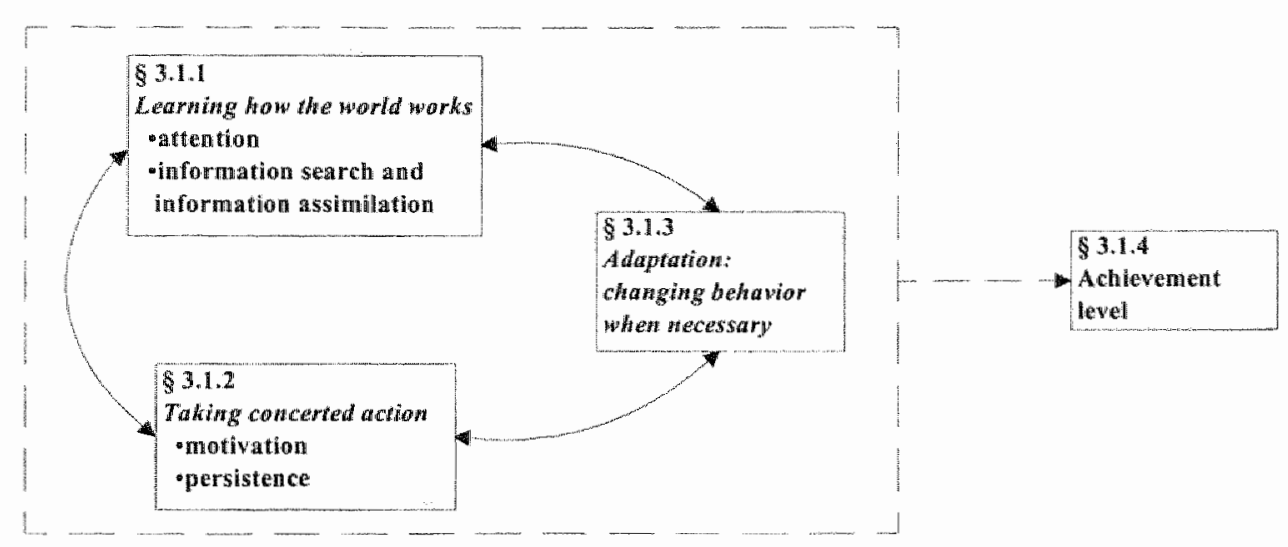

\subsubsection{Learning how the world works: attention, information search and -assimilation}

In order to understand the surrounding world, a number of cognitive faculties is important. The idea that people's locus of control is related to cognitive activities like alertness, information search and -assimilation is intuitively appealing. Internals should be more cautious and calculating about their choices than externals, as this heightens the probability of successfully regulating behavior (Lefcourt, 1982). Internals will question their assumptions more and be more attentive to information relevant to their decision making because they believe this may improve their performance. This is not so for externalls, who will therefore be much less active in establishing their position through these kinds of activities. Below, we give an overview of the empirical findings regarding attention, information search and information assimilation respectively.

\section{Attention}

Attention is defined as the way individuals focus upon cues that are relevant for goal attainment (Lefcourt, 1982). In a study by Lefcourt and Wine (1969), student subjects had to interview two persons of which they were to find out as much as possible concerning their personality. The first person behaved in a typical sociable fashion, whereas the second avoided eye contact and behaved rather aloof. It turned out, that internal subjects 1) looked more often at the face of the person who avoided eye contact than external subjects and 2) looked more often at the face of the aloof person than to that of the more conventional person. Apparently, it was concluded, internals are more likely to pay attention to potentially relevant cues than externals. When placed in ambiguous and skill-demanding tasks, further 
experimental evidence confirms that internals are more attentive to oues that help resolve uncertainties than externals (DuCette and Wolk, 1973; Wheeler and Davis, 1978). This result seems to hold even when no explicit cues are given as to the meaning of a task (Lefcourt, 1982). In a set of experiments by Wolk and DuCette (1974), students were to read a story and asked to check it for typographical errors. This was the intentional learning task. However, subjects were also assessed on content aspects of the story, like names or dates: the unintentional or incidental learning task. It turned out that internals outperformed externals on both learning tasks. When, in a second study, cues were provided in advance (i.e., when subjects were instructed that questions might be asked regarding content as well), externals improved considerably at the 'unintentional' task, however at the expense of the intentional task. To internals cue providing did not affect intentional nor unintentional learning. The experimenters conclude that: "[i]t appears that the external does not make full use of its attentional system until stimuli are made more salient or prominent. For the internal such an explication is redundant, since her strategy has been to deal with a task in a more organized fashion all along" (Wolk and DuCette, 1974: 99).

Further evidence shows that internals appear to be better able to focus their attention on the task and spent more time deliberating on a decision (Julian and Katz, 1968; Lefcourt, Lewis and Silverman, 1968). An important interaction with task type seems to exist. That is, when tasks are less skill demanding the attention of internals seems to wane: they become more careless and impulsive; the differences with externals then tend to disappear. To externals, on the other hand, task differences do not seem to matter much and if they do, they tend to be rather more attentive in chance determined tasks (Lefcourt, 1982). Clearly then, in these studies ambiguity and skills applicability has an important impact on internals' attention to tasks; it is in those circumstances that their curiosity as to important aspects of their task environment is raised. Note that this finding is in line with social learning theory and the results reported in section 2: in unfamiliar, ambiguous situations the relevance of generalized expectancies in directing behavior is highest.

\section{Information search and information assimilation}

From the former we may conclude that internals are more attentive to cues that are relevant to the task or situation. We now turn to the ways in which individuals actively engage in the seeking and processing of cues to come to grips with their situation. The basic hypothesis here, is that as internals want to maintain a situation of personal causation, they will be more likely to actively seek information to be better prepared to deal effectively with their surroundings (Phares, 1976; Lefcourt, 1982; Boone, De Brabander and Gerits, 1991). This information may range from relevant aspects of the environment to aspects of their own behavior that may hinder or enhance chances of success in getting valued reinforcements. Externals, on the other hand, are more likely to regard information unproductive in changing their situation and will thus be less active in collecting

Experimental laboratory research into these hypotheses has been consistently confirming (Lefcourt, 1982), although again an important interaction was noted with the type of task. If information is pertinent to outcome determination of the task, internals do appear to be more likely to engage in information seeking (Davis and Phares, 1967) and they vary their information seeking strategy in function of payoff feedback (Boone, De 
Brabander and Gerits 1991). Even when information is possibly threatening to the individual, like in case of illness, Seeman and Evans (1962) demonstrated that internal tubercular patients appeared to be more knowledgeable about the disease and their own situation than were externals. Furthermore, internals were more inquisitive with medical staff and were less satisfied with the amount of information they received. It seems fair to conclude, then, that internals as opposed to externals are more eager to collect information that is relevant to their purposes.

Better recall and use of information by internals is illustrated in a study by Phares (1968). Subjects in this study were given a fixed amount of information on each of four men and it was made sure that they recalled the information without error. A week later they were asked which of four girls and eight occupations matched best to each of the four men and to list their reasons for these matches. Internals were found to give more than $50 \%$ more reasons for their matches. Moreover, based on exactly the same information, internals stated correct reasons for matches three times as often as externals.

In summing up the above findings on cognitive activities, Phares (1976: 78) concludes that internals "[a]cquire more information, make more attempts at acquiring it, are better at retaining it, are less satisfied with the amount of information they possess, are better at utilizing information and devising rules to process it and generally pay more attention to relevant cues in the situation". All this provides strong support to the vallidity of the locus of control construct as it is indicative of a basic striving of the internal individual to actively engage in the seeking of relevant cues in his enviromment to determine and make sense out of his position and to guide or adapt his behavior accordingly.

\subsubsection{Taking concerted action: motivation and persistence}

Suppose we have a difficult task for which gratification is uncertain and/or delayed to some distant point in time. It seems reasonable, then, to assume that a person feeling in personal control over attaining the valued outcome (i.e., an internal) will be more motivated to apply himself to this task than a person who feels he has little or no influence over his results in working on the task. Likewise, the internal person will be more persistent in his striving despite intermediate setbacks than an external who is only likely to interpret the setbacks as a confirmation that he is indeed helpless. We will address the empirical research pertaining to these hypotheses subsequently.

\section{Morivation}

In researching the effects of perceived control on motivation, Patrick, Skinner and Connell (1993) find a strong correlation between more internal control perceptions and children's classroom motivated behaviors like effort, persistence, attention and participation during learning activities. They are thus able to replicate earlier results indicating that control beliefs account for more than $25 \%$ of the variance in teacher ratings of children's engagement in the classroom (Patrick, Skinner and Connell, 1993: 781). Moreover, Schmitz and Skinner (1993) found (intemal) control beliefs to be a significant predictor of children's exertion on homework and tests, even when the influence of task difficulty and $1 Q$ were 
taken into account.

Research into the connections between locus of control and job motivation or job involvement also provides support for the basic motivation hypothesis, as various researchers found significant correlations between internality (i.e, having an internal locus of control) and job motivation (Spector, 1982). For example, even in a very heterogeneous multi-national sample of over 3000 workers, Reitz and Jewell (1979) found internality to be significantly related to job involvement. Although much of this research may suffer from the fact that it is largely based upon self- or supervisor reports, the convergence of results makes it seem fair to conclude that a relationship exists between internality and job motivation or involvement.

Not many studies thus far have devoted attention to the question of intrinsic (i.e., not externally reinforced) motivation (Boone, 1992). The study of Reeve, Olson and Cole (1987) is an exception. Subjects were instructed to solve a puzzle faster than a competitor who knew the purpose of the experiment. Intrinsic motivation was measured as the time subjects spent on solving the puzzle when left alone during an 8 minute period after the game. Although alternative activities to spent the time (magazines and a tv set) were present, intemals appeared to spent more time on solving the puzzle than externals.

\section{Persistence}

If the gratification for working on a task is delayed to some distant point in time, in order to be effective one should persist in one's efforts even if there are intermediate setbacks. So the issue of persistence is in fact a matter of prolonged motivation when reinforcements are deferred. It makes sense to assume that this planning and working for distant goals would only be sufferable if one is firmly convinced that one is able to influence the outcomes of efforts, i.e., if one has an internal perception of control. In studying this relationship, an experiment by Srull and Karabenick (1975) involved giving insolvable puzzles to subjects and registering how long they would persist at attempting to solve them. Gratification (the solving of a puzzle) was thus endlessly delayed. Internals appeared to persist significantly longer at attempting to solve puzzles than externals, who were more likely to give up once a few failures were experienced. In a second study the effect of locus of control appeared to be reproducible and again highly significant (Karabenick and Srull, 1978). Other research on the relationship between locus of control and persistence while working on a difficult and frustrating task has also generally been supportive of the hypothesized relationship (Lefcourt, 1982), although, as with the motivation studies mentioned above, results vary in effect size and are not always consistent, possibly because research settings differ
considerably.

A final issue deals with persistence of effort despite serious setbacks, that is, with coping behavior in stressful situations. It was already demonstrated in section 2.1 , that perceived control can moderate the effects of stress ("distracting stimuli") on performance. Internals are expected to perceive greater control over stressful events and over possible
ways of dealing with them. Lefcourt (1982: 106), reviewing the impact of control
expectations on how people expectations on how people deal with various stressing life experiences, contends that "[i]nternals seem better equipped to survive their ordeals. They do not as readily succumb to dysphoric feelings and cease in their efforts to succeed in their various tasks as do those 
who hold external control expectancies". For example, Johnson and Sarason (1978) found the impact of negative life events on depression and trait anxiety (psychological maladjustment) in undergraduates to be stronger among externals than among internals. Among the latter the correlations were not even significant. Similarly, Kobassa (1979) in a sample of middle and upper level male executives of a public utility found that internals were less likely to fall ill under stressful situations than were externals. Furthermore, stronger perceptions of personal control have been shown to facilitate psychological adjustment to stressors such as abortion (Cozzarelli, 1993), chronic pain (Jensen and Karoly, 1991), cancer (Thompson et al., 1993) adaptation to college life (Aspinwall and Taylor, 1992) or negative life events in general (Lefcourt et al., 1981). Research thus seems to suggest that internals experience less stress (Gemmill and Heisler, 1972) and if they do, they suffer less from it in terms of depression or anxiety.

The moderating effect of internality on the relationship between stress and aversive effects to the individual, has been ascribed to a more active way of dealing with stress on the part of internals (Krause and Stryker, 1984). That is, internals tend to develop more problem solving behavior in response to stress, whereas externals exhibit rather passive and/or avoidant reactions, in particular of an emotional kind (Anderson, 1977; Parkes, 1984; Wiebe, 1991; Aspinwall and Taylor, 1992). For instance, Anderson (1977) analysed the way in which Pennsylvanian entrepreneurs reacted after severe damage was done to their business as a result of a hurricane. Internals were found to "[p]erceive less stress, employ more task-oriented coping behaviors and fewer emotion-centred coping behaviors than externals" (Anderson, 1977: 446). Task oriented coping-behaviors included obtaining resources to counter the initial loss, whereas withdrawal, hostility and aggression are examples of emotional reactions. Moreover, internal entrepreneurs appeared to be more successful after the disaster than external entrepreneurs. Similarly, in a sample of freshmen, Aspinwall and Taylor (1992) found that a more internal locus of control predicted better psychological adjustment (well-being and perceived stress) after the 3 initial months of college life through active instead of avoidant coping. We conclude that empirical evidence indicates that internals are generally less susceptible to stress and take a more effective problem-solving attitude when confronted with it.

\subsubsection{Adaptation: changing behavior when necessary}

In the previous section we dealt with the implications of control perceptions on the motivation (to persist) to work on more or less structured or ambiguous tasks, even when direct reinforcement is absent or uncertain, or when intermediate, sometimes stressing, failures occur. In the present section we will deal with how the locus of control is related to behavioral change or adaptation in response to environmental cues that current behavior is not effective, that is, to (adaptive) learning processes.

As indicated in section 2.1, the potential to learn is influenced by perceptions of control in a given situation. Similarly, persons differing in the extent to which they perceive outcomes as contingent upon their own actions will differ in their motivations to change or adapt their behavior if needed. Externals, who perceive no link between what they do and what befalls them, are likely to take a passive stance towards their environment, whereas 
internals, who do perceive a connection are more likely to undertake actions to correct an undesired situation and/or to gain some kind of mastery over their environment. This car be established by changing one's own ways, or by trying to influence the environment itsel and make it more conducive to one's purposes. In the following we will discuss the role 0 behavioral change and flexibility in adapting. The issue of influencing (others in) the environment will be treated in the next section on social (i.e. other-directed) behavior.

In studying the issue of behavioral adaptation it is useful to refer back to oun discussion in the previous section on coping behavior. It was argued there, that internals tend to employ more productive coping strategies than externals in a given stressful situation (Anderson, 1977). The question remained, however, whether the more effective coping by internals was due to the use of a single superior style of coping across all situations (much like as if the particular coping style is an inherent trait of the internal), or whether internals modify their coping style in relation to their appraisal of the situation. That is, does the individual's appraisal of the situation as to whether he can change it or should simply accept it, influence the choice of coping styles between internals and externals? Parkes (1984) studied this very issue in a sample of female student nurses. In structured interviews, subjects were asked to recall an event in the previous month that they had found particularly demanding or that had disturbed or troubled them in some way. They had to appraise this situation as to the extent they felt it was amenable to change ${ }^{4}$. Finally, they were to explain the way they dealt with it. Two specific types of coping that emerged from analysis were direct coping and suppression. Direct coping represents rational, task-oriented and problemfocused attempts to manage the situation and the avoidance of neurotic defense behavior like hostility and fantasizing or wishful thinking. Suppression involves attempts to suppress thoughts of the situation or to selectively ignore it. Results show a general tendency for internals to use more direct coping strategies across the board. More importantly, however, for our present discussion, a significant interaction appeared to exist, indicating that internals, in contrast to externals, vary their coping behavior depending on their appraisal of the situation. Specifically, when situations were appraised as amenable to change, intemals reported high levels of direct coping behavior, whereas their use of direct coping decreased and that of suppression increased as situations became less amenable to their influence. Externals, as stated, did not significantly vary their coping behavior according to their appraisal of the situation. As Parkes (1984) notes, direct coping is likely to be more effective if some control over a situation is possible, whereas suppression is a more appropriate response to situations that can not be controlled and must be accepted. She concludes that " $t]$ he patterns of coping reported by internals were potentially more adaptive in relation to types of appraisal than those of externals" (Parkes, 1984: 655). Externals' relatively strong reliance on suppression even in situations that they rate as being under their control further adds to the maladaptive character of their behaviors.

\footnotetext{
The appraisal of the amount of control one thad in the specifie situation appeared not to be related to the subject's
intemality.

Externals seem to be moret of externals has also been extensively researched in the area of psychopathology issues see Plares (1976). Lefourt (1982) and Boone et al (1990).
} 
Parkes' research lends strong support to the idea of internals being more effective adaptors of their own behavior than externals. Much in the same way as they choose the coping option that promises to be most effective, other research adds to the validity of this idea, showing that internals appear to be more willing to adapt in ways that may enhance their personal effectiveness (Phares, 1976). Even when it comes down to rectifying personal inadequacies, internals showed a greater willingness to take overt remedial action when presented the opportunity to do so (Phares, Ritchie and Davis, 1968). Other ways of mastering the environment are evident in internals' social behavior as will be discussed in section 3.2 below.

Implicit in many discussions above has been the observation that internals are better "learners" than externals. That is, they are more perceptive to relevant cues, use information better in guiding their decisions and choose more appropriate ways of reacting and adapting to their environments. All this can be seen as a logical consequence of a firm belief in personal efficacy that typifies internals.

\subsubsection{Achievement}

Combining the behavioral consequences of control perceptions as described in the foregoing sections, it may be expected that internals will be more effective in achieving their valued goals than externals. Two areas in which this prediction was tested are academic achievement and job performance.

As to academic achievement, significant positive relationships were found between subjects' internality and their achievement in school (Bar-Tal and Bar-Zohar, 1977; Schmitz and Skinner, 1993). Even more interestingly, the effect of internality on various scholarly achievement tests seems to be independent of intelligence (Lefcourt, 1982). However, in many cases the origin of the relationship was unclear because insufficient attention was paid to the conditions under which achievement was measured (Lefcourt, 1982). Therefore, research went in a more interactionist direction, questioning under which conditions locus of control would have the strongest effect on performance. An important variable in this respect is the instrumentality of good performance in obtaining other valued outcomes. Internal students appeared to perform better (attain higher grades) only when they felt these grades enabled them to get other valued outcomes (for example job opportunities), whereas among externals this connection between instrumentality and performance was insignificant (Batlis, 1978). What these results demonstrate, is that in academic settings internals are generally more achievement motivated and perform better, but more so under conditions they perceive as instrumental to attain their goals (Lefcourt, 1982).

As to the effects of internality on job performance, many studies point in the expected direction that "[i]nternals (...) exert greater effort and perform better on the job" (Spector, 1982: 489). If this is indeed the case, internals may be expected to exhibit higher career effectiveness as measured by salary increases and promotions. Several studies (Valecha, 1972; O'Brien, 1984) seem to confirm this expectation. For example O'Brien (1984) found that internals occupied jobs that were higher paid, better matched to their skills 
and provided more opportunities to exert influence. ${ }^{6}$. Thus far we have been reporting on the effects of control perceptions on the functioning of the individual in relation to the achievement of his personal goals. In the next section it will be shown that the locus of control construct also has important ramifications for interactions with others.

\subsection{Locus of control in a social context.}

As internals have great confidence in their potential to control the outcomes of their behavior, two clear expectations can be formulated in relation to their behavior in a social context. First, an internal would like to remain in control and not give it away to others in its environment. Thus, he will be resistant to manipulative efforts of others and try to behave more "independent" under social influence if he feels this to be in his interest. An external on the other hand is more likely to respond to external, social cues of proper behavior. Second, believing in his potential to do so, an internal will be more likely to influence others and thereby gaining additional control over his social environment. These two behavioral tendencies will subsequently be treated below.

\section{Susceptibility to social influence}

In social psychology, a classic way of measuring the tendency to conform to other people's opinions, is a so-called Asch experiment (Asch, 1956). In its basic form, it involves placing a subject in a group and asking him to give a judgement on a task, for example whether 4 lines projected have an equal length. The right answer is obvious, but the subject finds himself confronted with group members instructed to give the wrong answer. The tendency to conform to the wrong opinion of others is taken as the dependent variable. In an Asch-like experiment by Crowne and Liverant (1963) initially no difference was found in the amount of conformity between internals and externals. However, when money was at stake as subjects were asked to bet on the confidence they had in their own judgement, remarkable differences occurred. Internals appeared significantly less conforming to a majority than externals and they bet more money when going against the majority than did externals. Furthermore, internals did not differ in their bets on conforming and independent judgments, whereas externals displayed significantly less confidence in their independent than in their conforming judgments. What this demonstrates is, that internals, when working towards valued reinforcements, are less likely to conform and display greater confidence in their deviancy from the majority than externals do.

In a related type of research, the effect of experimenter manipulations on subjects' judgements was studied. Gore (1962) found that in general internals and externals are equally susceptible to experimenter's overt hints or suggestions on a task. However, internals were more affected than externals by subtle kinds of manipulation in that they resisted to display behavior that was apparently elicited from them by the experimenter"s subtle hints. The idea is that internals resist manipulations of a kind in which they feel treated as if they

\footnotetext{
"It whould be kept in mind, however, that it is unclear whether this effect is due to the fact that intemals were attracted
divectly to those jobs or gradually selected into them over time.
} 
are pawns that can be tricked into doing what the experimenter wants. They don't like to be fooled and tend to react in an oppositional manner to these kinds of manipulations (Lefcourt, 1982). Externals, on the other hand are more easily conditioned by experimental manipulation. This is not to say, of course, that internals are always more resistant to influence, but only that they are more discriminating in what influences they accept, because then, after all it is their decision to go along or not. As long as they feel in control of what happens, they will be eager to follow suggestions they feel are of walue in reaching their goals. This latter point is illustrated in research on attitude manipulation in internals and externals. Results indicate (Ritchie and Phares, 1969), that externals are more susceptible to attitude change following an argument from a high than from a low prestige person, whereas internals show no difference between the two argument sources; they seem more responsive to the content of the message than to the messenger's prestige. Likewise, it was shown that externals are more conforming to the opinion of high status individuals that had no relevant expertise on the matter at hand (Ryckman, Rodda and Sheman, 1972).

We may conclude that externals are more sensitive to social cues from their environment, regardless of the potential value of the information. Internals, on the other hand, appear more self-directing in the presence of social influence, and may even become resistant to it if they feel manipulated. They may as well conform or change their attitude in the direction desired by the influencer, but only on the basis of a careful analysis of the merits of the message.

\section{Exercising social influence}

As internals are characterized by greater personal effectiveness and confidence in their own efforts to affect their environment, they may be expected to engage in such efforts in their social environment as well. Essentially, we would expect internals to be more motivated and effective in influencing other people's attitudes or behavior in a direction that contributes to their purposes.

Regarding motivation for social change activity, Parker (1993) tested the hypothesis that perceived control is positively related to the willingness to engage in so-called reformist dissent when faced with injustice. Reformist dissent (as opposed to radical dissent) is dissent that occurs within the confines of an organization's norms and rules. On the other hand, when perceived control is low, voicing dissent is useless and leaving the organization may be a more appropriate action. In a sample consisting of female acute-care nurses from a variety of medical specialties, perceived control did indeed appear to be positively related to the willingness to dissent and to a belief that desired changes can be effected by speaking up. As expected, perceived control was negatively related to exit-intentions. Apparently, people possessing high perceptions of control are more motivated to try to fix an unsatisfactory situation, whereas those with low control perceptions are nore likely to lead to exit. Internals are also more effective in influencing other people" $s$ attitudes. A series of experiments reported by Phares (1976), demonstrated that internall experimenters tended to create a greater experimenter's bias in subjects" attitudes than external experimenters. That is, they were more persuasive in changing subjects' attitudes. This is an important finding as experimental settings are typically very controlled in that the content of what the experimenter says is fixed. Apparently, the way in which the information is conveyed 
through voice tones, gestures, postures or facial expressions, differs between internals and externals to the effect that internals produce higher attitude shifts than externals (Phares, 1976).

An area in which the influencing of others is especially important is that of leadership behavior. To accomplish a task a group's leader has different options in securing the subordinates effort and cooperation, ranging from sheer coercion and punitive control to consultative, participative styles of leadership (Bass, 1990). It has been hypothesized (Goodstadt and Hjelle, 1973), that externals, who expect less potential control over the behavior of others, will be more likely to use drastic and autocratic influence measures like coercion in dealing with subordinates. "Soft" influence mechanisms like discussion and personal persuasion are the kinds of controlled influence sharing that the self-confident internal is more likely to apply. Research in both experimental and field settings seems to corroborate this hypothesis. For instance in an experiment by Goodstadt and Hjelle (1973), students received the supervision over a group of people of which some group members were instructed to behave in an undesirable manner. Supervisors were given a range of options to influence group members' behawior, like punishments, transfers, rewards or personal persuasion. In dealing with the deviant person in their group, external supervisors used significantly more coercion by threatening with low ratings or firing. Internal supervisors on the other hand relied more on personal persuasion as an influencing method. Field studies (Mitchell, Smyser and Weed, 1975; Anderson and Schneier, 1978; Johnson, Luthans and Hennessey 1984) into the different leadership modes of internals and externals underscore these conclusions. The study by Anderson and Schneier (1978), for instance, involved interaction process analysis of small groups of students cooperating on course work over a period of 15 weeks. At the end of this period, subjects rated each other's behavior on a checklist and stated which group member had emerged as a leader. The results indicate, that the emergent leaders scored higher on internality than non-leaders. These internal leaders displayed much more instrumental and task-oriented behaviors, whereas external leaders had a more social-emotional leadership style. Finally, groups led by internals performed better on their group work ratings than groups led by externals.

It can be concluded that internals are generally better able to influence their social work environment in a productive manner than externals. An important explaining factor is the internal's preferred leadership style which combines a rather business-like, taskoriented stance with a persuasive instead of coercive way of resolving interpersonal difficulties. It may be that these characteristics predispose internals to gain leadership
positions more than externals.

\subsection{Some concluding remarks on the nature of control perceptions}

Because of their origin in social learning theory, control perceptions are traditionally regarded as emanating solely from people's continued involvements in situations with valued reinforcements. Indeed, much research has been devoted to social antecedents of control perceptions such as familly or, more broadly, social class characteristics. The idea is that the social learning environment in itself may have an important impact on the development of internal or external perceptions of control. In reviewing this research, Lefcourt (1982: 146) 
concludes that "[ $[a] \mathrm{n}$ attentive, responsive, critical and contingent milieu is a precursor of the development of an internal locus of control. Likewise, (...) the less responsive and less opportune milieu surrounding the poor, the ostracized and the deprived creates a climate of fatalism and helplessness (...) generating more external control expectations". More recent investigations, however, have tried to complement this social mechanism with more biological explanations. Strong indications were indeed found of a deeper constitutional basis of perceived control beyond simple interindividual cognitive differences.

Specifically, psychophysiological research shows that internals have more control over three important physiological processes than externals: the input of sensoric stimuli, the processing of these stimuli and motor output (Boone, 1992). An example of superior input control is the greater efficiency of internals in directing their attention to relevant stimuli and their quicker habituation to non-relevant and/or distracting stimuli'? Internals' greater verbal comprehension, fluency and reasoning skills are indicative of better processing abilities. Finally, internals seem to have greater control and awareness of their motor output and physical states as evidenced by superior results on biofeedback (i.e., mentally controlled physical reactions) and lower susceptibility to alcohol-placebo's (Boone, 1992). The underlying cause of these findings can be brought back to differences in the relative activation of the left versus the right brain hemisphere between internals and externals. Research suggests that internals are characterized by a higher tonic activation of the left hemisphere than externals (De Brabander, Boone and Gerits, 1992). It is precisely this left hemisphere that is specialized in the expressive (as opposed to receptive) functions (Tucker and Williamson, 1984) that play an important part in the control of the three physiological processes mentioned above. The bottom line is that generalized control expectancies are probably, at least in part, determined by biological predispositions, among which the relative activation of the hemispheres. Adding to the plausibility of a biological base for control perceptions are recent indications of a genetic factor (Miller and Rose, 1982). It is therefore not surprising that locus of control scores are relatively stable over time (Smith and Dechter, 1991; Boone, 1992).

\section{Summary and outlook: locus of control in management studies}

In the preceding sections we started by showing that the amount of control subjects perceive in a given situation has important ramifications for their motivation and success while working on tasks. This concept of perceived control appeared to be an important element in the social learning theory of Rotter. He argued that people learn what to expect through life experience, leading to more general expectations of what controls their fate. These generalized control expectations are relied upon most in novel or ambiguous situations. Research into the behavioral consequences of the locus of control indicates that intemals are generally more attentive, (intrinsically) motivated, task-oriented, persistent and stress resistant in their activities than externals. Internals also tend to have better learning skills in

\footnotetext{
"Wote that we alleady alluded to internals" better and more efficient use of their attention system in section 3.1.1.
} 
picking up and searching for task relevant cues from their environment and in using this information appropriately. Moreover, internals are more likely than externals to adapt their behavior according to the demands of the situation. Internals' greater reliance on personal control is also reflected in their social behavior: they are less susceptible to (subtle) directive outside influence and are better capable of influencing or leading others than are externals. Taken together, the bulk of empirical research strongly converges in underscoring the validity of the locus of control construct as an important "mediator of involved commitment in life pursuits" (Lefcourt, 1982: 184). In general terms, internals show a more active engagement in efforts to grapple with the environment in securing valued goals, whereas externals are more prone to fatalistic feelings leading to apathy or withdrawal. In novel or ambiguous situations individuals are likely to draw more on their generalized expectancies like the perception of control, so it is in these kinds of situations that individuals' locus of control is most likely to influence their behavior.

Once agreement rose over the validity of the locus of control construct and its basic behavioral consequences, research from the early " 70 s onwards started applications to more specific fields of interest, such as education, health behavior and psychopathology (see Phares, 1976; Lefcourt, 1984 and Halfens, 1985 for overviews in these areas). The application of locus of control in the field of management studies is relatively new and was not started before it became recognized that characteristics of people leading businesses can have an impact on strategies and outcomes of firms (see chapter 2). The 'face validity' of including control perceptions in management research follows from the nature of the business environment and the management task. Business environments generally possess the very environmental characteristics of ambiguity and uncertainty in which the effect of control perceptions on behavior, according to social learning theory, is likely to be strong. Also, the management task can be viewed as a persistent attempt to control the environment (Boone, De Brabander and Van Witteloostuijn, 1996). As stated before, much attention has been devoted over the last decade to the impact of individual managers' control perceptions on organizational variables. These studies will be reviewed in more detail in the empirical chapters (5-8) in order to formulate our hypotheses. In the present thesis we aim to study the impact on economic behavior of the locus of control composition of management teams. We will be distinguishing between teams having predominantly internal team members, predominantly external team members, or a mix of both, i.e., mixed teams. In developing hypotheses we will be mainly inspired by past research at the level of the individual manager. As we will argue later, management studies have been dealing almost exclusively with what kinds of decisions different managers are most inclined to, i.e., with their strategic preferences. However, from our review in this chapter it becomes clear that control perceptions are also or perhaps even more predictive of how decisions are made. The issues relating to this 'how question' are summarized in the model of figure 3.2. For the purpose of our study, these elements relate to the way strategic choices are made, implemented and, possibly, changed. That is: they relate to the process of strategy making. If we combine figures 2.3 and 3.2 , we arrive at our final research model, depicted in figure 3.3. It also provides an overview of what element we will be studying in each of the following chapters. We will start our analyses in Chapter 5 by looking whether teams with varying pro- 


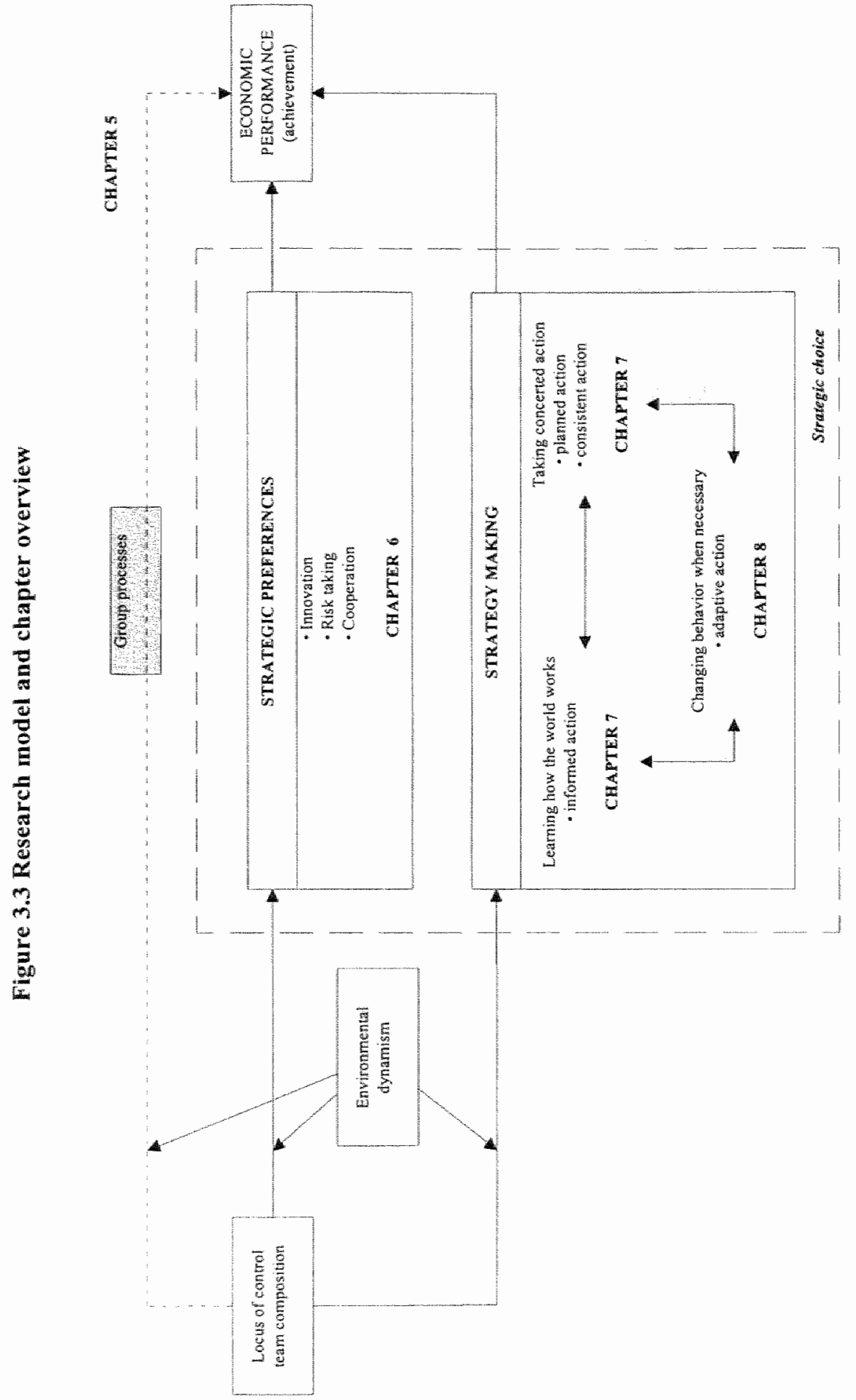


portions of internals and externals do indeed achieve different levels of economic performance. Next we will be looking at what might explain these performance differences. First, Chapter 6 explores whether it is in strategic content, i.e., whether teams have different strategic preferences for, say, innovation or risk taking. Next, in chapter 7 and 8 , we focus on differences in strategy making variables, like for instance information gathering or planning. In closing, it is important to note again, that we did not explicitly analyze intragroup processes. However, the matter of group interaction will be treated indirectly in Chapter 5, when we discuss the effects on performance of mixing people with different control perceptions. This is why the dotted arrow in figure 3.3. runs through the group processes box, whereas the box itself is shaded, i.e., not directly observed. 
Methodology and data description 
. 
In the present chapter we will first motivate and describe our research setting in section 2. Section 3 deals with the methods of data collection and provides descriptive statistics on our final sample of teams. In section 4 , we will go somewhat deeper into the measurement of two core variables in our study, namely the locus of control and environmental dynamism. Finally, in section 5 we make some remarks of statistical nature which apply throughout the thesis.

\section{Research setting}

\subsection{General description and motivation.}

The data for this study are drawn from a large scale management simulation, called the International Management Competition (IMC) ${ }^{1}$. In this game, teams lead a fictive company that competes with other firms in its industry. The objective is to maximize both current and future profitability and market shares. The IMC is organized yearly by MCC International b.v., a Dutch company that is by far the market leader in its business. In 1994, the year our data were collected, the game was played by individuals in 167 teams throughout Europe. Over the past 20 years about 25.000 young managers have participated in the game. Participants in the game are small teams (typically about four perm sons), composed of mainly young managers of a commercial or public organization. The game is used by the participating firms to train young managers, often as part of their management development program. Because participating is all but cheap (about 5000 Dutch guilders, additionally to time consumption), firms are likely to select employees who will seriously play the game. As a result, the selected managers are probably highly motivated to satisfy the objectives of their employers, represented by their direct supervisors.

Our choice for this particular research strategy to test the effects of team composition on competitive behavior was motivated by a number of considerations. First (as will become clear in the description of the game below) the IMC is a very elaborate and realistic simulation of a multi-faceted business environment. Teams must find their way amid decisions on regular and hired personnel and machine capacity, wage levels, efficiency improvements, promotion outlays, price levels, sales force volumes, dividend payments, borrowings, redemptions, quality and efficiency R\&D and a host of information on their own results and the actions of competitors. The latter is crucial as the effects of decisions are co-determined by the actions of competing teams. So, next to the internal realism of firm decisions we have the external realism of competitor interaction: both internal and external business environments are simulated. Teams must therefore lead sound internal policies on the one hand and develop strategic behavior on the other.

\footnotetext{
1 The description of the gane is based on the Players Mannal IMC Management Game 1904, issued by MCC International b.v. in Amsterdam, The Netherlands. Invaluable additional in-depth information on the game's functioning was kindly provided by the game"s principle developer, Ir. Jack. Koster at MOC International b.v.
} 
Second, because all teams face exactly the same starting conditions and the rules and competitive instruments do not essentially change during the game, it allows for a controlled comparison between teams of different composition, even over time. Moreover, all teams work toward the same final objective (maximization of current and future profitability) that is stated at the start of the game. Note that all this is in striking contrast to many past research (see Appendix A) in which often very diverse samples within industries or even across industries were used.

Third, although each firm has the same range of competitive instruments, the strategies they develop in employing them allows considerable impact on their competitive environments. Thus, like in reality, teams can partly create their own environments through their own actions and the interactions hereof with competing firms' actions.

Fourth, the game setting allowed us to make close contact with teams so as to identify exactly who were actively involved in taking the decisions, i.e., who were the real, active members comprising each team. In most past research the top management team is rather crudely identified by using some reference book of corporate managements, typically Dun and Bradstreet's. This method does not take into account variations in management participation or specialization in certain areas: it simply states who is at the top, not necessarily who takes the decisions under study. In fact, this difficulty of reaching the important decision makers and gaining their cooperation has been identified as one of the main obstacles to researching personality at the team level so far (Finkelstein and Hambrick, 1996). Our method consisted of personally contacting teams, which allowed for a more reliable and precise measurement of which people were directly involved in managing the 'firm'.

Fifth, the game provides complete latitude of decision making to the team. This means that we can be relatively sure that decisions were made free from structural and/or political constraints and that they reflect pure team intentions. Identifying this level of managerial discretion in field research has typically been a great problem as it influences the association between team composition and decisions. As our research is only a first attempt to study the effects of psychological team composition, we wanted to minimize the impact of possible confounding effects on our results. The known and relatively wellstructured environment of this management game seems therefore an acceptable starting point. A potential weakness of our method, however, may be the degree of generalizability of results to real business contexts i.e., the methods' external validity. For instance, one may question whether the model behind the game is a good representation of actual business life. We think, however, that the basic assumptions on which the game's model is build (see next paragraph) are fairly simple and generally accepted as stylized facts of economic business life. Furthermore, our research sample of young executives is highly representative of actors in the actual business world and the goals that teams seek to attain seem reasonably concurrent with those of actual management teams.

Below we will give an elaborate overview of the functioning of the game. Details on the specific aspects (like innovation or cooperation) that are of interest to our research will be treated in the respective chapters. 


\subsection{Game functioning and organization}

After subscription and payment, each team receives an elaborate game manual in which every aspect of the $\mathbb{M M C}$ is explained. Game management in Amsterdam is a team of people that works full-time to coordinate and manage the game. During the time the game is actually played this means answering questions, processing team decisions and reporting results back to teams. At the start of the game, groups of five teams are randomly formed by game management. Such a group of five teams is the game equivalent of an industry. The industry is where actual competition - with the other four industry members - takes place. Teams are informed of their four competitors" telephone numbers in order to be able to contact them in case they wish to set up cooperative arrangements. The game is played in two rounds, I and II: round I consists of six and round II of seven so-called decision periods, 1 to 6/7. Each decision period lasts two weeks. At the end of each two-week period, teams have to fax a decision form (see Appendix B) to game management in Amsterdam, specifying their decisions for the upcoming period. After processing the decisions of the five competing companies, game management provides a summary of a team's results for the current period (see Appendix $\mathrm{C}$ for an example). This feedback covers all relevant areas, including market shares, profit rates, financial and stock positions and the requested information items (see decisions 24 to 37 on the decision form). By the end of the six decision periods of round I (i.e., after 12 weeks), teams are ranked according to their so-called criterion score, being a composite measure of market share, profit and the projected continuity ${ }^{2}$ of the firm's market share in the period following the last period. This score therefore proxies short as well as long-run firm performance. On the basis of this ranking new groups (industries) of five teams are formed, by clustering strong and weak teams, to play round II. In doing so, teams compete against opponents of comparable strength in the second part of the game. After the end of the seven decision periods in round II, the top fifteen teams are invited to appear in the finals. This involves an intensive management game of one day, played at a conference center in the Netherlands. The winners are awarded a one-week business trip to Japan.

We decided to restrict the analyses in this thesis to the first-round of the game for two reasons. First, the re-composition of industries at the beginning of round II limits the opportunities to evaluate a team's performance over the whole game. As it leads to nonrandomly composed industries, teams cannot be meaningfully compared between industries in round II. Second, we expect that the effects of team composition will be particularly pronounced in the period before firms have developed routines that help to handle industry events. Moreover, control expectancies are most likely to be involved in behavjor in rather new situations (see paragraph 2.2 of Chapter 3 ).

2This 'continuity' is calculated as the extent to which the average market share obtained over the last ihree periods can be continued in the period after the last period. 


\subsection{Game content}

The IMC is a realistic simulation of complex real-world competition that is driven by an industry model derived from standard economic theory. The model, that by now contains over 1400 parameters, was gradually developed over the years from its first national edition in 1974 to its present form. Below, we will first sketch these general outlines of the game and then go into some specific characteristics.

The players manual lists the following most important economic regularities underlying the game. Regarding a firm's marketing expenses or policy:

a) demand for a product will decrease when its offering price increases

b) demand for a product will increase when its quality is raised

c) demand for a product will increase when promotion spending increases

d) demand for a product will increase when more credit facilities are granted

e) total industry demand will increase when total industry marketing efforts (a-d) increase.

These effects all operate under the ceteris paribus condition with regard to competitor behavior. Thus, if company $X$ reduces its price while its competitors lower their price more, company $X$ will still lose market share (given constant levels of other marketing expenditures) ${ }^{3}$. The market mechanism works in such a way that, as a rule, the combined effect of marketing instruments determines market shares.

General cost relationships are specified as follows:

f) average overhead cost per production capacity unit decreases as production capacity increases (scale economies)

g) variable costs per production unit will decrease with efficiency investments. Finally, the following two relationships with regard to investments in working conditions are assumed to hold:

h) production effectiveness (capacity utilisation) increases with investments in working climate

i) personnel tumover decreases with investments in working climate.

These assumptions set the general stage for the game $e^{4}$.

Each team of participants runs a firm that faces multi-faceted competition in a number of different product markets. The business environment created in the game is a highly realistic simulation of actual market conditions reflecting both autonomous and induced market developments, the latter deriving from the specific impact of individual firms' behavior on industry competition. Figure 4.1 shows a schematic overview of the game model. As shown, teams have to decide on strategy issues that cover all important business areas such as (investment in) production (capacity and quality), marketing (pricing, promotion and sales group deployment), finance (capital budgeting), personnel

\footnotetext{
${ }^{3}$ Several of the effects mentioned will reach a point of saturation; we will describe some of these mechanisms in more
detail in chapter 6 .

The strength of these effects depends on the choice of model parameters by game management at the start of round $I$ and II. These settings are identical for all teams and do not change during the game round. Teams can buy information
as to the se warious effect sizes; see Chapter 6 and 7 .
} 
(hiring, wages and layoff), market intelligence and R\&D. Additionally, tearns are allowed to cooperate with other firms in the industry (not shown in figure 4.1) so as to improve product quality and/or process efficiency. As mentioned above, in each decision period, the choices have to be filled out on a special decision form (Appendix B) that contains a total of 37 categories. The fictive manufacturing company that each team manages, produces three different unspecified products (1,2 and 3, respectively), which are to be sold in three different markets (A, B and C, respectively). Market A, for product 1 , consists of a home market and an export market. Initial demand in market $\mathrm{A}$ (home and export) is about half market B's level. In the third period, demand for a new product, to be supplied to market $\mathrm{C}$, starts to emerge. Initially, demand in this third market is low:

Figure 4.1: Schematic Game Model ${ }^{5}$

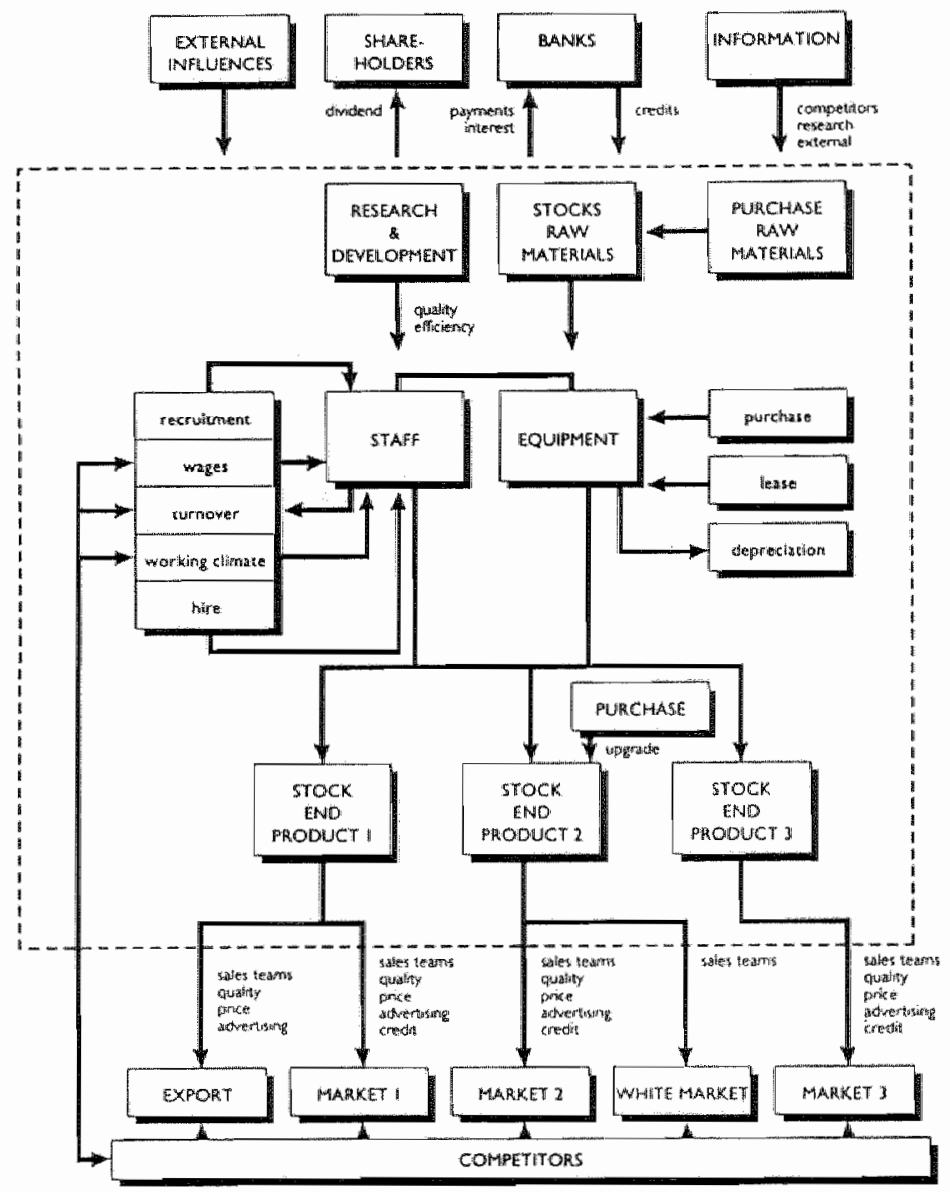

about 25 and 13 percent of the initial demand levels in market A and B, respectively. Products produced for market $B$ can also be dumped in a so-called 'white market' at a

${ }^{5}$ Copyright by MCC International b.v. Reprinted with permission. 
fixed price. Dumping, however, will generate lower demand for product 2 in the official market in the subsequent period. At the beginning of the two rounds, all five teams in an industry have equal market shares in market $A$ and $B$ (that is, 20\%). The share they obtain in the new product market $\mathrm{C}$ in period 3 , depends on their second-period investment in preparing third-period market entry. Market demand characteristics are summarized in Table 4.1.

By conducting market research, firms (teams) can gain insight into the development of market demand for their products. Demand development in all markets generally follows a smooth trend over time. In each period, however, external shocks can create disturbances in demand. Teams are given notice of these shocks in advance. Firm's marketing efforts influence demand development for their product: for example,

Table 4.1

Product market characteristics

\begin{tabular}{||l|l|l||}
\hline Product & Market & Initial demand (number of products) \\
\hline 1 & A- Hone & 100.000 \\
\hline & A- Export & 250.000 \\
\hline 2 & B- Official & 600.000 \\
\hline & B- "White" & Unlimited \\
\hline 3 & C & 80.000 \\
\hline
\end{tabular}

the average price level and total promotion outlays have a direct impact on demand in the current period and a limited lagged demand effect in the subsequent period. Also, credit facilities and investments in product improvement influence demand for a firm's products in later periods.

Because the game and the associated procedures are complex, the chances for misunderstanding by contestants were minimized by providing an elaborate manual, an information desk (reachable by telephone) and three short practicing rounds before the actual game started.

\section{Data collection and sample characteristics}

Data were collected through two routes. First, we received all team-level decisions and results from game management. Second, we mailed questionnaires to all team captains who agreed to distribute them among team members. The first questionnaire, $A$, consists of two parts. The first part contained questions relating to the members' backgrounds in terms of age, education, tenure, former work experience, team member familiarity and functional specialty. In the second part a validated psychological test measuring locus of control (Rotter, 1966) was administered (see below and Appendix D). Three weeks after the first mailing, non-responding teams were mailed reminders and new questionnaires A. Finally, four weeks later captains of non-responding teams were contacted by phone. Three months after starting the game, team members were asked to individually fill out a 
questionnaire B regarding group processes such as decision rules, leadership behavior and relative participation.

In the end, 58 'complete' teams, out of the 167 that participated in the 1994 edition of the game $(35.7 \%)$, returned both questionnaires. A "complete" team in our sample implies that $a l l$ team members returned both questionnaires $A$ and $B$. In sum, these teams consisted of 273 individuals. Based upon the results from questionnaire $B$, we removed from our sample all individuals that had not actually participated according to at least two fellow team members: 21 cases were dropped, resulting in an effective sample of 252 individuals. Analysis of variance revealed that the sample is not significantly different from non-sampled teams on any of the performance indicators (at $p<.10)^{6}$.

About half $(51 \%)$ of the participating teams is from service sector companies, predominantly professional business consultancy or audit firms. Another $37 \%$ is employed in industry (food, chemicals) and the remainder (12\%) in public sector companies. Table 4.2 provides descriptives of our sample at the individual and team level respectively.

As the game originated in the Netherlands, most teams in our sample are Dutch. In fact, in the 1994 edition of the game $88 \%$ of the total number of teams was Dutch, the remainder coming from such diverse countries as Belgium, Gemany, Greece, Hungary, Slovakia and Switzerland. With regard to team member characteristics, the sample includes only a small minority of women (13\%) and about $40 \%$ of team members hold a university degree. Participants average age is about 33, ranging from 21 to 55 , but with a modest variation. The typical game participant is therefore a young Dutch male executive with some in-company business experience. As the correlations in the upper right of table 4.2 indicate, men in our sample tended to be older and more tenured then women and more tenured people were more likely to hold university degrees. Note that locus of control scores in our sample correlated with only one individual characteristic: Dutch respondents had more internal (i.e., lower) scores than non-Dutch respondents ${ }^{7}$. Measurement of locus of control will be explained below.

The average size of a team is about 4 people, with only a small standard deviation. As a result, the individual and team level means do not differ much, although the averaging diminishes variances. Note that no all-women teams exist as the minimum fraction of men appears to be 25 . Most individual level relationships translate directly to the team level. Thus, teams with high mean tenures consisted of younger, male and higher educated participants. Similarly, Dutch teams had lower average locus of control scores.

\footnotetext{
6. Note that we could check for this selection bias because game management provided decisions and results for all participating teams.

${ }^{7}$ Further analysis revealed that the Dutch, on average score lower than participants from any of the other five countries in the sample (Belgium, Germany, Greece, Hungary and Switzerland). However, a Bonferroni multiple range test. showed only one difference to be traly signifucant (at $5 \%$ ): the 213 . Dutch are on average more internal than the five German participants. Although, because of sample size difference, the latter difference can probably be entirely atributed to chance, the consistently lower scores of the Dutch across countries maly indicate some cultural effect that warrants further investigation.
} 


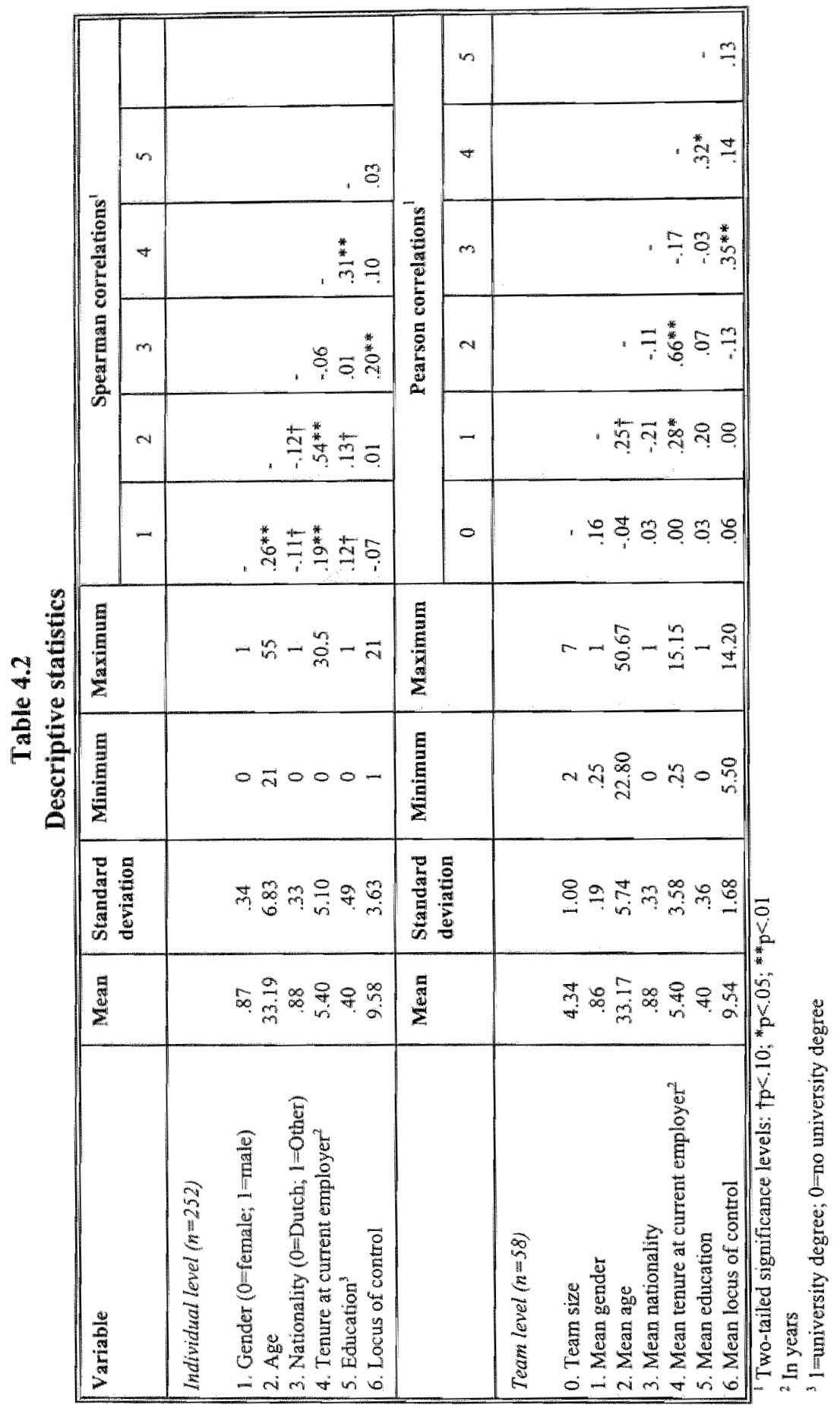


Throughout this thesis we will study the impact of team-level locus of control on various dependent variables under different levels of environmental dynamism. Below, we will therefore explain the measurement of these control perceptions and environmental turbulence as it is used in all subsequent chapters.

\subsection{Team level control perceptions}

Locus of control was measured with a Dutch translation of the well-known and widely used Rotter scale (Rotter, 1966). This scale is reproduced in Appendix D. It contains 37 forced-choice items, 23 of those items measuring control expectancies and 14 being filler items. Respondents have to choose between an internal control and an external control alternative. The following pair of statements provides an example: "Many times I feel that I have little influence over the things that happen to me" (extemal control alternative) and "It is impossible for me to believe that chance or luck plays an important role in my life" (internal control alternative). The total so-called 'Rotter score' is obtained by summing the number of external control alternatives chosen (with a minimum of 0 and a maximum of 23). As a result a high Rotter score corresponds to an external locus of control; a low score indicates an internal locus of control. The translated scale we used contains 14 filler items to make the purpose of the test more obscure. The reliability and validity of this Dutch translation" were repeatedly demonstrated (Boone et al., 1990; Boone, 1992; Boone and De Brabander, 1993; De Brabander, Boone and Gerits, 1992). Coefficient alpha of the scale in our sample was .70, which concurs with internal consistencies reported by Rotter (1966) and Robinson and Shaver (1973). Alpha's value is well abowe the lower limits of acceptability (Nunnally, 1978). The 14 filler items were designed to measure individuals' tendency to choose socially desirable altematives (see De Brabander and Boone, 1990). They are included as previous research suggests a weak association between internality and this social desirability (Boone, 1992). This association is commonly interpreted as an indication that, at least in Westem society, internality is a positive societal value. The correlation in our sample concurs with past findings as it amounts to only -.12 , which is not significant (at $\mathrm{p}=.05$ ). The answers to the filler items will therefore not be included in the analyses.

Teams of different compositions with regard to their individual members' Rotter scores had to be distinguished. To obtain these team composition categories, we followed a method quite different from the one usually employed in team studies. Conventionally, to assess heterogeneity of a team, some standard measure of variability is computed with regard to the variable under study - for instance, its standard deviation or its coefficient of variation". To measure the average level of the variable within a team, usually the arithmetic mean is employed. Analysis then proceeds by examining the effects of the

\footnotetext{
Non Dutch-speaking teams received version that was translated in Eaglish and checked by native speakers.

*ee Chapter 2.
} 
heterogeneity and mean level of the independent on the dependent variable. Apart from theoretical objections to these measures (see Chapter 2), these methods are inappropriate for our purposes. By using a standard variability measure, say the standard deviation of Rotter scores in a team, we do not arrive at a meaningful classification of teams because teams having the same variability score may be widely diverse in terms of composition. For instance, teams with very unbalanced Rotter score distributions (e.g., three internal (external) members and one external (internal) outlier) may yield identical standard deviation measures as teams with evenly distributed scores. Yet, conceptually, these teams are very different: only the latter category could be truly labeled heterogeneous in the sense of our hypotheses and their underlying theories, whereas the former teams are more reliably categorized as either (predominantly) internal or (predominantly) external. To arrive at a team classification that better fits with our purposes of measuring 'true' heterogeneity and distinguishing generic team types unambiguously, we proceeded as follows. First, all individuals were classified as being internal or external based on their Rotter scores being either below or above the sample median of 10. Second, team composition was evaluated by looking at the percentage of internals on the team. Teams characterized by more than two-third of their members being internals were classified as internal teams. Similarly, teams with less than one-third being internal are considered to be exiernal teams. Finally, (the remaining) teams having a relatively balanced number of internals and externals were designated as mixed teams. In doing so, we assured relative homogeneity of team members in the internal and external groups, and relative heterogeneity in the mixed group in a way that fits with the expected effects as stated in the hypotheses. It also yields relatively balanced subgroup counts appropriate for analyses. This procedure lead to the creation of 23 internal teams, 17 external teams and 18 mixed teams. ANOVA analyses revealed that these three team types show marginally significant differences only on mean tenure $(F=2.56 ; p=.09)$ and nationality $(F=2.95 ; p=.06)$. Specifically, according to post-hoc tests, external teams have longer average tenures. Furthermore, as all internal teams appeared to be Dutch, non-Dutch teams are more frequently found among mixed and external teams. These two weak correlates of our group definition (i.e., tenure and nationality) were routinely included in all analyses, but not explicitly reported as their impact never importantly affected the main results.

\subsection{Environmental dynamism ${ }^{10}$}

The relevant competitive environment in which teams find themselves is their industry of five firms. Environmental dynamism must therefore be calculated at this industry level. This was done by looking at movements in teams' market positions and their pricing behavior. In this way we operationalized dynamism not only by referral to what teams experience (changing share positions) but also to an important aspect of what they and their competitors do to create such shifts, i.e., changing prices. Note that these changes in prices and market positions also breed the kind of uncertainty regarding the future that is

\footnotetext{
${ }^{10}$ Throughout this thesis we will use the terms environmental dynamism, industry dynamism and market dynamism interchangeably.
} 
inherent in dynamic environments. Our proxy of industry dynamism was thus based on two measures: one related to market-share shifts over time and another measuring pricelevel turbulence. Following Murray (1989), we estimated dynamism in each market i within an industry by taking the average of inter-period variabilities in individual firm j's shares $\left(D_{M M S}\right)$ and prices $\left(D P R_{i j}\right)$, with $i=1$ to 3 and $j=1$ to $5^{11}$. Formally, this is, for each market,

$\mathrm{DMS}_{\mathrm{i}}=1 / 5 \sum_{\mathrm{j}=1}^{5} \sigma\left(\mathrm{MS}_{\mathrm{i}}\right)_{\mathrm{j}}$

[Average five-firm market share variation in market i]

and

$D P R_{i}=1 / 5 \sum_{j=1}^{5} \sigma\left(P R_{i}\right)_{j} \quad$ [Average five-firm price variation in market i]

with $\sigma\left(\mathrm{MS}_{\mathrm{i}}\right)_{j}$ and $\sigma\left(\mathrm{PR}_{\mathrm{i}}\right)_{\mathrm{j}}$ being the standard deviation of firm $j$ 's market shares and price level in market i over periods 1 to 6 , respectively.

Next we obtained overall industry dynamism scores in market shares and price levels by computing the average of $D M S_{i}$ and $D P R_{i}$ over the three markets. We performed a factor analysis on these two awerages (DMS and DPR) in order to obtain a robust composite measure of industry dynamism. This produced a single-factor solution explaining 87 percent of total variance. The factor scores were split at the median to distinguish stable from dynamic industries. Thus, dynamic industries are characterized by uncertain and therefore unpredictable price-level fluctuations accompanied by large shifts in market share positions. The opposite holds for stable industries.

\section{Some technical remarks}

In analysing our data we used parametric statistical techniques working under the standard assumptions of normality and equal variances between groups. These assumptions were checked for all variables in our study. However, we chose not to report them in each and every instance. Instead, we routinely examined these issues and corrected or checked our results when violations were detected. In this case we will mention it in the text. By default, then, variables are nomally distributed and groups have comparable variances.

Normality was examined using the Kolmogorov-Smimov tests at the $5 \%$ level of significance. If the normality assumption appeared to be violated we checked our parametric results by using non-parametric techniques like Kruskal-Wallis and Mann-Whit-

\footnotetext{
"One might argue that, because the firm's own behavior (prices) and outcomes (market shares) are an integral part. of this industry dynamism measure, the latter is not strictly exogeneous. This is correct, We feel however, that this is only realistic in a pentapoly-situation. Moreover, even when the dynamim measure were based onlly on (four) competions" behavion it was probably stith influenced by a team"s own price and (especially) market share fluctuations. In any case, we alsio calculated dynamsm scores based on only the four competitors. This lead to an $88 \%$ overlap with the currently used classification and did not importantly affect our results.
} 
ney $U$ tests. Fortunately, in almost all cases where significant effects were found, this check led to more instead of less significant results, in other words: our results appeared to be quite "method-proof"'? . However, as no non-parametric techniques for testing interactions exist, we had, in rare instances, to go along with parametric results even though their assumptions were not strictly met.

In all group comparisons (i.e., in t-tests of contrasts between groups) the homogeneity of variance assumption was checked using Levene's statistic. In case the homogeneity of variance hypothesis was rejected at $5 \%$, we used separate instead of pooled variance estimates of the population variance.

\footnotetext{
"12 Generally, it is fair to say that F- and t-statistics, as calculated in parametric methods, are 'robust' statistics in that
they resist wiolation of assumptions (Cohen and Cohen, 1083 ).
} they resist violation of assumptions (Cohen and Cohen, 1983). In fact, our findings also clearly attest to this. 


\section{Achievement: team locus of control composition and economic performance}




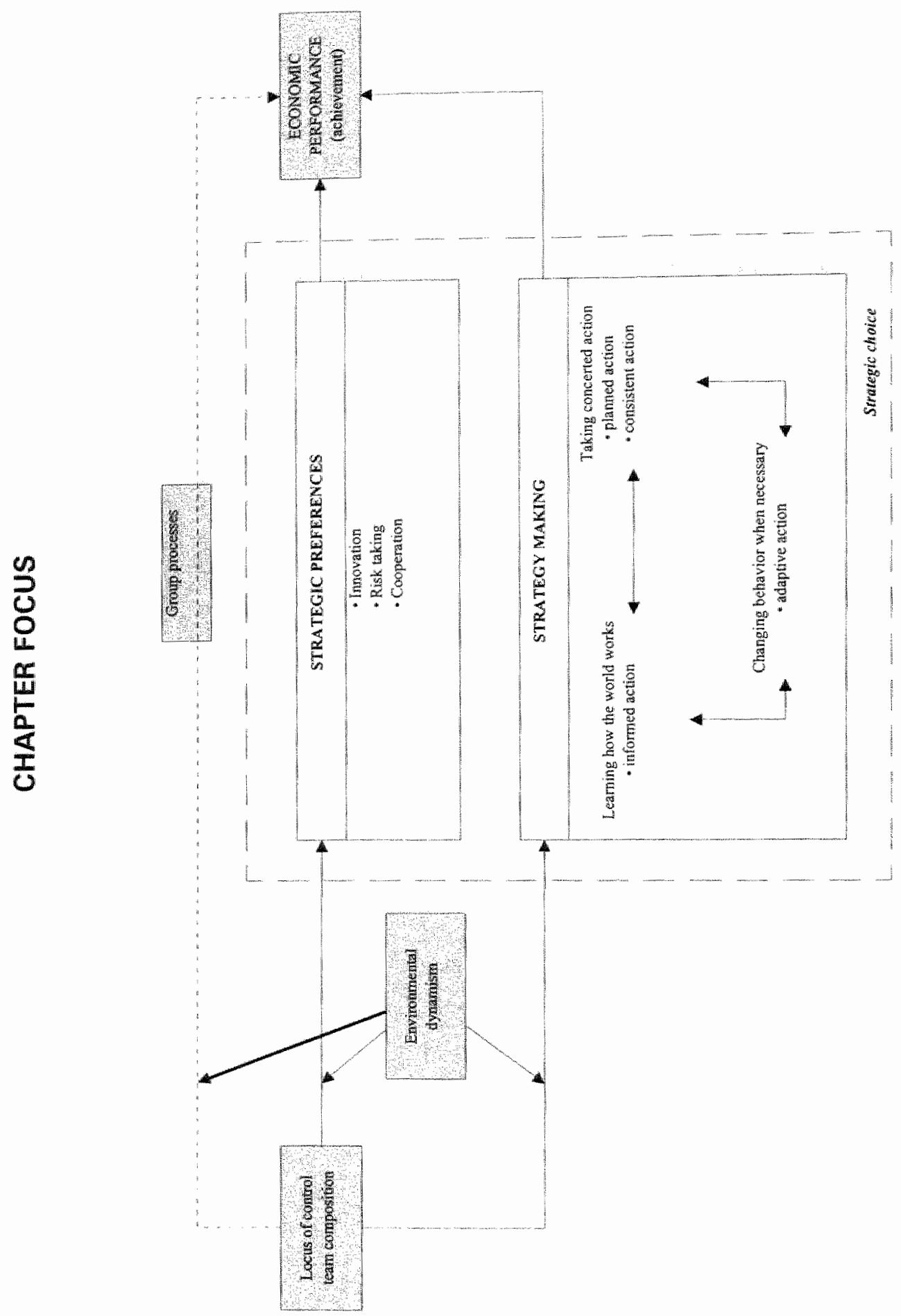


As a first step in our analysis, the current chapter examines, both theoretically and empirically, whether - and if so: to what extent - the locus of control make-up of a management team can explain performance differences in terms of market share and profitability. Regarding our model, we will be studying the overall effect as indicated by the dotted line in figure 3.3 (see left page, shaded area).

The structure of the chapter is as follows. In section 2 we will describe past research on the implications of control perceptions on individual managerial behavior and effectiveness. Combining this body of research with social psychological group research, we will formulate two sets of hypotheses on the impact of control perceptions at the group level. Section 3 presents and discusses the results. The final section is an appraisal.

\section{Locus of control and managerial effectiveness: theory and hypotheses}

The locus of control construct has attracted the attention of several upper echelons scholars. The reason for this is the face validity of the construct for studying the influence of chief executive officers (CEO's) on organizational outcomes: leading a company is in essence a persistent attempt to control the environment. Indeed abundant research clearly shows that locus of control expectancies give rise to behavioral differences which logically relate to managerial effectiveness (Boone, De Brabander and Van Witteloostuijn, 1996; Miller, Kets de Vries and Toulouse, 1982; Miller, 1983; Miller and Toulouse, 1986a, 1986b). Four relevant behavioral consequences are shortly discussed below.

First, the very definition of the concept implies that internals and externals are likely to use different strategies in learning about the environmental contingencies of success and failure. An individual believing in personal control will actively search for the laws ruling the way in which the environment reacts to his/her own behavior. The more extensively (s)he probes, the better the chances are of detecting the crucial contingencies. A believer in mere luck, whimsical fate or manipulation by uncontrollable forces cannot expect any significant payoff from such behavior. Experimental research (Boone, De Brabander and Gerits, 1991; Lefcourt, 1982) as well as field research (Miller, Kets de Vries and Toulouse, 1982; Welsch and Young, 1982) confirmed this general proposition. Internals are more inclined to search for relevant information and seem to learn more from feedback and past experiences than externals (Phares, 1976). Second, internals seem to perform better than externals in achievement-related domains such as career track and education (Andrisani and Nestel, 1976; Lefcourt, 1982; O'Brien, 1984). Achieving long-term goals requires the capacity of delaying immediate gratification (Lefcourt, 1982). It is unlikely that someone who believes that achieving long-term goals depends on luck or external forces, can persist in making such sacrifices. Third,

\footnotetext{
This chapter is based on: Boone, Van Olffen and Van Watteloostuin (1998), Psyclaological team make-up as a determinant of economic firma performance: an experimental study, Journal of Economic Psychology, 19: 43-73.
} 
salient for the research on top managers is that internals have a different leadership style than externals. Internals use more persuasion to influence the behavior of subordinates, whereas externals seem to rely more on coercion (Goodstadt and Hjelle, 1973; Johnson, Luthans and Hennessey, 1984; Mitchell, Smyser and Weed, 1975). Furthermore, task groups headed by internals perform better than groups led by externals (Anderson and Schneier, 1978; Johnson, Luthans and Hennessey, 1984). An important explanation is that internal leaders are more task-oriented, whilst external leaders are more emotionoriented (Anderson and Schneier, 1978). Fourth, internal individuals are less likely to become ill after the experience of stressful life events than external persons. The locus of control trait moderates the relationship between stress and illness (Ganellen and Blaney, 1984a, 1984b; Kobasa, 1979; Kobasa, Maddi and Kahn, 1982), which results from differences in coping behavior (Anderson, 1977; Parkes, 1984; Wiebe, 1991). Internals, on the one hand, react in a problern-solving way in the face of stressful events. Externals, on the other hand, respond emotionally or withdraw from the problem in question. Even in the absence of stressful life events, internals are less likely than externals to feel depressed or to become ill (Benassi, Sweeney and Dufour, 1988).

The consequences of these findings for Chief Executive Officer (CEO) behavior in organizations are nicely summarized by Lewin and Stephens (1994: 195): "CEOs with internal loci of control feel efficacious in controlling outcomes. Therefore, they are likely to believe in the concept of strategy, engage in strategic planning, implement the structures and processes for monitoring the environment that strategic planning entails, and restructure their organizations to fit the contingencies of their chosen strategies". Not surprisingly, previous research relating CEO locus of control to organizational performance produced the robust finding that firms headed by internal CEOs perform better than firms managed by external CEOs (see for a summary Boone, De Brabander and Van Witteloostuijn, 1996). Two qualifications are worth mentioning. First, internal CEOs achieve higher organizational performance irrespective of differences between internal and external CEOs concerning their strategic preferences. Second, although the performance-enhancing effect of internality can be observed in both stable and dynamic industries, it is more pronounced in dynamic environments (Miller and Toulouse, 1986a, 1986b). In dynamic environments, there is "more need for the CEO to interpret the environment; and thus more opportunity for him to enact conditions that reflect psychological as much as objective circumstances" (Miller and Toulouse, 1986a: 1393). These results show that the skills associated with internality (i.e., task-orientedness, motivation, involvement and stress resistance) contribute more to effectiveness in uncertain and ambigucus situations, which is compatible with Rotter's social learning theory (Rotter, 1975) and consistent with existing empirical evidence (Lefcourt, 1982).

Shifting from the individual to the group level adds complexity because now three generic types can be distinguished: teams with nembers who are predominantly internal, those with predominantly external members and mixed teams consisting of a balanced number of internals and externals. Henceforth, we will refer to these team types as internal, external and mixed teams. Two alternative sets of hypotheses, associated with different predictions as to the relative performance of these three team types, can be 
formulated, depending on whether either the importance of accumulating (the same) individual managerial skills in a team is stressed or the potential benefits of diversity are emphasized. Given the absence of theoretical and empirical research on this issue, we refrain from favoring a priori one of both sets of hypotheses, as will become clear below.

The first set of hypotheses is based on personality theory, merely extrapolating what is expected and/or known from individual-level studies on the behavioral and performance implications of locus of control. Specifically, as internal individuals outperform their external colleagues in terms of managerial qualities, accumulating such skills as much as possible in a team is important. Thus, team performance will increase with the number of members with an internal locus of control. As a result, we expect that internal teams will achieve higher performance than mixed teams, whilst the latter will outperform their external counterparts. Apart from this main effect (hypothesis 5.1a), personality theory would predict team type to interact with environmental dynamism (hypothesis $5.1 \mathrm{~b}$ ). Specifically, given that the saliency of skills associated with internality is higher in uncertain and ambiguous situations, we hypothesize that the differences between the three team types will be larger in dynamic as opposed to stable environments.

Hypothesis 5.1a: Internal teams perform better than mixed teams and mixed leams perform better than external teams in both stable and dynamic environments (main effect).

Hypothesis 5.1b: The relative performance differences predicted in hypothesis 5.19 will be larger in dynamic as opposed to stable environments (interaction effect).

The alternative set of hypotheses draws on the social and cognitive psychological studies into the potential effects of group variety on group behavior and outcomes. According to the notion of requisite varien (Weick, 1979), within team diversity must be matched with the complexity and non-routineness of the decision environment to perform well (Milliken and Martins, 1996). When a group faces a complex and non-routine decision environment, team performance may benefit from having a wide range of viewpoints which can be discussed and evaluated critically to arrive at appropriate solutions. High team diversity is likely to facilitate the production of such a wide spectrum of perspectives. As people are the carriers of cognitive capacities and as there are limits to the cognitive complexity any single individual can handle (Cyert and March, 1963), every team member can provide only part of the diversity needed to solve the problem. Varying individual cognitive resources must therefore be pooled to form diverse teams in order to solve complex dilemmas. Empirical research indeed reveals that in solving complex and non-routine problems groups are more effective when composed of members with a variety of skills, knowledge, abilities and perspectives (Filley, House and Kerr, 1976; Shaw, 1981; Wanous and Youtz, 1986). This is particularly evident in innovative activity (Bantel and Jackson, 1989; Katz, 1982; Murray, 1989). As many of people's abilities and perspectives are rooted in their personalities, diversity of psycho- 
logical type is also advocated by several scholars (Belbin, 1981; Blaylock, 1983; Hurst, Rush and White, 1989). Equivalently, the requisite variety principle implies that having diverse teams in simple and routine decision environments, requiring less built-in variety, is a waste of resources. Moreover, diversity has important drawbacks in relation to intra-group functioning, thus appearing to be a double-edged sword (Milliken and Martins, 1996). As many social-psychological studies have shown $n_{p}$ if team members have diverging frames of reference, attitudes and valnes, process losses occur as communication is hampered (McCain, O'Rellly and Pfeffer, 1983; Zenger and Lawrence, 1989). This, in turn, enhances the chance that conflicts, turnover (Wagner, Pfeffer and O'Reilly, 1984) and power struggles (Pfeffer, 1983) will occur, attracting attention away from the immediate tasks of the group. The operational efficiency of diverse teams in performing their tasks is then threatened because much time and energy are required to overcome communication barriers and power games. Thus, the benefits of diversity will only outweigh the costs of poor behavioral integration in complex and non-routine decision environments. In relatively stable environments, the benefits of cognitive variety are futile, and the process losses dominate.

Based on this strand of research, we may expect that mixed teams (i.e., diverse in terms of locus of control) will outperform the other two team types in dynamic but not in stable environments. The benefit of mixing internals with externals might stem from the higher adaptive capacity of mixed teams. Neuropsychologists argue that biological species are able to continuously adapt their behavior to changing environments because they have two different attentional control mechanisms at their disposal: activation and arousal (Pribram and McGuiness, 1975; Tucker and Williamson, 1984). On the one hand, activation controls the ability to act in a planned and goal-oriented way based on acquired insights in the structure of the environment. On the other hand, arousal controls the ability to stop acting so as to focus aftention on new environmental stimuli (such as danger, for instance). The latter is tantamount to an 'alarm system'. Likewise, the adaptive capacity of teams may depend on whether both mechanisms are available. It is clear that having a sensitive 'alarm system', which complements the ability to act, is especially important in a dynamic, rapidly changing, environment. Internal teams, which are characterized by high levels of action-orientedness, might be relatively insensitive to environmental alarm signals. For instance, extreme internality may give rise to what is called the illusion of control (Lefcourt, 1982). The extreme sense of having control in internal teams combined with the relative insensitivity for alarm signals may make this team type prone to the escalation of commitment phenomenon (Staw, 1981). An overly systematic approach, disregarding changing circumstances, will be most detrimental in dynamic environments (Frederickson and Mitchell, 1984). In this case, the team may need to be complemented by extemal managers to equip the group with the necessary alarm signal function. This would facilitate timely changes in investment strategy or resource allocation. Conversely, external teams lack the crucial ability to generate the action-oriented behavior which is a prerequisite for effective management. As externals are easier distracted and emotionally driven, they are more bound to pick up and react to (weak) signals from the environment. In other words, an external team would have an overly sensitive 'alarm system', without however having the skills to react appropriately. 
Consequently, this line of reasoning produces the conjecture that mixed teams, in which the action-orientedness of internals is pooled with the sensitivity of externals, will outperform predominantly internal and external teams in dynamic environments. The opposite will be true in stable environments in which the benefits of a higher adaptive capacity will be low compared to the drawback of diversity - i.e., low behavioral integration. Therefore, we propose the following non-monotonic interaction effect between team type and environmental dynamism.

Hypothesis 5.2a. In stable environments, non-mixed (i.e. intemal and external) teams will outperform mixed teams.

Hypothesis 5.2b: In dynamic environments, mixed teams will outperform non-mixed (i.e., internal and external) teams.

Note that the usual ceteris paribus assumption applies to both sets of hypotheses. Thus, hypotheses $5.2 \mathrm{a}$ and $5.2 \mathrm{~b}$ ignore potential differences between non-mixed teams as a result of the accumulation of different types of skills. Conversely, hypotheses $1 a$ and $b$ fail to take account of the potential benefits and drawbacks of diversity.

\section{Results and discussion}

Table 5.1 provides overall descriptive statistics of the variables under study $(n=58)$. Note the large variability of average market shares obtained in market $\mathrm{C}$ (MSC). Evidently, a number of teams even decided not to enter that market at all, whereas others were able to capture up to a $38 \%$ market share ${ }^{2}$. Moreover, return on equity (ROE) varies widely with some teams even realizing strongly negative returns.

We will analyze the variance in performance measures in two ways. First, we perform between-subject analyses of variance to assess average differences between team types. Specific contrasts between different factor levels are computed to test the hypotheses presented above. Next, we focus on the dynamics of the game by treating team performance in every period as a within-subject measurement. This allows us to assess how team-type differences evolve in time. The unique sums of squares approach for the partitioning of variance was employed for every analysis of variance reported below. This procedure is recommended by Tabachnik and Fidell (1989) when the number of cases in each cell is unequal (i.e., unbalanced design), as is the case in the present study.

\subsection{Between-subject analyses}

In Table 5.2 average performance is reported for internal, external and mixed teams in stable and dynamic industries, and for all industries combined. To get a first grasp of sys-

\footnotetext{
${ }^{2}$ Remember that market $C$ emerged in period 3, so average shares in this market are calculated from period 3 to 6 (instead of 1 to 6 )
} 
Table 5.1

Descriptive statistics

\begin{tabular}{|c|c|c|c|c|}
\hline & Mean & SD & Minimum & Maximum \\
\hline Firm performance: & & & & \\
\hline Market A share (MSA) & 20.10 & 1.39 & 15.68 & 23.15 \\
\hline Market B share (MSB) & 20.07 & 2.46 & 13.11 & 24.83 \\
\hline Marker C share (MSC) & 21.25 & 6.65 & 0.00 & 37.60 \\
\hline Return on equity (ROE) & 1.68 & 1.84 & -4.75 & 6.73 \\
\hline Market dynamism: & & & & \\
\hline Market-share shifts (DMS) & 2.47 & .87 & 1.11 & 4.90 \\
\hline Price-level shifts (DPR) & 35.05 & 18.116 & 13.54 & 74.03 \\
\hline & \multicolumn{4}{|c|}{ Number of observations } \\
\hline Team types: & \\
\hline Internal & \multicolumn{4}{|c|}{23} \\
\hline Extennal & \multirow{2}{*}{\multicolumn{4}{|c|}{$\begin{array}{l}17 \\
18\end{array}$}} \\
\hline Mixed & & & & \\
\hline
\end{tabular}

tematic differences between the means reported in Table 5.2, we performed a multivariate analysis of variance (MANOVA) with four dependent variables (i.e., MSA, MSB, MSC and ROE) and two factors: team type and industry dynamism. These results are summarized in Table 5.3, together with four univariate ANOVAs, one for each dependent variable. The MANOVA results point to a significant main effect of team type on the combined performance measures (Wilk's Lamba $=.73$ with $p<.05$ ), as well as an interaction effect of team type by industry dynamism (Wilk's Lambda $=.71$ with $p<$ .05 ). Thus, there are overall systematic differences in average performance between different team types. Moreover, these differences appear to depend on the degree of environmental dynamism. The univariate ANOVAs show that the main effect of team type is most pronounced for MSB (F-value $=4.70$ with $\mathrm{p}<.05)$ and for $\mathrm{ROE}(\mathrm{F}$-value $=$ 6.50 with $p<.01$ ). The interaction effect only materializes on MSA. (F-value $=3.00$ with $p<10)$ and, again, on $\operatorname{ROE}(\mathrm{F}$-value $=5.52$ with $\mathrm{p}<.01)$.

Inspection of the means in Table 5.2 gives a first impression with respect to the source of these significant differences. It appears that, on average, for all industries combined, internal teams outperform their mixed and extemal counterparts on every performance measure, except for MSC (Column 3 of Table 5.2). With respect to ROE, internal teams realized a profitability that is $70 \%$ higher than the profitability of the second-best team type, i.e., external teams (2.47 versus 1.45). Note that the differences between team types are especially pronounced in dynamic industries (Column 2 of Table 5.2).

\footnotetext{
${ }^{3}$ These analyses were also performed with four covariates included: average tenure of tenm members, avarage age of team members, percentage of team members with a wiversity degree and percentage of male team nembers. The resuits are identical to the ones reported here.
} 
Table 5.2

Team types and performance under different environmental conditions ${ }^{1}$

\begin{tabular}{|c|c|c|c|c|}
\hline \multirow[t]{2}{*}{ Dependent variables } & \multirow[t]{2}{*}{ Team type } & \multicolumn{3}{|c|}{ Enwironmental condition } \\
\hline & & $\begin{array}{l}\text { Stable industries } \\
\text { (Column 1) }\end{array}$ & $\begin{array}{l}\text { Dynamic indus- } \\
\text { tries } \\
\text { (Colum 2) }\end{array}$ & $\begin{array}{l}\text { All industries } \\
\text { (Column } 3 \text { ) }\end{array}$ \\
\hline $\begin{array}{l}\text { Market A share } \\
\text { (MSA) }\end{array}$ & $\begin{array}{l}\text { Intemal } \\
\text { External } \\
\text { Mixed }\end{array}$ & $\begin{array}{c}19.85 \\
(91 ; 13) \\
20.79 \\
(.87 ; 6) \\
19.89 \\
(1.55 ; 11)\end{array}$ & $\begin{array}{c}20.96 \\
(1.20 ; 10) \\
19.96 \\
(1.28 ; 11) \\
19.31 \\
(2.16 ; 7)\end{array}$ & $\begin{array}{c}20.33 \\
(1.16 ; 23) \\
20.25 \\
(1.20 ; 17) \\
19.67 \\
(1.77 ; 18)\end{array}$ \\
\hline $\begin{array}{l}\text { Market } B \text { share } \\
\text { (MSB) }\end{array}$ & $\begin{array}{l}\text { Internal } \\
\text { External } \\
\text { Mixed }\end{array}$ & $\begin{array}{c}20.86 \\
(1.67 ; 13) \\
19.87 \\
(1.91 ; 6) \\
19.41 \\
(2.21 ; 11) \\
\end{array}$ & $\begin{array}{c}21.72 \\
(1.37 ; 10) \\
19.12 \\
(3.18 ; 11) \\
18.96 \\
(3.37 ; 7) \\
\end{array}$ & $\begin{array}{c}21.23 \\
(1.57 ; 23) \\
19.39 \\
(2.76 ; 17) \\
19.24 \\
(2.63 ; 18)\end{array}$ \\
\hline $\begin{array}{l}\text { Market C share } \\
\text { (MSC) }\end{array}$ & $\begin{array}{l}\text { Internal } \\
\text { External } \\
\text { Mixed }\end{array}$ & $\begin{array}{c}21.25 \\
(4.28 ; 13) \\
22.54 \\
(3.95 ; 6) \\
18.17 \\
(6.52 ; 11)\end{array}$ & $\begin{array}{c}21.43 \\
(6.06 ; 10) \\
22.00 \\
(7.17 ; 11) \\
23.55 \\
(11.49 ; 7)\end{array}$ & $\begin{array}{c}21.33 \\
(5.00 ; 23) \\
22.19 \\
(6.09 ; 17) \\
20.27 \\
(8.38 ; 18)\end{array}$ \\
\hline $\begin{array}{l}\text { Return on equity } \\
\text { (ROE) }\end{array}$ & $\begin{array}{l}\text { Internal } \\
\text { External } \\
\text { Mixed }\end{array}$ & $\begin{array}{c}1.71 \\
(1.16 ; 13) \\
1.60 \\
(1.53 ; 6) \\
1.56 \\
(1.21 ; 11)\end{array}$ & $\begin{array}{c}3.46 \\
(1.60 ; 10) \\
1.36 \\
(1.60 ; 11) \\
-.11 \\
(2.80 ; 7)\end{array}$ & $\begin{array}{c}2.47 \\
(1.60 ; 23) \\
1.45 \\
(1.53 ; 17) \\
.91 \\
(2.08 ; 18)\end{array}$ \\
\hline
\end{tabular}

Standard deviations and number of observations in parentheses.

Table 5.2 also reveals that some differences deviate from the pattern described above. This is especially the case for market $C$. This deviation might be the result of differences in the profit potential of markets. That is, building market share does not necessarily imply higher profitability. To explore this possibility, we correlated the three market share variables with ROE. These correlations are $.30(\mathrm{p}<.05), .65(\mathrm{p}<.001)$ and .04 (ns) for MSA, MSB and MSC, respectively. Thus, building market share especially pays off in market B, but not at all in market $C$. Note that this finding is consistent with the rank order of the markets in terms of initial demand reported in Table 4.1 (previous chapter), with market $B$ having the highest and market $C$ the lowest demand.

To test the hypotheses, specific contrasts between team types were calculated and tested for significance. Results are summarized in Table 5.4 (hypotheses $5.1 \mathrm{a}$ and $5.1 \mathrm{~b}$ ) and Table 5.5 (hypotheses $5.2 \mathrm{a}$ and $5.2 \mathrm{~b}$ ).

For hypothesis 5.1 a, the average performance of internal teams is cormpared to 
Table 5.3

Between-subject effect of team type and industry dynamism on performance

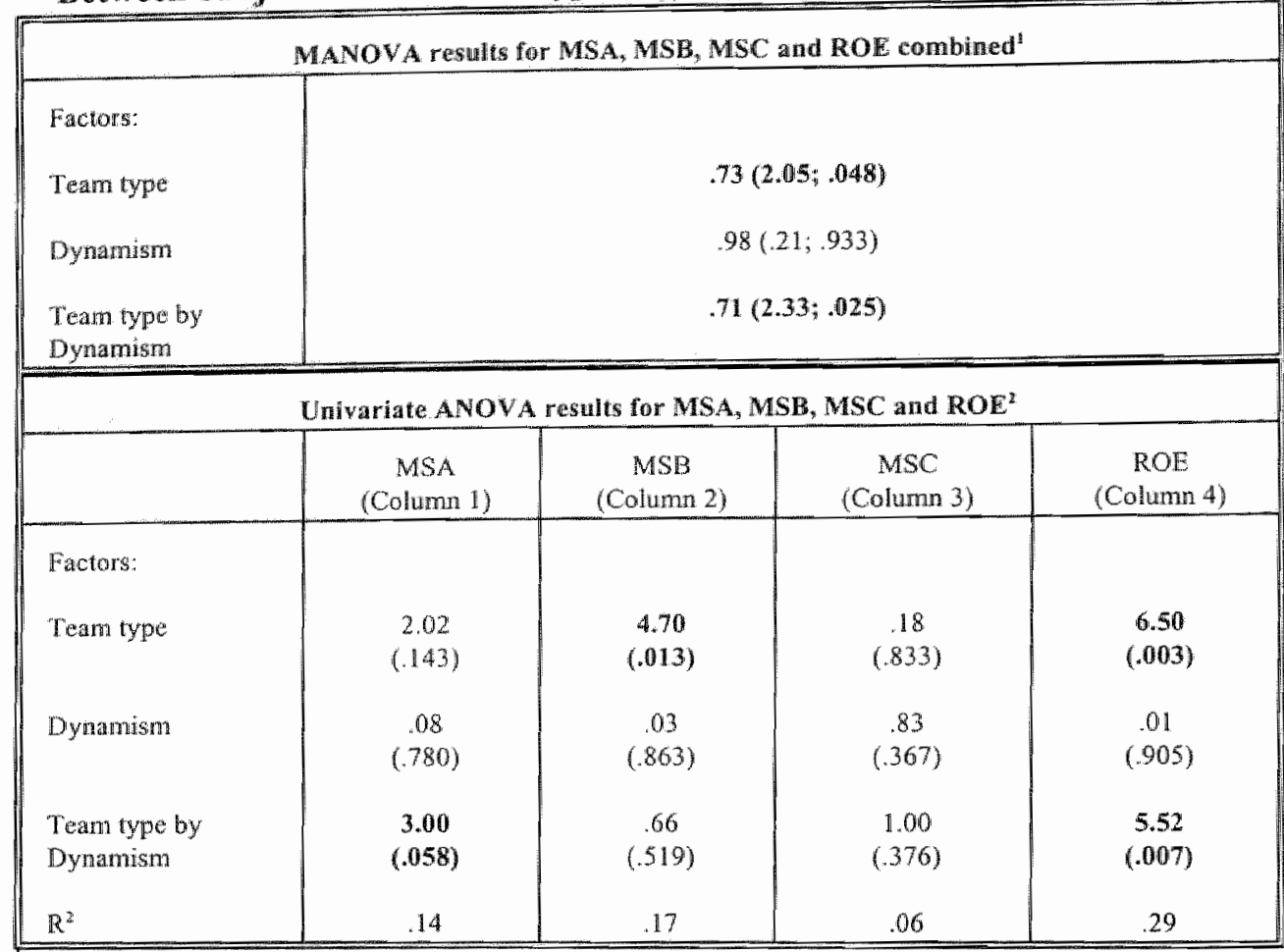

Wilk's Lamubda is reported. F-value and probability of F*value are indicated in parentheses. Significant $F$-values. are printed in bold.

${ }^{2}$ F-values are reported. Probability of F-value is indicated in parentheses. Significant. F-values are printed in bold.

mixed teams, and mixed teams are contrasted to external teans. Internal teams indeed perform better than mixed teams. Three out of the four contrasts are positive in stable as well as in dynamic industries (see rows (1) and (4) of Table 5.4). Five of these six positive contrasts are significantly different from zero (one-tailed $t$-tests). However, contrary to hypothesis $5.1 \mathrm{a}$, mixed teams fail to outperform external teams; if anything, they systematically perform worse. In fact, one out of the eight differences computed is positive, indicating that mixed teams only perform better than external teams in market $C$ when the industry is dynamic (see rows (2) and (5) of Table 5.4). The differences between mixed and external teams, however, are smaller than those between internal and mixed teams. As external teams outperform mixed teams, we also made a post hoc comparison between internal and external teams in stable and dynamic circumstances. These contrasts are reported in rows (3) and (6), respectively. Internal teams outperform external teams on ROE and on the most profitable market (MSB) in both stable and dynamic industries. However, these differences are only significant in dynamic environments. External teams achieve higher market share in market $\mathrm{C}$ which does not contribute to profitability. If we leave this unprofitable market aside, five out of the six contrasts are positive, indicating the superiority of internal over external teams. 
Table 5.4

Contrasts related to hypotheses 5.1 and $5.1 \mathrm{~b}^{\mathrm{I}}$

\begin{tabular}{|c|c|c|c|c|}
\hline & \multicolumn{4}{|c|}{ Dependemt variable } \\
\hline & MSA & $\mathrm{MSB}$ & MSC & ROE \\
\hline \multicolumn{5}{|c|}{ Main contrasts related to hypothesis 5.1 a } \\
\hline \multicolumn{5}{|l|}{ Stable environments } \\
\hline linternal vs. Mixed (1) & .04 & $1.45 *$ & $3.08+$ & .15 \\
\hline Mixed ws. External (2) & $-.90+$ & -.46 & $-4.37 *$ & -.04 \\
\hline Intemal vs. Extemal (3) & $-93+$ & 98 & -1.29 & 11 \\
\hline \multicolumn{5}{|l|}{ Dynamic enwironments } \\
\hline Internal ws. Mixed (4) & $1.65^{*}$ & $2.76^{*}$ & -2.12 & $3.57 * *$ \\
\hline Mixed ws. External (5) & -.65 & -.16 & 1.55 & $-1.47+$ \\
\hline Intemal ws. External (6) & $1.00 \dagger$ & $2.60^{*}$ & -.57 & $2.09 * *$ \\
\hline \multicolumn{5}{|c|}{ Dynamism interaction contrasts related to hypothesis $5.1 \mathrm{~b}$} \\
\hline$(6)=(4)-(1)$ & $1.69 *$ & 1.32 & -5.21 & $3.42 * *$ \\
\hline$(7)=(5) \cdot(2)$ & .25 & $.30 \dagger$ & 5.92 & -1.43 \\
\hline$(8)=(6)-(3)$ & $1.93^{*}$ & 1.62 & .72 & $1.99 *$ \\
\hline
\end{tabular}

" $+\mathrm{p}<.10, * \mathrm{p}<.05$ and $* * \mathrm{p}<.01$ (one-tailed t-test). The contrasts reported are the differences between the specified means presented in Columns 1 and 2 of Table 5.2.

Table 5.5

Contrasts related to hypotheses $5.2 \mathrm{a}$ and $5.2 \mathrm{~b}^{1}$

\begin{tabular}{|c|c|c|c|c|}
\hline & \multicolumn{4}{|c|}{ Depeudent variable } \\
\hline & $\mathrm{MSA}$ & $\mathrm{MSB}$ & $\mathrm{MSC}$ & $\mathrm{ROE}$ \\
\hline \multicolumn{5}{|c|}{ Contrasts melated to hypothesis 5.1 a } \\
\hline \multicolumn{5}{|l|}{ Stable envirommenis } \\
\hline $\begin{array}{l}\text { Irutemal and External } \\
\text { vs. Mixed teams (1) }\end{array}$ & .42 & .95 & $3.73 *$ & .09 \\
\hline \multicolumn{5}{|c|}{ Contrasts related to hypothesis $5.1 b$} \\
\hline Dyramic environment & & & & \\
\hline $\begin{array}{l}\text { Intemal and External } \\
\text { us. Mixed teams (2) }\end{array}$ & $1.15^{*}$ & 1.46 & -1.84 & $2.52 *$ \\
\hline
\end{tabular}

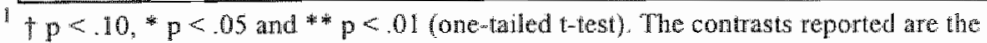
differences between the specified means presented in Columins 1 and 2 of lible 5.2 .

To summarize, hypothesis $5.1 \mathrm{a}$ is only partially supported. That is, internal teams outperform mixed and, to a lesser extent, external teams, but mixed teams fail to achieve better results than their extemal counterparts. Note that the differences between internal teams on the one hand and mixed and external teams on the other hand are larger in 
dynamic as opposed to stable industries. This brings us to hypothesis $5.1 \mathrm{~b}$.

The results indicate a significantly widening gap between internal and mixed teams (again not in market $C$ ) when industry dynamism increases, but not between mixed and external teams (see rows (5) and (6) of Table 5.4). Environmental dynamism thus appears to increase the lead of internal teams over mixed teams, but does almost nothing to the position of mixed vis-a-vis external teams. Again, hypothesis $5.1 \mathrm{~b}$ is only supported with respect to internal and mixed teams, but not to mixed and external teams. A post hoc comparison reveals that the difference between internal and external teams also increases systematically with industry dynamism. The internal versus external team by dynamism interaction contrasts are $1.93(\mathrm{p}<.05), 1.62(\mathrm{~ns}), .72(\mathrm{~ns})$ and $1.99(\mathrm{p}<.05)$ for MSA, MSB, MSC and ROE, respectivelly.

Hypothesis 5.2 a predicted that mixing internals with externals would not pay off in stable environments. The contrasts reported in Table 5.5 (first row) tend to support this argument. That is, internal and external teams combined outperform mixed teams on every performance indicator in stable industries. Only the contrast for MSC, however, is significant. The potential benefits of variety clearly do not materialize in the present sample (hypothesis 5.2b) - on the contrary. Except for MSC, the difference between nonmixed and mixed teams is even larger in dynamic industries, being significant for MSA and ROE (see lower row in Table 5.5). Apparently, process losses as a result of mixing internals with externals seem to dominate in both stable as well as dynamic industries.

Combining these findings, the following overall conclusion can be drawn. The pattern of results partially supports the managerial skills perspective (hypotheses 5.1 a and $5.1 \mathrm{~b}$ ) in that having predominantly internal teams increases performance substantially. The average ROE of internal teams, for instance, is $7 \%$ higher compared to external teams (the second-best type) in stable industries. In dynamic environments, this difference increases up to an impressive $154 \%$. The latter result also illustrates the general finding that internal managerial skills appear to be more salient in dynamic industries. This is also reflected in the explanatory power of team differences on the average team $R O E$ in each environmental context. In stable environments they show no explanatory value on $\mathrm{ROE}$ at all $\left(\mathrm{R}^{2}=00\right)$, whereas in dynamic environments team type differences appear to explain $37 \%$ of the ROE variation! At the same time, our findings also confirm previous social psychological findings stressing the process losses resulting from team diversity (hypothesis 5.2a). Contrary to the principle of requisite variety, however, the potential benefits of diversity did not outweigh the costs of behavioral integration (hypothesis 5.2b). The final implication is that adding internal managerial skills (i.e., internal individuals) to a team does not necessarily increase performance. In fact, if the outcome is a mixed team, performance deteriorates.

\subsection{Within-subject analyses}

In Table 5.6, we report the within-subject effects of four univariate repeated measures analyses of variance in which we treat the period in the game as a within-subject factor.

The period effect is only significant for ROE. In addition, the analyses show a very significant period by team type and a period by team type by dynamism interaction 
Table 5.6

Univariate repeated measures analyses of variance: within-subject effects ${ }^{1}$

\begin{tabular}{|l|c|c|c|c|}
\hline Within-subject effects & MSA & MSB & MSC & ROE \\
\hline Period & .42 & .49 & .32 & 31.21 \\
& $(.79)$ & $(.73)$ & $(.75)$ & $(.000)$ \\
Period by Team type & 1.56 & 3.47 & .85 & 2.92 \\
& $(.14)$ & $(.001)$ & $(.51)$ & $(.002)$ \\
Period by Dynamism & .36 & .66 & 1.27 & .42 \\
& $(.84)$ & $(.60)$ & $(.29)$ & $(.83)$ \\
Period by Team type by & 1.49 & 1.72 & 1.02 & 2.42 \\
Dynamism & $(.17)$ & $(.10)$ & $(.40)$ & $(.01)$ \\
\hline
\end{tabular}

${ }^{1}$ - - values are reported (probability of $F$ in parentheses). Significant F-values are printed in bold. As our data did not meet the assumption of sphericity of variance and covariance matrices, we applied the Huyn-Feldt correction factor to adjust the degrees of freedom of the univariate tests presented in this table (see Tabachnik and Fidell, 1989).

effect on ROE. Although these interaction effects are not significant for MSA and MSB, the findings point in the same direction. Note that MSC behaves again very different compared to the other performance indices. A reason for this has been suggested above. To be able to interpret these interaction effects, we printed graphs of the trend of the performance indicators for each of the three team types for all the industries combined and for stable and dynamic industries separately. Figure 1,2 and 3 present these graphs for ROE, as these are most illustrative. However, the graphs of the market shares (except market C) reveal similar patterns. Recall that each team started the game with the same resources and market shares. It is therefore not surprising to find a significant period by team type interaction. That is, the differences between the team types increase steadily over time (see Figure 5.1 for the all industries case). The three-way interaction suggests that this pattern is different in stable as opposed to dynamic industries. In stable environments (Figure 5.2), team types move closely together and ROE improves substantially for each team type beginning from period 2. In dynamic environments (Figure 5.3), however, ROE starts to diverge greatly from period 2 onwards. As of period 2, internal teams show the same steady increase in ROE as in stable industries. The other team types are not able to sustain this growth. Specifically, the external teams' ROE deteriorates after period 4 and the ROE of mixed teams goes up and down. Note that the last period results of the game precisely match the findings reported in section 3.1: internal teams outperform external and mixed teams, in that order, especially in dynamic environments.

In this chapter we presented the results of a first attempt to systematically link the psychological make-up of a management team to firm performance in a competitive mar- 
Figure 5.1: Average ROE per period (all ind ustries)

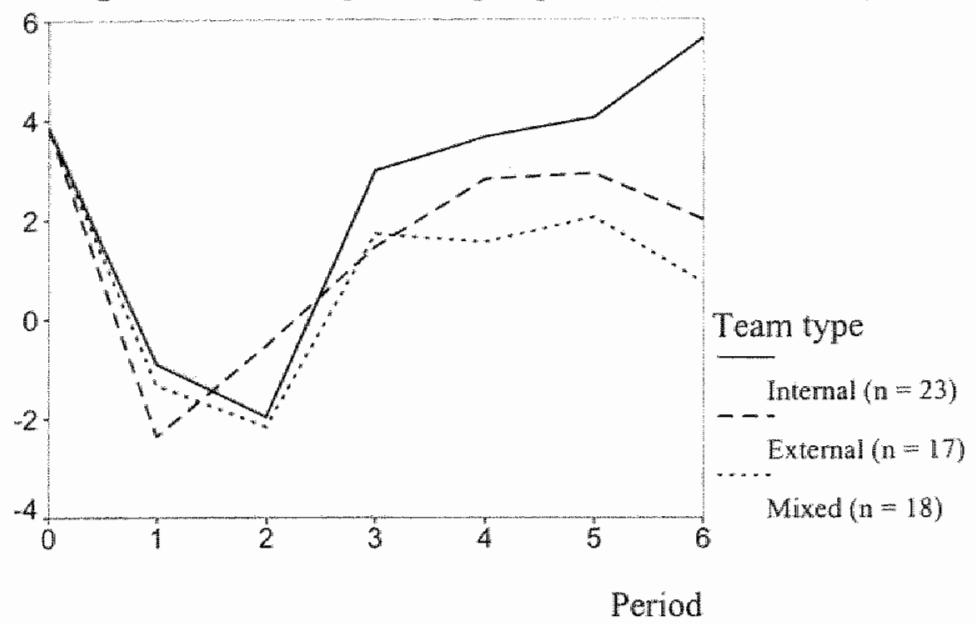

Figure 5.2: Average ROE per period (stable industries)

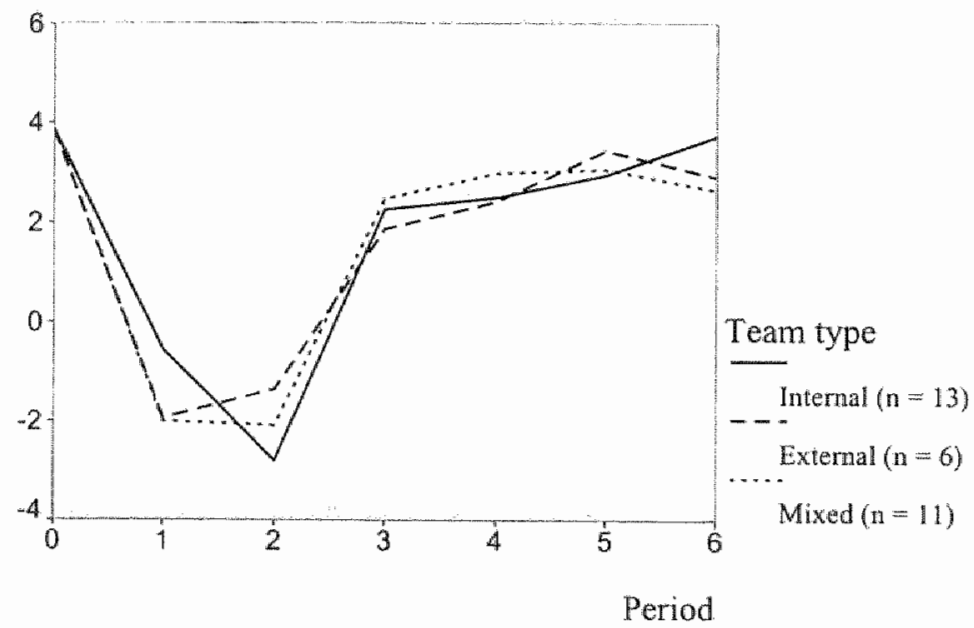

Figure 5.3: Average ROE per period (dynamic industries)

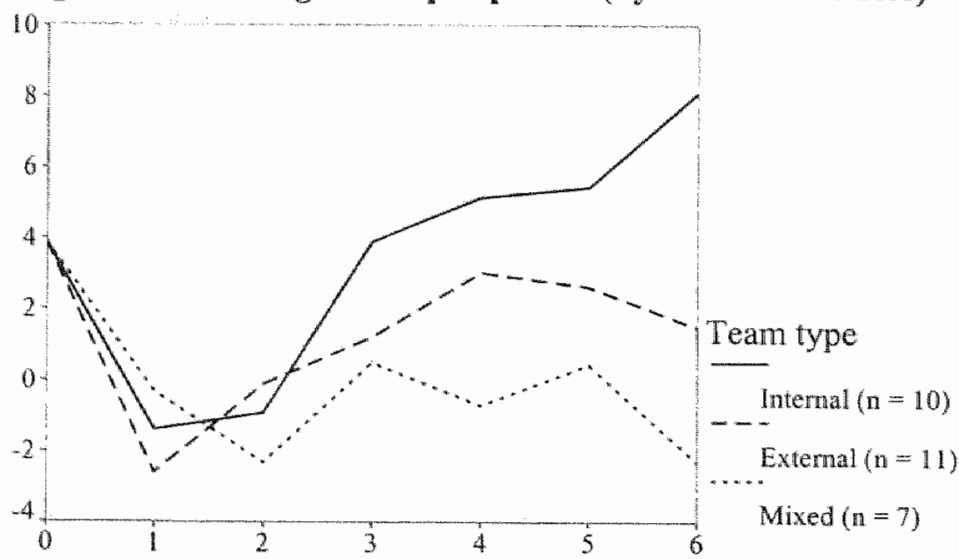

Period 
ket environment. The key finding is that, on average, predominantly internal teams systematically perform better than differently composed teams. This result confirms earlier research on CEO locus of control. The explanation of internal teams' superiority will be the focus of the coming chapters. Broadly speaking, two options exist: either internal teams take different and better decisions (chapter 6) or they have a superior way of making and adapting strategies (chapters 7 and 8 ).

However, apart from underlining the merits of internals on the team, there appears to be a subtle difference with past research as well, which is basically the result of shifting the level of analysis from the individual to the group. We can see this by referring to the surprisingly bad record of mixed teams. Apparently, adding internal individuals to teams does not linearly increase performance because this might invoke process losses depending on the locus of control of the other team members. Specifically, the higher performance of external over mixed teams is indicative of additional problems of integration arising in mixed teams that are not present in relatively homogeneous teams. To check whether this explanation of mixed teams" bad results is correct, close observation of social interaction within teams is necessary, which was practically impossible in our research project. For now, we can only conclude that apparently, diversity does not work with respect to locus of control; quite to the contrary. This might be surprising for a growing number of scholars advocating diversity to increase the adaptive capacity of organizations in an uncertain and changing business environment. Our findings suggest that the negative consequences of diversity should not be underestimated. Finally, the superiority of internal teams in the present game, especially in dynamic environments, points to the possibility that it is useless to compose a diverse team when the capacity to adapt resides in the individual itself. As indicated in chapter 3 , locus of control research indeed suggests that external individuals are more rigid than their internal counterparts. This means that in order to get an adaptive team, it should be homogeneously internal! We will explore differences in adaptive capacities of teams more directly in Chapter 8.

In the next chapter we will look at whether the performance differences can be explained by differences in the general strategic preferences between team types. 
6 Strategic preferences 


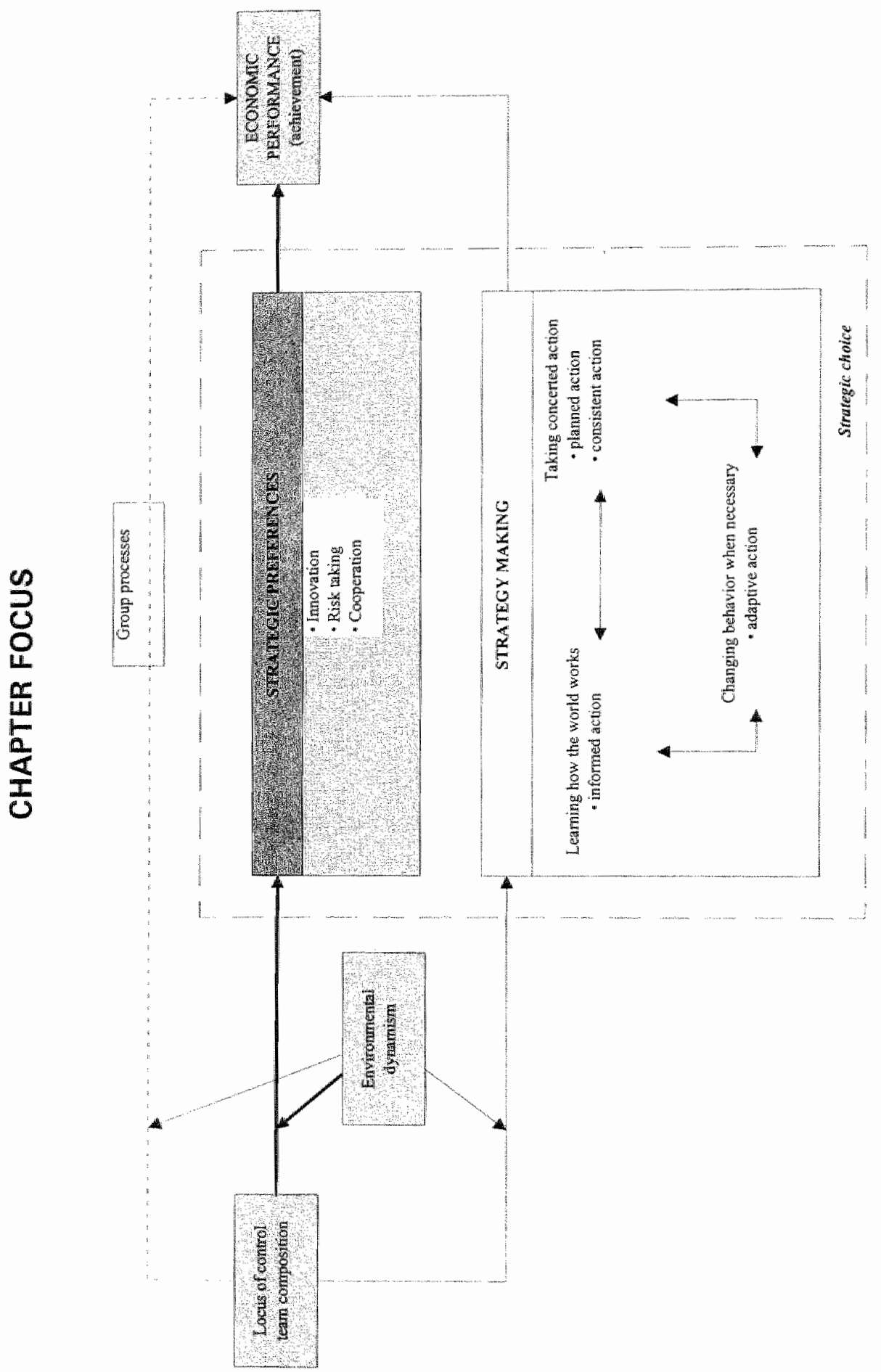


In the previous chapter it was shown that the mix of internals and externals within a team has a considerable impact on performance. We do not know yet, however, what it is that makes some team types perform better than others. A first step in this direction is to take a more in-depth look at the decisions or strategies teans follow, that may account for the performance differences (shaded area in figure on the left page). The only study thus far making a comprehensive attempt at unraveling the link between managers" locus of control and their performance is undertaken by Boone, De Brabander and Van Witteloostuijn (1996). In a sample of Flemish furniture manufacturers, they establish a clear link between CEO's control perceptions and their inclination to choose and successfully implement certain strategies. The findings point out that, compared to external CEO's, internal CEO's tend to pursue more innovative strategies and are more successful at implementing them, even if their strategy is not the most appropriate to follow. Clearly then, internals seem to hold specific strategic preferences that they are also particularly able to implement. While this study pertained to individual CEO's, no study to date has examined these relationships at the team level. Therefore, following this encouraging finding on individuals' strategic preferences, in the present chapter we will try to determine how teams of varying psychological make-up differ in terms of preferred strategic choices. If certain preferred choices appear more profitable than others, possibly the performance differences found in the previous chapter can be attributed to these different preferences.

The chapter is structured as follows. Section 2 will summarize the most important empirical findings on strategic preferences of managers with different perceptions of control. From this we will derive our hypotheses. In section 3 we explain our operationalizations and methods. Section 4 presents the results of our analyses. Finally, section 5 provides a discussion of the results and a conclusion.

\section{Teams' strategic preferences and the locus of control trait}

Our predictions on teams' strategic preferences emanate from studies into characteristics of (individual) entrepreneurs and entrepreneurial firms undertaken mainly by Miller and his associates (e.g., Miller, Kets de Vries and Toulouse, 1982; Miller, 1983; Miller and Toulouse, 1986a). These studies, in turn, were based on evidence of internals' higher entrepreneurial intentions and activity (Durand and Shea, 1974; Brockhaus, 1975). But what is it in internals' behavior that makes them more entrepreneurial than externals? In Miller's studies it is hypothesized that "The task- and action-orientation of internal executives and their greater ability to deal with stressful situations also may prompt them to adopt particular styles of strategy making (...). It is hypothesized that there will be a strong relationship between CEO locus of control and levels of product-market innovation, amount of risk-taking, proactiveness and possibly planning horizons (futurity). The more internal the manager, the higher the scores on variables that measure these characteristics" (Miller, Kets de Vries and Toulouse, 1982: 240). Thus, 'entrepreneurial' characteristics are defined in terms of innovativeness, risk-taking, proactivemess and plan- 
ning. As proactiveness and planning refer more to the process of strategy making instead of preferences for specific strategic choices (like risk-taking or innovation), their treatment will be postponed to the next chapter. For now, we will only select to study internals" preference for innovative and more risky strategies.

A third entrepreneurial strategic preference we think can be linked to locus of control is the amount of cooperation sought with outside parties. As internals are generally more aware of environmental contingencies that may further their performance we expect them to value cooperation with their competitors more. Below we will give a more elaborate theoretical treatment on these strategy-related preferences mentioned and state the specific hypotheses we aim to test.

\subsection{Innovation}

Executives who feel they have control over the destinies of their firms and environments (i.e., internals) may be expected to take an active entrepreneurial role in bringing about change, which often involves innovative activity (Miller and Toulouse, 1986). External executives on the other hand are likely to be more passive because they believe events are beyond their control (Miller, Kets de Vries and Toulouse, 1982). In their opinion, innovation is likely to create competitive turmoil leading to more environmental ambiguity in which they are even less confident of their own actions. Indeed, this tendency for externals to perform worse in dynamic environments is well documented in psychological research (cf. Lefcourt, 1982; see also chapter 3 and 5). Quite some empirical work was undertaken to establish the link between internal control perceptions and innovative activity. In a sample of firms from 11 different industries Miller, Kets de Vries and Toulouse (1982) found a strong relationship between CEO locus of control and innovation in both products and processes. In a similarly heterogeneous sample Miller (1983) again found a strong association between internality and product imovation. Both studies further showed, that the 'executive effect' (Hambrick, 1987) on innovation was stronger in firms characterized by small size and more centralized decision making, augmenting CEOs personal impact on decisions. Similar results were obtained by Miller and Toulouse $(1986 \mathrm{a}, 1986 \mathrm{~b})$, justifying the general conclusion that internal CEOs are more inclined than external CEOs to employ strategies of complex and bold product-market innovation (Boone, De Brabander and Van Witteloostuijn, 1996). We therefore state the following. hypothesis:

Hypothesis 6.1a: Team internality will be positively associated with innovative activities: internal teams will be more innovative than mixed teams and mixed teams will be more innovative than external teans (main effect).

As with all other hypotheses to come, we expect effects from control perceptions to be generally stronger in more uncertain and ambiguous, i.e., dynamic environments. 
Hypothesis 6.16: The differences in innovative activity between team types will be higher in dynamic than in stable environments (interaction effect).

\subsection{Risk-taking}

As risk-taking can be considered an important aspect of entrepreneurship (Kets de Vries, 1977,1980 ), the entrepreneurial spirit of internals in general should also be reflected in a stronger propensity to take (calculated) risks. Indeed, in many studies risk-taking appears to be an integral element of the more entrepreneurial decision sty]e that also incorporates innovativeness. This is of course hardly surprising as most (product) innovation is inherently risky when it involves entering new markets or starting new product lines for which the potentials are as yet uncertain. The correlation between risk-taking and innovation is therefore found to be consistently (strongly) positive (Miller, Kets de Vries and Toulouse, 1982; Miller, 1983; Boone, 1992). Tuming to the association between internality and risk-taking, Miller, Kets de Vries and Toulouse (1982) do indeed find a significantly positive relationship, especially in small firms. This finding is further supported by other research (Miller, 1983; Boone, 1992), although the effect does not always reach statistical significance (Ahmed, 1985; Miller and Toulouse, 1986a; Khan and Manopichetwattana, 1989). Boone, De Brabander and Van Witteloostuijn (1998) report experimental evidence that internals are more likely than externals to take the risk of exposing oneself to the opponent's opportunism in a bilateral prisoner's dilemma. Using financial-statement data to capture risk taken, Begley and Boyd (1987) find that internal business-founders hold lower levels of liquid assets, which they speculate reflect their higher willingness to take liquidity risk. Following the latter research, we will also assume that risky management is reflected in the decisions and financial structures of the firm. Companies can be ran in a financially conservative and relatively "save" manner or in a more risk-taking manner. In line with the research mentioned above we therefore expect internal teams to manage their firms in a more risky fashion. This higher risk taking will also be evident in firm performance. Thus:

Hypothesis 6.2a: The more internal the team, the more risk their actions and performance outcomes will reflect: internal teams will take more risk than mixed teams and mixed teams will take more risk than external teams (main effect).

And:

Hypothesis 6.2b: The differences in risk taking between team types will be higher in dynamic than in stable environments (interaction effect).

\subsection{Cooperation}

The sparse literature on the levels of cooperation to be expected of internals and externals tends to hypothesize a negative relationship between cooperation and internality. 
Bialer (1961), for example, argues that internals greater awareness of their own part in success and failure will cause them to strive harder. He infers from this a stronger competitive stance. Externals, in this reasoning, display more helplessness and will thus "[d]isplay dependency on others and a form of passive cooperation" (Cook and Sloane, 1985: 621). Cook and Chi (1984) in an experimental board game played by dyads of 810 year old children, did indeed find a tendency for external dyads to cooperate more than internal dyads. However, Cook and Sloane (1985), employing the same game serting, were unable to replicate the significant main effect of dyads' locus of control composition (i.e., internal vs. internal, internal vs. external, etcetera) on competitiveness. Only a marginally significant effect was found for dyads of boys; the more external the dyad, the more cooperative the behavior. The (socio-cultural) explanation the authors provide for this result remains rather speculative. In contrast with these findings, Boone, De Brabander and Van Witteloostuijn (1998) find a strong and significant overall relationship between internality and cooperative behavior in a set of bilateral prisoners" dilemma games among university students. The direction of the effect is consistent over various experimental manipulations and appears to be strongest when the other party is non-anonymous, and interactions are repeated. Note that in a repeated prisoners' dilemma game, the issue of trust plays a major role (Pruitt and Kimmel, 1977) and cooperative choices of one party may be retaliated by opportunistic counter parties. Cooperation in this setting is therefore also a risky strategy in which one party tries to induce the other to cooperate and maximize the combined payoffs.

Generally, we feel that the hypothesized tendency of internals to compete rather than cooperate rests on shaky theoretical grounds. In the above mentioned studies by Cook and his colleagues, cooperation is seen too much as a passive kind of withdrawal strategy, whereas in ambiguous situations it may be a well contemplated attempt to reduce uncertainty and an active strategy to co-determine certain parameters of the environment. Especially if cooperation is an option in attaining one's ends, we would expect internals to be most willing to engage in cooperative agreements rather than refrain from them. Externals are less likely to have confidence in tying their fate up with an other party and thereby introducing a new source of uncertainty as they will probably perceive it. The study by Boone et al. (1998) illustrates this attempt of internals to induce cooperation to achieve mutual profit. In our experimental setting in which the possibility of cooperation is explicitly offered to improve profitability we therefore expect the following:

Hypothesis 6.3a: The more internal the team, the stronger its cooperative activities. Internal teams will show more cooperative activity than mixed teams and mixed reams will show more cooperative activity than external teams (main effect).

Hypothesis 6.3b: The differences in cooperative activity between team types are higher in dynamic than in stable environments (interaction effect). 


\subsection{Innovative activity: product quality levels through $R \& D$ investment}

To explain how we measured teams' innovative tendency, it is important first to clarify the process of quality $R \& D$ investments and its effects. In the game, teams can compete for market share by trying to reach higher levels of product quality than their competitors. They can increase these quality levels through innovation in the form of quality R\&D investments". All teams start out with products having quality level 0 . Investments in quality R\&D are made in units of 150.000 ECU's. In every game period, a team can invest a maximum of 20 units of quality $R \& D$ in each of its three products. Teams can choose to invest these units on their own or in cooperation with others. Every quality R\&D unit invested on one's own will increase the quality level of the product in the next period by one unit. If the investment is made in cooperation with another player, however, the investment is more productive: in that case the quality level will be raised by 1.45 units $^{2}$. Anyway, a simple and direct relationship exists between investments in quality $R \& D$ and resulting levels of product quality. The increase in a products' quality (dQ) is a simple function of units invested $a$ lone ( $\mathrm{I} a$ ) and units invested via cooperation (Ic) with others: $\mathrm{dQ}=1 *$ Ia $+1.45 *$ Ic. On the other hand, existing product quality will deteriorate at a fixed rate of $20 \%$ per period. Continued R\&D investment is therefore necessary to keep product quality at a stable level. For instance, if in period 1 a team invests an amount of 20 in quality R\&D for a product (say 14 in cooperation and 6 on its own) jt will raise the quality of the products manufactured in that same period (i.e., period 1) by $1 * 6+1.45 * 14=26.3=26$ units. These products will be supplied to the market one period later, i.e., in period 2 . If in period 2 no additional quality R\&D investments are made, the products manufactured in that period (and supplied to the market in period 3) will have a quality level of only $80 \%$ of $26=21$. Without additional quality R\&D for this product, its quality will continue to deteriorate at this rate in the following periods.

Players are instructed that a leadl in the quality of a product will ceteris paribus increase salles and market shares for that product. As to the precise effects of quality leads on their market shares, tearns can buy information from game management (see item 27 on the decision form in Appendix B). In each period teams can specify two quality levels for which they want to know the associated leads in market share on each market. This information will reveal that product quality is not equally important in all markets: in some markets a quality lead will increase market share more than in other markets. Figure 6.1 provides the actual effect curves for quality leads on market $A, B$ and

\footnotetext{
In fact, theams conld also invest in efficiency R\&D. However, the effect of these investments is more direct and carries less uncertainty: efficiency R\&D lowers teams" own variable costs and raw materials use. Thus, their immediate effect (lowering cost) is not dependent on the invesiments of competitors. As such, these decisions do not carry a really "innovative" character in the sense that quality $R \& D$ decisions do.

${ }^{2}$ The associated cost of this higher producivity lies in the effort one has to make in contacting partners, specifying contracts etc. For details see section 3.3 on cooperation.
} 
C. On the vertical axis it shows the market share percentage that a team can expect to be ahead of its competitors (i.e., its market share lead) at a certain level of quality provided 0 quality levels (i.e., no quality $R \& D$ investments) of competitors. These levels are unknown at the moment the quality $R \& D$ decision has to be made. As Figure 6.1 shows, a lead in quality R\&D pays off more for product $I$ and 3 than it does for product 2 and the effect on market shares tapers off at higher levels of product quality. It is important to note, that the uncer-

Figure 6.1: Effects of product quality levels

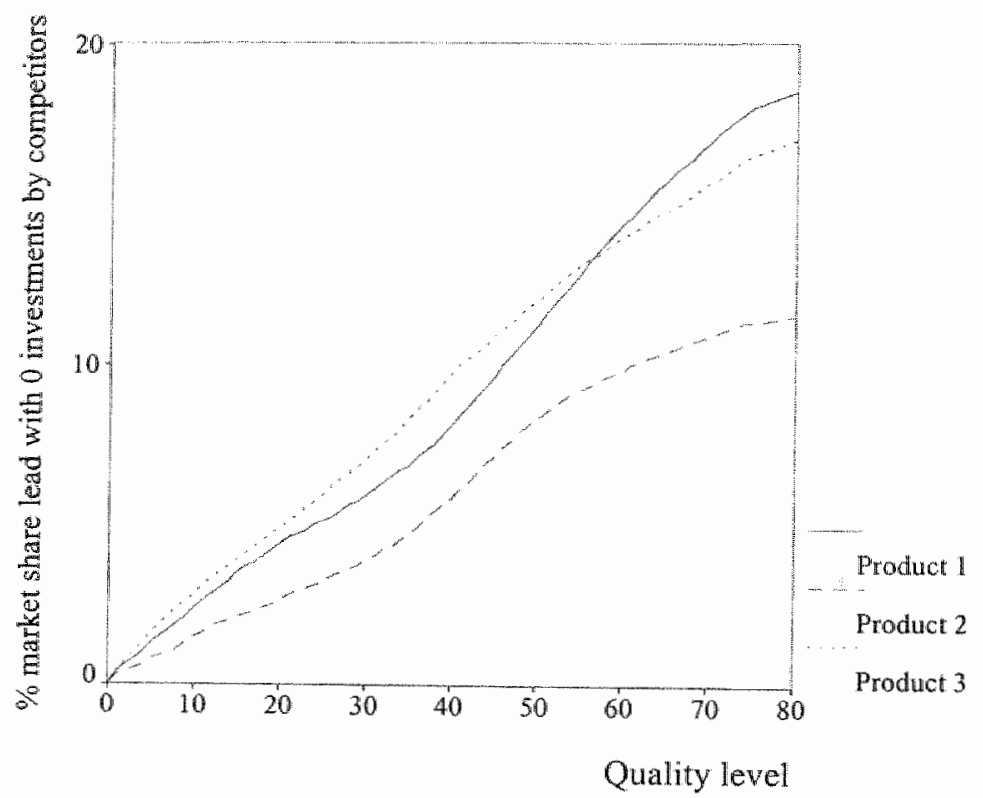

tainty element that is typical of innovative decisions resides in the unknown R\&D levels of competitors who make simultaneous investment decisions. As in each period teams make decisions simultaneously, the ingredients of a classic prisoners' dilemma are present. If a player invests heavily in R\&D and so do its competitors, the effect on the demand for his product (and thus on his market share) is likely to be low. On the other hand, a player that decides to invest low amounts in quality R\&D may lose market share if other parties invest higher amounts in quality R\&D. Furthermore, even if investment in a certain market may seem relatively unattractive, one may simply need to follow competitors if they do invest, because a backlog may be expensive in terms of market share. As such, the effects of innovation are strongly linked to what competitors do. Like in reality, being innovative in an area means being ahead of your competitors. This is exactly what we would expect more innovative teams to do. It is for this reason that we measured teams' innovative stance by looking at the average lead in product quality relative to competitors. That is: we calculated a teams' average quality level over the six decision periods and subtracted the average industry quality. A lead relative to industry average will thus show up as a positive number. 


\subsection{Risk taking}

In all but one of the studies mentioned (i.e., Begley and Boyd (1987)), risk-taking was measured via questionnaires mailed to CEOs asking them to rate their propensity to choose save over risky investment projects and their preference to either wait or act in uncertain situations. Here, we will partly follow the approach followed by Bildersee (1975), who predicted companies' stock market risk by using accounting information ${ }^{3}$. The amount of risk that is inherent in the teams' operations was measured in two ways using financial statement-based variables. First, the risk of insolvency refers to the balance between equity and debt capital. The more equity is used as compared to debt, the less likely it will be that debtors will take the firm into suspension and ultimately bankruptcy if debt cannot be repaid (Shapiro and Titman, 1989). Equity-financing is less risky as equity providers are last in row for refunding investments when the company fails; any other payment to them is voluntary in the form of dividend. In the game, debt capital is provided by the bank, who requires interest payments. The firm is forced to pay redemptions plus a higher interest when a certain credit limit is surpassed. This credit limit was set by the bank at $210 \%$ of equity capital. Borrowing is risky as bad results lower total equity and may lead to forced redemptions of debt capital to the bank. This can, in turn, jeopardize operations and/or liquidity, posing a threat to the company's survival. We measured the firm's solvency by taking the equity/debt ratio (Capital + Reserves/creditors including taxes due). The lower this ratio, the more financial risk is taken. The measure was reverse scaled (i.e., multiplied by -1 ) to reflect insolvency risk. Second, and related to this, is the risk of illiquidity. Liquidity is commonly measured by the current ratio (current assets/current liabilities= (all assets - means of production( $=$ fixed assets)y/(creditors including taxes due)). The current ratio measures the amount of liquid "coverage' of rather immediate debts. Conversely, illiquidity is the risk of not being able to pay or repay debtors because to much assets are held in a fixed or quasi-fixed form (for instance stocks). It thus rises with lower current ratio's, so we again reverse scaled the current ratio to have a positive measure of illiquidity risk. As expected, Bildersee (1975) found these two risk measures to correlate substantially with companies' risk profile as assessed by the variability of their shares on the stock market.

Our third risk measure looks at the expected effects of a risky strategy on returns. By definition, taking risk implies that returns may be either very high or very low. Consequently, returns may be expected to vary more strongly in between periods if more risk is taken. A continued commitment to risky strategies is therefore likely to lead to a more erratic pattern of returns over time than does a risk averse strategy that is likely to yield a more smooth pattern of returns. It is important to stress that the 'jumpiness' or 'non-smoothness' of returns we are interested in, is not the same as the variability of returns as measured by standard variability measures like the standard deviation. Figure 6.2 illustrates this point using two teams from the sample. Both teams' return pattern over

3 For a good review of this and other methodls see Fosier (1986), chapter 10. Thanks to professor Steven Maijoor for bringing this to my antention. 
time yields a comparable standard deviation (2.59 and 2.66). However, it is clear that the returns of team 139 are more volatile than those of team 246 . Clearly, we need some different measure that meaningfully measures how erratic the pattern is. To arrive at such a measure, we looked at increases and decreases in adjacent time periods and counted the number of turnarounds in the trend. Take figure 6.2 as an example. We will denote each increase between periods with a ' $t$ " and each decrease with a " - . A sequence of similar signs is called a 'run'. For team 139 the sequence of signs is then: $(-,+,+,-,+,-)$, producing a total of 5 changes of sign (runs). In the case of team 246 we have $(-,-,+$, ,,+++ ), i.e., 2 runs. Team 139 is therefore considered to be more erratic than team 246.

\section{Figure 6.2: Erraticness: two illustrative teams}

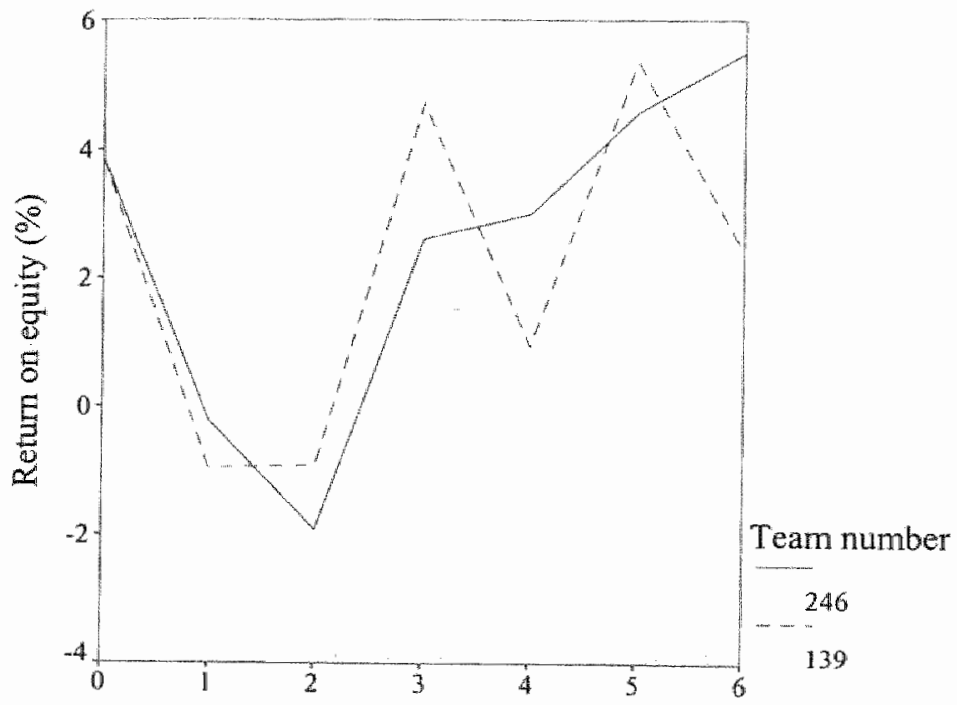

Period

Finally, to obtain an overal measure of risk taking, we standardized each individual risk measure over all 58 teams and summed these three standardized scores for each team ${ }^{4}$. In this way we arrived at an overall, composite measure of relative risk.

\subsection{Cooperative activity: R\&D deals.}

To increase the effectiveness of their R\&D expenditures, firms can cooperate with other firms in the industry. This cooperation can involve both product quality and efficiency R\&D for each of the three products. Thus, six different cooperation agreements ("deals") are possible. All deals are closed for one period only at the beginning of each new period. Teams can cooperate with all four competitors in the industry. However, in each

\footnotetext{
4 This is generally a proper procedure if the different aspects are of anadditive nature, i.e., if they measure various forms of an underlying construct (risk taking) that are not necessarily correlated.
} 
period they can close each of the six possible deals only once; the maximum amount of deals per cooperation partner is two. For instance, team 1 can cooperate with team 2 on quality R\&D for product 2 and efficiency R\&D for product 3 . At the same time, team 1 can cooperate with team 3 on quality R\&D for product $\mathbb{1}$ and efficiency $R \& D$ for product 2 . For each product, the maximum amounts of $R \& D$ expenditures either stand-alone or in cooperation are 20 units for quality $R \& D$ and 10 units for efficiency $R \& D$ per period. Thus, teams have a choice between investing this maximum on their own or (partly) in cooperation with others. It is pointed out to players by the game manual, that cooperation will lead to a faster improvement in quality and efficiency levels than will stand-alone investments. For instance, if in a certain period a team decides to invest 6 units of quality R\&D on its own and 14 units in cooperation with a partner, this will raise product quality by $6+1.45^{*} 14=25.6=26$ units $^{5}$. Thus, every unit invested via cooperation yielded a 1.45 instead of the usual 1 unit increase in product quality and efficiency level. This factor (1.45) was not actually mentioned to players, but it is a constant game parameter which could easily be computed after investments through cooperation were made.

To cooperate, teams have to contact each other by phone and agree on the number of units of product and process R\&D they want to invest together in the upcoming period. A standard game cooperation agreement form is then filled out, signed by both parties and faxed to game management, together with the decision form of the upcoming period.

Teams' commitment toward cooperation, was measured by a set of characteristics of their cooperative behavior. Specifically, we looked at the average number of deals closed in each period, the total number of periods that deals were closed, the first period a deal was closed, the maximum number of periods with one partner and, finally, the number of different partners teams cooperated with. Following hypothesis $3 \mathrm{a}$ and $\mathrm{b}$, we expected that teams with a stronger commitment to cooperation would close more deals per period, cooperate longer and earlier, choose more different partners and have longer contracts with any one partner. Similarly to our risk measures, the different aspects of cooperation were standardized over all teams and then summed, resulting in a composite measure of cooperation.

\section{$4 \quad$ Results}

\subsection{Innovation}

Table 6.1 reports on the average product quality positions of different team types under different environmental conditions. All positions reported are in units relative to the

\footnotetext{
${ }^{5}$ Remember, however, that product quality investments depreciate at a rate of $20 \%$ of their former lewel each period as noted, this is not so for efficiency levels.

"It is important to note that we have not used the number of units invested wia cooperation as they simply measure the propensity to innovate (treated in section 3.1). If we had, we would for instance have considered a team closing one deal for 15 units to be as cooperative as a team closing three different deals for 5 units. Instead, we are interested in the team's cooperation attitude: it's cooperation frequency and elaborateness.
} 
team's industry average. For instance, in stable industries, internal teams had an average product 1 quality level that was 2.08 units below the industry mean, whereas mixed teams were on average 2.27 units above their industry means. Note the surprising overall first rank of mixed teams in stable environments (column 1, bottom cell) and their last rank in dynamic environments (column 2, bottom cell). Internal teams take the first position in product 1 and 3 in dynamic environments as well as on relative overall quality (column 2, bottom cell). They are systematically lowest in relative product 2 quality. As column 3 of Table 6.1 shows, there seems to be a general tendency for all teams in our sample to be somewhat below their industry means in product quality. However, over all products and industries (bottom right corner cell in Table 6.1) none of the teams ${ }^{x}$ relative quality levels $(-.63,-.13$ and -1.43$)$ deviated significantly from 0 (i.e., the industry average) using two-tailed i-tests). Thus, sampled teams did not generally differ significantly from the population average in established quality levels.

Table 6.1

Descriptive statistics: Innovativeness ${ }^{1}$

\begin{tabular}{|c|c|c|c|c|}
\hline \multirow[t]{2}{*}{ Dependent variables } & \multirow[t]{2}{*}{ Team type } & \multicolumn{3}{|c|}{ Environmental condition } \\
\hline & & $\begin{array}{c}\text { Stable industries } \\
(\text { Column } 1)\end{array}$ & $\begin{array}{c}\text { Dynamic industries } \\
\text { (Column 2) }\end{array}$ & $\begin{array}{l}\text { All industries } \\
\text { (Collumn } 3)\end{array}$ \\
\hline Rellative product 1 quality & $\begin{array}{l}\text { Internal } \\
\text { Mixed } \\
\text { External }\end{array}$ & $\begin{array}{c}-2.08 \\
(6.69 ; 13) \\
2.27 \\
(4.35 ; 11) \\
-.51 \\
(7.92 ; 6) \\
\end{array}$ & $\begin{array}{c}3.50 \\
(6.47 ; 10) \\
-5.18 \\
(5.45 ; 7) \\
-3.02 \\
(6.64 ; 11) \\
\end{array}$ & $\begin{array}{c}35 \\
(7.04 ; 23) \\
-.63 \\
(5.97 ; 18) \\
-2.13 \\
(6.98 ; 17) \\
\end{array}$ \\
\hline Relative product 2 quality & $\begin{array}{l}\text { Internal } \\
\text { Mixed } \\
\text { External }\end{array}$ & $\begin{array}{c}-2.79 \\
(2.99 ; 13) \\
.17 \\
(4.88 ; 11) \\
-.19 \\
(5.96 ; 6)\end{array}$ & $\begin{array}{c}-1.29 \\
(5.86 ; 10) \\
-1.27 \\
(4.57 ; 7) \\
-1.02 \\
(4.29 ; 11)\end{array}$ & $\begin{array}{c}-2.14 \\
(4.42 ; 23) \\
-.39 \\
(4.68 ; 18) \\
-.73 \\
(4.77 ; 17) \\
\end{array}$ \\
\hline Relative product 3 quality & $\begin{array}{l}\text { Internal } \\
\text { Mixed } \\
\text { External }\end{array}$ & $\begin{array}{c}-1.38 \\
(4.22 ; 13) \\
1.31 \\
(4.25 ; 11) \\
-1.05 \\
(4.93 ; 6) \\
\end{array}$ & $\begin{array}{c}1.57 \\
(3.92 ; 10) \\
-.41 \\
(5.14 ; 7) \\
-1.62 \\
(5.52 ; 11) \\
\end{array}$ & $\begin{array}{c}-10 \\
(4.27 ; 23) \\
.64 \\
(4.55 ; 1.8) \\
-1.42 \\
(5.17 ; 17) \\
\end{array}$ \\
\hline $\begin{array}{l}\text { Relative overall product } \\
\text { quality }\end{array}$ & $\begin{array}{l}\text { Internal } \\
\text { Mixed } \\
\text { External }\end{array}$ & $\begin{array}{c}-2.08 \\
(3.79 ; 13) \\
1.25 \\
(2.54 ; 11) \\
-58 \\
(4.97 ; 6) \\
\end{array}$ & $\begin{array}{c}1.26 \\
(3.25 ; 10) \\
-2.29 \\
(4.76 ; 7) \\
-11.89 \\
(4.71 ; 11) \\
\end{array}$ & $\begin{array}{c}-.63 \\
(3.88 ; 23) \\
-13 \\
(3.87 ; 18) \\
-1.43 \\
(4.69 ; 17) \\
\end{array}$ \\
\hline
\end{tabular}

deviations and number of observations in parentheses

To test for general team differences, a two-way analysis of variance was applied on 
relative quality levels with team type and industry dynamism as factors. The results of the ANOVA analysis are presented in Table 6.2. They show no significant main effect of team type or industry dynamism. Apparently, team types did not differ on average quality leads in their markets. Consequently, hypothesis $6.1 \mathrm{a}$ is not supported. However, a very significant interaction effect exists with regard to product 1 , causing the interaction effect on the average of all three products (last column in Table 6.1) to be significant as well. We may conclude from this, that although no systematic overall differences between team types exist, the significant interaction points at a different relationship between team type and innovativeness in stable than in dynamic environments, at least for certain products or markets.

\section{Table 6.2 \\ Innovativeness}

ANOVA results on hypotheses $6.1 \mathrm{a}$ and $6.1 \mathrm{~b}^{1}$

\begin{tabular}{|c|c|c|c|c|}
\hline & \multicolumn{4}{|c|}{ Dependent wariable } \\
\hline & $\begin{array}{l}\text { Relative product } 1 \\
\text { innovativeness }\end{array}$ & $\begin{array}{l}\text { Relative product } 2 \\
\text { innowativeness }\end{array}$ & $\begin{array}{l}\text { Relative product } 3 \\
\text { innovativeness }\end{array}$ & $\begin{array}{l}\text { Overall product } \\
\text { innovativeness }\end{array}$ \\
\hline \multicolumn{5}{|l|}{ Factors: } \\
\hline Team type & $\begin{array}{l}.92 \\
(.40)\end{array}$ & $\begin{array}{l}.65 \\
(.53)\end{array}$ & $\begin{array}{l}.68 \\
(.51)\end{array}$ & $\begin{array}{c}.22 \\
(80)\end{array}$ \\
\hline Dynamism & $\begin{array}{l}.74 \\
(.40)\end{array}$ & $\begin{array}{l}.04 \\
(.84)\end{array}$ & $\begin{array}{l}.03 \\
(.86)\end{array}$ & $\begin{array}{l}22 \\
(64)\end{array}$ \\
\hline $\begin{array}{l}\text { Team type by dyna- } \\
\text { mism. }\end{array}$ & $\begin{array}{l}5.50 \\
(.01)\end{array}$ & $\begin{array}{l}.55 \\
(.74)\end{array}$ & $\begin{array}{l}1.38 \\
(.26)\end{array}$ & $\begin{array}{l}3.94 \\
(.03)\end{array}$ \\
\hline $\mathrm{R}^{2}$ & .20 & .05 & .08 & .15 \\
\hline
\end{tabular}

${ }^{2} \mathbb{F}$ walmes are reported. Probability of $F$ in parentheses. Significant $F$ walues printed in bold.

To see how differences vary between environmental conditions, contrasts were calculated between team types in either condition, using column 1 and 2 of Table 6.1. These contrasts are reported in Table 6.3. The interaction effect appears to be caused by a reversal of the relative positions of teams in stable and dynamic environments in product 1 and (to a lesser degree) product 3 innovative activity. Specifically, as can be seen in Table 6.1 as well, internal teams show lowest innovative activity in stable environments, but highest innovative activity in dynamic environments. This causes the interaction contrasts with internal teams in the lower part of Table 6.3 to be significant. The differences between external and mixed teams remain insignificant in either environment. In dynamic environments the internal team contrasts are significant in the expected direction, whereas in stable environments they are not. The pattern of the interaction, therefore, does not support hypothesis $6.1 \mathrm{~b}$ in a strict sense, as it predicted an increase in positive contrasts. Note (in Table 6.3 and Figure 6.1 ), that significant interaction differences onlly occurred in those markets where innovative activity is most productive in potential market share gain, i.e., in markets $A$ and $C$. 
Table 6.3

Innovativeness: Contrasts related to hypotheses $6.1 \mathrm{a}$ and $6.1 \mathrm{~b}^{\mathrm{I}}$

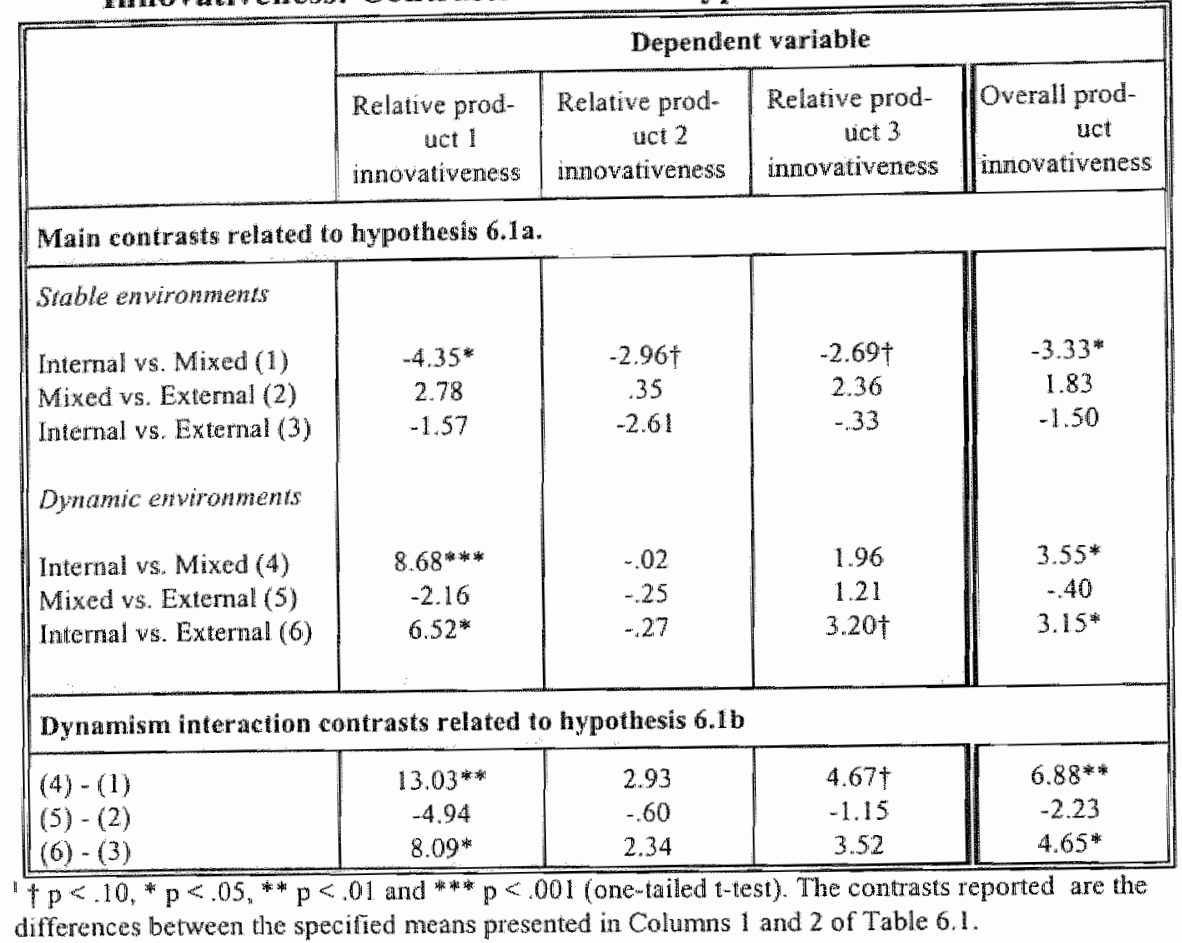

\subsection{Risk taking}

Table 6.4 provides subgroup descriptives on the risk taking variables. The means of team types with regard to the number of return on equity (ROE) runs, illiquidity and insolvency hardly differ. Only the number of runs shows differences at first sight. Note that the ROE sequences on average contain almost 4 runs out of the maximum of 6 , rendering the average sequence rather erratic.

The ANOVA results in Table 6.5 reflect the general lack of systematic differences as the combined risk variables show no significant main effect for team type nor dynamism. The interaction effect does not reach significance either. Only the insolvency variable shows a main effect for team type. An analysis of what happened to produce this effect, revealed that over time insolvency rises sharply for all team types, but strongest for internal teams. The reason for this, is that internals' debt financing rose sharply after period 3, whereas that of other team types leveled off. Consequently, internals ended up with significantly lower solvency ratios and, thus, higher insolvency, as expected. The other iwo risk measures, however, showed no systematic differences between team types. Taken together, there is very limited support for hypothesis $6.2 \mathrm{a}$ as internals' results do not reflect more risk-taking than those of other teams, except for a small insolvency difference. We are led to reject the interaction hypothesis on risk taking (i.e., hypothesis $6.2 \mathrm{~b})$ as well, as none of the interaction effects is significant. 
Table 6.4

Descriptive statistics: Risk taking ${ }^{1}$

\begin{tabular}{|c|c|c|c|c|}
\hline \multirow[t]{2}{*}{ Risk measure } & \multirow[t]{2}{*}{ Team type } & \multicolumn{3}{|c|}{ Enyîronmental condition } \\
\hline & & $\begin{array}{l}\text { Stable industries } \\
\text { (Column 1) }\end{array}$ & $\begin{array}{c}\text { Dynamic industries } \\
\text { (Column 2) }\end{array}$ & $\begin{array}{l}\text { All industries } \\
\text { (Column } 3)\end{array}$ \\
\hline Nimber of runs & $\begin{array}{l}\text { Internal } \\
\text { Mixed } \\
\text { External }\end{array}$ & $\begin{array}{c}3.69 \\
(48 ; 13) \\
3.73 \\
(1.19 ; 11) \\
3.50 \\
(55 ; 6)\end{array}$ & $\begin{array}{c}3.60 \\
(.70 ; 10) \\
3.71 \\
(1.11 ; 7) \\
3.91 \\
(.70 ; 11)\end{array}$ & $\begin{array}{c}3.65 \\
(.57 ; 23) \\
3.72 \\
(1.13 ; 18) \\
3.76 \\
(.66 ; 17)\end{array}$ \\
\hline Thiguidity & $\begin{array}{l}\text { Intermal } \\
\text { Mixed } \\
\text { External }\end{array}$ & $\begin{array}{c}-1.22 \\
(.02 ; 13) \\
-1.23 \\
(.02 ; 11) \\
-1.22 \\
(.02 ; 6)\end{array}$ & $\begin{array}{c}-1.23 \\
(.02 ; 10) \\
-1.22 \\
(.02 ; 7) \\
-1.23 \\
(.02 ; 11)\end{array}$ & $\begin{array}{c}-1.22 \\
(.02 ; 23) \\
-1.22 \\
(.02 ; 18) \\
-1.23 \\
(.02 ; 17)\end{array}$ \\
\hline Insolvency & $\begin{array}{l}\text { Internal } \\
\text { Mixed } \\
\text { External }\end{array}$ & $\begin{array}{c}-.39 \\
(.01 ; 13) \\
-.41 \\
(.02 ; 11) \\
-.40 \\
(.02 ; 6)\end{array}$ & $\begin{array}{c}-.40 \\
(.02 ; 10) \\
-41 \\
(.01 ; 7) \\
-.41 \\
(.01 ; 11)\end{array}$ & $\begin{array}{c}-.39 \\
(.02 ; 23) \\
-411 \\
(.02 ; 18) \\
-.40 \\
(.01 ; 17)\end{array}$ \\
\hline $\begin{array}{l}\text { Relatiwe overall } \\
\text { risk taking }\end{array}$ & $\begin{array}{l}\text { Internal } \\
\text { Mixed } \\
\text { External }\end{array}$ & $\begin{array}{c}.95 \\
(1.42 ; 13) \\
-.51 \\
(1.66 ; 11) \\
-25 \\
(1.96 ; 6)\end{array}$ & $\begin{array}{c}.01 \\
(2.27 ; 10) \\
-12 \\
(2.44 ; 7) \\
-.41 \\
(1.81 ; 11)\end{array}$ & $\begin{array}{c}.54 \\
(1.85 ; 23) \\
-.35 \\
(1.94 ; 18) \\
-.35 \\
(1.80 ; 17)\end{array}$ \\
\hline
\end{tabular}

"Group averages are reported Standard deviations and number of observations in parentheses.

Table 6.5

Risk taking: ANOVA results on hypotheses $6.2 \mathrm{a}$ and $6.2 \mathrm{~b}^{\prime}$

\begin{tabular}{|l|c|c|c||c|}
\hline & \multicolumn{3}{|c|}{ Dependent variable } \\
\hline & Number of runs" & Illiquidity & Insolvency & \begin{tabular}{|l} 
Relative overall \\
risk taking
\end{tabular} \\
\hline Factors: & & & & \\
Team type & .05 & .45 & 4.24 & 1.19 \\
& $(.96)$ & $(.64)$ & $(.02)$ & $(.31)$ \\
Dynamism & .20 & .58 & .34 & .21 \\
& $(.65)$ & $(.44)$ & $(.56)$ & $(.65)$ \\
Team type by dynamism & .46 & 1.50 & .12 & .62 \\
& $(.63)$ & $(.23)$ & $(.89)$ & $(.54)$ \\
$\mathrm{R}^{2}$ & .02 & .09 & .16 & .08 \\
\hline
\end{tabular}

${ }^{1} \mathrm{~F}$ values are reported. Probability of $\mathrm{F}$ in parentheses. Significant $\mathrm{F}$ values printed in bold.

2 Variable is not normally distributed. 


\subsection{Cooperation}

Table 6.6 summarizes the results regarding cooperation. We added ranks ( 1 =highest) to the reported averages for ease of reference $e^{7}$. The rank orderings in column 1 and 2 indicate that stable and dynamic industries seem to possess reverse patterns. In stable industries external teams have the most frequent number one ranking, whereas in dynamic industries this position is most often recorded for internal teams. The summary measure in the lower row displays a similar ordering.

\section{Table 6.6}

Descriptive statistics: cooperative activities"

\begin{tabular}{|c|c|c|c|c|c|c|c|}
\hline \multirow[t]{2}{*}{ Cooperation aspect } & \multirow[t]{2}{*}{ Team type } & \multicolumn{6}{|c|}{ Enwironmental condition } \\
\hline & & \multicolumn{2}{|l|}{$\begin{array}{c}\text { Stable industries } \\
\text { (Column 1) }\end{array}$} & \multicolumn{2}{|c|}{$\begin{array}{c}\text { Dynamic industries } \\
(\text { Column } 2)\end{array}$} & \multicolumn{2}{|l|}{$\begin{array}{l}\text { All industries } \\
\text { (Column 3) }\end{array}$} \\
\hline $1 . H$ efficiency deals & $\begin{array}{l}\text { Internal } \\
\text { Mixed } \\
\text { Extennal }\end{array}$ & $\begin{array}{l}1.69(2.02 ; 13) \\
1.27(1.19 ; 11) \\
3.00(3.03 ; 6)\end{array}$ & $\begin{array}{l}2 \\
3 \\
1\end{array}$ & $\begin{array}{l}3.20(2.62 ; 10) \\
3.43(4.47 ; 7) \\
.91(.94 ; 11)\end{array}$ & $\begin{array}{l}2 \\
1 \\
3\end{array}$ & $\begin{array}{l}2.35(2.37 ; 23) \\
2.11(3.01 ; 18) \\
1.65(2.12 ; 1.7)\end{array}$ & $\begin{array}{l}1 \\
2 \\
3\end{array}$ \\
\hline 2. \#quality deals & $\begin{array}{l}\text { Internal } \\
\text { Mixed } \\
\text { Exterinal }\end{array}$ & $\begin{array}{l}1.85(2.54 ; 13) \\
2.55(2.81 ; 11) \\
2.17(1.47 ; 6)\end{array}$ & $\begin{array}{l}3 \\
1 \\
2\end{array}$ & $\begin{array}{l}4.30(2.63 ; 10) \\
4.43(5.59 ; 7) \\
1.55(2.11 ; 11)\end{array}$ & $\begin{array}{l}2 \\
1 \\
3\end{array}$ & $\begin{array}{l}2.91(2.81 ; 23) \\
3.28(4.07 ; 18) \\
1.76(1.89 ; 17)\end{array}$ & $\begin{array}{l}2 \\
1 \\
3\end{array}$ \\
\hline $\begin{array}{l}\text { 3. Hefficiency } \\
\text { cooperation periods }\end{array}$ & $\begin{array}{l}\text { Unternal } \\
\text { Mixed } \\
\text { Extermal }\end{array}$ & $\begin{array}{l}1.31(1.57 ; 13) \\
1.18(.87 ; 11) \\
2.17(2.14 ; 6)\end{array}$ & $\begin{array}{l}2 \\
3 \\
1\end{array}$ & $\begin{array}{l}2.20(1.81 ; 10) \\
1.86(2.34 ; 7) \\
.91(.94 ; 11)\end{array}$ & $\begin{array}{l}1 \\
2 \\
3\end{array}$ & $\begin{array}{l}1.70(1.69 ; 23) \\
1.44(1.58 ; 18) \\
1.35(1.54 ; 17)\end{array}$ & $\begin{array}{l}1 \\
2 \\
3\end{array}$ \\
\hline $\begin{array}{l}\text { 4. If quality } \\
\text { cooperation periods }\end{array}$ & $\begin{array}{l}\text { Mnternal } \\
\text { Mixed } \\
\text { External } \\
\end{array}$ & $\begin{array}{l}1.31(1.32 ; 13) \\
1.73(1.56 ; 11) \\
1.67(1.03 ; 6)\end{array}$ & $\begin{array}{l}3 \\
1 \\
2 \\
\end{array}$ & $\begin{array}{l}3.00(1.70 ; 10) \\
2.00(2.65 ; 7) \\
1.18(1.33 ; 11) \\
\end{array}$ & $\begin{array}{l}1 \\
2 \\
3 \\
\end{array}$ & $\begin{array}{l}2.04(1.69 ; 23) \\
1.83(1.98 ; 18) \\
1.35(1.22 ; 17) \\
\end{array}$ & $\begin{array}{l}1 \\
2 \\
3 \\
\end{array}$ \\
\hline $\begin{array}{l}\text { 5. Nirst afficiency } \\
\text { cooperation period }\end{array}$ & $\begin{array}{l}\text { Internal } \\
\text { Mixed } \\
\text { External }\end{array}$ & $\begin{array}{l}4.46(2.54 ; 13) \\
3.27(2.65 ; 11) \\
2.00(2.45 ; 6)\end{array}$ & $\begin{array}{l}3 \\
2 \\
1\end{array}$ & $\begin{array}{l}2.20(2.53 ; 10) \\
3.86(3.02 ; 7) \\
4.09(2.88 ; 11)\end{array}$ & $\begin{array}{l}1 \\
2 \\
3 \\
\end{array}$ & $\begin{array}{l}3.48(2.73 ; 23) \\
3.50(2.85 ; 18) \\
3.35(2.73 ; 17) \\
\end{array}$ & $\begin{array}{l}2 \\
3 \\
1\end{array}$ \\
\hline $\begin{array}{l}\text { 6. First quality } \\
\text { cooperation period }\end{array}$ & $\begin{array}{l}\text { Internal } \\
\text { Mixed } \\
\text { External }\end{array}$ & $\begin{array}{l}3.54(2.54 ; 13) \\
3.45(2.62 ; 11) \\
2.50(2.51 ; 6)\end{array}$ & $\begin{array}{l}3 \\
2 \\
1\end{array}$ & $\begin{array}{l}2.00(1.94 ; 10) \\
4.43(3.21 ; 7) \\
3.73(3.13 ; 11) \\
\end{array}$ & $\begin{array}{l}1 \\
3 \\
2\end{array}$ & $\begin{array}{l}2.87(2.38 ; 23) \\
3.83(2.81 ; 18) \\
3.29(2.91 ; 17)\end{array}$ & $\begin{array}{l}1 \\
3 \\
2\end{array}$ \\
\hline $\begin{array}{l}\text { 7. Max periods } \\
\text { with one parther }\end{array}$ & $\begin{array}{l}\text { Interinal } \\
\text { Mixed } \\
\text { External }\end{array}$ & $\begin{array}{l}1.54(1.39 ; 13) \\
1.36(1.29 ; 11) \\
1.83(1.33 ; 6) \\
\end{array}$ & $\begin{array}{l}2 \\
3 \\
1 \\
\end{array}$ & $\begin{array}{l}2.90(1.73 ; 10) \\
2.14(2.48 ; 7) \\
1.18(1.17 ; 11) \\
\end{array}$ & $\begin{array}{l}1 \\
2 \\
3 \\
\end{array}$ & $\begin{array}{l}2.13(1.66 ; 23) \\
1.67(1.81 ; 18) \\
1.41(1.23 ; 17)\end{array}$ & $\begin{array}{l}1 \\
2 \\
3 \\
\end{array}$ \\
\hline $\begin{array}{l}\text { 8. } \text { t different } \\
\text { partners }\end{array}$ & $\begin{array}{l}\text { Internal } \\
\text { Mixed } \\
\text { External } \\
\end{array}$ & $\begin{array}{l}1.23(1.09 ; 13) \\
1.45(1.29 ; 11) \\
1.67(1.21 ; 6) \\
\end{array}$ & $\begin{array}{l}3 \\
2 \\
1 \\
\end{array}$ & $\begin{array}{l}1.80(1.14 ; 10) \\
1.71(1.89 ; 7) \\
1.18(1.08 ; 11) \\
\end{array}$ & $\begin{array}{l}1 \\
2 \\
3\end{array}$ & $\begin{array}{l}1.48(1.12 ; 23) \\
1.56(1.50 ; 18) \\
1.35(1.11 ; 17) \\
\end{array}$ & $\begin{array}{l}2 \\
1 \\
3\end{array}$ \\
\hline $\begin{array}{l}\text { Relative overall } \\
\text { cooperation }\end{array}$ & $\begin{array}{l}\text { Internal } \\
\text { Mixed } \\
\text { External }\end{array}$ & $\begin{array}{l}-21(72 ; 13) \\
-11(77 ; 11) \\
.20(81 ; 6) \\
\end{array}$ & $\begin{array}{l}3 \\
2 \\
1\end{array}$ & $\begin{array}{l}51(.82 ; 10) \\
16(1.47 ; 7) \\
-.32(.67 ; 1)\end{array}$ & $\begin{array}{l}1 \\
2 \\
3\end{array}$ & $\begin{array}{l}.10(.83 ; 23) \\
.00(1.06 ; 18) \\
-.14(.74 ; 17) \\
\end{array}$ & $\begin{array}{l}1 \\
2 \\
3\end{array}$ \\
\hline
\end{tabular}

Group averages are reported. Standard deviation and number of observations in parentheses. Ranks are printed in
bold.

${ }^{7}$ Note that ranking first on cooperation variables 5 and 6 means: being earliest, that is, having the lowest score. 


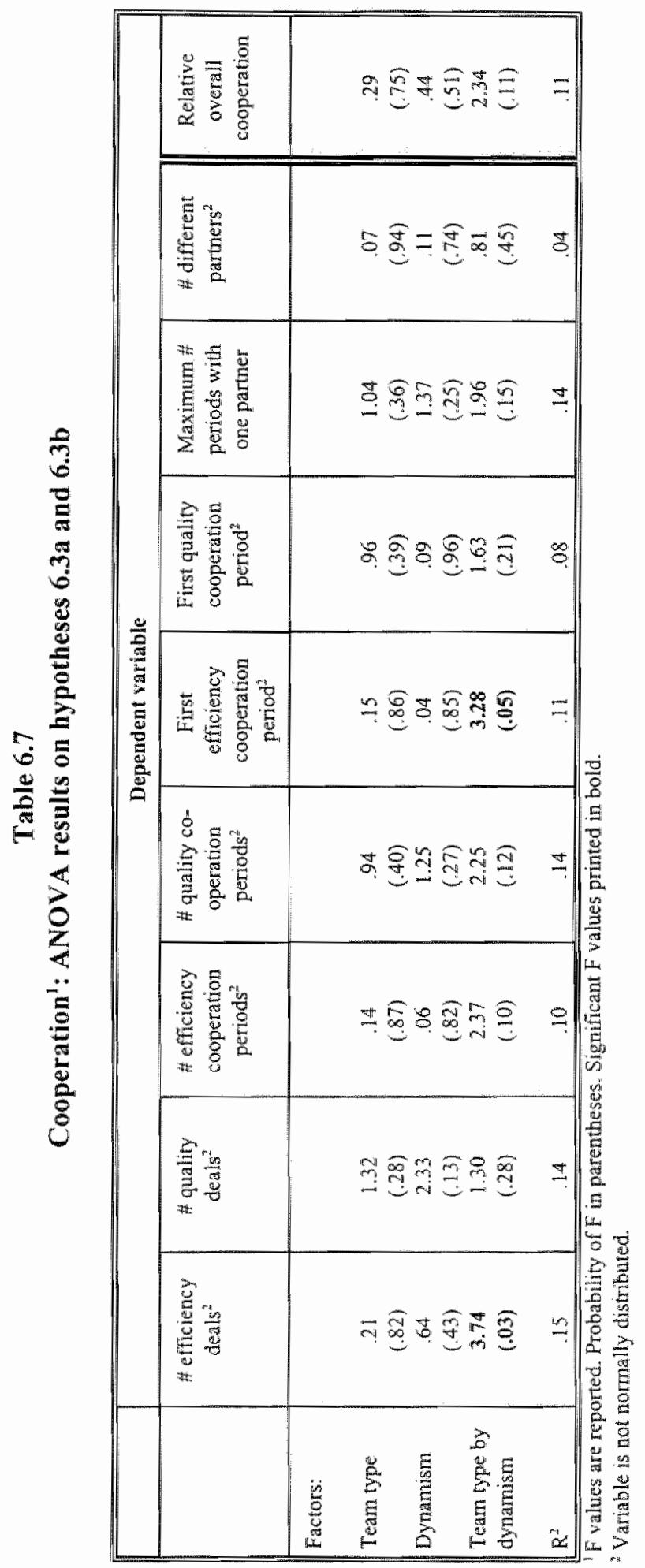


Table 6.7 shows the results of the ANOVA analyses. No significant main effects are detected of team type and dynamism on cooperative activity, which leads us to reject hypothesis $6.3 \mathrm{a}$. Internals do not generally show more cooperative activity than mixed or external teams. The interaction effect generally appears to be insignificant as well, so hypothesis $6.3 \mathrm{~b}$ should also be rejected. Only with regard to the number of efficiency deals and to the first efficiency cooperation period, a truly significant interaction is detected. However, various variables show interactions bordering on significance. We therefore decided to have a closer look at the cooperation variables in either environment. Team contrasts (not reported) show only insignificant negative (i.e., counterhypothesized) team differences in stable environments, whereas in dynamic environments contrasts carry the hypothesized positive sign and only the internal-external contrast is highly significant. Specifically, in dynamic environments internal teams close more deals (one-sided $p<.05$ ), cooperate longer (one-sided $p<.05$ ), cooperate earlier (one-sided $p<.10$ ) and cooperate longer with a single partners (one-sided $p<.01$ ) than external teams (see also Table 6.6). In short, internal teams show more cooperative activity than external teams in dynamic conditions. Mixed teams take the middle ground as expected but their differences to either side do not reach significance. Thus, contrary to our hypotheses, the expected effect only turns up in dynamic environments, just like it did in our analysis of innovative activity. The near-significant (and for some variables significant) interaction effect in Table 6.7 is produced by the switch from the insignificant negative contrasts in stable environments to the significant positive contrasts in dynamic environments. For the relative overall cooperation measure (lower row in Table $6.6)$, this change (i.e., the interaction contrast) is only significant for the differences between internal and external teams (one-sided $\mathrm{p}<.05$ ) and between mixed and external teams (one-sided $p<.10$ ). However, as Table 6.7 indicated, this is not enough to render the overall interaction significant.

\section{Discussion}

In the present chapter we tested whether different team types held different strategic preferences with regard to innovation, risk-taking and cooperation. In general, we expected internals to take the lead in all three area's, and especially so in dynamic environments. In the end, none of our hypotheses were completely supported as internals appeared to lead in innovative and cooperative activities only when the environment is dynamic. Thus, although our results do not support these hypotheses, they do provide
some interesting findings.

Regarding innovation, internals only took the hypothesized lead in dynamic environments, whereas they lagged behind in stable environments. As Table 6.3 shows, these differences are only found in market $\mathrm{A}$ and, to a much lower degree, in market $\mathrm{C}$. If we look at the profitability of innovativeness in these markets and circumstances, the following picture emerges. In stable environments, the correlations between relative innovativeness and profitability (i.e., return on equity) amount to .29 (n.s.), .13 (n.s.) and .29 (n.s.) in markets $\mathrm{A}, \mathrm{B}$ and $\mathrm{C}$, respectively. The same correlations in dynamic environments are $.49(\mathrm{p}<.01), .04(\mathrm{n} . \mathrm{s})$ ) and $.46(\mathrm{p}<.05)$. This means that internal teams took the 
lead in exactly the markets ( $\mathrm{A}$ and $\mathrm{C}$ ) and environmental circumstances (dynamic) where relative innovation was most profitable. It appears therefore, that they are not interested in innovation per se, but only in using the quality R\&D instrument in those instances where it is profitable to do so. Still, we are left with an unexpected lead of mixed teams regarding innovativeness in stable environments. As Table 6.1 shows, both other team types in these environments remained below industry averages, whereas mixed teams were consistently above. In dynamic environments on the other hand, mixed teams were consistently below industry averages and internal teams were most innovative. We could not come up with a satisfactory explanation of this behavior of mixed teams. Perhaps our linited findings with regard to innovativeness in general have something to do with our interpretation of quality $R \& D$ as an innovative activity. Possibly, although it was presented as such, quality $R \& D$ is not interpreted by players as an innovative activity in the traditional sense of earlier studies, but simply as a proactive action to stay ahead of competitors.

With risk-taking we were led to conclude that no differences exist between team types. Risk-taking as measured by the erraticness of profit patterns over time did not differ between team types; all had approximately the same number of 'ups and downs' in profitability. Unlike previous research by Begley and Boyd (1987), we did not find the expected higher liquidity risk among more internal teams either. The only risk measure that did produce a difference in the expected direction was insolvency. Internals, both in stable and dynamic environments, tend to use slightly more debt financing than other team types. Thus, the results are very modest and do not show a general attitude towards more risk taking among more internal tearns. Possibly the discrepancy between our nonfindings and the positive findings of others (Miller, Kets de Vries and Toulouse, 1982; Miller, 1983) is due to differences in method. Risk preferences measured through a pen and paper questionnaire (as in previous research) may well deviate from revealed risk taking in a business situation like ours. If one is specifically interested in business risk taking (as all management studies are), we feel it is best to measure attitudes at the point where they take effect, that is: in company records like financial structure and profit fluctuation. Preferences that are not acted out are not interesting from a management science point of view. As far as we could determine teams did not run their company with varying degrees of riskiness. More in-depth analysis of concrete real-life business situations and decisions is necessary to determine whether strategies of internal teams carry more risk than those of other team types. Rating specific strategies for riskiness, however, is not an easy thing to do and might involve the use of industry expert panels and broad time windows. We feel our game setting is too limited to undertake a valuable attempt at this.

The analysis of cooperative behavior differences revealed no main or interaction effect of team type and environmental dynamism on cooperative activity. All teams were more or less equally active in searching partners and investing in cooperative agreements. Possibly these non-findings must be attributed to the quite obvious (cost-) benefits of drawing up cooperation contracts in the game. When guidelines for 'proper' game behavior are so clear, individual differences lose predictive power as the situation will be equally assessed by all. Nevertheless, when different environments are analyzed sepa- 
rately, we find that the expected differences do show up, but only when environments are dynamic. Specifically, in dymamic environments internals did appear to be more cooperative than external teams. In these environments the differences between team types are also higher than in stable environments. Apparently then, environmental dynamism serves to bring out the cooperative tendencies of team types. This can be taken as evidence for the fact that when the environment bears more uncertainty through shifting prices and market shares, internals are more inclined than externals to reduce uncertainty through cooperation. Cooperation can help reducing some of the uncertainty in two ways. First, by cooperating with more partners you get at least some clues as to what they are doing. This information is the more valuable if positions are changing rapidly. Second, by cooperating you can at least fix some of your competitors to known levels of investment in product or efficiency R\&D as they are specified in the cooperation agreements. Our results in dynamic environments underscore the findings of a more cooperative stance of internals in the study by Boone, De Brabander and Van Witteloostuijn (1998). More general, we feel that the results support the argument that if cooperation is presented to players as a means to reach valuable ends (as it is in our case) internals will be more inclined to engage in it than externals, but only when the environmental circumstances render this profitable. To see whether the profitability of cooperation differs between environmental circumstances, we calculated correlations between profitability (return on investment) and relative overall cooperation in either condition. In stable industries, the correlation amounts to .18 (n.s.), whereas in dynamic industries it is .42 $(\mathrm{p}<.05)$. Apparently, internal teams had a better feeling for when cooperation paid off and when it did not, and if it did, they invested most. Note that we reached a similar conclusion in case of innovative activity!

Finally, we might wonder how important the variables studied in the current chapter are in explaining the differences in profitability between teams. As chapter 5 demonstrated, strong performance differences exist between tearn types in dynamic environments. Specifically, internal teams performed systematically better than external and mixed teams. It was shown above, that internals made higher yielding decisions (innovation and cooperation) in dynamic environments. We now wish to test to what extent these choices mediated the link between team make-up and performance. To do so we apply a two-step moderated regression analysis on the average return on equity (ROE) in dynamic industries. In this procedure we first estimate the effect of team type on profitability. Next, we include this chapter's strategic preference variables as covariates to see whether they affect the relationship between team type and profitability. The successive regressions are given in Table 6.8. Model 1 shows the simple team type effect of Chapter 5 that, on its own, explains $31 \%$ of all variation ${ }^{8}$ in profitability in dynamic environments. The dummies are coded to represent internal (Di) and mixed teams (Dm). Because of this so-called effects-coding scheme ${ }^{9}$ (Cohen \& Cohen, 1983), the coeffi-

\footnotetext{
${ }^{3}$ Note that we use the adjusted $R^{y}$ in order to compare across regressions with unequal numbers of independents: model $\mathrm{R}^{2}$ actually amounts 10.37 (see Chapter 5, section 3.2).

An extensive treatment of this and alternative schemes for coding nominal scales in regression analysis is given in
Cothen and Cohen (1983), Chapter 5 .
} 


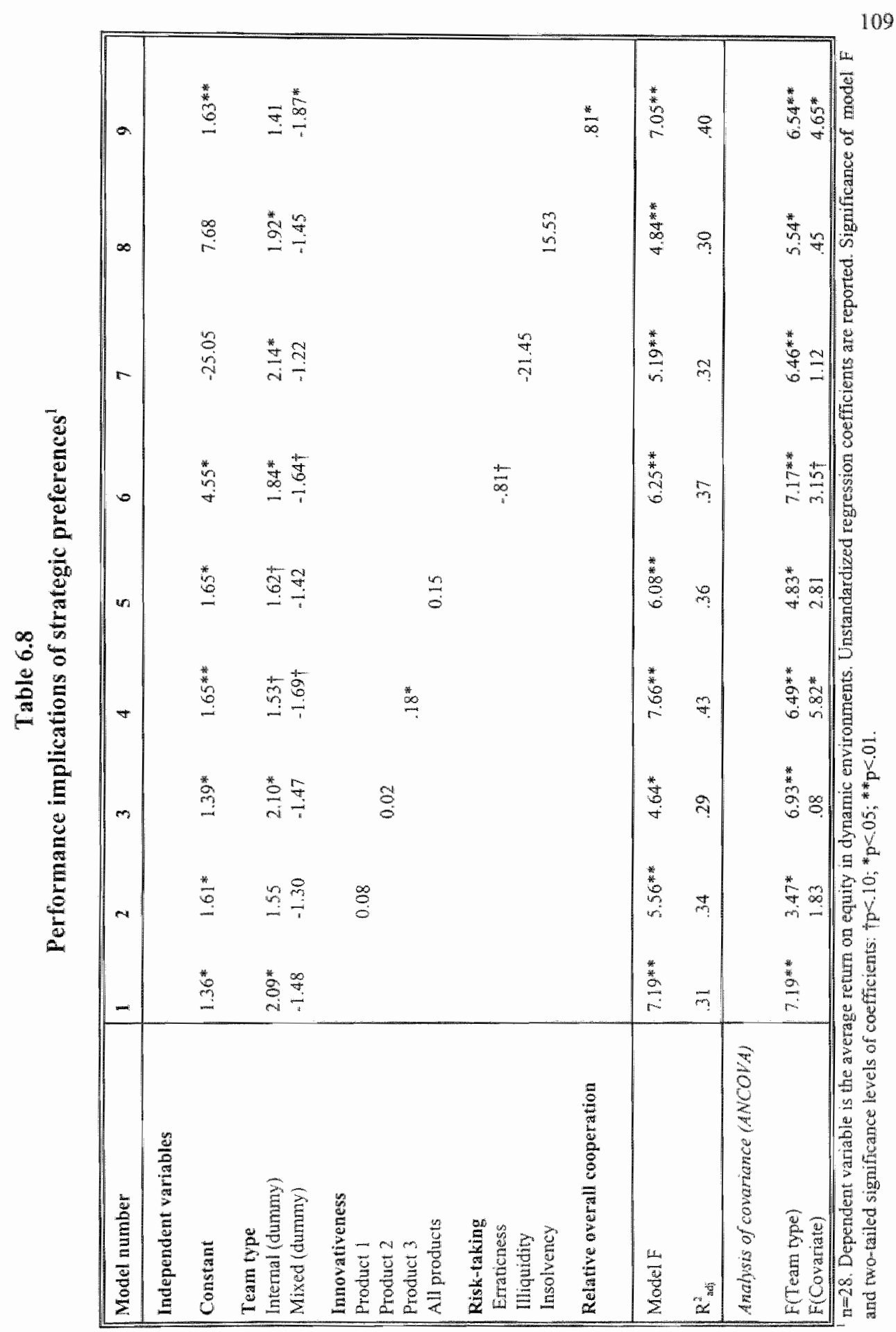


cients of these dummies are in fact team type contrasts that estimate the difference in profitability of internal and mixed teams compared to the remaining group, i.e., external teams. So internal teams have on average a $2.09 \%$ higher and mixed teams a $1.46 \%$ lower return on equity than external teams, whose ROE is represented by the constant, i.e., $1.36 \%$ (check Table 5.2, bottom row, column 2). In collumns 2 to 9 the strategic preference variables are separately added as single covariates to the column 1 equation, to see what happens to the team effects, i.e., to the size and significance of the team dummies. If the dummy coefficients decline, this indicates a mediating effect of the covariate; if the dummy coefficients increase, however, the covariate works as a socalled supressor of an in fact much stronger direct effect of team type on profitability. To see what happens to the significance of the team type factor as a whole, we also included a simple analysis of covariance (ANCOVA) at the bottom of Table 6.8 , in which we added each covariate to an analysis of variance with team type as a factor. In doing so, we obtain an estimate of the team type effect on ROE when the effect of the covariate is 'partialled out' (see Cohen and Cohen, 1983, chapters 5 and 10). If we focus on the diminishing of team differences in Table 6.8 , we see that only the inclusion of the innovation variable in market $\mathrm{A}$ and the cooperation variable diminish the significance of the internal team dummy (Di) to below 10\% significance (models 2 and 9 in Table 6.8). The other resulis remain rather identical. In case of innovation and cooperative activity the difference with internal teams (Di) gets smaller because internal teams innovate and cooperate more (see Table 6.1), and both innovation and cooperation are strongly correlated with profitability, as we saw above. The significance of the negative mixed tearm dummy (Dm) rises after controlling for cooperative activities, which points at a suppressing effect of cooperation on the differences between mixed and external teams. By suppression we mean the following. Mixed teams generally show more cooperative activity than external teams (see Table 6.6), which is profitable (see above). The covariate for cooperation in model 9 serves to cancel this effect out, showing the result when the cooperation differences had not been present. The result is an even lower performance of mixed teams vis-â-vis extemals $(-1.87$ instead of -1.48 in model 1$)$. Thus, the higher cooperation of mixed teams as compared to external teams suppresses mixed teams" arrears to external teams: had they not cooperated so much, their profitability would have been even worse. Note that the team type significance remained high $(6.54, p<.01)$ after controlling for cooperation, exactly because on the one hand, the difference (of external teams) with internals is lowered, but on the other hand the difference with mixed teams is increased. In case of market $A$ innovativeness (model 2), we do see a strong decline in the team type effect, as both dummies are smaller. The bottom line is, that internals' higher innovative activities and cooperation are important explanations of their higher profitability in dynamic environments. An explanation of mixed teams' relatively bad record can not be derived from these results.

We may conclude that overall, the strategic preferences of internal, mixed and external team types do not emerge from our data in the way we expected. Internals did not in general show a stronger preference for innovation, risk-taking or cooperation. They are not more innovative, risk taking or cooperative by character. Rather, they (successfully) use these activities instrumentally where they yield most. Note, however, 
that this almost opportunistic behavior does concur with their character: if you think your actions can make a difference, you are more likely to look for and apply the instruments that have the highest impact in a given situation. In other words: internal teams tend to adapt their behavior to the demands of the situation. We will be returning to this point in the following chapters, where we will be delving deeper into the question of how teams made their choices instead of what the particular content of their choices was. 
7 strategy making I Informed, planned and consistent action 


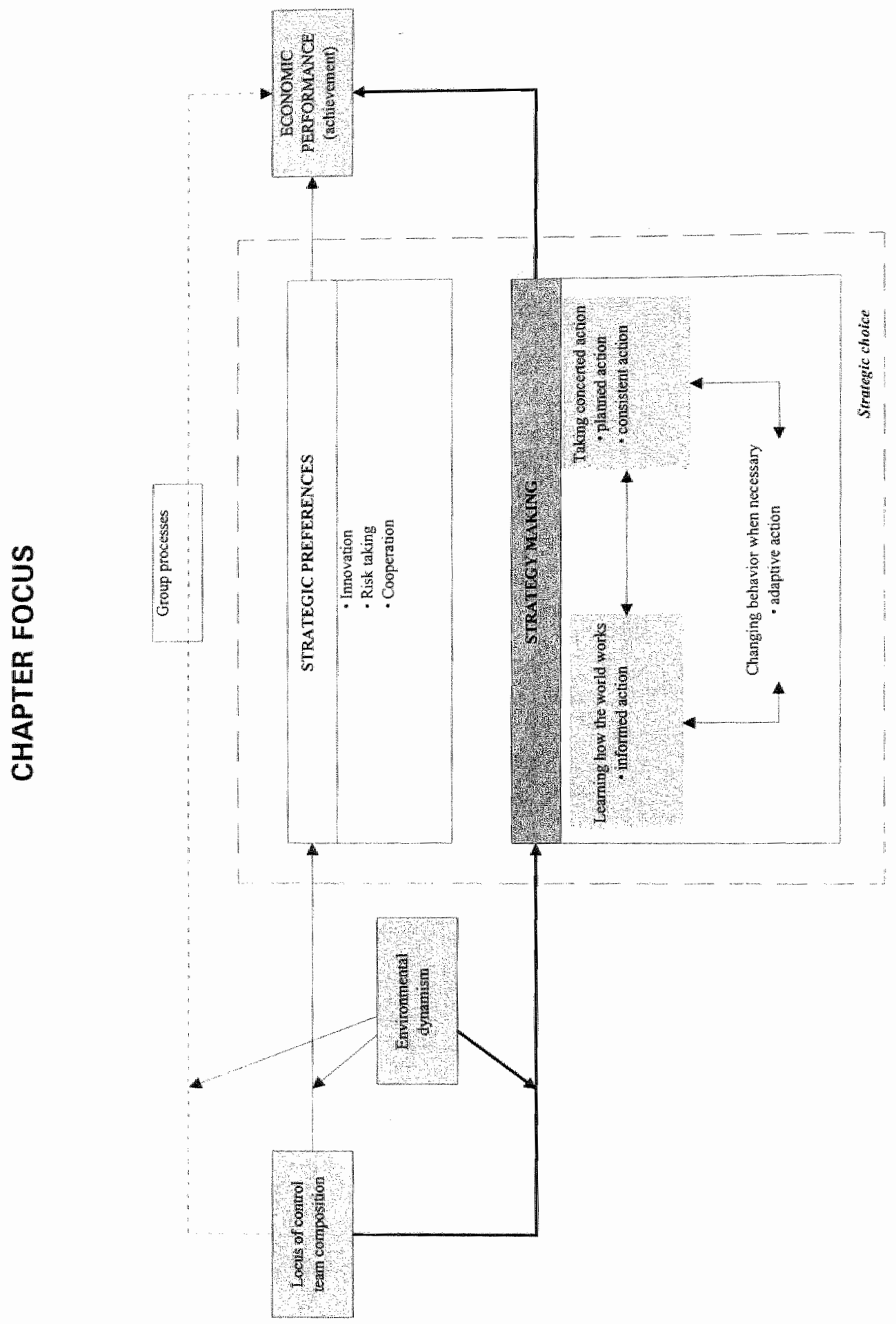


In the previous chapters it was shown that considerable differences in performance exist between team types (chapter 5) that are, however, difficult to account for by the standard explanations of differing overall strategic preferences (chapter 6). Rather, internal teans appeared to take the lead in certain activities only when and where this was profitable. This suggests a more sophisticated type of behavior than mere preferences for certain actions over others. We will now expand upon this finding by arguing that the locus of control trait has much broader potential implications for behavior than past management studies have acknowledged. In fact, the concept of internal perceptions of control as described in chapter 3 is a much richer one than previous research in management suggests. We therefore aim to take the analysis beyond sheer preference differences and explore some hitherto neglected aspects of strategic behavior in relation to teams' dominant control perceptions that can be derived from past psychological research. Specifically, it will be argued that perceptions of control in a business context may influence the various ways in which strategies are formed through a process of exploration, planning and adaptation. We will formulate and test hypotheses concerning team differences in this process of what might be called strategy making.

The performance differences between teams may well be associated with the process of arriving at a strategy, in the way teams go about in determining choices, in planning and monitoring their execution and in adapting them to changing circumstances. We have good reason to assume that internal, mixed and external teams differ in their faculties regarding these processes as they concur closely with the self-directed behaviors of internals described in section 3.1. Remember that in the same section we introduced a framework for explaining the higher effectiveness of internal over external individuals in achieving valued goals through the interplay of three processes. This figure 3.2 is reproduced below.

\section{Figure 7.1: Analytic framework}

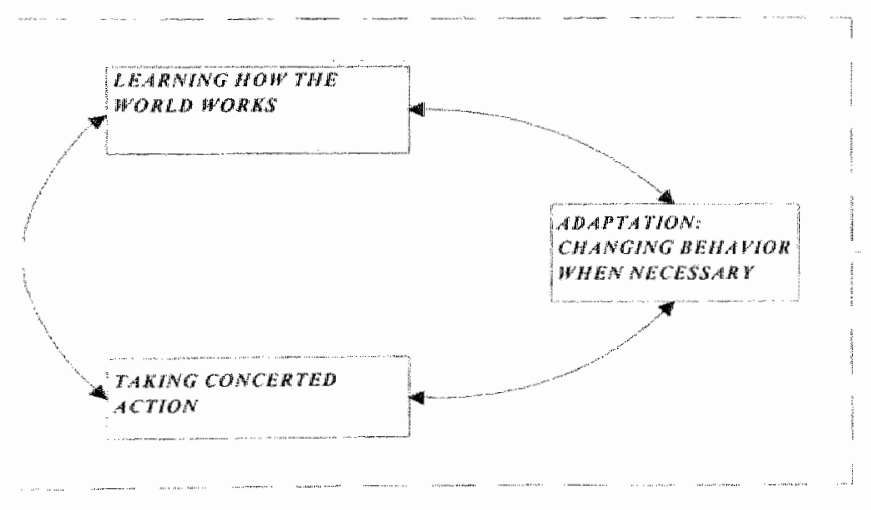


The three aspects mentioned in figure 7.1 and their relation to strategy making are the following.

\section{Learning how the world works (Esiablish position)}

This part refers to the more inquisitive nature of internals over externals. Internals are more attentive to important cues from their environment, they search more actively for relevant information and assimilate it better. Another important aspect of this active atritude to make sense out of their environment is a higher rate of trial-and-error learning (Boone, De Brabander and Gerits, 1991). In order to determine what the important aspects of the environment are and how they may affect them, individuals (and teams) need to go out and gather information to base their action on. To capture this fact-finding process in the game, we will analyze teams' behavior with regard to information search and informed action.

\section{Taking concerted action}

The second part of figure 7.1 deals with the undertaking of more motivated and persistent action by internals to implement a strategy that is believed to lead to success. Once the environment is sufficiently mapped, choices are made as to how to deal with the various contingencies. These choices will be confidently and carefully implemented in order to maximize their potential success. This requires careful planning to keep strategies consistent and to smooth the internal functioning of the organization. In our game setting this should be evident in the quality of planning and in the consistency of actions both internally and over time.

\section{Adaptation: changing behavior when necessary}

It was established in chapter 2 , that internals show more adaptive behavior than externals and are generally more successful in adapting when circumstances necessitate change. We wish to test whether and how different teams react to weak and stronger signals that change might be necessary. To sum up the above, we expect differences in team' actions regarding the level of informedness, planning, consistency and adaptability. In the present chapter we will derive specific hypotheses on each of the action characteristics in the first three categories. Because of its elaborateness, we will postpone the treatment of the adaptation aspect to chapter 8 .

For the sake of readability, the current chapter is structured in three main sections: information search and informed action (section 2), planned action (section 3) and consistent action (section 4). In each part we will specify, operationalize and test hypotheses and discuss the results. The final section 5 provides an appraisal of the combined results. 


\section{Information search and informed action}

\subsection{Theory and hypotheses}

In experimental studies of individuals, it is hypothesized, that internals will want to find out what the important aspects of their surroundings are, as this will heighten their effectiveness in dealing with them (see Chapter 3). That is: internality will be associated with more active information search behavior (Phares, 1976; Lefcourt, 1982). This hypothesis was confirmed in experiments and field studies (Davis and Phares, 1967; Seeman and Evans, 1962; Boone, De Brabander and Gerits, 1991) and it "(...) seems to be the single most consistent finding running throughout the I-E research literature" (Phares, 1991: 489). If internality does indeed lead to a more inquisitive stance, more internal teams may be expected to collect more information and as they value this information more, they will be more willing to spend money on it. The monetary value of the information collected by more internal teams should therefore be higher than that of mixed and external teams respectively. As explained previously, the differences may be expected to be more pronounced in dymamic situations.

Hypothesis 7.1a: Internal teams will spend more on information than mixed teams and mixed teams will spend more on information than external teams (main effect).

Hypothesis 7.1b: The differences mentioned in hypothesis 7.1 a will be greater in dynamic than in stable environments (interaction effect).

Studies at the individual level of analysis thave established that internals are not only more inquisitive in general, but they are also more likely to pay specific attention to those cues that are potentially relevant to a task and may help to resolve uncertainties than externals (DuCette and Wolk, 1973; Wheeler and Davis, 1978). So quite apart from the amount of information that is collected throughout the gane, it is important to look at the connection between actions taken and previous information gathered. That is: the extent to which specific actions are preceded by relevant prior in formation search activity. Based on the studies mentioned above, we may expect that internal teams will gather more relevant information prior to an action than less internal teams. In other words: the likelihood that actions are pre-informed will be higher for internal than for external teams.

Hypothesis 7.2a: Interna! teams' actions will be more informed than mixed teans actions and mixed teams 'actions will be more informed than external teams" actions (main effect).

As usual, we expect the differences to be more pronounced in dynamic than in stable environments. 
Hypothesis 7.26: The differences menioned in hyothesis $7.2 a$ will be greater in dynamic than in stable enviromments (interaction effect).

\subsection{Methods}

As the game decision form in Appendix B shows, in every period teams could buy 14 different kinds of information. The information requests are made simultaneously with the rest of the decisions.

Table 7.1 : Internal information content

\begin{tabular}{|c|c|c|}
\hline $\begin{array}{l}\text { Itetin num- } \\
\text { ber }\end{array}$ & Information request & Information provided \\
\hline $\begin{array}{l}27 \\
\text { (Product } \\
\text { Radi) }\end{array}$ & $\begin{array}{l}\text { What is the effect of specilied } \\
\text { level of product quatioy? } \\
\text { (Two levels can be requested per } \\
\text { period) }\end{array}$ & $\begin{array}{l}\text { The market share percentage that a company will be } \\
\text { ahead of its competitors uin each market at each of } \\
\text { the specified product quality levels, all ceters part- } \\
\text { bus, i. wy provided that competions have not inwested } \\
\text { at all and all other marketing efforts remain the same. }\end{array}$ \\
\hline $\begin{array}{l}28 \\
\text { (Process } \\
\text { ReD) }\end{array}$ & $\begin{array}{l}\text { What is the effect of a specified level } \\
\text { of afficiency? } \\
\text { (1"wo levels can be requested per } \\
\text { period) }\end{array}$ & $\begin{array}{l}\text { The variable costs and the use of raw materials per } \\
\text { unit at each of the specilied effeciency levels for each } \\
\text { product. }\end{array}$ \\
\hline $\begin{array}{l}29 \\
\text { (Machine } \\
\text { capacily) }\end{array}$ & $\begin{array}{l}\text { What w the effect of a specificd ma- } \\
\text { chine capacity level on fixed costs? } \\
\text { (Two levels can be requested per } \\
\text { period) }\end{array}$ & $\begin{array}{l}\text { The total fixed costs at each of the specified machine } \\
\text { capaciry levels. }\end{array}$ \\
\hline 30 & $\begin{array}{l}\text { What is the effect of a specified level } \\
\text { of promotional expenditures? } \\
\text { (One level per market can be re- } \\
\text { quested per period) }\end{array}$ & $\begin{array}{l}\text { The matket share percentage that a company will be } \\
\text { ahead of its competitors in each market at each of the } \\
\text { specifted level of promotion: all cereris paribus, ite. } \\
\text { provided that competitors have not inverted at all } \\
\text { and all other marketing afforts remain the same. }\end{array}$ \\
\hline
\end{tabular}

${ }^{1}$ Numbers refer to items on the decision fom in $A$ ppendix $B$.

After all decisions are processed, game management provides the results of that period along with an overview of the requested information (see Appendix $\mathrm{C}$ ) on which teams can then base their new decisions. A priori, two broad categories of information can be discerned, which we labeled internal information and external information!. Internal information (items $27-30$ on the decision form) deals with the potential effects of own behaviors. Teams know (from the manual) what certain actions of their own will accom-

\footnotetext{
1 This a priori classification of information itens in two categories was subjected to a confirmatory factor analysis using LISREL (see Bollen, 1989 or Jöreskog and Sörbom, 1993). The proposed wo-factor solution appeared to describe the information requests teams made very well (model chi-square $=145.98 ; \mathrm{df}=77 ; \mathrm{p} \approx 001$; adjusted goodness of fit index $=.91$ ). This solntion was superior ( $\Delta$ chi square $=84.08 ; \mathrm{d} f=1 ; \mathrm{p}<.001$ ) to a one factor solution. LISREL analysis is based on the 105 unique elements in the variance covariance matrix of the 14 information iterns. The onefactor model has one degree of freelom less because the covariance between the two factors is omitted. Special thanks to Dr. Martin "Magic" Wetzels for LISREL advice and programming.
} 
plish, for instance that higher product quality will, ceteris paribus, raise market share. They have to buy information, however, as to how strong this effect is on either market. The content of this internal information is summarized in Table 7. la. This means that once a few, say 3 or 4 , points on the effect curve have been obtained, the team has a fair idea of how an instrument works and more information does not add a lot. In other words: the marginal value of additional internal information decreases with the amount already in possession. Note that the effect of various levels are fixed in time, i.e., the effect curves do not change during the game, so that internal information is additive: each new piece of information (i.e., each effect level) complements the information on effects that were received in earlier periods. Thus, the value of past information remains the same.

Table 7.1b: Extermal information content

\begin{tabular}{|c|c|c|}
\hline $\begin{array}{l}\text { Iren } \\
\text { number }\end{array}$ & Information request & Information provided \\
\hline 24 & What are the prices of competitors? & Prices set by all companies in all markets. \\
\hline 25 & What are the final stocks of competitors? & $\begin{array}{l}\text { End-product stocks (in units) of all products for all } \\
\text { companies at the end of the currem period. }\end{array}$ \\
\hline 26 & $\begin{array}{l}\text { What is the production capacity of com- } \\
\text { petitors? }\end{array}$ & $\begin{array}{l}\text { Total number of personnel and machine capacity } \\
\text { wnits at the disposal of each competitor in the pe- } \\
\text { riod under review. }\end{array}$ \\
\hline 31 & $\begin{array}{l}\text { What are the conpetitors' shares in pro- } \\
\text { motion expendirunes? }\end{array}$ & $\begin{array}{l}\text { Percantage share in the industry total of promotion } \\
\text { expenditures per market in the period under re- } \\
\text { view. }\end{array}$ \\
\hline 32 & $\begin{array}{l}\text { What are the product quality levels of } \\
\text { competitors? }\end{array}$ & $\begin{array}{l}\text { Quality level per product per competitor in the } \\
\text { next period. }\end{array}$ \\
\hline 33 & $\begin{array}{l}\text { How many sales groups do competitors } \\
\text { employ? }\end{array}$ & $\begin{array}{l}\text { Number of sales groups at the competitors' dis- } \\
\text { posal in the period under rewew. }\end{array}$ \\
\hline 34 & Provide estimate of market demands. & $\begin{array}{l}\text { Estimates of market demands in the next two peri- } \\
\text { orls. }\end{array}$ \\
\hline 35 & $\begin{array}{l}\text { What are the competitors" shares in work- } \\
\text { ing conditions improvemeat expendifures } \\
\text { ? }\end{array}$ & $\begin{array}{l}\text { Percentage share of each company in the tolal cu- } \\
\text { mulintive working conditions expenditures. }\end{array}$ \\
\hline 36 & What are competitors" makkel shares? & $\begin{array}{l}\text { Percentage shares of each company in the sales on } \\
\text { wach market in the period under review. }\end{array}$ \\
\hline 37 & What are competitors" wage costs? & $\begin{array}{l}\text { Costs per unit persionel capacily (wage level) for } \\
\text { encin company in the period under review. }\end{array}$ \\
\hline
\end{tabular}

\footnotetext{
Numbers refer to items on the decision form in Appendix B.
}

The second type of information is external (or current) information requests (items 24-26 and 31-37 on the decision form: see Appendix B). They are given in Table 7.16. As shown, these items provide information on the competitive environment like, for instance, market demand and competitors' prices, quality levels, machine capacity or 
wage levels. In contrast to internal information, the content of extemal information changes every game period as competition develops. This means that only the informan tion requested one period earlier (and received at the moment a decision is made) is relevant in taking a certain action. For instance, if a team raises its wage level, this action should ideally be supported by information on the current wage level of competitors, so they should have requested this information one period earlier. Remember that with internal information all previously requested information remains valid as input in new actions; external information is only valid for one period and "should" be updated (i.e., requested) at least every time an associated action is taken.

To test hypothesis 7.1 we measured the teams' 'willingness to pay' for information by looking at their information search expenditures. To assess the total cost of the information requested in each period, we simply summed ${ }^{2}$ the expenditures within the internal and external information categories. In doing so we obtained for each team the value of information bought in each category in each period.

In passive observation, as in our case, it is generally not possible to assess whether subjects acted on information or not; in fact, not acting can be a conscious response to certain information as well: we simply cannot tell. This is why in the present study we have to turn things around and ask ourselves: if we witness a certain decision, did the team properly inform itself beforehand? Therefore, to assess how informed certain actions are (hypothesis 7.2), we have to analyze the information teams have when they carry out a certain action. Thus, our unit of analysis is an observed action and we are interested in the level of informedness of these undertaken actions. That is: given that a certain manifest action is taken, we look whether relevant information was gathered prior to the action in order to support it: we explicitly link actions to prior information requests.

We selected a set of different actions in the game, for which very clear prior information requests exist to support them. Of course, in a complex environment like the one simulated in the game, many prior internal and/or external information requests can be used as input to an action. We, however, selected only those that were connected most obviously and directly to certain actions and should be requested anyway if an action is taken. For instance, prior to an expansion of machine capacity, it makes perfect sense to inguire for the installed capacity of competitors. Similarly, if investments in product quality are made, it is quite obvious to request information as to the effects of quality levels on market shares. Several actions may require both internal and external information. Table 7.2 shows the various actions and the respective information precedents that we analyzed. Note that the unit of analysis is an action in a certain field, irrespective of the period in which it is taken. We recorded that an action was taken when the respective

\footnotetext{
2The fourtion information items ranged in price from 30.000 10 100.000 ECU per request. This variance is, however, atremely small. Requesting al information in a certain period will cost 910,000 ECU, being only 1 . 4 , of of the average
rotal indirect costs of all teams and less relatively very cheap. Consequenty, the information of total turnover. This meats that information in the garne $\mathrm{s}$ not pay special attention to them.
} 
Geld on the decision form was filled out. If so, we looked at whether a matching information item was requested beforehand.

Table 7.2

Actions and associated preceding information requests

\begin{tabular}{|c|c|c|}
\hline \multicolumn{3}{|c|}{ A. Arthons preceded by internal (general) information requests } \\
\hline Action laken at to & $\begin{array}{l}\text { Preceding internal intormation request(s) on } \\
\text { trt }^{*}\end{array}$ & $\begin{array}{l}\text { Item numy- } \\
\text { bet }\end{array}$ \\
\hline $\begin{array}{l}\text { 1. Product quality improvement expenditure } \\
\text { 2. Effuchency improvenent expenditure } \\
\text { 3. Expansion of machine capacity } \\
\text { 4. Mromotion expenditure on.... } \\
\text {-Market } 1 \\
\text { - Export market } \\
\text {-Market } 2 \\
\text { - Market } 3\end{array}$ & $\begin{array}{l}\text { 1. Effects of product quality inprovement an } \\
\text { market share lead } \\
\text { 2. Efects of efficiency improvement on } \\
\text { product costs and raw materials use per unit } \\
\text { 3. Effects of expans don on fixed costs } \\
\text { 4. Effects of promotion expenditure on... } \\
\text { - Market I share lead } \\
\text { - Export market share lead } \\
\text { - Market } 2 \text { share lead } \\
\text { - Market } 3 \text { share liead }\end{array}$ & $\begin{array}{l}27 \\
28 \\
29 \\
30 \\
30 \\
30 \\
30\end{array}$ \\
\hline \multicolumn{3}{|c|}{ B. Actions preceded by external (current) information requests } \\
\hline Action taken at & $\begin{array}{l}\text { Preceding external information request }(s) \text { on } \\
t^{* *}+1\end{array}$ & $\begin{array}{l}\text { liten num- } \\
\text { ber }^{!}\end{array}$ \\
\hline 1. Price change on all markets & 1. Competitor price levels & 24 \\
\hline $\begin{array}{l}\text { 2. Maxmum allowable price change on any } \\
\text { market }\end{array}$ & 2. Competitor price levels & 24 \\
\hline 3a. Expansion of nachine capacity (1) & 3a. Competitor installed machine capacity & 26 \\
\hline 3o. Expansion of machue capacity (2) & 3b. Estimated future rnarket demand & 34 \\
\hline 4. Promorion expenditure on any market & 4. Competitor promotion outlays & 31 \\
\hline 5. Product quality improvement expenditure & 5. Competitor quality levels & 32 \\
\hline 6. Expansion of sales groups & 6. Competitor number of sites groups & 33 \\
\hline 7. Inuprowement of working conditions & 7. Competitor working conditions & 35 \\
\hline 3. Wage rase & 8. Competitor wage lewels & 37 \\
\hline
\end{tabular}

Numbers refer to items on the decision fom in Appendix $B$

A very important remark must be made here conceming the already mentioned difference between internal and external information. If an action is taken for which external information is necessary (see lower part of Table 7.2), we can simply look at whether or not the corresponding (current) information request was made in the preceding period. For instance: is a raise in wages (action) preceded by a request for current competitor wage levels (intormation) or not? Thus, in the case of external information items, actions are coded as being either informed (1) or uninformed (0). However, to measure whether actions were informed based on internal information (upper half of Table 7.2), we have to take into account all preceding periods, as this information builds up gradually to form the effect curves (see for instance figure 6.1 in Chapter 6). For example, if we want to know how well an action to invest in efficiency improvement was pre-informed by the effects hereof on product cost, it is not sufficient to look only at the requests made in the period directly prior to the action. Instead, we want to know the total amount of informa- 
tion (i.e., the number of requested effect levels) on this issue that was gathered beforehand and on which the focal action was presumably based. Therefore, in case of internal information, we measured the degree to which an action is informed by counting the total number of previously (i.e., in any period) collected internal information items. $\mathrm{We}_{\mathrm{e}}$ divided this by the maximum possible amount of information items that could have been obtained by then. This division was made to control for an artificial positive dependency on time as the number of internal information items gradually builds up over time. The resulting measure represents the percentage of the maximum obtainable information a team had in possession prior to a decision. This measure can theoretically range from 0 (no information at all) to 1 (all possible information in possession) We will clarify this with an example. In each period a team can request information on the effects of two levels of efficiency expenditures. The levels requested in $t$ can be used for decision making in all periods after $t$. So, if a team decides to request two levels at $t$ (the initial period) and one level at $t+1$, it will have two levels at their disposal at $t+1$ and three levels at $t+2$ (because internal information is additive). Suppose that, based on their information, the team invests two times in efficiency improvement, namely at $t+1$ and $t+2$. We thus record two actions and want to know how informed they were. The first action was based on two information items, which is the maximum amount one could possibly have at $t+1$. Therefore, the action's informedness is $2 / 2=1.00$ or $100 \%$, i.e., all possibly obtainable information at $t+1$ is used. In case of the second action, three information items were available. However, at $t+2$ the team could have bought already four effect levels. Thus, they use only $3 / 4=.75$ or $75 \%$ of the maximum obtainable informa. tion at $t+2$. We end up with two actions, one $100 \%$ informed and another $75 \%$ informed.

In case of external information we face a different methodological problem as our dependent variable is either 1 or 0 depending of whether information was (1) or was not (0) requested in the period immediately prior to the action. For this type of dependent variables we can no longer use ordinary analysis of variance or linear OLS regression? Instead, we will use logistic regression analysis to estimate the probability of an information request prior to a certain action for each team type and environmental condition. In particular, we estimated the main and interaction effects mentioned in our hypotheses $7.2 \mathrm{a}$ and $7.2 \mathrm{~b}$ by applying a two-step logistic regression procedure. In the first step we estimate the main effects of tearn type and dynamism on the probabilities of requesting information prior to an action by including three dummy variables. The first two dummies, Di and Dm, represent internal and mixed teams. The estimated coefficients of these dummies indicate the difference in the probability ${ }^{4}$ of making a prior information request

\footnotetext{
3 As Gujarat (1988) points out, the reason for this is, that the standard assumptions of normally distributed and homoscedastic disturbances are violated and that $\mathrm{R}^{2}$ as a goodness of fir measure becomes questionable. More importanty, the expected vilues of the dependent variable at diffenent levels of predictors (i.e., E(Y, $\left.Y_{i}\right)$ ing such a model are not constraned to the 0 -1 range. A more fundamental problem is that probabilities are unlikely to be lineaty dependent on predictors, but are ather more likely to approach both 0 and 1 asymptotically. The shape of a logistic
curve is therefore intuitively appealing.

Ir fact, the logistic nodel estimates not the probability (P) itsel but the naturallogarithm of the so-called odds-ratio, i.e. $\ln (\mathrm{P} / 1-\mathrm{P})$. This means that the dummy coeffeients estimate the difference in the ln(odds) benwen our categories. Note, however, that the interpretation remains esserthally the same and odds can be easily recalculated to probabilities.
} 
in comparison to the remaining team type, in our case external teams. So, positive coeficients of these coefficients indicate that internal and/or mixed teams have a higher probability than external teams to be pre-informed on a certain action. Similarly, the coefficient of the dynamism dummy estimates the difference in probability of making a prior information request between stable and dynamic environments for all teams. The dummy has the value 0 in stable environments and the value 1 in dynamic environments. Thus, a positive estimated coefficient indicates that teams in general are more likely to be pre-informed on their actions in dynamic industries than in stable industries. The reverse holds true in case of a negative coefficient of the dynamism dummy. In the second step of our analysis we wish to tesit for a possible interaction between team type and dynamism. To do so, we add the product terms of either team type dummy with the dynamism dummy to the regression equation of step 1 (Cohen and Cohen, 1983). The resulting coefficients of these product regressors reflect the magnitude of the interaction effect, that is: the extent to which differences in probabilities between team types vary between envirommental circumstances.

\subsection{Results}

Hypothesis 7.1 a predicted that internals spend more on information than mixed teams, who in turn spend more than external teams. Table $7.3 \mathrm{a}$ reports on the average value of information collected in periods 1 to $5^{5}$. A breakdown by team types and environmental conditions is shown in Table 7.3b. Table 7.4 presents the results of the ANOVA analyses to test hypothesis 7.1 a and 7.1b. These results indicate that no significant main effect of team type exists, so we reject hypothesis $7.1 \mathrm{a}$ and conclude that no general differences in spending on internal or extemal information exist between team types. The dynamism factor indicates that the value of information gathered does not significantly differ between stable and dynamic environments, either. Still, as Table $7.3 \mathrm{~b}$ shows, individual team types do differ in their information spending between environmental conditions. Internal and mixed teams spend more on information in dynamic as opposed to stable environments, whereas externals spend less.

\section{Table 7.3a}

Descriptives: Information search

Value of requested information per period [1000 ECU]

\begin{tabular}{|l|l|l|l|l|l|l|}
\hline \hline Dependent variable & $\mathbf{n}$ & Mean & $\begin{array}{l}\text { Standard } \\
\text { deviation }\end{array}$ & Minimum & Maximum & $\begin{array}{l}\text { Theoretical } \\
\text { maximum }\end{array}$ \\
\hline Internal information value & 58 & 56.17 & 61.68 & 0 & 260 & 380 \\
Exiemal information value & 58 & 253.83 & 117.15 & 30 & 520 & 530 \\
Toial information value & 58 & 310.00 & 163.02 & 50 & 748 & 910 \\
\hline
\end{tabular}

See footnote 9 for an example.

${ }^{3}$ Note that information requests in period 6 are useless, since this is the last game period after which final scores are calculated and the information will therefore not even be received. As a result, all analyses are based on the information gathered in periods I to 5 . 
The interaction hypothesis ( $7.1 \mathrm{~b})$ predicted that differences between team types would be greater in stable than in dynamic environments. As Table 7.4 indicates, only a marginally significant interaction effect exists with regard to the value of external information collected. To see which differences produce this interaction and to qualify the effect, contrasts were calculated and reported in Table 7.5. The significant interaction contrasts appears to be the ones related to the difference with external teams. Specifically, the strong negative differences between external teams on the one hand and internall and mixed teams on the other in stable environments $(-140.54$ and -104.46 , respectively) change significantly to weakly positive differences ( 34.27 and 27.56 , respectively) in dynamic environments.

Table 7.3b

Descriptives: Information search

Value of requested information per period $[1000 \mathrm{ECU}]$

\begin{tabular}{|c|c|c|c|c|c|c|}
\hline \multirow{3}{*}{$\begin{array}{l}\text { Dependent wariable } \\
\begin{array}{l}\text { Internal information } \\
\text { value }\end{array}\end{array}$} & \multirow{3}{*}{$\begin{array}{l}\text { Tean type } \\
\text { Internal } \\
\text { Mixed } \\
\text { External }\end{array}$} & \multicolumn{5}{|c|}{ Environmental condition } \\
\hline & & $\begin{array}{l}\text { Stable industries } \\
\text { (Column I) }\end{array}$ & \multicolumn{2}{|c|}{$\begin{array}{l}\text { Dynannic industries } \\
\text { (Column 2) }\end{array}$} & \multicolumn{2}{|l|}{$\begin{array}{l}\text { All industries } \\
\text { (Column 3) }\end{array}$} \\
\hline & & $\begin{array}{l}46.92 \\
(70.87 ; 13) \\
54.00 \\
(59.44 ; 11) \\
53.33 \\
(68.27 ; 6) \\
\end{array}$ & $\begin{array}{l}82.00 \\
(43.60 ; 10) \\
73.14 \\
(93.94 ; 7) \\
36.55 \\
(37.03 ; 11) \\
\end{array}$ & $\mathbb{1}$ & $\begin{array}{l}62.17 \\
(61.91 ; 23) \\
61.44 \\
(72.70 ; 18) \\
42.47 \\
(48.80 ; 17)\end{array}$ & 1 \\
\hline $\begin{array}{l}\text { External information } \\
\text { value }\end{array}$ & $\begin{array}{l}\text { Internal } \\
\text { Mixed } \\
\text { External }\end{array}$ & $\begin{array}{l}212.46 \\
(127.39 ; 13) \\
248.55 \\
(130.03 ; 11) \\
353.00 \\
(83.09 ; 6) \\
\end{array}$ & $\begin{array}{l}269.00 \\
(102.94 ; 10) \\
262.29 \\
(116.96 ; 7) \\
234.73 \\
(108.67 ; 11) \\
\end{array}$ & 1 & $\begin{array}{l}237.04 \\
(118.35 ; 23) \\
253.89 \\
(121.74 ; 18) \\
276.47 \\
(113.72 ; 17) \\
\end{array}$ & 3 \\
\hline $\begin{array}{l}\text { Total information } \\
\text { value }\end{array}$ & $\begin{array}{l}\text { Intemal } \\
\text { Mixed } \\
\text { Esxternal }\end{array}$ & $\begin{array}{l}259.38 \\
(181.05 ; 13) \\
302.55 \\
(177.85 ; 11) \\
406.33 \\
(149.12 ; 6)\end{array}$ & $\begin{array}{l}351.00 \\
(139.02 ; 10) \\
335.43 \\
(196.65 ; 7) \\
271.27 \\
(126.72 ; 11)\end{array}$ & 1 & $\begin{array}{l}299.22 \\
(167.16 ; 23) \\
315.33 \\
(180.35 ; 18) \\
318.94 \\
(146.32 ; 17)\end{array}$ & 3 \\
\hline
\end{tabular}

Means ante reported. Standard deviations and number of observations are printed in parentheses. Rank orders are printed in bold.

As Table 7.36 shows, the strongly negative contrasts are caused by the significantly higher amounts external teams in stable environments spend in comparison to the other tearn types. In dynamic environment this difference has vanished. Contrary to our hypothesis, the differences are smaller in dynamic than in stable environments. We must therefore reject hypothesis $7.1 \mathrm{~b}$ as well. 
Table 7.4

ANOVA results on hypothesis $7.1 \mathrm{a}$ and $b$.

\begin{tabular}{|c|c|c|c|}
\hline & \multicolumn{3}{|c|}{ Dependent variable } \\
\hline & $\begin{array}{c}\text { Internal information } \\
\text { value } \\
\text { (Column 1) }\end{array}$ & $\begin{array}{c}\text { External information } \\
\text { value } \\
\text { (Column 2) }\end{array}$ & $\begin{array}{c}\text { Total information } \\
\text { value } \\
\text { (Column } 3)\end{array}$ \\
\hline \multicolumn{4}{|l|}{ Factors: } \\
\hline $\begin{array}{l}\text { Team type } \\
\text { Dymamism }\end{array}$ & $\begin{array}{c}.53 \\
(.59) \\
.54\end{array}$ & $\begin{array}{r}1.00 \\
(.38) \\
26\end{array}$ & $\begin{array}{l}.20 \\
(.82) \\
01\end{array}$ \\
\hline & $\begin{array}{l}.34 \\
(.47)\end{array}$ & $\begin{array}{r}.26 \\
(.61)\end{array}$ & $\begin{array}{l}.01 \\
(.94)\end{array}$ \\
\hline Team type by Dynamism & $\begin{array}{c}.80 \\
(.45)\end{array}$ & $\begin{array}{l}2.73 \\
(.08)\end{array}$ & $\begin{array}{l}2.28 \\
(.11)\end{array}$ \\
\hline $\mathrm{R}^{2}$ & .07 & .11 & .08 \\
\hline
\end{tabular}

${ }^{2} F$-values are reported. Probability of F-value is indicated in parentheses. Significant F-values are printed in bold.

Table 7.5

Contrasts related to hypotheses $7.1 b^{1}$

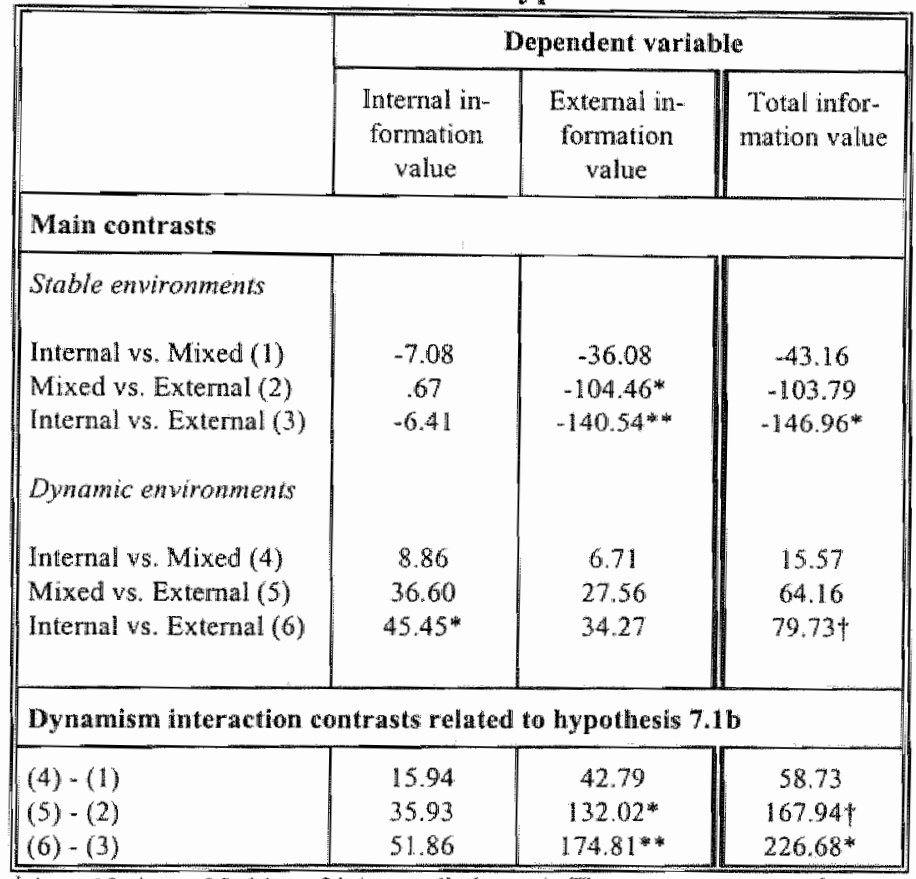

${ }^{*} \mathrm{p}<10,{ }^{*} \mathrm{p}<.05 * * \mathrm{p}<01$ (one-tailed t-test). The contrasts reported are

the differences between the specified means in column 1,2 and 3 of Table 7.3b.

In passing, note that internals do seem to take the lead in the amount of internal information gathering in dynamic environments.

We conclude that no general team type differences exist with regard to information gathering. Only a counter-hypothesized tendency for external teams to spend more 
on external information than other teams was found in stable environments, but this effect vanishes in dynamic environments.

Turning to the relative informedness of actions (i.e., hypothesis $7.2 \mathrm{a}$ and $\mathrm{b}$ ), Table $7.6 \mathrm{a} / \mathrm{b}$ and $7.8 \mathrm{a} / \mathrm{b}$ give the relevant descriptives for internal and external information respectively.

Table 7.6a

Descriptives: Informed action

Internal information in possession prior to action ${ }^{1}$

\begin{tabular}{|l|l|l|l|l|l|}
\hline Action & $\mathbf{n}^{2}$ & Mean & $\begin{array}{l}\text { Standard } \\
\text { deviation }\end{array}$ & Minimum & Maximum \\
\hline 1. Product quality improvement expendinure & 201 & .30 & .36 & 0 & 1 \\
2. Efficiency improvernent expenditure & 137 & 32 & .39 & 0 & 1 \\
3. Expansion of machine capacity & 229 & .12 & .27 & 0 & 1 \\
4. Promotion expenditure on market 1 & 225 & .33 & .36 & 0 & 1 \\
Promotion expenditure on export market & 201 & .33 & .36 & 0 & 1 \\
Promotion expenditure on market 2 & 242 & .37 & .37 & 0 & 1 \\
Promotion expenditure on market 3 & 208 & .24 & .33 & 0 & 1 \\
All actions & & & & & \\
\hline
\end{tabular}

"Reported is the fraction of the maximum avallable information teams possessed prior to the respective action (see text). For the particular information request associated with each action, see the upper half of Table 7.2 .

${ }^{2}$ Number of times a specific action was undertaken.

Table $7.6 \mathrm{~b}$

Descriptives: informed action

Internal information in possession prior to action ${ }^{t}$

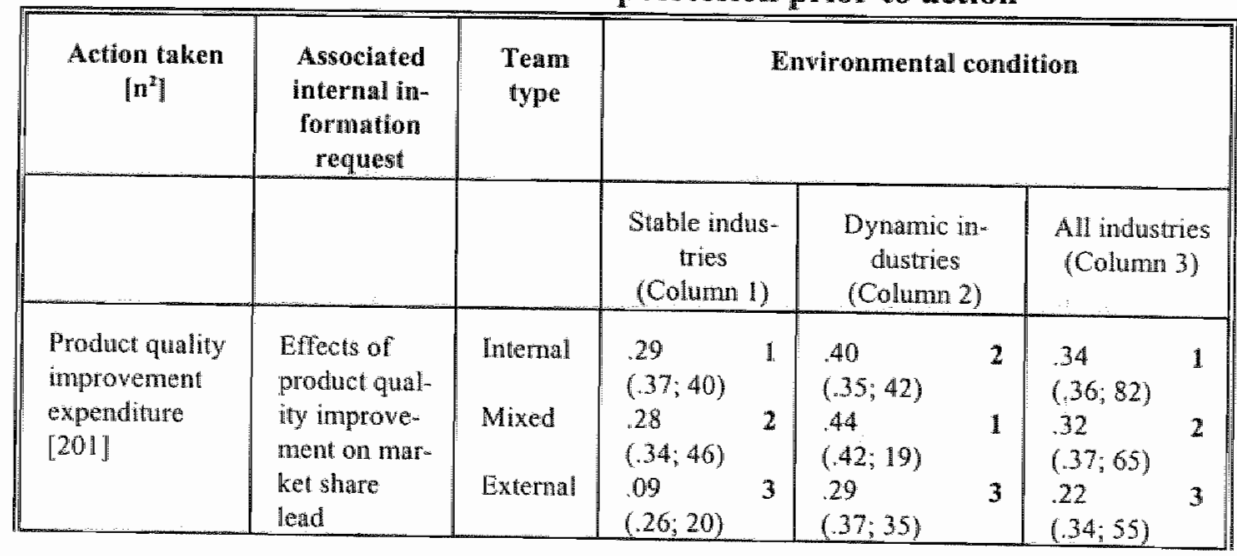

\footnotetext{
"No relationship appeared to exist between team type and the number of actions, nor between the number of actions and their relative informedness.
} 


\begin{tabular}{|c|c|c|c|c|c|c|c|c|}
\hline $\begin{array}{l}\text { Efficiency im- } \\
\text { provement ex- } \\
\text { penditure } \\
{[137]}\end{array}$ & $\begin{array}{l}\text { Effects of } \\
\text { efficiency } \\
\text { improvement } \\
\text { on product } \\
\text { costs and raw } \\
\text { matmerials use }\end{array}$ & $\begin{array}{l}\text { Internal } \\
\text { Mixed } \\
\text { Externa: }\end{array}$ & $\begin{array}{l}19 \\
(32 ; 30) \\
.28 \\
(.38 ; 29) \\
.15 \\
(32 ; 19)\end{array}$ & $\begin{array}{l}2 \\
1 \\
3\end{array}$ & $\begin{array}{l}.67 \\
(.34 ; 24) \\
.36 \\
(.41 ; 16) \\
.27 \\
(39 ; 19)\end{array}$ & $\begin{array}{l}1 \\
2\end{array}$ & $\begin{array}{l}.40 \\
(40 ; 54) \\
31 \\
(39 ; 45) \\
.21 \\
(36 ; 38)\end{array}$ & 1 \\
\hline $\begin{array}{l}\text { Expansion of } \\
\text { machine capac- } \\
\text { my } \\
{[229]}\end{array}$ & $\begin{array}{l}\text { Effects of } \\
\text { expansion on } \\
\text { fixed costs }\end{array}$ & $\begin{array}{l}\text { Intemal } \\
\text { Mixed } \\
\text { Extermal }\end{array}$ & $\begin{array}{l}13 \\
(30 ; 52) \\
.09 \\
(.20 ; 42) \\
.09 \\
(.22 ; 23) \\
\end{array}$ & 1 & $\begin{array}{l}.22 \\
(35 ; 46) \\
.21 \\
(31 ; 22) \\
03 \\
(10 ; 44)\end{array}$ & 1 & $\begin{array}{l}.17 \\
(.32 ; 98) \\
.13 \\
(25 ; 64) \\
.05 \\
(15 ; 67)\end{array}$ & 3 \\
\hline $\begin{array}{l}\text { Promotion ex- } \\
\text { penditure on } \\
\text { manket } 1 \\
{[225]}\end{array}$ & $\begin{array}{l}\text { Effects of } \\
\text { promotion } \\
\text { expenditure } \\
\text { on market } 1 \\
\text { share lead }\end{array}$ & $\begin{array}{l}\text { Internal } \\
\text { Mixed } \\
\text { External }\end{array}$ & $\begin{array}{l}.32 \\
(38 ; 51) \\
.31 \\
(36 ; 45) \\
.24 \\
(30 ; 24) \\
\end{array}$ & $\begin{array}{l}1 \\
2\end{array}$ & $\begin{array}{l}44 \\
(.32 ; 35) \\
.43 \\
(.42 ; 25) \\
.24 \\
(.33 ; 45) \\
\end{array}$ & 1 & $\begin{array}{l}.37 \\
(36 ; 86) \\
.35 \\
(38 ; 70) \\
.24 \\
(31 ; 69)\end{array}$ & 1 \\
\hline $\begin{array}{l}\text { Promotion ex- } \\
\text { penditure on } \\
\text { expont market } \\
{[201]}\end{array}$ & $\begin{array}{l}\text { Effects of } \\
\text { promotion } \\
\text { expenditure } \\
\text { on export } \\
\text { market share } \\
\text { lead }\end{array}$ & $\begin{array}{l}\text { Internal } \\
\text { Mixed } \\
\text { External }\end{array}$ & $\begin{array}{l}.34 \\
(.41 ; 32) \\
31 \\
(36 ; 39) \\
.24 \\
(31 ; 20)\end{array}$ & $\begin{array}{l}1 \\
2 \\
3\end{array}$ & $\begin{array}{l}.47 \\
(31 ; 39) \\
.40 \\
(.41 ; 28) \\
19 \\
(.29 ; 43)\end{array}$ & $\begin{array}{l}2 \\
3\end{array}$ & $\begin{array}{l}.41 \\
(.36 ; 71) \\
35 \\
(.38 ; 67) \\
.21 \\
(.29 ; 63)\end{array}$ & 1 \\
\hline $\begin{array}{l}\text { Promorion ex: } \\
\text { penditume on } \\
\text { market } 2 \\
{[242]}\end{array}$ & $\begin{array}{l}\text { Erfects of } \\
\text { promotion } \\
\text { expenditine } \\
\text { on market } 2 \\
\text { share lead }\end{array}$ & $\begin{array}{l}\text { Internal } \\
\text { Mixed } \\
\text { Extermal }\end{array}$ & $\begin{array}{l}33 \\
(39 ; 43) \\
36 \\
(.37 ; 51) \\
.42 \\
(.42 ; 26) \\
\end{array}$ & 3 & $\begin{array}{l}.52 \\
(31 ; 50) \\
.41 \\
(41 ; 27) \\
20 \\
(30 ; 45) \\
\end{array}$ & $\begin{array}{l}1 \\
2 \\
3\end{array}$ & $\begin{array}{l}.43 \\
(36 ; 93) \\
38 \\
(38 ; 78) \\
28 \\
(.36 ; 71) \\
\end{array}$ & $\mathbb{1}$ \\
\hline $\begin{array}{l}\text { Promotion ex- } \\
\text { perdinure on } \\
\text { market } 3 \\
{[208]}\end{array}$ & $\begin{array}{l}\text { Elfects of } \\
\text { promotion } \\
\text { expenditure } \\
\text { on market } 3 \\
\text { share lead }\end{array}$ & $\begin{array}{l}\text { Intemal } \\
\text { Mixed } \\
\text { External }\end{array}$ & $\begin{array}{l}19 \\
(32 ; 41) \\
.29 \\
(35 ; 40) \\
.18 \\
(33 ; 25) \\
\end{array}$ & 2 & $\begin{array}{l}.33 \\
(.29 ; 38) \\
.42 \\
(.40 ; 24) \\
.08 \\
(.16 ; 40) \\
\end{array}$ & $\begin{array}{l}2 \\
1 \\
3\end{array}$ & $\begin{array}{l}.26 \\
(32 ; 79) \\
34 \\
(38 ; 64) \\
12 \\
(.24 ; 65) \\
\end{array}$ & 2 \\
\hline $\begin{array}{l}\text { All actions } \\
{[1444]}\end{array}$ & $\begin{array}{l}\text { All internal } \\
\text { effects }\end{array}$ & $\begin{array}{l}\text { Intermal } \\
\text { Mlixed } \\
\text { External. }\end{array}$ & $\begin{array}{l}25 \\
(36 ; 289) \\
.28 \\
(35 ; 292) \\
21 \\
(33 ; 157)\end{array}$ & 2 & $\begin{array}{l}.42 \\
(.34 ; 274) \\
.38 \\
(.40 ; 161) \\
18 \\
(.29 ; 271)\end{array}$ & $\begin{array}{l}1 \\
2\end{array}$ & $\begin{array}{l}33 \\
(36 ; 563) \\
31 \\
(37 ; 453) \\
.19 \\
(31 ; 428)\end{array}$ & 1 \\
\hline
\end{tabular}

Reported is the fracion of afre mianinum awailable information teams possessed prior to the respective action (see text). Standard. dewiation and namber of obserwations are in parentheses. Rank crders are printed in bold.

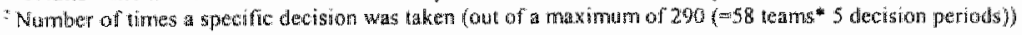

We will deal with internal and external informedness separately as they require different testing techniques (see section 3 ). 
Internally informed action (hypothesis $7.2 a$ and $7.2 b$ ).

The test results ${ }^{7}$ on the internal informedness of the decisions under study are reported in Table 7.7a. There appear to be strongly significant effects of team type, environmental dynamism and the team type by dynamism interaction. Contrasts were calculated to qualify these effects; they are reported in Table 7.7b. First, consider the team type main effect. As the contrasts in Table 7.7b show, the team type differences are predominantly positive as predicted, which supports our hypothesis $7.2 \mathrm{a}$. It appears that the differences with external teams (i.e., contrasts $2,3,5$ and 6 ) are particularly pronounced so that internal and mixed teams rather "move together' vis à vis external teams who clearly lag behind on internal informedness. This can be seen in the last row and column of Table $7.6 \mathrm{~b}$ as well. Internals and mixed teams have on average about one-third $(33 \%$ and $31 \%$, respectively) of the maximum obtainable internal information at their disposal when they take a decision; externals, however, have only a fifth (19\%). Second, as the same lower row of Table $7.6 \mathrm{~b}$ indicates, the main effect of dynamism is produced by a strong tendency in internal and mixed teams alike, to be more informed in dynamic as opposed to stable environments; external teams on the other hand tend to be even less internally informed in dynamic environments. Third, the interaction factor appears to be very significant as well. This effect can be seen at first glance in the upper half of Table $7.7 \mathrm{~b}$, as the main contrasts with external teams are generally higher in dynamic as opposed to stable environments. These differences appear to be significant as the interaction contrasts in the bottom row of Table $7.7 \mathrm{~b}$ indicate. Again, the effect is most pronounced when comparing external versus other team types, but the internal-mixed contrast also reaches (marginal) significance in the summary measure in the last column. Taken together, these results lend clear support to the interaction hypothesis $7.2 \mathrm{~b}$ as well: the differences between team types are greater in dynamic than in stable environments. We conclude that external teams' actions are less internally informed than other teams types, especially in dynamic environments.

\section{Externally informed action (hypothesis $7.2 a$ and $7.2 b$ ).}

Turning to the results on the external, competitive informedness of actions, see Table $7.8 \mathrm{a}$ and $\mathrm{b}$ for descriptives. As the dependent variable in these analyses is either 0 (not pre-informed) or 1 (pre-informed), the team means calculated per decision in Table 7.8a represent the proportions of actions that were preceded by a relevant competitive information request. Apparently, for some decisions prior external information was deemed more important than for others. For instance, only one fifth of all decisions to raise wages were based on knowledge of competitor wage levels. On the other hand almost 90 percent of the decisions to change prices on all markets at once were backed by informa-

\footnotetext{
${ }^{7}$ Kolmogorov-Smimov tests of the distributions of these variables showed that they were in fact not normally distributed. As non-parametric methods do not generally allow for testing interactions (Boone, 1992), we kept using parametric tests whilst checking the results on main effects with non-parametric tests (i.c. Kruskal-Wallis tests and the non-parametric multiple range tests described by Aczel (1993), pp. 658-659. It appeared that our basic results and conclusions remain unaffected if non-parametric techniques are applied.
} 


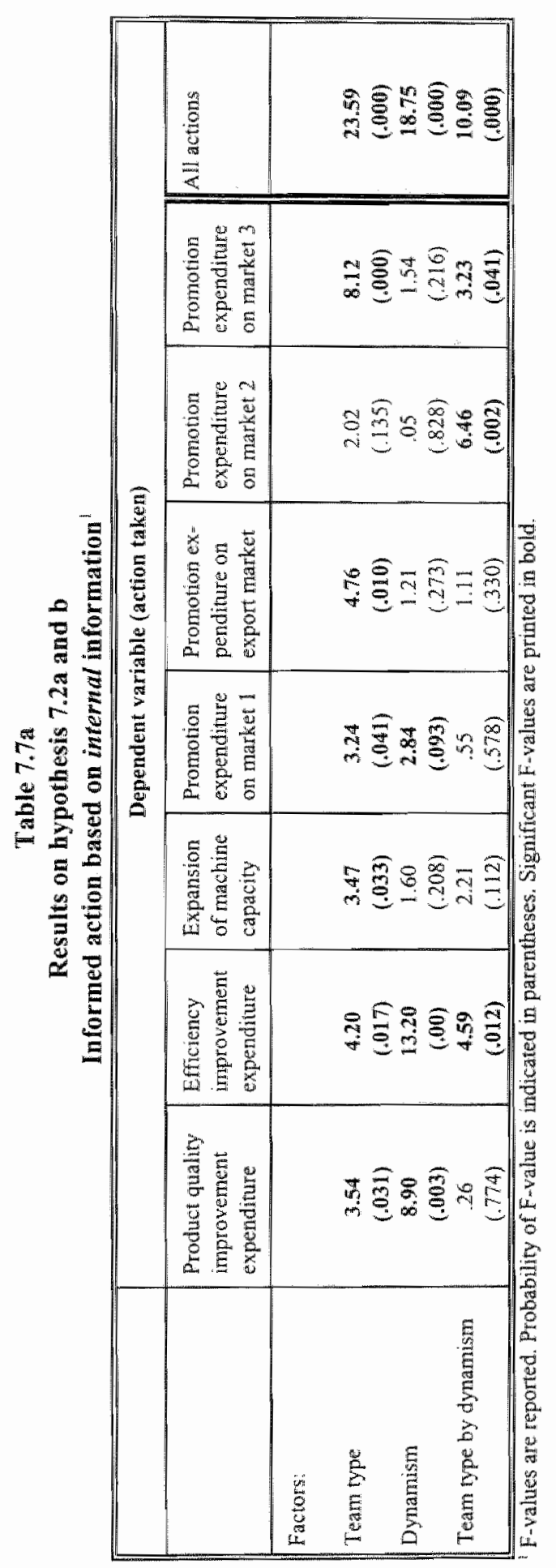




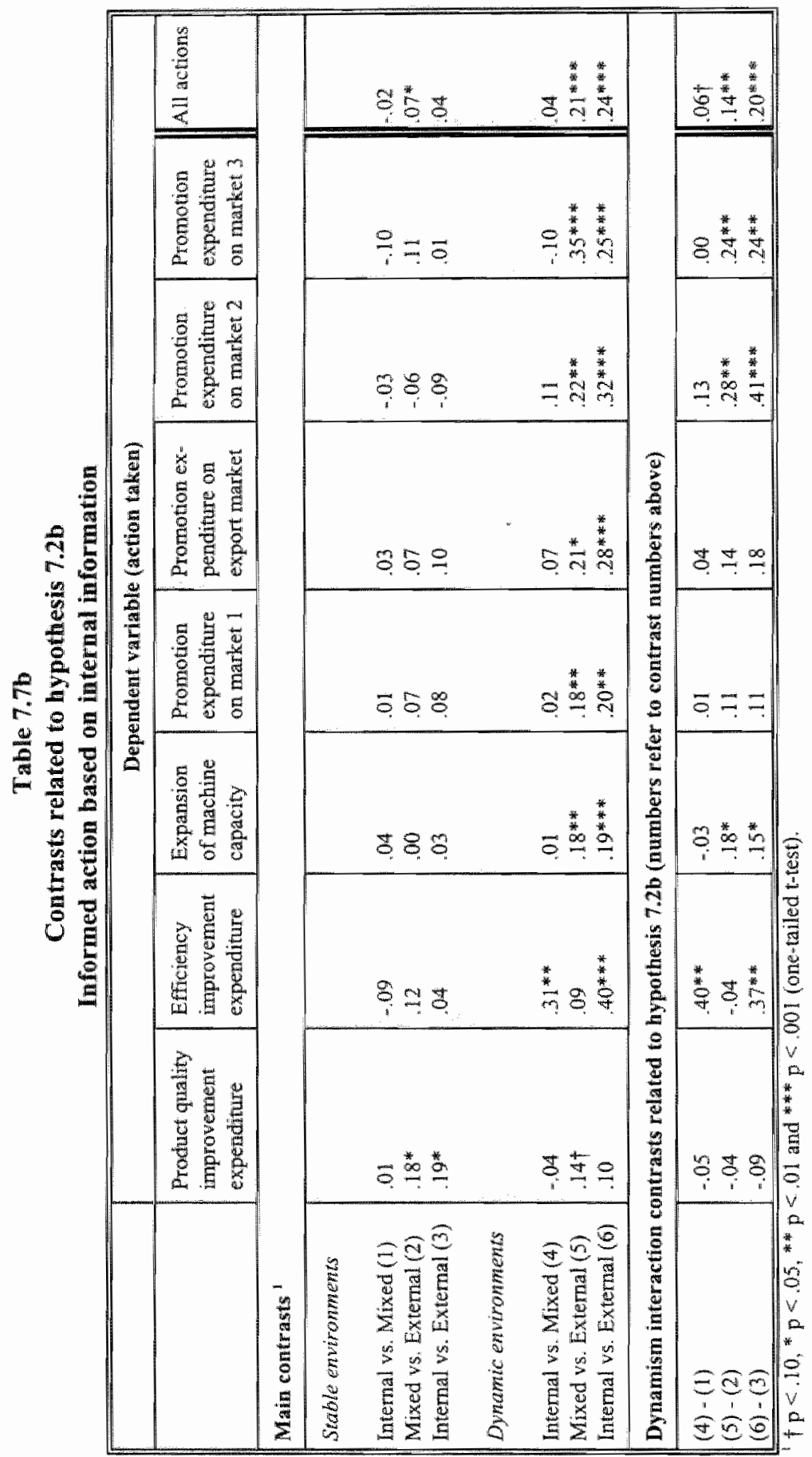


Table $7.8 \mathrm{a}$

Descriptives: informed action

Proportion of decisions preceded by relevant external information requests

\begin{tabular}{|l|l|l|l|l|l|}
\hline Action taken & $\mathrm{n}^{*}$ & Mean & $\begin{array}{l}\text { Standard } \\
\text { deviation }\end{array}$ & Minimum & Maximum \\
\hline 1. Price change on all markets & 103 & .88 & .32 & 0 & 1 \\
2. Maximum allowable price clange on any market & 65 & .83 & .38 & 0 & 1 \\
3a. Expansion of machine capacity (1) & 218 & .19 & .39 & 0 & 1 \\
36. Expansion of machine capacity (2) & 218 & .70 & .46 & 0 & 1 \\
4. Promotion expenditure on any market & 255 & .53 & 50 & 0 & 1 \\
5. Product quality improvernent expenditure & 192 & .50 & 50 & 0 & 1 \\
6. Expansion of sales groups & 209 & .20 & .40 & 0 & 1 \\
7. Improvement of working conditions & 201 & .17 & .38 & 0 & 1 \\
8. Wage raise & 227 & .21 & .41 & 0 & 1 \\
All actions & & & & & 1 \\
\hline
\end{tabular}

For the particular information request associated with each action, see the lower half of Table 7.2.

"Number of times a specific action was undertaken.

Table $7.8 b$

Descriptives: informed action

Proportion of decisions preceded by relevant external information requests ${ }^{1}$

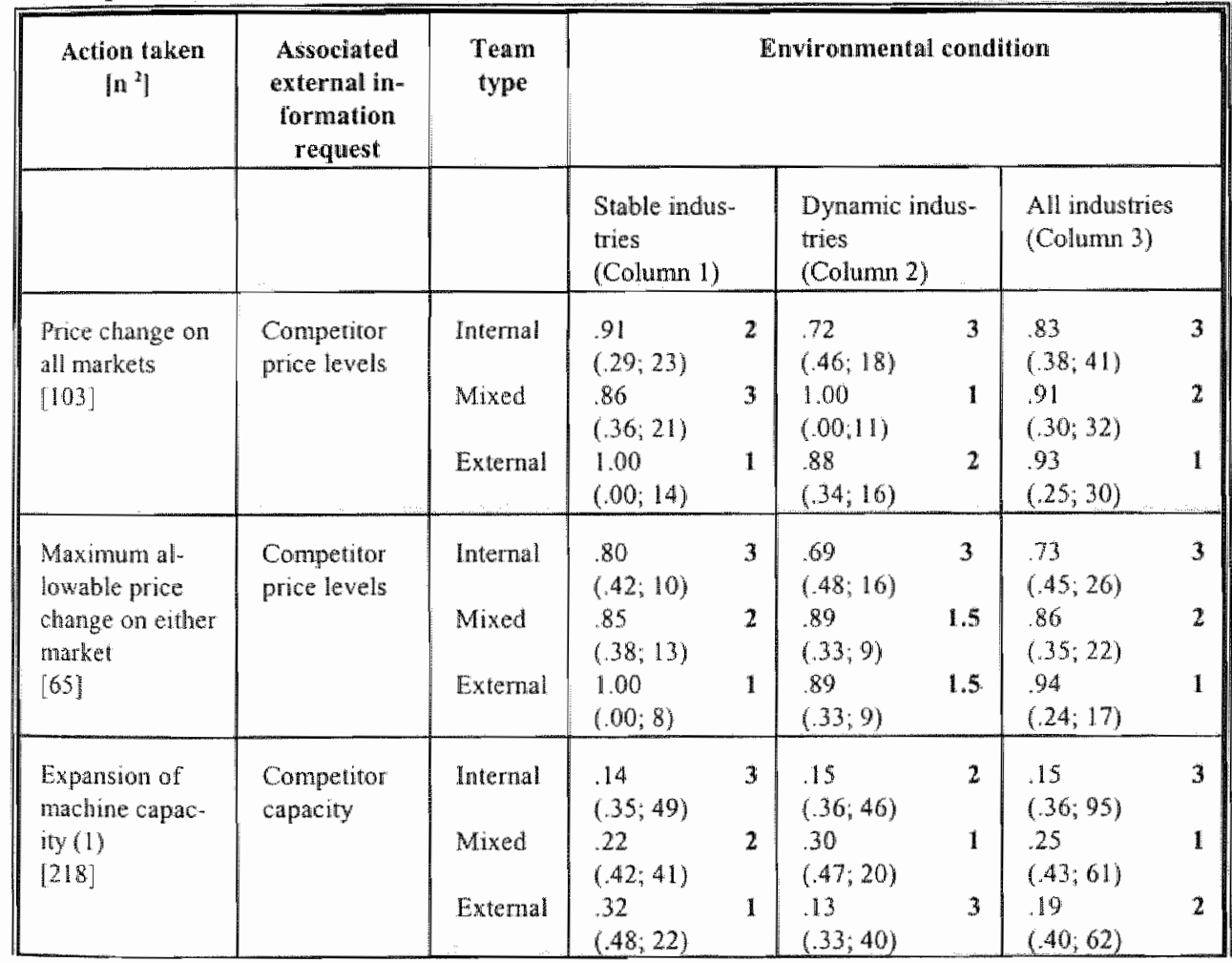




\begin{tabular}{|c|c|c|c|c|c|c|c|c|}
\hline $\begin{array}{l}\text { Expansion of } \\
\text { machine capac- } \\
\text { ity }(2) \\
{[218]}\end{array}$ & $\begin{array}{l}\text { Market de- } \\
\text { mand }\end{array}$ & $\begin{array}{l}\text { Internal } \\
\text { Mixed } \\
\text { External }\end{array}$ & $\begin{array}{l}57 \\
(.50 ; 49) \\
71 \\
(.46 ; 41) \\
.91 \\
(.29 ; 22)\end{array}$ & $\begin{array}{l}3 \\
2\end{array}$ & $\begin{array}{l}.67 \\
(.47 ; 46) \\
.70 \\
(.47 ; 20) \\
.75 \\
(.44 ; 40)\end{array}$ & 3 & $\begin{array}{l}.62 \\
(.49 ; 95) \\
.70 \\
(.46 ; 61) \\
.81 \\
(.40 ; 62)\end{array}$ & 3 \\
\hline $\begin{array}{l}\text { Promotion ex- } \\
\text { pendinure } \\
255]\end{array}$ & $\begin{array}{l}\text { Compertitor } \\
\text { promotion } \\
\text { levels }\end{array}$ & $\begin{array}{l}\text { Internal } \\
\text { Mixed } \\
\text { External }\end{array}$ & $\begin{array}{l}.47 \\
(.50 ; 51) \\
.45 \\
(.50 ; 51) \\
.81 \\
(.40 ; 27) \\
\end{array}$ & $\begin{array}{l}2 \\
3 \\
3\end{array}$ & $\begin{array}{l}.52 \\
(50 ; 50) \\
.39 \\
(50 ; 28) \\
.63 \\
(.49 ; 48) \\
\end{array}$ & 2 & $\begin{array}{l}.50 \\
(.50 ; 101) \\
43 \\
(50 ; 79) \\
.69 \\
(.46 ; 75) \\
\end{array}$ & 2 \\
\hline $\begin{array}{l}\text { Product im- } \\
\text { provement } \\
{[192]}\end{array}$ & $\begin{array}{l}\text { Competitor } \\
\text { quality levels }\end{array}$ & $\begin{array}{l}\text { Internal } \\
\text { Mixed } \\
\text { Extternal }\end{array}$ & $\begin{array}{l}.32 \\
(47 ; 38) \\
.53 \\
(.50 ; 45) \\
.56 \\
(.51 ; 18) \\
\end{array}$ & $\begin{array}{l}3 \\
2\end{array}$ & $\begin{array}{l}.52 \\
(51 ; 42) \\
.56 \\
(.51 ; 16) \\
58 \\
(50 ; 33) \\
\end{array}$ & 3 & $\begin{array}{l}.43 \\
(50 ; 80) \\
.54 \\
(.50 ; 61) \\
.57 \\
(50 ; 51) \\
\end{array}$ & 3 \\
\hline $\begin{array}{l}\text { Expansion of } \\
\text { sales groups } \\
{[209]}\end{array}$ & $\begin{array}{l}\text { Competitor } \\
\text { number of } \\
\text { sales groups } \\
\text { employed }\end{array}$ & $\begin{array}{l}\text { Internal } \\
\text { Mixed } \\
\text { External }\end{array}$ & $\begin{array}{l}.09 \\
(.29 ; 45) \\
.16 \\
(.37 ; 37) \\
.44 \\
(.51 ; 25) \\
\end{array}$ & $\begin{array}{l}3 \\
2 \\
1\end{array}$ & $\begin{array}{l}20 \\
(.41 ; 44) \\
43 \\
(51 ; 23) \\
.06 \\
(.24 ; 35) \\
\end{array}$ & 2 & $\begin{array}{l}.15 \\
(36 ; 89) \\
.27 \\
(.45 ; 60) \\
.22 \\
(42 ; 60) \\
\end{array}$ & 3 \\
\hline $\begin{array}{l}\text { Improvement of } \\
\text { working condi- } \\
\text { tions } \\
{[20 \mathrm{l}]}\end{array}$ & $\begin{array}{l}\text { Competitor } \\
\text { working con- } \\
\text { ditions }\end{array}$ & $\begin{array}{l}\text { Internal } \\
\text { Mixed } \\
\text { External }\end{array}$ & $\begin{array}{l}.16 \\
(37 ; 43) \\
.16 \\
(37 ; 44) \\
.26 \\
(.45 ; 23) \\
\end{array}$ & $\begin{array}{r}2.5 \\
2.5 \\
1\end{array}$ & $\begin{array}{l}.18 \\
(.38 ; 40) \\
.29 \\
(.46 ; 21) \\
.07 \\
(.25 ; 30) \\
\end{array}$ & 2 & $\begin{array}{l}.17 \\
(.38 ; 83) \\
.20 \\
(.40 ; 65) \\
.15 \\
(.36 ; 53) \\
\end{array}$ & 2 \\
\hline $\begin{array}{l}\text { Wage raise } \\
{[227]}\end{array}$ & $\begin{array}{l}\text { Competitor } \\
\text { wage level }\end{array}$ & $\begin{array}{l}\text { Internal } \\
\text { Mixed } \\
\text { External }\end{array}$ & $\begin{array}{l}.22 \\
(.42 ; 50) \\
.17 \\
(.38 ; 41) \\
.41 \\
(50 ; 27) \\
\end{array}$ & 2 & $\begin{array}{l}.21 \\
(.42 ; 42) \\
.26 \\
(45 ; 27) \\
.05 \\
(22 ; 40) \\
\end{array}$ & 2 & $\begin{array}{l}.22 \\
(41 ; 92) \\
.21 \\
(.41 ; 68) \\
19 \\
(40 ; 67)\end{array}$ & 1 \\
\hline $\begin{array}{l}\text { All decisions } \\
{[1689\rfloor}\end{array}$ & $\begin{array}{l}\text { All associ- } \\
\text { atred informtan } \\
\text { tion }\end{array}$ & $\begin{array}{l}\text { Internal } \\
\text { Mixed } \\
\text { External }\end{array}$ & $\begin{array}{l}.34 \\
(.47 ; 358) \\
.40 \\
(.49 ; 334) \\
.59 \\
(.49 ; 186)\end{array}$ & $\begin{array}{l}2 \\
1\end{array}$ & $\begin{array}{l}.39 \\
(49 ; 344) \\
.47 \\
(.50 ; 175) \\
38 \\
(.49 ; 291)\end{array}$ & 2 & $\begin{array}{l}37 \\
(.48 ; 702) \\
.42 \\
(.49 ; 509) \\
.46 \\
(.50 ; 477)\end{array}$ & 1 \\
\hline
\end{tabular}

As all dependent variables are dichotomous $(0 / 1)$, the reported means are the proportions of actions that are preceded by the associated information request. Standard deviations and number of observations are in parentheses. Rank orders are printed in bold.

"Number of times a specific decision was taken (out of a maximum of $290(=58$ teams." 5 decision periods)).

tion on the prices of competitors. Table $7.8 \mathrm{~b}$ shows how the likelihood of requesting prior information relates to team types and environmental conditions. 
Hypothesis $7.2 \mathrm{a}$ predicted highest informedness of internal teams, followed by mixed and external teams. The 'model 1 ' columns of Table 7.9 a contain the results of the logistic regression analyses to test this hypothesis. Higher informedness of internal and mixed teams as opposed to external teams should result in positive coefficients of the intemal and mixed team dummies, Di and Dm. As it happens, however, these coefficients are typically negative. In the last column of Table $7.9 \mathrm{a}$, the analysis of all pooled decisions indicates that internal teams in general are significantly less pre-informed by external information than external teams. Mixed teams take a general position in between internal and external teams. This can also be seen in the last column of Table $7.8 \mathrm{~b}$ in which mixed teams tend to take the second rank position. Counter to hypothesis $7.2 \mathrm{a}$, external teams are generally best informed on external competitive information, as shown by their frequent first rank in Table $7.8 \mathrm{~b}$. The results indicate no general tendency to be more externally informed in dynamic than in stable environments. However, inspection of Table $7.8 \mathrm{~b}$ indicates that this is not true for each individual team type. Specifically, as the lower row indicates, internal and mixed teams are generally somewhat better informed in dynamic as opposed to stable environments, whereas extemal leams are less informed.

To test the interaction hypothesis $7.2 \mathrm{~b}$, see the Model 2 columns of Table $7.9 \mathrm{a}$. The interaction factors that are added at step 2 appear to be positive and reach considerable significance, especially on the last three variables and in the summary analysis on all actions, reported in the last column. In order to interpret the interaction effect, we reran the regressions in stable and dynamic environments separately as reported in Table $7.9 \mathrm{~b}$. Note that the value of the interaction coefficient is the difference between the corresponding coefficients in dymamic and stable enviromments. For instance, on price change the internal team dummy"s (Di) coefficient in stable and dynamic environments are -7.85 and -.99 respectively in Table $7.9 \mathrm{~b}$. The difference between the two $=-.99-(-$ $7.85)=6.86$ which is the coefficient of the $\mathrm{Di} *$ Dynamism interaction term in Table 7.9a. When we compare the coefficients in stable and dynamic environments, we see that they are generally smaller in dynamic than in stable environments, which is contrary to our hypothesis $7.2 \mathrm{~b}$. We can now more precisely qualify the counter hypothesized main effect of external teams. It appears that this is mainly caused by a tendency of external teams to be significantly more externally informed in stable environments. This can be seen in Table 7.1 b as external teams rank consistently first in stable environments, whereas this lead vanishes in dynamic environments. To sum up, we must conclude that both hypotheses with regard to external informedness must be rejected. If anything, axternal teams are the ones that are best externally informed, especially in stable environments ${ }^{9}$.

\footnotetext{
${ }^{8}$ Because the magnitude of an action (for instance the size of a capacity expansion or promotion expenditure) may well influence the probability of inquiry, we checked all analyses by adding the action magnitudes as covariates. The inclusion of these covariates appeared not to affect the results and conclusions reported.

The proportions in Table 7.86 and the coefficients in Table 7.96 are connected as follows. The dummy coefficients represent the difference in the In(odds) between team types. These odds can be easily calculated from the reported probabilities. For instance, take the "all decisions" row in "Table 7.86 and the stable environments cell. Probabilities for intemal and extemal teams are: 34078 and .58602 , so the odds are: 51694 and 1.41558 and the $\ln$ (odds) are: -60161 and 34754 . The difference between the two is -1.00915 or -1.01 . This is the value of the internal dummy coefficient (Di) in the "all actions stable" collum in Table 7.9 b.
} 


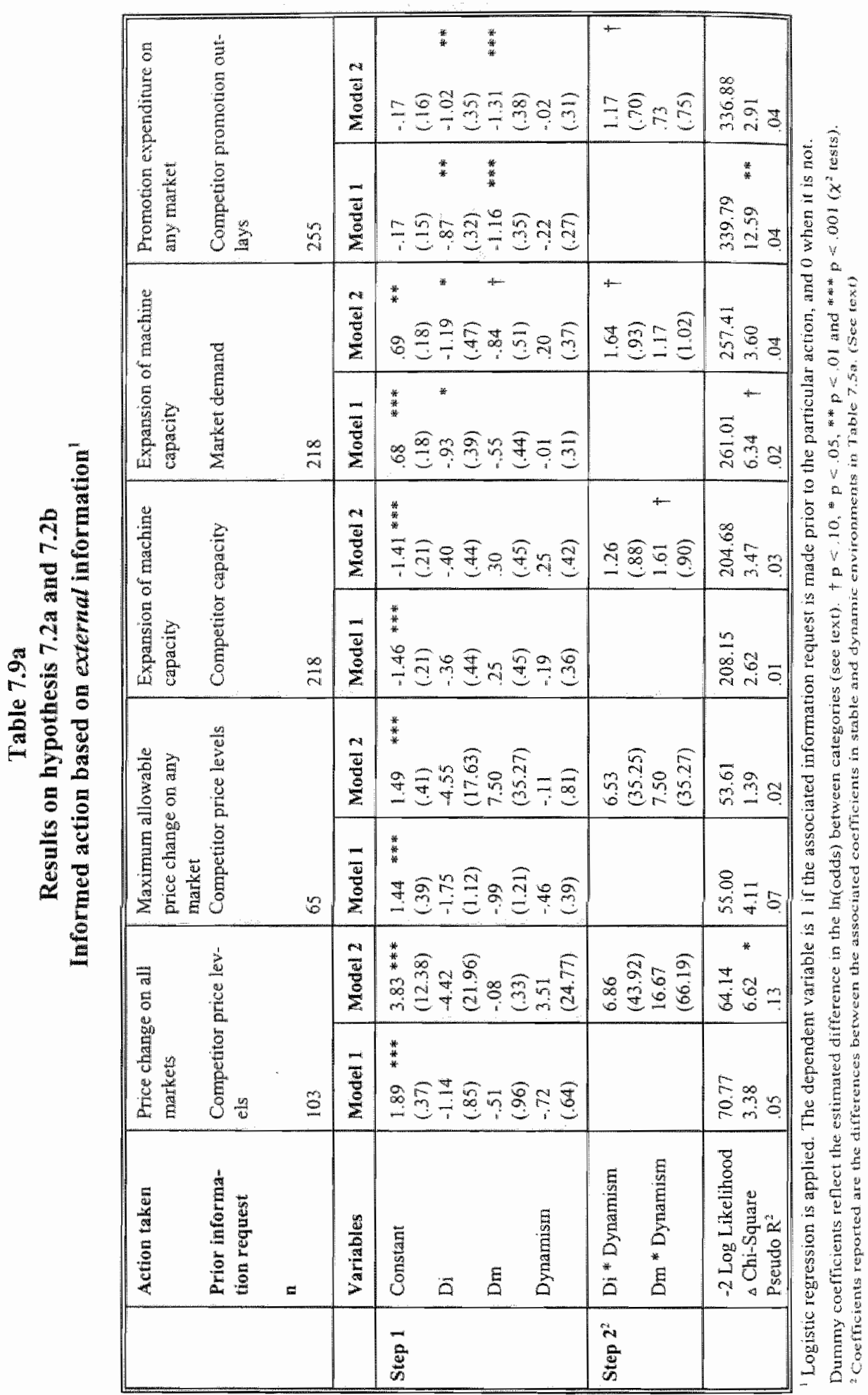




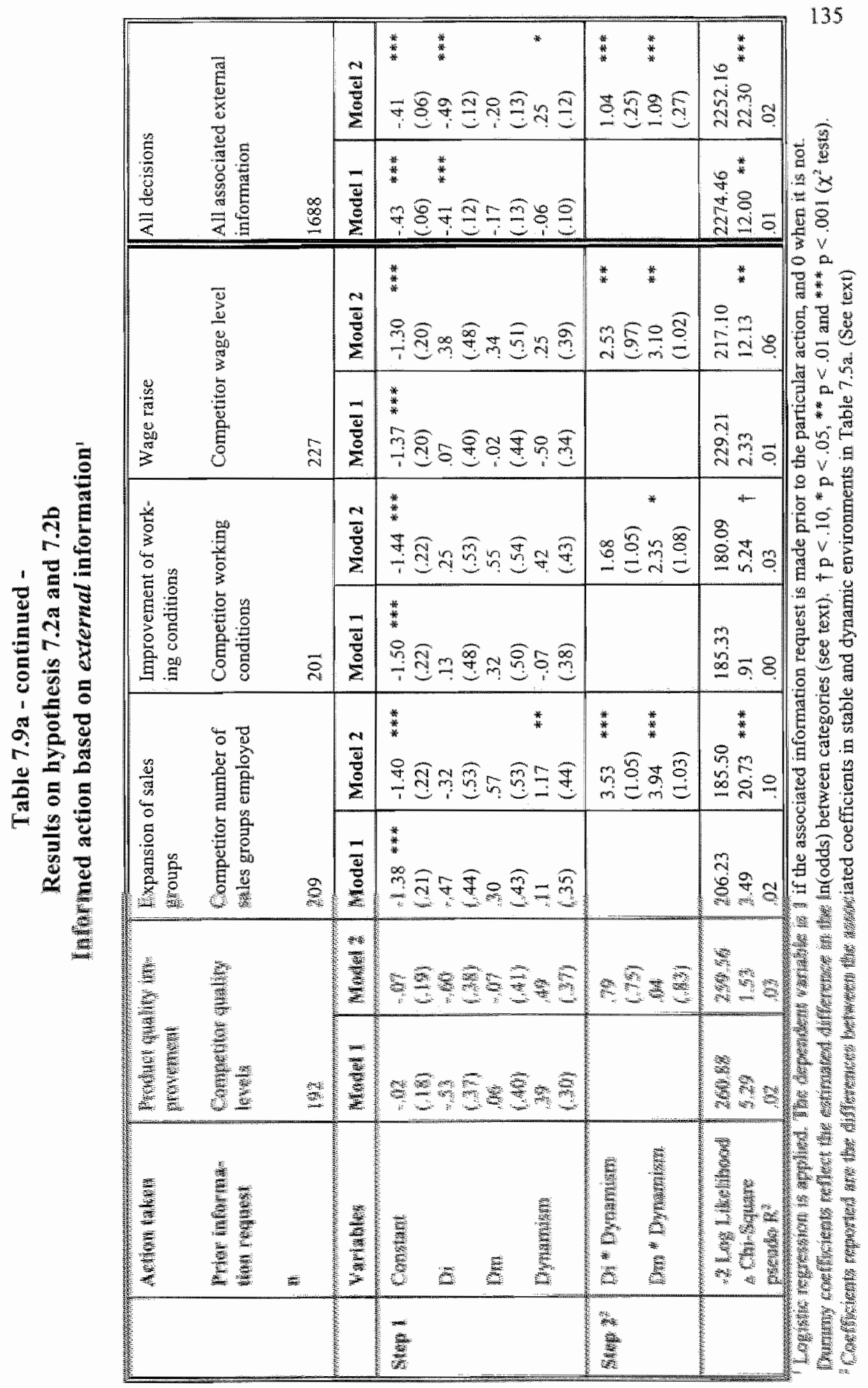




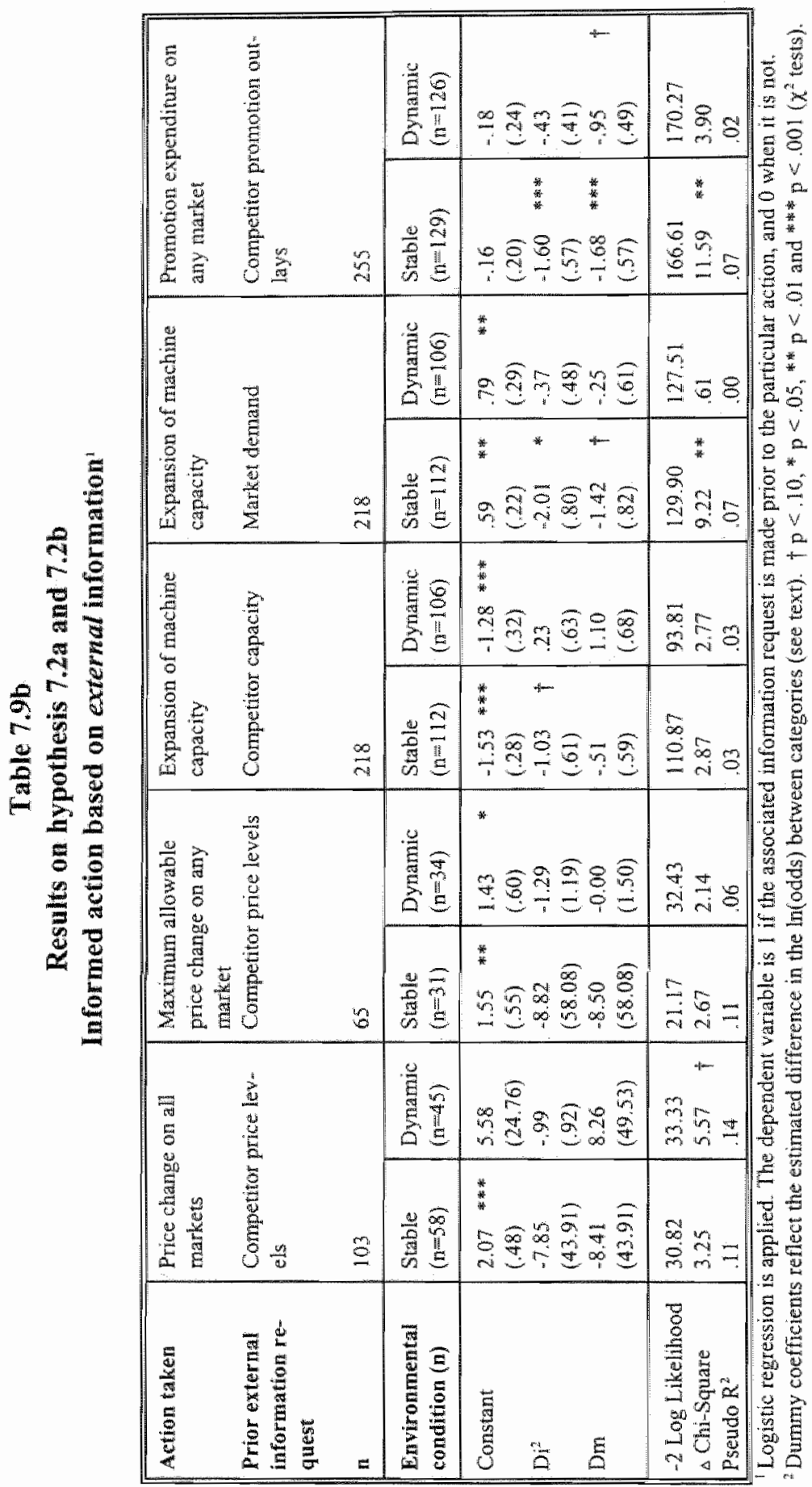




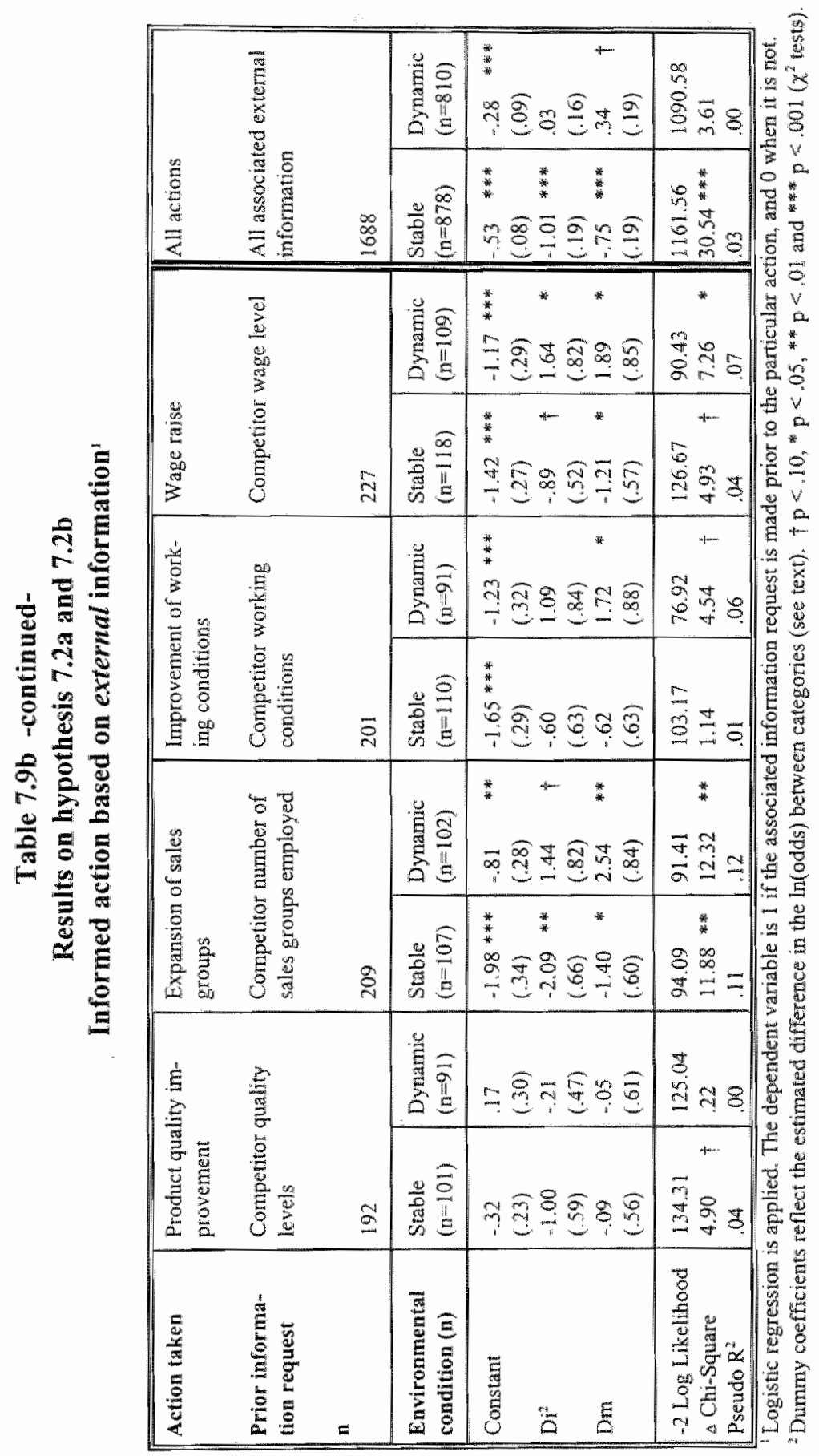




\subsection{Discussion}

Concerning the gathering of information, we expected internals to be generally more active than mixed or external teams because their belief in own efficacy would inspire a more inquisitive stance. This appeared not to be generally the case. When it comes down to simply spending on information, teams do not differ much; they all seem to recognize the importance of having a certain amount of information at their disposal. However, when we look at how this information is used to take action, more pronounced differences are detected. Concerning internal information, both the main and interaction effects were found as hypothesized. Internal and mixed teams are indeed better informed on the effects of their own actions before they undertake them than external teams. On the other hand, external teams tended to take more externally informed actions. With regard to information related behavior, mixed teams closely resemble internal teams. This preference for different types of information prior to action between teams is intriguing. Note that the same thing can be found in the reverse ordering of team types on internal and external information value in the last column of Table $7.3 \mathrm{~b}$ : internals rank first on internal information value and last on external information value, whereas the reverse holds true for external teams. This phenomenon may be explained by internals" greater desire to seek out and map the important manageable variables in their direct environment. They approach things, so to speak, in a more practical self-oriented fashion and are generally less interested in what competitors do. If they are interested in competitors at all, however, it is again in the internal circumstances that prevail in competitor's companies and not in what they exactly do. External teams, on the other hand, lacking clear clues as to what appropriate action is, tend to take a more outward oriented focus: they apparently learn by looking at the behaviors of other parties and have less attention for the effectiveness of the instruments they can directly manipulate.

Another important finding concerns the attuning of information search and informed action on environmental conditions. It makes intuitive sense to assume that being well-informed is more crucial in dynamic environments than in rather placid environments. Now what we see is, that in all information analyses internals and mixed teams seem to match their information gathering to situational requirements: total information spending is higher in dynamic than in stable situations (see Table 7.3b), and actions are better informed, both internally as externally, in dynamic than in stable environments (see last rows in Tables $7.6 \mathrm{~b}$ and $7.8 \mathrm{~b}$ ). In sharp contrast to this pattern, external teams systematically decrease their information-related actions in dynamic as opposed to stable environments. When we compare the correlations between the four information variables (internal and external information value and internally and externally informed action) on the one hand and profitability on the other, we see clear support for our prior intuition. In stable environments these correlations are $.17, .17, .14$ and .20 (all non-significant). In dynamic environments they are $.59(\mathrm{p}=.001) ; .303$ (n.s.), $.64(\mathrm{p}<.000)$ and .19 (n.s.). We may conclude that information is generally much more important in dynamic than in stable environments, something internal and mixed teams seem to have recognized. External teams, however, show a rather "maladapted" information behavior pattern in relation to the environmental needs. These correlations also underline the superior 
importance of internal over external information in raising profitability; the latter pays off much less than the former. External teams' huge investments in external information in stable environments seems therefore doubly misplaced.

What we have established, then, is an important qualification to past research results that indicated more inquisitiveness on part of internals. Rather than a quantitative effect, we found an important qualitative effect, in which internals search for more practical, manageable information that allow them to understand the effects of their own actions. They are much less interested in what others exactly do and seem to rely on their own situation and the possibilities it offers. When environments are less stable information becomes more important, so they typically collect more information. Externals tend to look at others in general and before they act, which is in line with their less selfconfident character. They tend to collect less instead of more information when environments are more dynamic and thus seem to have less feeling for the type and amount of information that is most useful or appropriate to collect.

\section{$3 \quad$ Planned action}

\subsection{Theory and hypotheses}

An obvious way to actively control what will happen in the future, is to plan for it. No surprise, therefore, that planning for the future (sometimes referred to as futurity) was found to be an important characteristic of managers with internal control perceptions (Miller and Toulouse, 1986a; Miller, Kets de Vries and Toulouse, 1982; Miller, 1983; Lewin and Stephens, 1994). For instance, Miller and Toulouse (1986a) show that the more internal the manager, the more planning they tend to report. The results, as expected, are stronger in small firms and dynamic environments. Unfortunately, the strategy-making variables 'planning', 'futurity', future/planning' are used in different articles without a proper definition. It is unclear, for instance, whether reference is made to the act of planning itself or to the length of planning horizons. It is nevertheless striking that the result reappears across studies in the expected direction. In the present study we wish to go beyond the mere subjective self-report measurement of planning aspects by readily observing the objective outcomes of effective planning activity. As planning can be seen as a concerted effort to simultaneously optimize and control several aspects of a firm's functioning, internal teams may be expected to outperform others for two reasons. The first is simply that they believe and engage in planning more (as in Miller's studies). The second reason is that internals are better able to cognitively process and integrate the different cues in a complex planning problem, which is needed to solve it (Phares, 1976). In particular, internals are more sensitive to potentially relevant cues and crucial contingencies in ambiguous situations than are externals. This would qualify them better for performing complex tasks (Spector, 1982) like the planning task under study. Thus: 
Hypothesis 7.3a: The planning quality of internal teams will be higher than that of mixed teams; the planning quality of nixed teams will be higher. than that of external teams (main effect)

Additionally, we expect the usual interaction with dynamism.

Hypothesis 7.3b: The differences specified under hypothesis $7.3 a$ will be greater in dynamic than in stable environments (interaction effect)

\subsection{Methods}

Planning can be conceived of as an activity to simultaneously optimize and control different aspects of the environment in order to reach a goal. The planning activity of teams itself is unobservable in our research design. We can, however, measure its effectiveness, that is, the resulting quality of planning, which is adequate for our purpose, as will be explained. As shown in Appendix E, four important planning domains can be distinguished in the game: capacity planning (machines and personnel), input-output planning (raw materials and end products stocks and production levels), sales planning and financial or liquidity planning. Both between and within these domains, the game consists of several interrelated processes that must be carefully monitored and planned to arrive at cost effective operations. Effective planning can be discerned at various planning "moments of truth", which are depicted in the Appendix E diagram by a double arrow $(\Longleftrightarrow)$. Planning quality is high, when at these places tight 'matches' can be achieved. It is clear that without any conscious planning effort good matches are almost impossible to occur, let alone a simultaneous match. ${ }^{10}$ The bottom line is, that although conscious planning efforts are not measured directly, good matches are almost impossible to occur without them. Below we describe the planning effectiveness measures at the matching points (capitals $A$ to $F$ in $A$ ppendix $E$ ) in each of the planning domains.

\section{Capacity planming: machines and personnel utilisation.}

In order to get most productivity out of investments in machines and personnel, it is important to minimize idle production capacity (matches $A$ and $B$ ). This means that the highest degrees of capacity utilisation must be aimed for. The utilisation of machine and personnel capacity was measured as the fraction of the total installed capacity that was used in each period to produce that period's production run, i.e, (total machines (persont nel) capacity used) / (total machine (personnel) capacity installed). This measure was averaged over the six playing periods. If production runs ('start production') and the available production capacity are well matched, capacity utilisation is high and the best use is made of these resources. Thus capacity utilisation of personnel $(A)$ and machines

\footnotetext{
${ }^{10}$ Teams are somewhat aided by the possibility to use a spreadsheet-like planning program. However, this only signaled whether certain decisions are plysically possible of not for instance whether a certain amount of production can be reached given resources). That is : it registers impossibilities but gives no gridance as to the right levels of certain variables or the proper ways to solve or anticipate problems.
} 
(B) proxies planning quality. If teams want to start a too high production volume, which cannot be produced with the available production capacity, game management interferes and decreases production starts proportionally until they fall within available capacity limits ${ }^{11}$. As this interference represents an instance of bad planning on the part of the team as well, we measured the average percentage of forced downward production adjustment (i.e., (volume of forced production adjustment)/ (total planned production volume $* 100$ ) as a third indicator $(C)$ of bad planning in this domain.

\section{Input/ output planning: raw materials and end product stock increases.}

The level of raw materials stock at the end of period $t$ is determined (mainly) ${ }^{12}$ by the stock at the end of $t-1$ and the ballance between raw materials inflow and outflow during t. As Appendix E illustrates, raw materials flow in at the start of $t$ when the raw materials orders placed at $\mathrm{t}-1$ are received. Raw materials flow out, on the other hand, as they are used in producing period t's production nun. Similarly, the level of the end products stock at the end of $t$ is determined by the end level of $t-1$ plus the balance between the inflow and outflow of end products during $t$. End products flow in as the production run of $t-1$ is delivered by the production department or when externally manufactured end products ordered in $\mathrm{t}-1$ are delivered. Outflow of end products is driven by the sales in t. The difficulty in managing both raw materials and end products stock levels therefore lies in the planning of production, ordering and sales both in volumes and across time. As to the levels of these stocks, teams may prefer to set them lower or higher, possibly reflecting the amount of safety they want to build in. However, strong and consistently rising stocks $(D$ and $E)$ are an indication of faulty planning as either production or sales volumes were not properly matched. We therefore summed the volumes of stock rises that occurred between periods and used this total as an inverse indicator of planning quality $^{1,3}$.

\section{Sules planning: no-sales}

Sales planning involves the matching of production to stock and the demand for the product which is importantly influenced by the firm's marketing outlays. The question here, is whether the firm is capable of serving the market in large enough quantities. If more units are produced than can be sold, stocks will (ceteris paribus) rise. This aspect of sales planning is therefore already captured in the above mentioned measure $E$. On the other hand, if firms cannot satisfy demand (i.e., if demand is higher than supply), socalled 'no-sales' (denoted by $F$ in Appendix E) occur. This is caused by the fact that either the firm has planned badly against the trend in generic demand or because its owrs relative marketing efforts have generated more specific demand than can be supplied to the market, that is: marketing and production are badly matched. In either case the total

\footnotetext{
"The same thing happens when insulficient raw materials are avaliable.

12 For the exact influerces and an elaborate explanation see appendix. $E$.

Stow wows would be an alternative measure, but their effects are already captured ellsewhere: raw materials shortage wads to game management interfence by reducing teams" planned production levels ( measure Cj; end products shortage leads 10 mo-sales (-measure $F$; see under 3).
} 
volume of no-sales $(F)$ over all periods can serve as a reverse indicator of the quality of these planning efforts.

\section{Financial planning: cash shortage.}

In order to pay current expenses, enough cash must be generated and secured. The amount of cash that firms hold can be taken as a safety stock just like the aforementioned end products and raw materials. If careful planning of the cash balance fails, however, firms may end up with a deficit $(G)$. In case this happens they have to borrow more money (i.e., get a so-called additional credit) at a higher interest rate or (in case the deficit is too large) they have to request suspension of payment. If they had anticipated the shortage they might have decided to borrow more in the preceding period. In any case, the total amount of cash shortage during the game inversely indicates the quality of liquidity planning. We measured this by calculating a team's cash position at the end of each period before the granting of additional credits. All cash deficits that occurred during the game are then summed to obtain our (inverse) measure of liquidity planning quality.

Thus, a total of seven different measures $(A-G)$ were formulated to capture the different aspects of planning quality in the game. As we are ultimately interested in the concerted effort to plan all aspects simultaneously, we also developed an omnibus measure from the separate planning measures. To obtain this measure, we first reverse coded $C$ to $G$ to positively indicate planning quality and subsequently we standardized all scores. Finally, all standardized scores were added to obtain the measure of overall planning quality $(H)$.

\subsection{Results}

Table $7.10 \mathrm{a}$ and $7.10 \mathrm{~b}$ report the total sample descriptives and group averages in different environments of all seven planning measures plus the overall planning measure ${ }^{14}$. Table 7.II shows the ANOVA results on the planning quality hypotheses $7.3 \mathrm{a}$ and $7.3 \mathrm{~b}$. Hypothesis 7.3a predicted a higher planning quality of internal over mixed and external teams. The ANOVA results reveal a very significant effect of team type on most planning measures and on the overall measure. To see what causes these differences, see the figures and rank orders ( 1 =best planning quality; $3=$ worst planning quality) in column 3 of Table $7.10 \mathrm{~b}$. It appears that internal teams plan best on four out of seven planning quality measures and on the overal] measure. At first glance, we conclude that support was found for our main hypothesis: internals plan best across the board. Interestingly, it is not external but mixed teams that take the lowest planning quality position on almos: all measures. External teams take the position in-between and they tend to be closer to internal teams than to mixed teams.

\footnotetext{
14 Mewsures $C, D, E$ and $G$ appeared to be non-normally distributed. Additional non-parametric analyses, however, head to the same results and conclusions as the ones reported.
} 
Table 7.10a

Descriptives: Planned action

Planning quality and accuracy

\begin{tabular}{|c|c|c|c|c|c|}
\hline Planning measure & n & Mean & $\begin{array}{l}\text { Standard } \\
\text { deviation }\end{array}$ & Mininum & Maximum \\
\hline A. Personnel capacity utilisation proportion & 58 & .82 & .02 & .76 & .88 \\
\hline B. Machine capacity utilisation proportion & 58 & .96 & .03 & .89 & .99 \\
\hline $\begin{array}{l}\text { C. Average \% forced downward production } \\
\text { adjustments }\end{array}$ & 58 & .83 & 1.31 & 0 & 5.30 \\
\hline $\begin{array}{l}\text { D. Total end producis stock rises }[10.000 \\
\text { units] }\end{array}$ & 58 & 4.02 & 10.86 & 0 & 83.34 \\
\hline $\begin{array}{l}\text { E. Total raw materials stock rises }[1.0 .000 \\
\text { units }]\end{array}$ & 58 & 129.16 & 149.04 & 4 & 1116 \\
\hline F. Totall no-sales [ 100 units] & 58 & 1208 & 999 & 105 & 4788 \\
\hline G. Total cash shortage [1000 ECU] & 58 & 7247 & 11051 & 0 & 57377 \\
\hline H. Overall planning quality & 58 & .04 & 4.16 & -1.7 .44 & 4.38 \\
\hline
\end{tabular}

Table $7.10 \mathrm{~b}$

Descriptives: Planned action

Planning quality and accuracy ${ }^{\mathrm{t}}$

\begin{tabular}{|c|c|c|c|c|c|c|}
\hline \multirow{2}{*}{$\begin{array}{l}\text { Planning measure } \\
\text { (Dependent variable) }\end{array}$} & \multirow{2}{*}{$\begin{array}{l}\text { Team } \\
\text { type }\end{array}$} & \multicolumn{5}{|c|}{ Environmental condition } \\
\hline & & $\begin{array}{l}\text { Stable industries } \\
\text { (Column 1) }\end{array}$ & $\begin{array}{l}\text { Dynamic } \\
\text { (Column } 2\end{array}$ & & $\begin{array}{l}\text { All industries } \\
\text { (Column 3) }\end{array}$ & \\
\hline $\begin{array}{l}\text { A. } \\
\text { Persomel capacity } \\
\text { utilisation }(+)^{2}\end{array}$ & $\begin{array}{l}\text { Internal } \\
\text { Mixed } \\
\text { External }\end{array}$ & $\begin{array}{l}.82 \\
(.02 ; 13) \\
.83 \\
(03 ; 11) \\
.83 \\
(.02 ; 6)\end{array}$ & $\begin{array}{l}.84 \\
(.02 ; 10) \\
.80 \\
(.03 ; 7) \\
.83 \\
(.02 ; 11)\end{array}$ & $\begin{array}{l}1 \\
3 \\
2\end{array}$ & $\begin{array}{l}.82 \\
(.02 ; 23) \\
.82 \\
(.03 ; 18) \\
.83 \\
(.02 ; 17)\end{array}$ & $\mathbb{d}$ \\
\hline $\begin{array}{l}\text { B. } \\
\text { Machine capacity } \\
\text { uilisation (t) }\end{array}$ & $\begin{array}{l}\text { Internal } \\
\text { Mixed } \\
\text { External }\end{array}$ & $\begin{array}{l}.95 \\
(.04 ; 13) \\
.96 \\
(.02 ; 11) \\
.98 \\
(.00 ; 6)\end{array}$ & $\begin{array}{l}.97 \\
(.03 ; 10) \\
.94 \\
(.04 ; 7) \\
.97 \\
(.02 ; 11)\end{array}$ & $\begin{array}{l}1 \\
3\end{array}$ & $\begin{array}{l}.96 \\
(.03 ; 23) \\
.95 \\
(.03 ; 18) \\
.97 \\
(.01 ; 17)\end{array}$ & 1 \\
\hline $\begin{array}{l}\text { C. } \\
\text { Average \% forced down- } \\
\text { ward production adjust- } \\
\text { ments }(-)\end{array}$ & $\begin{array}{l}\text { Internal } \\
\text { Mixed } \\
\text { External }\end{array}$ & $\begin{array}{l}.66 \\
(1.11 ; 13) \\
.85 \\
(1.10 ; 11) \\
.06 \\
(.09 ; 6)\end{array}$ & $\begin{array}{l}.30 \\
(52 ; 10) \\
2.09 \\
(2.02 ; 7) \\
.95 \\
(1.47 ; 11)\end{array}$ & 1 & $\begin{array}{l}.51 \\
(.90 ; 23) \\
1.28 \\
(1.55 ; 18) \\
.64 \\
(30 ; 17)\end{array}$ & 1 \\
\hline
\end{tabular}




\begin{tabular}{|c|c|c|c|c|c|c|c|}
\hline $\begin{array}{l}\text { D. } \\
\text { Total end products stock } \\
\text { rises (in } 10.000 \text { unis) (-) }\end{array}$ & $\begin{array}{l}\text { Internal } \\
\text { Mixed } \\
\text { External }\end{array}$ & $\begin{array}{l}2.75 \\
(2.20 ; 13) \\
9.84 \\
(24.5 ; 11) \\
1.46 \\
(1.42 ; 6)\end{array}$ & 2 & $\begin{array}{l}1.61 \\
(1.13 ; 10) \\
2.91 \\
(3.23 ; 7) \\
4.01 \\
(2.56 ; 11)\end{array}$ & 1 & $\begin{array}{l}2.26 \\
(1.87 ; 23) \\
7.15 \\
(19.23 ; 18) \\
3.11 \\
(2.51 ; 17)\end{array}$ & $\mathbb{1}$ \\
\hline $\begin{array}{l}\mathbb{E} \text {. } \\
\text { Total raw materials stock } \\
\text { rises (in } 10.000 \text { units) }(-)\end{array}$ & $\begin{array}{l}\text { Internal } \\
\text { Mixed } \\
\text { External }\end{array}$ & $\begin{array}{l}126.3 \\
(41.0 ; 13) \\
99.1 \\
(62.3 ; 11) \\
53.8 \\
(23.6 ; 6)\end{array}$ & 2 & $\begin{array}{l}73.6 \\
(48.9 ; 10) \\
279.2 \\
(370.5 ; 7) \\
158.8 \\
(108.3 ; 11)\end{array}$ & $\begin{array}{l}3 \\
2\end{array}$ & $\begin{array}{l}103.4 \\
(51.1 ; 23) \\
169.1 \\
(24.7 ; 18) \\
121.6 \\
(100.9 ; 17)\end{array}$ & 2 \\
\hline F. & $\begin{array}{l}\text { Internal } \\
\text { Mixed } \\
\text { External }\end{array}$ & $\begin{array}{l}958 \\
(775 ; 13) \\
1130 \\
(857 ; 11) \\
1170 \\
(775 ; 6)\end{array}$ & $\mathbb{1}$ & $\begin{array}{l}1035 \\
(676 ; 10) \\
2166 \\
(1925 ; 7) \\
1148 \\
(739 ; 11)\end{array}$ & 1 & $\begin{array}{l}991 \\
(713 ; 23) \\
1533 \\
(1418 ; 18) \\
1156 \\
(728 ; 17)\end{array}$ & 2 \\
\hline $\begin{array}{l}\text { G. } \\
\text { Total casth shortage (-) }\end{array}$ & $\begin{array}{l}\text { Internal } \\
\text { Mixed } \\
\text { Extermal }\end{array}$ & $\begin{array}{l}5416 \\
(7850 ; 13) \\
6707 \\
(7561 ; 11) \\
7258 \\
(11167 ; 6)\end{array}$ & 1 & $\begin{array}{l}1591 \\
(2082 ; 10) \\
20607 \\
(21958 ; 7) \\
6584 \\
(6878 ; 11)\end{array}$ & 1 & $\begin{array}{l}3753 \\
(6256 ; 23) \\
12113 \\
(15887 ; 18) \\
6822 \\
(8285 ; 17)\end{array}$ & 1 \\
\hline $\begin{array}{l}\mathrm{H} \\
\text { Overall planning quality } \\
\text { (omnibus measture) (t) }\end{array}$ & $\begin{array}{l}\text { Internal } \\
\text { Mixed } \\
\text { External }\end{array}$ & $\begin{array}{l}.08 \\
(3.04 ; 13) \\
-.38 \\
(3.76 ; 11) \\
2.36 \\
(1.31 ; 6)\end{array}$ & 2 & $\begin{array}{l}2.50 \\
(1.62 ; 10) \\
-6.05 \\
(6.91 ; 7) \\
.35 \\
(2.41 ; 11) \\
\end{array}$ & 3 & $\begin{array}{l}1.13 \\
(2.76 ; 23) \\
-2.58 \\
(5.77 ; 18) \\
1.06 \\
(2.27 ; 17)\end{array}$ & 1 \\
\hline
\end{tabular}

Averages on the respective measures (see lext) are reported. Standard deviations and number of observations are printed in parentheses. Rank orders are printed in bold $(1=$ highest planning quality; $3=$ lowest planning quality)

${ }^{2}$ In parentheses the assistmed positive or negative association wath planning quality is indicated

Regarding the interaction hypothesis $7.3 \mathrm{~b}$, Table 7.11 clearly indicates that an interaction between team type and dynamism exists. To see whether this supports our hypothesis that differences are greater in dynamic than in stable environments, team type contrasts were calculated in stable and dynamic environments. The results are reported in Table 7.12. In stable environments the frequent and significantly negative contrasts with external teams indicate a general tendency for external teams to have higher planning quality than both mixed and internal teams. This is also evident from the frequent first ranks of external teams in stable environments (Table 7.10b). In dynamic environments the order seems to be reversed as internal teams consistently show the highest planning quality and produce significant differences as compared to external and mixed teams. Especially the latter show extremely bad planning scores in dynamic circumstances: they appear to have seriously lost track in controlling stocks, planning production and manag. ing their cash balances. Because the interaction is nonmonotonic (i.e., the orderings 


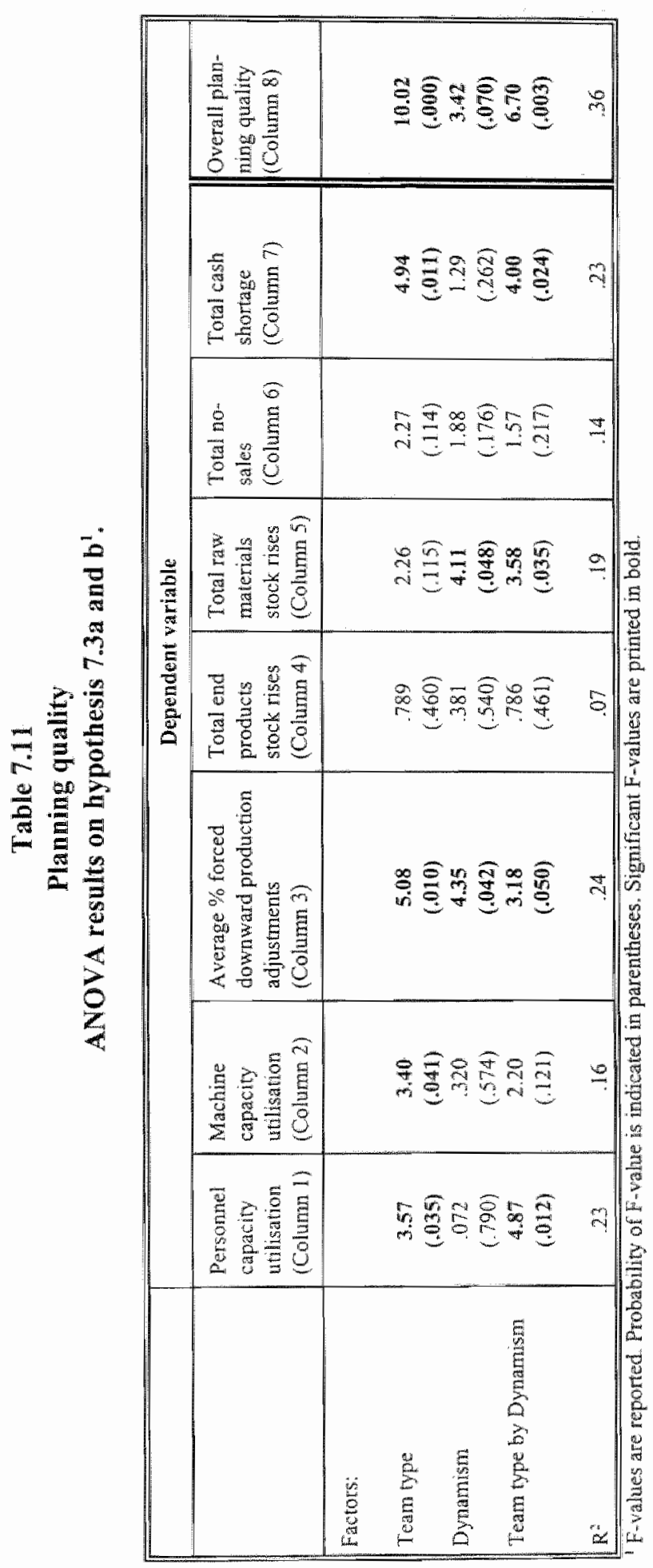




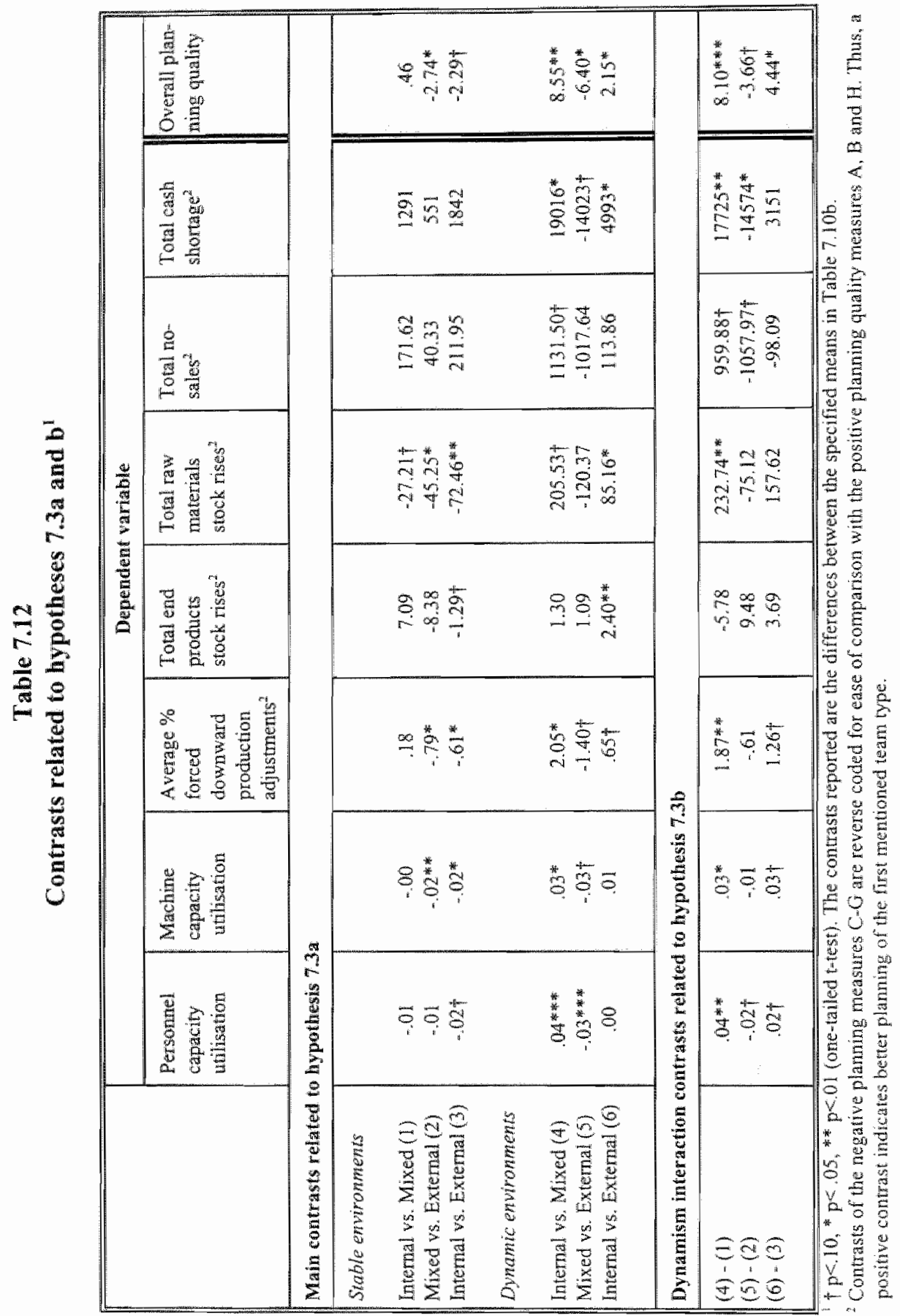


of team types are reversed in dynamic as opposed to stable enwironments), hypothesis $7.3 \mathrm{~b}$ is not confirmed. Taken together, the interaction analysis importantly qualifies the conclusion drawn above. That is, internal teams do plan better but only in dynamic enviromments. In stable environments, external teams seem to take the lead, which is not as predicted. Surprisingly, mixed teams plan worst across the board. Note from Table $7.10 \mathrm{~b}$ that both external and mixed teams" planning quality is worse in dynamic than in stable environments, whereas exactly the opposite holds true for internal teans.

\subsection{Discussion}

The relative quality of planning between teams appeared strongly dependent on competitive dynamism. If environments are stable, external teams are best in the planned optimizing of their operations. However, if circumstances are less predictable and the planning task is, consequently, getting progressively difficult, it is internal teams that do best. External and mixed teams" planning quality lags strongly behind in these circumstances. These results may be interpreted from a motivational point of view (Spector, 1982; Govindarajan, 1989), indicating that external teams are significantly better at "attending the shop" when environmental developments are of a smooth nature and developments can be easily foreseen. Internals in the same situation may tend to neglect intricate planning and possibly consider it rather superfluous. When many changes in the environment occur, however, externals' pessimistic view on the controllability of developments may be self-fulfilling as they let control slip, whereas internal teams now recognize the need for careful and simultaneous attention to the different planning factors. The idea that planning is more crucial to results in dynamic than in stable environments is reflected in the fact that the correlation between profitability and overall planning quality in dynamic environments $(.74 ; p<.000)$ is significantly higher (at $\left.p<.05^{15}\right)$ than it is in stable environments $(.44 ; p<.05)$. Given these differences, internal teams' behavior may again be considered more appropriate or adapted than that of externals: when planning efforts are most needed, internals engage in it more and externals less. The remarkable bad record of mixed teams on planning may be caused by the fact that in the planning task the integration of various aspects of the company into joint action is crucial, whereas this integration may be exactly the Achilles' heel of mixed teams (Pfeffer, 1983).

\section{Consistent action}

\subsection{Theory and hypotheses}

As internals are more likely to follow a planned course of action, we would also expect to observe differences in the extent to which actions are coordinated. That is: we would expect internals to engage in more concerted actions; actions that show more consistency

\footnotetext{
${ }^{15}$ Fisher"s $\mathrm{r}$ to $z^{3}$-transformation is used for iesting differences between comelations. See Cohen and Cohen, 1983, pp. $53-55$.
} 
or coherence. As stated before, the whole concept of a strategy as a consciously engineered action pattern to reach a goal has more appeal to internals than it has to extemals. The latter will tend to expect little from this kind of coordination across actions and are thus more likely to show more incoherent and fragmented action patterns. Moreover, as in the case of planning, this coordination across actions requires a more organized mode of attention, which internals are more likely to possess than externals (see section 3.1.1). For these reasons we expect internal teams to show greater coherence in their competitive repertoire (i.e., in their actions) than external teams. The differences will be more pronounced in dynamic environments.

Hypothesis 7.4a: Internal teams will show greater coherence among actions than mixed teams and mixed teams will show greater coherence among actions than external teams (main effect).

Hypothesis 7.4b: The differences mentioned in hypothesis $7.4 a$ will be greater in dynamic than in stable environments (interaction effect).

Internal teams may be expected to show more consistency in their actions over time as well. Based on their analysis of the situation and their motivated choice for a certain course, internals will show more (initial) commitment or persistence to their chosen competitive posture than externals. The latter will tend to be more volatile and whimsical, showing difficulty to hold on to a chosen course. Thus:

Hypothesis 7.5a: Internal teams will show more action persistence than mixed teams and mixed teams will show more action persistence than external teams (main effect).

The usual interaction with envirommental dynamism is expected as well.

Hypothesis 7.5b: The differences specified under hypothesis 7.5 a will be greater in dynamic than in stable environments (interaction effect).

\subsection{Methods}

Two types of consistency are mentioned in the hypotheses. First is the consistency between different actions, which we called action coherence (cf. hypothesis 7.4). Second is the consistency of certain chosen postures over time; called action persistence (cf. hypothesis 7.5). Operationalization of both types of action consistency will be described subsequently.

In determining action coherence, the use of a normative framework is inevitable. We tried, however, to remain as close as possible to quasi-objective common sense by distinguishing strategies on a single strategic continuum running from an emphasis on low cost to an emphasis on high value added. These extremes are defined as follows: 
Low cost:

Low prices with investments in cost reduction and a low emphasis on marketing expenses.

High value added: Investments in marketing expenses sustained by high prices and a low emphasis on cost reductions.

Five variables were used to measure these strategic orientations: price level, promotion level, product quality level, level of credit ${ }^{16}$ granted to customers and efficiency level. Strategies take effect only in comparison with those of other teams in the industry. Therefore, in each period we measured the within-industry rank (1 to 5) of a team on each of these variables. A team scoring highest on a variable receives the highest rank: 1 , a team scoring lowest receives the lowest rank: $5^{17}$. This means that a team following a high value added strategy should on average rank high (- be either first or second) on price, promotion, quality and credit facilities, but low on efficiency expenses. A typical low-cost strategy would result in high ranks for efficiency levels, but low ranks for price, credit facilities, promotion and quallty. An example of the ranks associated typically with either a low cost or a high value added strategy are given in Figure 7.2 below.

Figure 7.2

Measuring action coherence: three hypothetical teams

\begin{tabular}{|c|c|c|c|}
\hline & Teara 1 & Team 2 & Team 3 \\
\hline Strategy type & Low cost & High value added & Incoherent \\
\hline Price level rank $\left(R_{1}\right)$ & 5 & 1 & 5 \\
\hline Promotion level rank $\left(\mathrm{R}_{2}\right)$ & 4 & 2 & 3 \\
\hline Quality level rank $\left(R_{3}\right)$ & 4 & 2 & 1 \\
\hline Credi facility rank $\left(\mathbb{R}_{4}\right)$ & 5 & 1 & 4 \\
\hline (Efficiency level rank - originally) & (1) & (5) & $(2)$ \\
\hline Efficiency level rank (recoded) $\left(R_{5}\right)$ & 5 & 1 & 4 \\
\hline (a) $2 \sum\left|\mathbb{R}_{i}-\mathbb{R}_{i}\right|$ & 6 & 6 & 18 \\
\hline (b) Action coherence (24-(a)) & 1.8 & 18 & 6 \\
\hline
\end{tabular}

However, we are not interested in the specific strategy that was followed, but in the consistency of the five action levels. For instance, does a team with a high rank in quality and promotion (like Team 2 in Figure 7.2) sustain this policy by a high price rank and a low rank in efficiency expenditures? Conversely, does a low price-ranked team (like Team 1) also rank low on quality and promotion but high on efficiency levels? Moreover, a "middle ground' strategy may also be very consistent: this would require moderate ranks on all five variables. An important thing to note now, is that in coherent strategies the ranks of all variables except for the efficiency rank should be roughly identical.

\footnotetext{
th The credit fachly granted to buyers is a matketing instrument that refers to the percentage of turnower that clie tats are allowed to pay after two instead of one pariod.

Whe that we use the tem "Migh rank" do denore a low rank figure! This may cause some confusion, but, as will become clear shorty, the specific coding order of ranks is of no importance to our wltimate purpose with thes measure.
} 
In order to include the efficiency level in our measure of coherent actions as well the efficiency level ranks were reverse coded so that consistent policies are now characterized by comparable ranks on all five variables. Thus, if actions are coherent, the differences between these ranks must be low. So, the sum of the absolute rank differences between the five variables constitutes an inverse measure of how coherent the actions are. To obtain a positive measure of consistency, we subtracted the summed rank differences from their theoretical maximum of $24^{18}$. Formally, our action consistency measure now looks as follows:

$$
\text { Action coherence }=24-\sum_{i=1}^{4} \sum_{j=i+1}^{5}\left|R_{i}-R_{j}\right|
$$

In figure 7.2 the action coherence of the three teams is calculated ${ }^{19}$. Team 1 and 2 , although following quite different strategies have the same high coherence score. The third team took very incoherent rank positions and ends up with a low coherence score. The action coherence measure was calculated in each period for every market separately. The coherence scores were then averaged over time to obtain mean action coherence on home market 1, export market 1, market 2 and market 3 (from period 3 onwards). Finally, an overall action coherence score was calculated by averaging the coherence scores on all four markets.

Action persistence was operationalized as the stability in the rank of an action level over time. To assess this, for each market the standlard deviation of ranks in period 1 to 6 was calculated for six action types, namely the level of prices, promotion, efficiency, product quality, sales group employment and credit facility. We then calculated the mean variability of each action type over the three markets. Because the standard deviation of ranks is in fact a measure of variability, all standard deviations were multiplied by -1 to obtain a measure that correlates positively with persistence. So we have for each action type:

Action type persistence $=-$ standard deviation (Action type rank $\left.{ }_{11-16}\right)$

These six action type persistence measures were then averaged to obtain an overall temporal consistency or action persistence measure. Thus, actions are considered to be persistent if, over time, teams keep occupying the same position on a certain action variable within their industry, that is: if rank variations are low.

\subsection{Results}

Action coherence (hypotheses $7.4 a$ and $7.4 b$ )

Table $7.13 \mathrm{a}$ and b give the descriptives of the action coherence variables.

\footnotetext{
": The maximum was derived through simulation. I leave the formal proof to mathematicians.

${ }^{19}$ For irustance, Team 1 's score $=24 \times(15-4|+| 5-4|+| 5-5|+| 5-5|+| 4-4|+| 4-5|+| 4-5|+| 4-5|+| 4-5|+15-5|)=6$
} 
To test hypothesis 7.4a, ANOVA analyses were performed on the action coherence measure of every market separately. The average coherence on all markets is added as a summary measure. The results, shown in Table 7.14 , indicate the absence of team type and dynamism main effects. One must conclude, therefore, that no general differences between teams exist in action coherence so hypothesis $7.4 \mathrm{a}$ is rejected. Still, significant interaction effects do appear to exist and Table 7.15 shows how they are caused. It appears that almost no significant differences exist in stable environments (although the ordering is consistently as expected), whereas in dynamic environments external teams are much more consistent than the other team types. As column 1 and 2 of Table $7.13 \mathrm{~b}$ indicate, external teams change their position from being consistently lowest on action coherence in stable environments to consistently highest in dynamic environments. The magnitude of this switch causes the significant change in the contrasts of external versus other team types between stable and dynamic environments (i.e., the interaction contrasts in the lower part of Table 7.15). They do not, however, provide any evidence for an interaction of the kind expected in hypothesis $7.4 \mathrm{~b}$. We can only conclude, that teams do not on average differ on coherence of their actions, although in dynamic environments external teams are much more coherent then other team types. Note also that internal and mixed teams are less coherent in dynamic as opposed to stable environments, whereas external teams are more coherent in dynamic than in stable environments (see Table 7.13b).

\section{Table 7.13a \\ Descriptives: Consistent action}

Action coherence

\begin{tabular}{|l|l|l|l|l|l||}
\hline Dependeuni variable & n & Mean & $\begin{array}{l}\text { Standard } \\
\text { deviation }\end{array}$ & Minimum & Maximum \\
\hline Home market 1 action coherence & 58 & 8.74 & 3.36 & 2.83 & 14.67 \\
Export marke 1 action coherence & 58 & 8.69 & 3.37 & 3.25 & 15.50 \\
Market 2 action coherence & 58 & 9.45 & 3.37 & 2.17 & 16.50 \\
Market 3 action coherence & 58 & 9.11 & 3.76 & 3.00 & 17.50 \\
All markets action coherence & & & & & 13.42 \\
\hline
\end{tabular}

Action persistence (hypothesis $7.5 a$ and $7.5 b$ ).

The six policy variables used to measure the temporal consistency of actions are summarized in Table $7.16 \mathrm{a}$ and b. Hypothesis $7.5 \mathrm{a}$ predicted that action persistence would be highest among internal teams and lowest among external teams. The results of the analysis of variance in Table 7.17 do not support the existence of average differences between team types with regard to action persistence. And indeed, as the third column in Table $7.16 \mathrm{~b}$ shows, only minor differences in general persistence and varying team orderings across action areas exist. Even in the overall measure the main team type effect is not significant, so we reject hypothesis $7.5 \mathrm{a}$. In the same table, we do detect a significant interaction effect. Contrasts in stable and dymamic environments were calculated to explore the nature of the effect; they are reported in Table 7.18. In stable environments, internal teams are consistently the most persistent. This can also be seen in the first co- 


\section{Table 7.13b \\ Descriptives: Consistent action}

Action coherence $^{1}$

\begin{tabular}{|c|c|c|c|c|c|c|c|}
\hline \multirow{3}{*}{\begin{tabular}{|l} 
Dependent variable \\
$\begin{array}{l}\text { Home market } 1 \text { action } \\
\text { colverence }\end{array}$
\end{tabular}} & \multirow{3}{*}{$\begin{array}{l}\begin{array}{l}\text { Team } \\
\text { type }\end{array} \\
\text { Internal } \\
\text { Mixed } \\
\text { External }\end{array}$} & \multicolumn{6}{|c|}{ Environmental condition } \\
\hline & & \multicolumn{2}{|c|}{$\begin{array}{l}\text { Stable industries } \\
\text { (Column } 1 \text { ) }\end{array}$} & \multicolumn{2}{|c|}{$\begin{array}{l}\text { Dynamic industries } \\
\text { (Column 2) }\end{array}$} & \multicolumn{2}{|c|}{$\begin{array}{l}\text { All industries } \\
\text { (Column 3) }\end{array}$} \\
\hline & & $\begin{array}{l}9.10 \\
(3.16 ; 13) \\
8.38 \\
(3.18 ; 11) \\
7.33 \\
(3.68 ; 6)\end{array}$ & $\begin{array}{l}1 \\
2 \\
3\end{array}$ & $\begin{array}{l}7.20 \\
(3.16 ; 10) \\
7.86 \\
(2.80 ; 7) \\
11.38 \\
(3.09 ; 11)\end{array}$ & $\begin{array}{l}3 \\
2 \\
1\end{array}$ & $\begin{array}{l}8.28 \\
(3.24 ; 23) \\
8.18 \\
(2.96 ; 18) \\
9.95 \\
(3.77 ; 17)\end{array}$ & $\begin{array}{l}2 \\
3 \\
1\end{array}$ \\
\hline $\begin{array}{l}\text { Export market } 1 \text { action } \\
\text { coherence }\end{array}$ & $\begin{array}{l}\text { Internal } \\
\text { Mixed } \\
\text { Extemal }\end{array}$ & $\begin{array}{l}8.85 \\
(3.59 ; 13) \\
8.39 \\
(3.26 ; 11) \\
7.36 \\
(2.70 ; 6)\end{array}$ & $\begin{array}{l}1 \\
2 \\
3\end{array}$ & $\begin{array}{l}8.32 \\
(3.37 ; 10) \\
7.29 \\
(3.01 ; 7) \\
10.78 \\
0.45 ; 11)\end{array}$ & $\begin{array}{l}2 \\
3 \\
1\end{array}$ & $\begin{array}{l}8.62 \\
(3.43 ; 23) \\
7.96 \\
(3.12 ; 18) \\
9.57 \\
(3.54 ; 17)\end{array}$ & $\begin{array}{l}2 \\
3 \\
1\end{array}$ \\
\hline $\begin{array}{l}\text { Market } 2 \text { action coher- } \\
\text { ence }\end{array}$ & $\begin{array}{l}\text { Internal } \\
\text { Mixed } \\
\text { Extermal }\end{array}$ & $\begin{array}{l}10.58 \\
(2.74 ; 13) \\
9.26 \\
(2.89 ; 11) \\
7.75 \\
(4.25 ; 6) \\
\end{array}$ & $\begin{array}{l}1 \\
2 \\
3\end{array}$ & $\begin{array}{l}9.20 \\
(4.32 ; 10) \\
7.48 \\
(3.09 ; 7) \\
10.73 \\
(2.78 ; 11) \\
\end{array}$ & $\begin{array}{l}2 \\
3 \\
1\end{array}$ & $\begin{array}{l}9.98 \\
(3.49 ; 23) \\
8.56 \\
(3.01 ; 18) \\
9.68 \\
(3.55 ; 17) \\
\end{array}$ & $\begin{array}{l}1 \\
3 \\
2\end{array}$ \\
\hline $\begin{array}{l}\text { Market } 3 \text { action coher- } \\
\text { ance }\end{array}$ & $\begin{array}{l}\text { Internal } \\
\text { Mixed } \\
\text { External }\end{array}$ & $\begin{array}{l}9.31 \\
(3.93 ; 13) \\
8.57 \\
(3.40 ; 11) \\
8.50 \\
(4.51 ; 6)\end{array}$ & $\begin{array}{l}1 \\
2 \\
3\end{array}$ & $\begin{array}{l}9.07 \\
(3.95 ; 10) \\
8.68 \\
(4.94 ; 7) \\
10.05 \\
(3.12 ; 11)\end{array}$ & $\begin{array}{l}2 \\
3 \\
1\end{array}$ & $\begin{array}{l}9.21 \\
(3.85 ; 23) \\
8.61 \\
(3.93 ; 18) \\
9.50 \\
(3.61 ; 17)\end{array}$ & $\begin{array}{l}2 \\
3\end{array}$ \\
\hline Overall action coherence & $\begin{array}{l}\text { Internial } \\
\text { Mixed } \\
\text { Extemal }\end{array}$ & $\begin{array}{l}9.46 \\
(2.50 ; 13) \\
8.65 \\
(2.57 ; 11) \\
7.74 \\
(2.55 ; 6) \\
\end{array}$ & $\begin{array}{l}1 \\
2 \\
3\end{array}$ & $\begin{array}{l}8.45 \\
(2.18 ; 10) \\
7.82 \\
(2.23 ; 7) \\
10.73 \\
(1.97 ; 11) \\
\end{array}$ & $\begin{array}{l}2 \\
3 \\
1\end{array}$ & \begin{tabular}{|l|}
9.02 \\
$(2.37 ; 23)$ \\
8.33 \\
$(2.41 ; 18)$ \\
9.68 \\
$(2.58 ; 17)$ \\
\end{tabular} & 1 \\
\hline
\end{tabular}


Table 7.14

Action coherence

ANOVA results on hypothesis $7.4 \mathrm{a}$ and $\mathbf{b}^{1}$.

\begin{tabular}{|l|c|c|c|c||c||}
\hline & \multicolumn{5}{|c|}{ Dependent variable } \\
\hline & $\begin{array}{c}\text { Home mar- } \\
\text { ket 1 action } \\
\text { colerence }\end{array}$ & $\begin{array}{c}\text { Export mar- } \\
\text { ket 1 action } \\
\text { colierence }\end{array}$ & $\begin{array}{c}\text { Market 2 } \\
\text { action co- } \\
\text { herence }\end{array}$ & $\begin{array}{c}\text { Market 3 } \\
\text { action co- } \\
\text { herence }\end{array}$ & $\begin{array}{c}\text { Overall action } \\
\text { coherence }\end{array}$ \\
\hline Factors: & & & & & \\
Team type & .828 & .579 & 1.036 & .143 & .812 \\
Dyrnamism & $(443)$ & $(.564)$ & $(.362)$ & $(.867)$ & $(.49)$ \\
Team type by Dynamism & .392 & .435 & .005 & .200 & .370 \\
& $(.543)$ & $(.512)$ & $(.947)$ & $(656)$ & $(.546)$ \\
R & 4.219 & 2.267 & 2.647 & .255 & 3.937 \\
$(.020)$ & $(.114)$ & $(.080)$ & $(.776)$ & $(.026)$ \\
\hline
\end{tabular}

IF-walues are reported. Probability of Fwalue is indicated in parentheses. Significant F-values are printed in bold.

Table 7.15

Contrasts related to lyypotheses $7.4 a$ and $b^{t}$

\begin{tabular}{|c|c|c|c|c|c|}
\hline & \multicolumn{5}{|c|}{ Dependent variable } \\
\hline & $\begin{array}{l}\text { Etome rnar- } \\
\text { ket } 1 \text { action } \\
\text { coherence }\end{array}$ & $\begin{array}{l}\text { Export mar } \\
\text { ket } 1 \text { action } \\
\text { coherence }\end{array}$ & $\begin{array}{l}\text { Market } 2 \\
\text { action coher- } \\
\text { ence }\end{array}$ & $\begin{array}{l}\text { Market } 3 \\
\text { action coher- } \\
\text { ence }\end{array}$ & $\begin{array}{c}\text { Overall ac- } \\
\text { lion colner- } \\
\text { ence }\end{array}$ \\
\hline \multicolumn{6}{|c|}{ Main contrasts related to hypothesis 7.4 a } \\
\hline 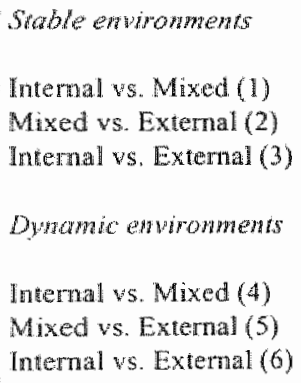 & $\begin{array}{c}.72 \\
1.05 \\
1.77 \\
\\
-.66 \\
-3.52 * \\
-4.18 * *\end{array}$ & $\begin{array}{c}1.03 \\
-3.49 \\
-2.46 t\end{array}$ & $\begin{array}{c}1.72 \\
-3.25^{*} \\
-1.53\end{array}$ & $\begin{array}{l}.40 \\
-1.37 \\
-.97\end{array}$ & $\begin{array}{c}.62 \\
-2.91 * \\
-2.29 *\end{array}$ \\
\hline \multicolumn{6}{|c|}{ Dymanism interaction contrasits related 10 hypothesis 7.4 b } \\
\hline $\begin{array}{l}(4)-(1) \\
(5)-(2) \\
(6)-(3)\end{array}$ & $\begin{array}{c}-1.38 \\
-4.57 \\
-5.95\end{array}$ & $\begin{array}{c}.57 \\
-4.52 \\
-3.95 \\
\end{array}$ & $\begin{array}{c}.40 \\
-4.76 \\
-4.35\end{array}$ & $\begin{array}{r}-.34 \\
-1.44 \\
-1.78 \\
\end{array}$ & $\begin{array}{c}-.19 \\
-3.83 \\
-4.01 \\
\end{array}$ \\
\hline
\end{tabular}

$+p<10, p<.05, p<01$ (one-talled t-tesi). The contrasts reported are the differences betwoen the specified means in Table ?,13b. 
Table 7.16a

Descriptives: Consistent action

Action persistence

\begin{tabular}{|l|l|l|l|l|l|}
\hline Dependent variable & $\mathbf{n}$ & Mean & $\begin{array}{l}\text { Standard } \\
\text { deviation }\end{array}$ & Minimum & Maximum \\
\hline Price levell rank variability & 58 & -1.01 & .24 & -1.55 & -.41 \\
Promotion level rank variability & 58 & -.87 & .30 & -1.75 & -.23 \\
Efficiency level rank variability & 58 & -.73 & .32 & -1.29 & -.00 \\
Product quality level rank variability & 58 & -.82 & .17 & -1.20 & -.27 \\
Sales group employment rank variability & 58 & -.86 & .23 & -1.30 & -.41 \\
Credit facility rank variability & 58 & -.44 & .27 & -.98 & -.00 \\
& & & & -.06 & -.49 \\
\hline
\end{tabular}

Table 7.16b

Descriptives: consistent action

Action persistence ${ }^{1}$

\begin{tabular}{|c|c|c|c|c|c|c|c|}
\hline \multirow{3}{*}{$\begin{array}{l}\text { Dependent variable } \\
\text { Price level tank stability }\end{array}$} & \multirow{3}{*}{$\begin{array}{l}\text { Team type } \\
\text { Internal } \\
\text { Mixed } \\
\text { External }\end{array}$} & \multicolumn{6}{|c|}{ Environmental condition } \\
\hline & & \multicolumn{2}{|c|}{$\begin{array}{l}\text { Stable industries } \\
\text { (Column 1) }\end{array}$} & \multicolumn{2}{|c|}{$\begin{array}{l}\text { Dynamic industries } \\
\text { (Column 2) }\end{array}$} & \multicolumn{2}{|c|}{$\begin{array}{l}\text { All industries } \\
\text { (Column } 3 \text { ) }\end{array}$} \\
\hline & & $\begin{array}{l}-.96 \\
(.27 ; 13) \\
-1.09 \\
(.29 ; 11) \\
-1.07 \\
(.11 ; 6)\end{array}$ & $\begin{array}{l}1 \\
3 \\
2\end{array}$ & $\begin{array}{l}-.90 \\
(.24 ; 10) \\
-1.11 \\
(.27 ; 7) \\
-.98 \\
(.14 ; 11)\end{array}$ & $\begin{array}{l}1 \\
3 \\
2\end{array}$ & $\begin{array}{l}-.94 \\
(.25 ; 23) \\
-1.10 \\
(.28 ; 18) \\
-1.01 \\
(.13 ; 17)\end{array}$ & 2 \\
\hline $\begin{array}{l}\text { Promotion level rank sta. } \\
\text { bility }\end{array}$ & $\begin{array}{l}\text { Internal } \\
\text { Mixed. } \\
\text { External }\end{array}$ & $\begin{array}{l}-73 \\
(.31 ; 13) \\
-1.03 \\
(.29 ; 11) \\
-1.03 \\
(.18 ; 6)\end{array}$ & $\begin{array}{l}1 \\
2 \\
3\end{array}$ & $\begin{array}{l}-.86 \\
(.39 ; 10) \\
-.74 \\
(.29 ; 7) \\
-.89 \\
(.11 ; 11)\end{array}$ & $\begin{array}{l}2 \\
1 \\
3\end{array}$ & $\begin{array}{l}-.79 \\
(.34 ; 23) \\
-.92 \\
(.32 ; 18) \\
-94 \\
(.15 ; 17)\end{array}$ & 1 \\
\hline $\begin{array}{l}\text { Efficiency level rank sia- } \\
\text { bility }\end{array}$ & $\begin{array}{l}\text { Internal } \\
\text { Mixed } \\
\text { Extemal }\end{array}$ & $\begin{array}{l}-.68 \\
(.33 ; 13) \\
-.72 \\
(.33 ; 11) \\
-.88 \\
(.32 ; 6)\end{array}$ & 1 & $\begin{array}{l}-.81 \\
(.21 ; 10) \\
-.70 \\
(.35 ; 7) \\
-.66 \\
(.39 ; 11)\end{array}$ & $\begin{array}{l}3 \\
2 \\
1\end{array}$ & $\begin{array}{l}-.73 \\
(.29 ; 23) \\
-.71 \\
(.23 ; 18) \\
-.74 \\
(.37 ; 17)\end{array}$ & 2 \\
\hline $\begin{array}{l}\text { Product quality level molk } \\
\text { stability }\end{array}$ & $\begin{array}{l}\text { Internal } \\
\text { Mixed } \\
\text { External }\end{array}$ & $\begin{array}{l}-.82 \\
(.18 ; 13) \\
-.85 \\
(.15 ; 11) \\
-.88 \\
(14 ; 6)\end{array}$ & $\begin{array}{l}1 \\
2\end{array}$ & $\begin{array}{l}-.79 \\
(.13 ; 10) \\
-.84 \\
(.29 ; 7) \\
-.80 \\
(.17 ; 11)\end{array}$ & $\begin{array}{l}1 \\
3 \\
2\end{array}$ & $\begin{array}{l}-80 \\
(.16 ; 23) \\
-84 \\
(.21 ; 18) \\
-.83 \\
(.16 ; 17)\end{array}$ & 1 \\
\hline
\end{tabular}




\begin{tabular}{|c|c|c|c|c|c|c|c|}
\hline $\begin{array}{l}\text { Sules group employment } \\
\text { rank stability }\end{array}$ & $\begin{array}{l}\text { Intemall } \\
\text { Mixed } \\
\text { External }\end{array}$ & $\begin{array}{l}-.76 \\
(.23 ; 13) \\
-.86 \\
(.26 ; 11) \\
-.90 \\
(.24 ; 6)\end{array}$ & 1 & $\begin{array}{l}-.88 \\
(.23 ; 10) \\
-.84 \\
(.14 ; 7) \\
-.93 \\
(24 ; 11)\end{array}$ & $\begin{array}{l}2 \\
1\end{array}$ & $\begin{array}{l}-.82 \\
(.24 ; 23) \\
-85 \\
(.22 ; 18) \\
-.92 \\
(.23 ; 17)\end{array}$ & $\begin{array}{l}1 \\
2 \\
3\end{array}$ \\
\hline $\begin{array}{l}\text { Credit facility rank stabil- } \\
\text { ity }\end{array}$ & $\begin{array}{l}\text { Internal } \\
\text { Mired } \\
\text { External }\end{array}$ & $\begin{array}{l}-.37 \\
(.19 ; 13) \\
-50 \\
(.32 ; 11) \\
-.42 \\
(.15 ; 6)\end{array}$ & 1 & $\begin{array}{l}-.52 \\
(.31 ; 10) \\
-.34 \\
(.30 ; 7) \\
-.45 \\
(.29 ; 11)\end{array}$ & $\begin{array}{l}3 \\
1 \\
2\end{array}$ & $\begin{array}{l}-.44 \\
(.25 ; 23) \\
-44 \\
(.31 ; 18) \\
-.44 \\
(.24 ; 17) \\
\end{array}$ & $\begin{array}{r}1.5 \\
3 \\
1.5\end{array}$ \\
\hline Overall action persistence & $\begin{array}{l}\text { Internal } \\
\text { Mixed } \\
\text { Extenal }\end{array}$ & $\begin{array}{l}-.72 \\
(.11 ; 13) \\
-84 \\
(.11 ; 11) \\
-.87 \\
(.11 ; 6) \\
\end{array}$ & 1 & $\begin{array}{l}-.79 \\
(.11 ; 10) \\
-.76 \\
(.14 ; 7) \\
-.79 \\
(.08 ; 11)\end{array}$ & $\begin{array}{l}3 \\
1 \\
2\end{array}$ & $\begin{array}{l}-.75 \\
(11 ; 23) \\
-81 \\
(.12 ; 18) \\
-81 \\
(10 ; 17)\end{array}$ & 1 \\
\hline
\end{tabular}

"Means are reported (see text). Standard deviation and number of observations in parentheses. Rank orders $(1=$ ruost persisient; $3=$ least persistent) are printed in bold.

lumn of Table $7.16 \mathrm{~b}$, where internal teams rank first on all persistence measures. Consequently, in Table 7.18 , both contrasts with internal teams are positive on all measures and reach strong significance in the summary measure of the last column. In dynamic environments, however, the effect is completely gone. As shown in the last row, the difference in effect size between dynamic and stable environments is large enough to produce significant interaction contrasts. As said, however, the differences get smaller in dynamic environments, so we must reject hypothesis $7.5 \mathrm{~b}$ as well. We conclude that no overall differences in action persistence between teams exist. In stable environments, however, internal teams are more persistent than mixed and external teams, but this difference vanishes in dynamic environmental conditions. From Table 7.160 it also follows that internal teams are more persistent in stable enviromments than in dynamic ones; the other team types, however, are generally more persistent in dynamic than in stable environments.

\subsection{Discussion}

Contrary to our hypothesis, we found no general differences between teams in the coherence or persistence of actions. The differences between teams do, however, vary between environmental conditions, but not in the direction stated in the interaction hypotheses. Internal teams appear to be the most coherent and persistent team type in stable environments. In dyramic environments all teans are equally persistent. Interestingly, action coherence (and persistence to a lesser extent) is higher in dynamic than in stable environments among external teams. Precisely the opposite is true for internal teams. Possibly the explanation for these findings must again be sought in a similar adaptation argument as we made previously. When the environment is stable and predictable, policies can be configured rather strictly, whereas more dynamic circumstances may warrant partial ad- 


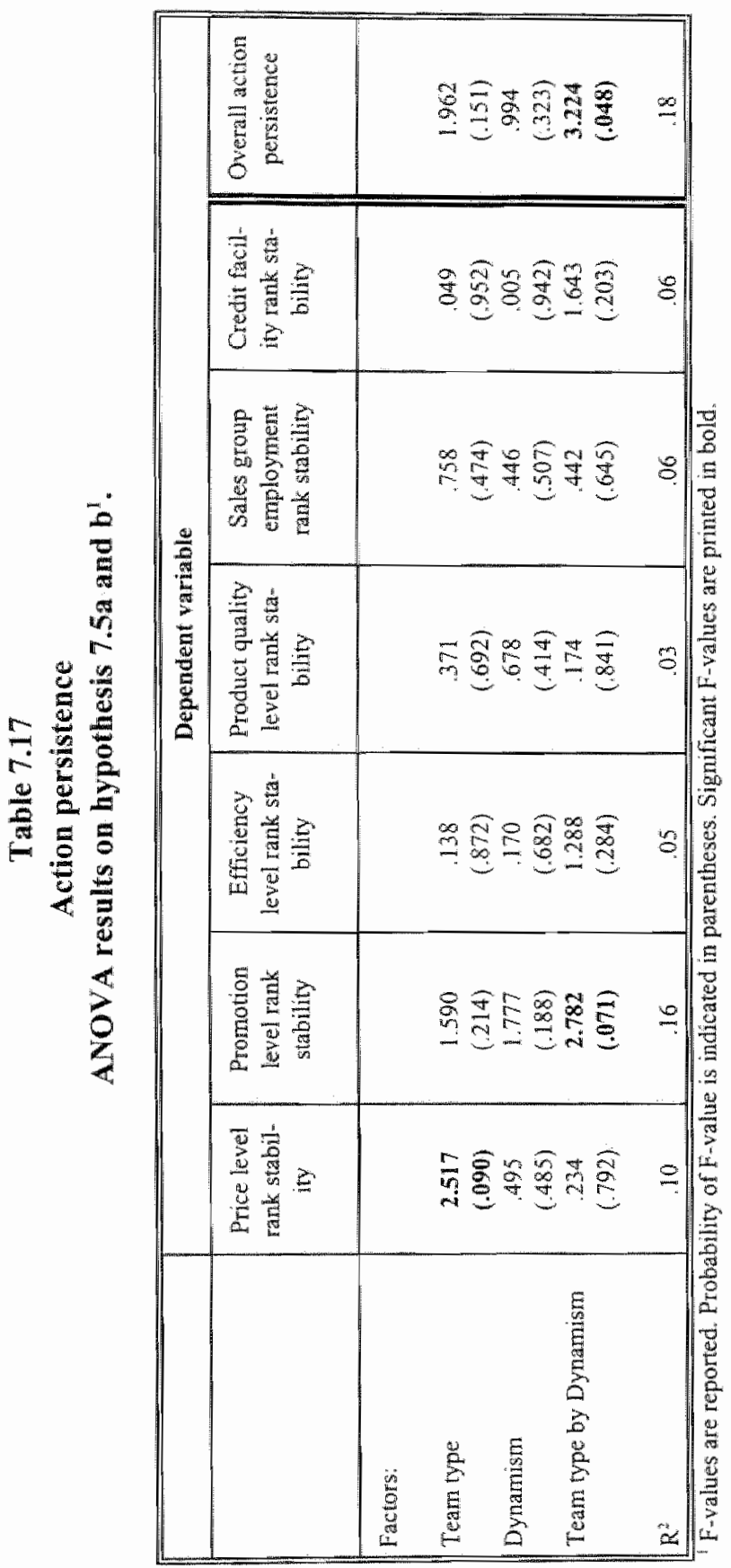




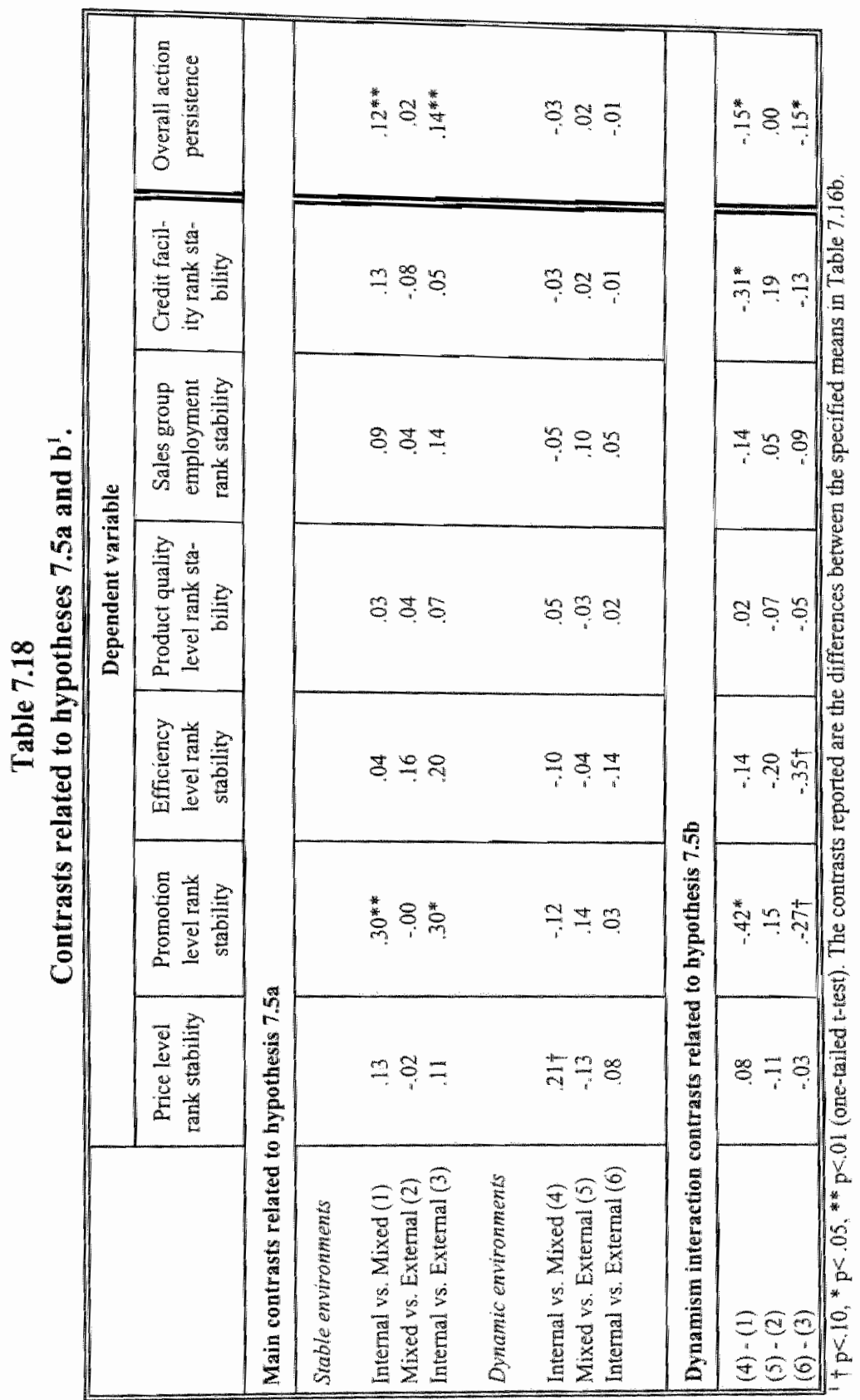


justments on several policy aspects that render them less consistent but better suited for the prevailing circumstances. Internal teams are more prone to show this kind of adaptive behavior than external teams and they do indeed seem to follow such an adaptive pattern of behavior, that is: they are most consistent in stable environments and considerably less so in dynamic environments. External teams show the opposite "maladapted" behavior: they get more coherent and persistent in dynamic as opposed to stable environments. Strict policies like the ones externals follow in dynamic environments may indicate a certain flight into rigidity, a withdrawal into strictness as a primitive defense against the need for changes that go against the 'wisdom' of a consistently configured policy. Unfortunately, this theoretical explanation is not reflected in the payoff of consistent behavior in the game. The overall correlations of action coherence and action persistence with profitability are -.14 (n.s.) and -.12 (n.s.). So no overall relationship exists between consistent policies and profitability. The correlations in stable environments are -28 (n.s.) and -.08 (n.s.) and in dynamic environments: -.08 (n.s.) and -.16 (n.s.). We can therefore only conclude that although teams do seem to adjust in ways that are, at least intuitively, sensible and in accordance to their psychological make-up, this does not in fact pay off in our particular experimental research setting.

\section{$5 \quad$ Appraisal}

In the present chapter, instead of looking at the content of teams" strategies, we examined three aspects of strategy making that can be theoretically linked to team's locus of control composition. We will now try to integrate our conclusion on these issues. First, in Table 7.19 the correlations are presented between the various variables in this chapter. Note that the informed action variables 3 and 4 were originally defined at the action level, whereas all other variables are defined at the team level. In order to deal with this, the informed action variables were aggregated to the team level as well. As shown, huge (but largely definitional) correlations exist between information value and the percentage of internally and externally informed choices. More interesting, however, are the correlations of information gathering with planning quality. As may be expected, well-planned operations are related with both information spending and taking well-informed action. Moreover, note that the relative emphasis in our planning measure on optimizing internal operations may be responsible for slightly (but not significantly) higher correlations of planning quality with the intemal information value (.41 versus .38$)$ and internal informedness of actions ( .37 versus .31 ). Consistent action does not appear to correlate significantly with either the information nor the planning variables. The consistency measures do, however, correlate modestly and significantly with each other. Specifically, the coherence between actions is positively associated with their persistence over time. Apparently, the more teams configure a coherent strategy, the more they tend to hold on to that configuration over time as well.

In order to find out whether the differences in strategy making that were found in this chapter can account for the strong performance differences between team types in dynamic environments, we applied the same two-step regression procedure as in Chapter 
6. The results are reported in Table 7.20. After including the covariates, we se a decline of the internal team dummy coefficient below $5 \%$ significance in columns $2,4,6$ and 7 .

Table 7.19

Correlations among main strategy making variables

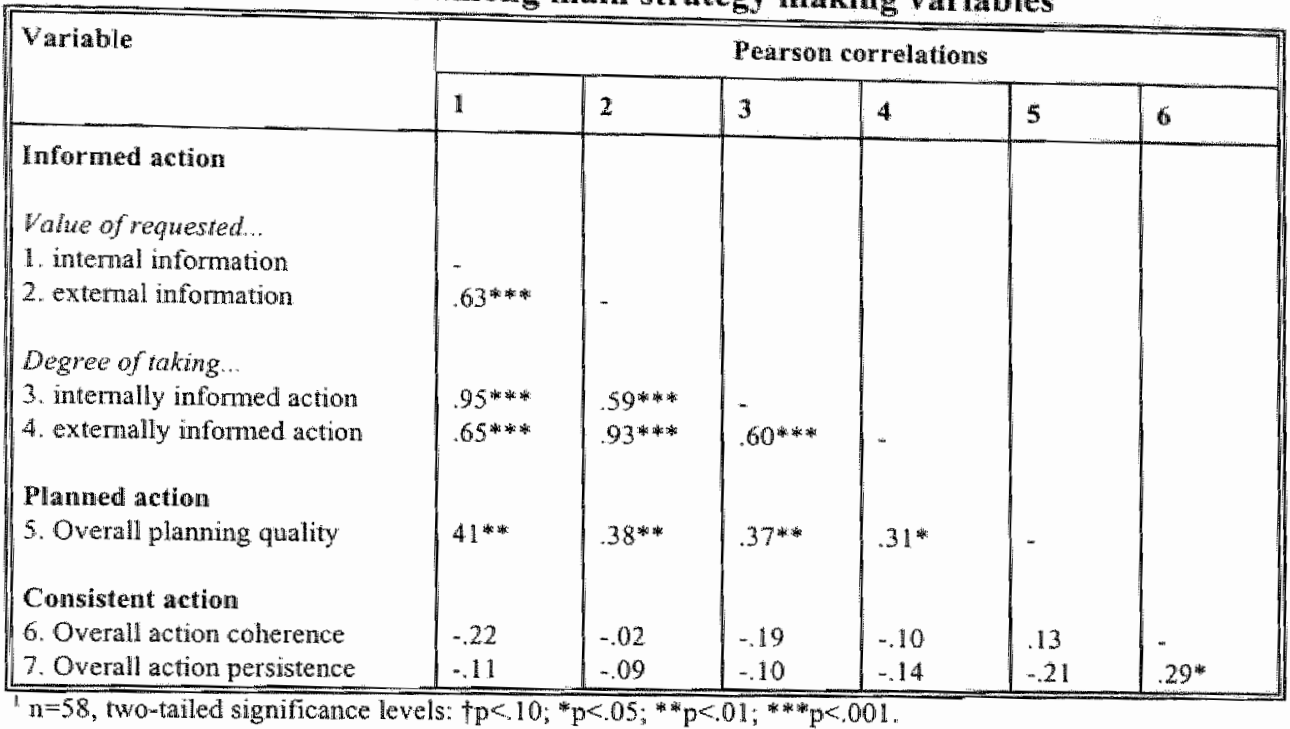

This means that an important part of internals' performance lead over externals can be attributed to their information handling, their planning and, to a lesser extent, their policy consistency. If we focus on the first two factors, internal information gathering, informed action and planning quality are correlated at .68 (p<.000), .63 ( $<<.000)$ and .71 $(\mathrm{p}<.000)$ with the average return on equity in dynamic environments and it is on all these variables that irtemals score significantly higher than externals (see Tables $7.3 \mathrm{~b} ; 7.6 \mathrm{~b}$ and $7.10 \mathrm{~b}$ ). so more internal information gathering and higher quality planning partly cause the superiority of internal over external teams.

If we look at the relative position of mixed teams vis-a-vis externals, the first columm shows a replication of our finding in chapter 6 , that mixed teams perform even worse than externals. Interestingly, however, the inchusion of the various information covariates increases the mixed teams backlog even to $1 \%$ significance levels. It is this increased difference of mixed teams relative to the other team types that makes the significance of the team type effect in the ANCOVA rise as well even though the differ ences between internal and extemal teams decline! This means, that these covariates serve as suppressors of an actually even worse performance of mixed teams as compared to external (and, consequently, internal) teams. Strongest suppression seems to occur in case of the internal information search variables (columns 2 and 4 ). As Tables 7.36 and $7.6 \mathrm{~b}$ show, mixed teams are indeed better informed than external teams, which increases their performance in dynamic enviromments, but not enough to surpass externals. Thus, because they are relatively well-informed (almost as good as internal teams), mixed teams are able to compensaye somewhat for their bad performance: otherwise their per- 


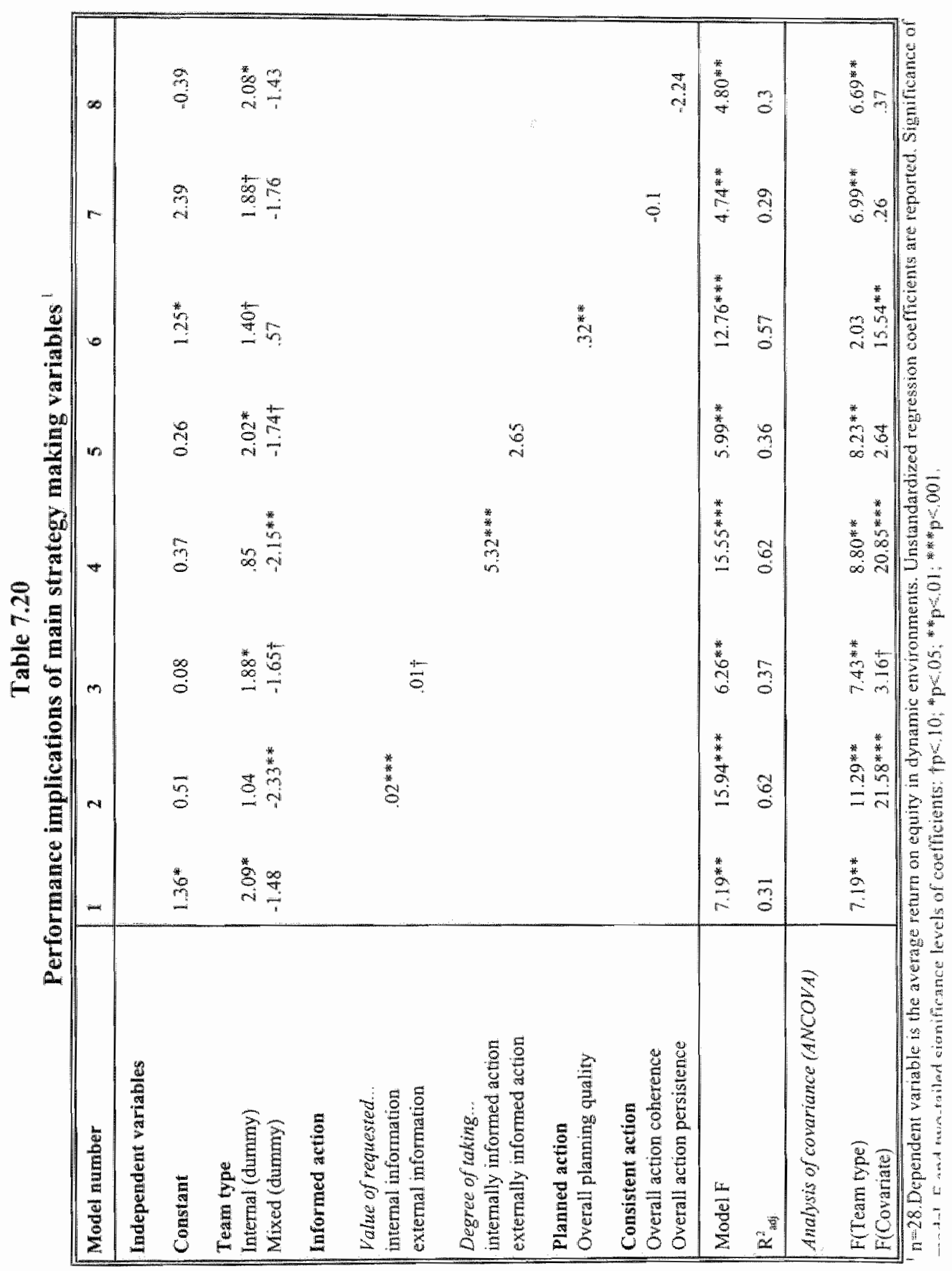


formance would have been even worse than it already is. Note that both the internal information variables and the planning measure lead to a doubling of the explained variance.

The analyses also provide an important clue as to what causes mixed teams" surprisingly bad record in dynamic environments. After controlling for planning quality, the mixed teams" dummy has switched to an insignificant positive sign. This suggests, that mixed teams' extremely low planming quality in dynamic environments (see Table $7.10 \mathrm{~b}$ ) is mainly responsible for their bad results. Note that the lead of internals over extemal teams is also reduced to marginal significance when planning quality is added as a covariate. In fact, planning quality is the only covariate that renders the tean type effect insignificant in the analysis of covariance. We must therefore conclude that an important mediating factor in explaining the profitability differences between team types is the quality of their planning.

A few important conclusions can be drawn from this study. First, it is clear that differences between teams with different locus of control make-up translate into differences in the formation of strategies, but mainly, and often only, in interaction with environmental dynamism. Many aspects of strategy making we dealt with yielded significant and interpretable differences. This is in striking contrast to our findings in the previous chapter where virtually no differences in overall strategic preferences were detected. It underscores the validity of the locus of control trait as a determinant of (pro)active involvement in (complex) situations as it becomes manifest in information gathering, informed action, planning and configuring consistent actions. All this can be seen quite apart from the specific content of choices made. Taken together, these findings point to the importance of strategic implementation effectiveness as a key factor in the success of intemal managers.

Second, the relative ordering of teams with regard to performance appears to be strongly affected by how much information they gather and how well they have planned. Internals" superiority is partly brought about by their well-informedness on internal issues when that is most crucial and by their greater ability to integrate various actions to arrive at well planned operations. Externals do much worse in this respect, and especially mixed teams have great difficulty in achieving high quality action planning. They can however compensate somewhat for this as compared to external teams, because they are generally better informed.

Third, an important hidden theme behind many of the results we encountered in the present chapter seems to be that of internals' adaptive action, that is, internals" actions seem to be tailored to the situation they find themselves in. They inform themselves more when more information is needed, they plan when planning is most crucial and they define strict and looser strategies according to environmental pressures. Externals, on the other hand do seem to follow purposive strategies, but they often lack appropriateness. It is this theme of adaptation or adjustment that will be of focal interest in the final chapter. 
Strategy making II

Adaptive action 


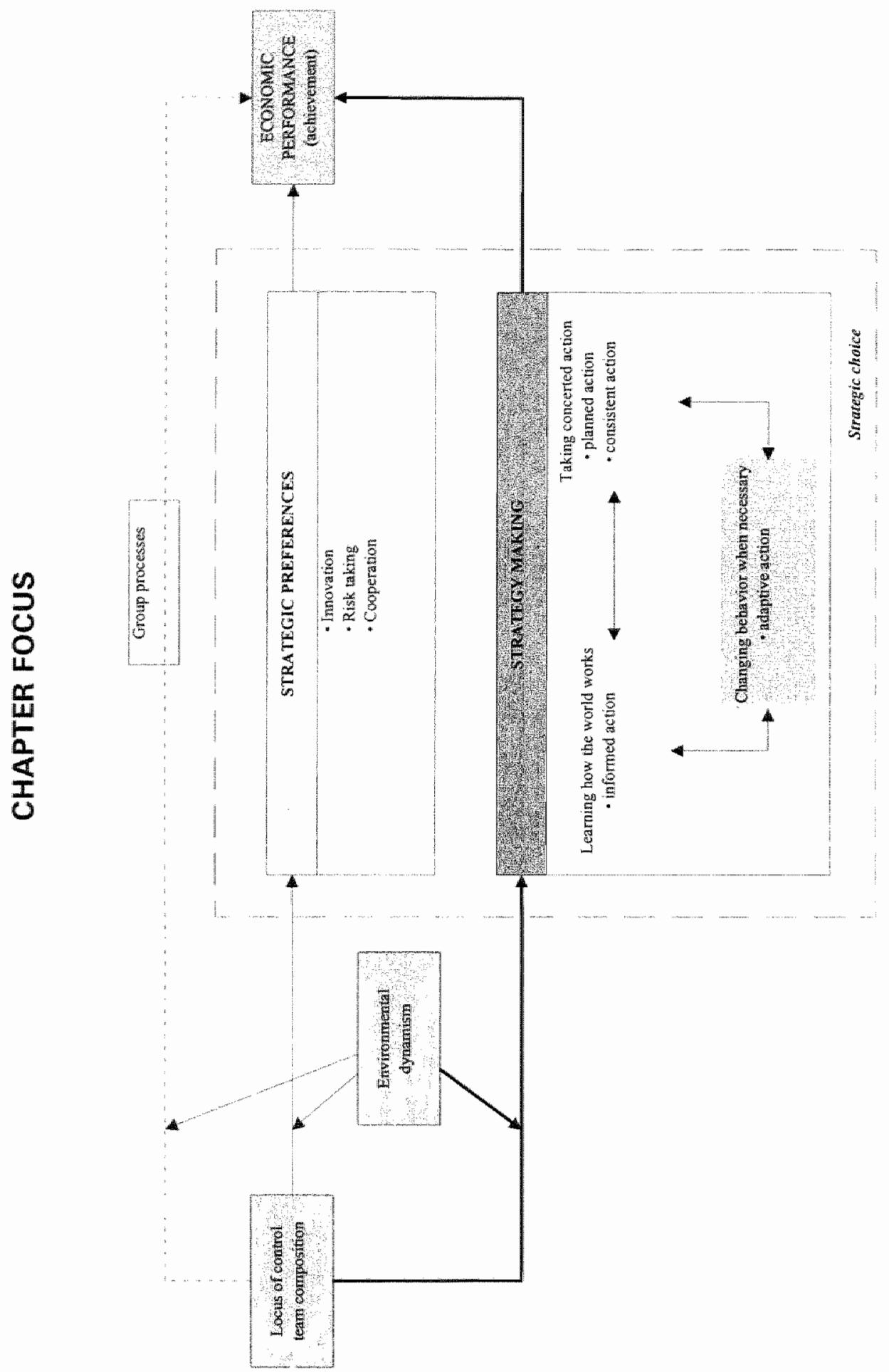


In the present chapter we will deal with adaptive action, being the last component of strategy making (see figure 7.1). In previous chapters we already found some indirect evidence that internal teams undertake actions that are more appropriate (i.e., profitable) to prevailing environmental circumstances. Specifically, internal teams innovate and cooperate more when this yields most (chapter 6). Similarly, they gather more (internal) information, plan more and define more consistent strategies when this is most required (chapter 7). Combined, these findings strongly suggest a particular faculty of internal teams to adapt their behavior to fit environmental contingencies. In this final analytical chapter we wish to explore this adaptive aspect of team behavior more directly.

Adaptation can be rightly called a hot topic in organization studies. The issue has been studied at the level of both organizations and managers. The organization literature of the past 15 years has been replete with studies into the adaptive capacities of organizations. This research was partly inspired by a major theoretical debate (Boone, De Brabander and Van Witteloostuijn, 1995). On the one hand, scholars like Hannan and Freeman $(1977,1984)$ in their so-called organization ecology approach, severely doubt the possibilities of individual firms to survive through adaption. In their view, internal and external factors such as sunk costs and structural or bureaucratic inertia prevent firms from adapting timely. As a result, the market functions as a selection mechanism that favors the well-adapted over the ill-adapted firms. On the other hand, proponents of the strategic leadership approach argue that firms can survive and perform well by choosing strategies and competitive domains that match their particular strengths (Sousa and Hambrick, 1989). In other words: they can and should fine tune their strategies to changing circumstances. Empirical research on this issue of inertia versus adaptation reveals that these opposing views are in fact both too narrow (Burgelman, 1991). On the one hand, organizations sometimes change drastically in response to environmental changes, although with varying success (Tushman, Newman and Romanelli, 1988; Singh, House and Tucker, 1986; Delacroix and Swaminathan, 1991). On the other hand, certain characteristics of organizations, such as age and size appear to produce inertia (Kelly and Amburgey, 1991).

In any event, the ultimate choice to change course (adapt) or to remain inert is made by management and as chapter 2 showed, various team studies (e.g., Finkelstein and Hambrick, 1990; Wiersema and Bantel, 1992) do indeed indicate a relationship between team characteristics (i.e., mean tenure and educational specialization) and the level of strategic change. Similarly, Lant, Milliken and Batra (1992) found that companies with more heterogeneous teams were more likely to reorient than companies with less heterogeneous teams. Their results also indicate that "managerial interpretations of their environmental context and of their past performance outcomes are important predictors of the likelihood of strategic reorientation" (Lant, Milliken and Batra, 1992: 601). As personality importantly affects interpretations, the latter is indeed an encouraging finding for studying the relationship between team locus of control and adaptive team actions. In deriving our hypotheses on this issue, we will mainly be extending existing research on adaptive behavior of internal and external individuals to the team level. In 
doing so, we hope to conmect these individual adaptive capabilities to the adaptive competitive actions of teams. In particular, we wish to explore whether the relationship between teams ${ }^{3}$ adaptive actions ${ }^{\prime}$ and either environmental circumstances or firm performance, depends on their locus of control make-up.

The analyses in this chapter will be exploratory in that we will only test some very general expectations. Moreover, we will use rather broad and straightforward statistical techniques. The chapter is structured as follows. In section 2 we will specify hypotheses on the relationships between team type and adaptive behavior. Next, in section 3, we describe our operationalization of adaptive action. Section 4 reports on the results of the analysis and section 5 concludes the chapter with a discussion of our findings and an appraisal.

\section{Theory and hypotheses}

In section 4.3 of chapter 3 it was already argued that internals generally have a higher potential to learn and adapt their behavior if necessary than externals. The theoretical rationale is quite straightforward. If a person beliefs he has control over what happens to him, he will be more inclined to take responsibility and try to correct an unsatisfactory position than when he believes to have little influence. This can be underscored by two lines of research: internals seem to attribute bad (task) performance to their own doing and they are more inclined to take remedial action because they feel this is potentially useful. Studies at the individual level have indeed shown that externals attribute more blame for task failure to the environment than do internals (Phares, Wilson and Klyver, 1971), whereas internals rather blame themselves (Davis and Davis, 1972). Although assuming responsibility for bad performance is not a necessary condition for changing behavior, it is likely to produce additional motivation for corrective action. Similarly, when externals fail on a skill demanding task, they are more likely to play down its value or importance than internals (Phares, 1971). The latter "tend to value skill reinforcements- particularly those difficult to achieve - and thus would leave intact the value of such goals" (Phares, 1976: 134). Consequently, as externals tend to deny responsibility or diminish the value of their goals ex post, they are less likely to do something about an undesired state. In chapter 3 we already cited research on internals' higher motivation and persistence in completing frustrating (unsolvable) tasks (e.g., Srull and Karabenick, 1975). They also show more active problem-solving behavior in a range of distressing situations (Anderson, 1977; Aspinwall and Taylor, 1992). Internals, in the words of Lefcourt (1982: 103), "more actively join in the struggle for survival" as they are more goal-oriented and stress-resistant. For instance, De Brabander, Boone and Gerits (1992) report evidence that internals make fewer mistakes after failure in a reaction experiment than do externals (Boone, 1992). The prospect of failure seems to raise motivation in internals. Gregory (1978) found that internals spend more time on complet-

\footnotetext{
'We will use the terms (organizational) 'change' and 'adaptation' interchangeably, although in our conceptualization, as will become clear later, adaptation is the narrower concept as it refers to change in response to some cue that currem behavior is inappropriate.
} 
ing a task than extermals only when this led to the avoidance of a negative outcome, but not when they could attain a positive outcome. Even when adjusting behavior involves correcting personal inadequacies, intemals show greater motivation to take remedial action when offered the possibility to do so than externals (Phares, Ritchie and Davis, 1968). Taken together, these results support the theoretical expectations on adaptive behavior stated above. That is, internals have a greater propensity then externals to change or adapt their behavior when their current behavior does not lead to satisfactory performance. They are less distressed by failure and it may even raise their motivation to act.

Changing or adapting behavior usually takes place in response to some oue that current behavior is no longer optimal. In this case, behavior must be changed in order to reach a new satisfactory state of affairs. In our research setting we chose to explore two rather straightforward cues for change to which teams can adapt. First, we looked at teams' adaptation to the general dynamism in the environment. If enwironments are volatile, the need for change in order to stay ahead of market developments is higher than in stable environments. We would expect internal teans to adapt their rate of change to these situational demands. Specifically, this means that they will carry out more changes when their environment is dynamic than in case it is stable. External teams on the other hand will show less sensitivity to environmental circumstances, so their rate of change will not differ between competitive situations. Mixed teams will take a position in between. This means that we expect an interaction effect of team type and envirommental dynamism on the rate of change: teams change reactions to environmental dynamism will depend on their locus of control make-up.

Hypothesis 8.1. Internal teams will adapt their rate of change to competitive circumstances. Specifically, their rate of change will be greater in dynamic than in stable environments. Other team types will show less differences between competitive circumstances.

Second, we will explore teams" reactions to feedback concerning their performance. It makes intuitive sense to assume that one is more inclined to change when performance is bad as opposed to good. As Miller and Chen (1994: 4) put it: "[G]ood performance induces managers to believe that they have "gotten it right". It makes them reluctant to change". Poor performance, on the other hand, motivates remedial action as aspiration levels are not reached (Cyert and. March, 1963). Performance thus serves as a simple system of punishment and reward to which managers respond by taking more or less corrective actions, respectively. These kinds of learning processes have been labeled "reactive" or "experimental" (March, 1991; Miller et al., 1996). However, Miller and Chen (1994) also point at conflicts in the literature. For instance, poor results may lead threatened managers to defend their policies and reputations by escalating their commitment to a certain course of action (Staw, 1976; Brockner, 1992). This will hold particularly in enviromments with strong political pressures on decision makers, which are, however, very unlikely in our game setting. In fact, Miller and Chen (1994) try to resolve the conflict by distinguishing between strategic and tactical changes. Strategic changes 
involve, for instance, significant and (quasi)-irreversible retrenchments or expansions into new businesses. Tactical changes like price or promotion level changes are more easy to make and to reverse. The latter are supposed to create less embarrassment than the former and Miller and Chen (1994) do indeed find, that poor recent performance leads to more tactical but not strategic changes ${ }^{2}$. As will become clear below, the kinds of changes we study are also more tactical than strategic in nature. At least with regard to these kinds of decisions, a simple reactive learning model thus seems appropriate to describe adjustments following performance: tactical adjustments are more common when poor performance signals the need to act (Miller and Chen, 1994; Lant and Montgomery, 1987). We will therefore compare the relative differences between team types in adaptive responses following performance feedback. Because internals have a greater potential to learn and adapt their behavior when necessary, as stated above, it is to be expected that internal teams will be more inclined to change course when performance is low or worsening than externals. So, internals will show a stronger relationship between their performance in a certain period of time (i.e., their performance feedback) and the amount of adaptative activity following this feedback. More precisely, the lower their performance, the more internals will adapt their actions. For external and mixed teams we expect this relationship to be weaker. Thus:

Hypothesis 8.2 The (negative) relationships between performance and adaptative actions will be stronger for internal teams than for external and mixed teams.

Regarding different reactions of teams to negative feedback (poor or worsening results), we wish to tentatively test a final expectation developed by Boone, De Brabander and Van Witteloostuijn (1995) which is based on differences in attentional control systems between internals and externals. As explained in Chapter 5 , individuals can adapt to changing eircumstances because they have two different attentional control mechanisms at their disposal: activation and arousal (Pribram and McGuiness, 1975; Tucker and Williamson, 1984). Activation controls the ability to act in a planned and goal-oriented way, based on acquired insights in the structure of the environment. Arousal on the other hand, controls the ability to stop acting so as to focus attention on new environmental stimuli (such as danger, for instance). The latter attentional control mechanism functions as an 'alarm system'. As argued earlier, the adaptive capacity of teams may depend on whether both mechanisms are available (Boone, De Brabander and Van Witteloostuijn, 1995). As externals are easier distracted and emotionally driven, they are more bound to pick up and react to (weak) signals from the environment. In other words, an external team would have an overly sensitive 'alarm system", without however having the skills to react appropriately (i.e., take concerted action: see Chapter 7). Under conditions of negative feedback (i.e., low or declining profits in our case) this overly sensitive alarm system may be expressed in the variance of externals' adaptive behavior. Specifically,

\footnotetext{
${ }^{2}$ Another reason for this, however, may simply be that poor recent performance is not attributed to important underlying strategic weaknesses that need to be corrected.
} 
they will tend to adapt in rather extreme ways, leading to either "paralysis" (no change at all) or hyperactivity (Hambrick and $D^{3}$ Aveni, 1988), i.e, either to some inactive 'cramp" or to a panicking reaction. In either case, externals" reaction is rather uncontrolled. On the other hand, we expect internal teams to show a more steady hand in dealing with negative feedback, based on their greater action-rientedness and stress resistance. Mixed teams will take a position in between the extremes. Under non-distressing conditions (i.e., when positive feedback is received) reactions will tend to be similarly spread among different team types. Based on these considerations we expect the following:

Hypothesis 8.3: The variance of change reactions to negative profit feedback will be greater among external than among internal teams. After positive feedback the variation of reactions will tend to be equal anong team types.

\section{Methods}

To operationalize adaptation, we followed the method by which Miller and Chen (1994) defined its opposite, namely competitive inertia. Our measure of competitive adaptation then, refers to "the level of activity that a firm demonstrates in altering its competitive stand. It reflects the number of market-oriented changes a company makes" (Miller and Chen, 1994: 2). Moreover, we were also able to measure this alteration of competitive stand in a number of comparable categories as Miller and Chen (1994: 1) used for their inertia measure, being "areas such as pricing, advertising, new product or service introductions". We proceeded as follows.

To measure teams' competitive change or adaptation, we looked for important decision categories that are relatively easy to change and can, as such, be used as instruments of rather instant adaptation ${ }^{3}$. To choose decision categories for which to calculate these changes, we statted from our operationalization of strategy (coherence) in figure 2 of chapter 7. This operationalization included prices, promotion and quality outlays, credit facilities and efficiency outlays. The latter two categories were excluded for oun current purpose. The credit facility instrument appeared to be hardly used as an adaptation instrument as credit facility levels were changed in only $13 \%$ of all cases. The efficiency level was dropped because it can only be adjusted upwards and not downwards. On the other hand, we included the deployment of sales groups as they can be increased and decreased as well as shifted between markets thereby indicating shifting market emphases. So we end up using four decision categories whose inter-period changes will be measured, namely: price changes, changes in promotion and quality outlays and changes in sales group deployment.

To arrive at a single general index of change we followed a procedure akin to that of Miller and Chen (1996). This implies that the amount of change in each period is neasured relatively to the other teams. To this end the following steps were taken. First,

${ }^{3}$ Note again that this leads to an adaptation measure that is more tactical them strategic in nature. 
the absolute changes between periods in each of the decision categories were calculated. For instance, we added the absolute differences in promotion outlays (on each market) between two periods. So, if in period t a team has promotion outlays of 20 and 40 on market 1 and 2, respectively, and in period $t+1$ these outlays are 15 and 50 , the change amounts to $|20-15|+|40-50|=15$. Next, the absolute change in each category was standardized over all 58 teams in each period. In doing so, we obtained change scores relative to the overall mean changes in that period thereby eliminating possible time trends. The standardizing procedure also allowed us to pool the observations over time and to add the four category change scores to one overall measure of change. Thus, each teams' change score from period $\mathrm{t}$ to $\mathrm{t}+1$ is calculated as follows:

Relative rate of change ${ }_{\left(t_{\mathrm{t}}+1\right)}=$

$Z_{58}\left(\sum_{p=1}^{4}\right.$ Price changes $\left.s_{(i ; i+1)}\right)+Z_{58}\left(\sum_{p=1}^{3} \mid\right.$ Sales group deployment changes $\left.s_{(i ; t+1)}\right)+$

$Z_{58}\left(\sum_{p=1}^{4}\right.$ Promotion outlays changes $\left.s_{(t ; t+1)}\right)+Z_{58}\left(\sum_{p=1}^{3}\right.$ Quality outlays changes $\left.s_{(i, t+1)}\right)$.

with $p=$ product and/or market number ${ }^{4}$ and $Z_{58}$ is the standardized value of the summed changes over all 58 teams.

Note that in the above definition all change categories carry the same weight. This leads to weighting more common changes (like price changes) equally heavy as less frequent changes (like quality outlay changes) (Miller and Chen, 1996). In order to correct for this unbalanced weighting, we also calculated a weighted relative change measure in which each change type in the above calculation received a weight that is inversely proportional to its frequency in each period. In doing so, we obtained a measure in which less common change types carry higher weights than more frequent change types ${ }^{5}$.

As our sample consists of 58 teams playing 6 periods, we were able to measure a maximum of 5 inter-period changes in behavior per team, resulting in a total of $58 * 5=290$ observations. In doing so we measure quite instantaneous changes from one decision period to the immediate next, whereas in fact changes may take longer to carry out. Therefore, we also calculated changes between longer adjacent periods, in particular between the average of the first two ("early") periods and the average of the following two, three or four ('late") periods. We took several "late" time spans because $a$ priori it is unclear what the proper time span to implement changes is. In doing so we also obtain a more robust change measure although, of course, only one change observation per team results. The split after the second period is necessarily somewhat arbitrary, but we

\footnotetext{
"Note on the decision form in Appendix B (decisions 19 to 22a), that sales group employment and product improvement are defined for each of the three products (so $\mathrm{p}=1$ to 3 ), whereas price change and promotion change relate to the four product markers, i.e., including the export market (so $\mathrm{p}=1$ to 4 ).

5 Out of $290(=58 * 5)$ possible inter-period changes the absolute change frequencies are 281 (prices), 248 (sales groups), 268 (promotion) and 212 (quality). These relative frequencies do not vary much between periods.
} 
gathered that after feedback on two decision periods teams should have a fair idea of how they are doing and could make rather well contemplated directional changes. Moreover, as figure 5.1 in Chapter 5 indicates, it seems a rather natural point in the game, as teams on average perform rather poor in the first two periods, and some kind of recovery sets in from period 3 onwards. The changes on all categories were then standardized and added in the same way as above.

The early-late distinction is also used to test hypothesis 8.3 where we have to discern meaningful categories of negative and positive feedback in order to be able to compare team's reactions to those feedback conditions. For this purpose we used increases and decreases of financial results (i.e., profit or loss levels) in the early part of the game. After the first decision period of the game, all sampled teams experienced a decline in results. After the second period, however, 25 teams were able to reverse the trend by increasing their results, whereas the other 33 teams' results went down for another period. So roughly half of all teams experienced a decline followed by an increase, whereas the other half experienced two declines in a row. These two early developments of team results can be taken to represent positive and negative feedback signals, respectively. They may lead teams to undertake different amounts of action change from period 3 onwards. Specifically, if results decline in two consecutive periods (i.e., the negative feedback condition) this should be proper notice that current policies are not appropriate. If, on the other hand, an initial decrease in results is followed by an increase this may be taken as an indication that a (temporal) setback was successfully countered by current policies: it serves as positive feedback concerning these policies. Using this distinction we will be able to test wether externals' reactions to negative feedback show greater variation than other teams' reactions.

\section{$4 \quad$ Results}

Table 8.1 shows the descriptive statistics of the unweighted and weighted period-byperiod change measure when pooled over 58 teams, plus three change measures reflecting change from the average in the "early periods' 1 and 2 with the averages in 'late periods', either $(3,4),(3,4,5)$ or $(3,4,5,6)$. This summarizes all change measures we used.

Hypothesis 8.1 predicted that internals' rate of change differs more between environmental circumstances than the change rates of other team types. Table 8.2 lists the general weighted and unweighted rates of change of team types under different environmental conditions. ANOVA results on the differences between environmental circumstances are shown in Table 8.3. It is clear from these results that there is no interaction effect of team type and environmental dynamism on teams' change rates, so we have to reject our hypothesis 8.1. Apparently, team types do not differ in their chan-

"As for this hypothesis we are interested in general, overall change activity, we did not report on the early vs. Jate period change results. Howewer, they reveal comparable patterns as the results reported, although significance is not reached due to smaller sample size. 
Table 8.1

Descriptives: Adaptive action

\begin{tabular}{|c|c|c|c|c|c|c|c|c|}
\hline \multirow[t]{2}{*}{ Actioli change measure } & \multirow[t]{2}{*}{ til } & \multirow[t]{2}{*}{ Mean } & \multirow[t]{2}{*}{ SD } & \multirow[t]{2}{*}{ Min. } & \multirow[t]{2}{*}{ Max. } & \multicolumn{3}{|c|}{ Correlations' } \\
\hline & & & & & & 2 & 3 & 4 \\
\hline 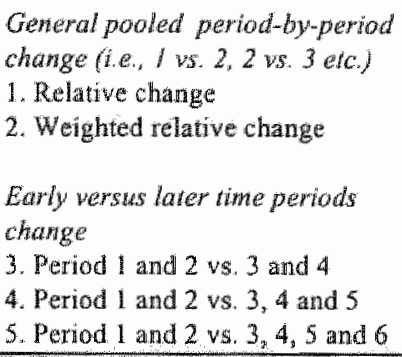 & $\begin{array}{l}58 \\
58 \\
58 \\
\end{array}$ & $\begin{array}{l}0.00 \\
0.00 \\
0.00\end{array}$ & $\begin{array}{l}2.13 \\
2.15 \\
2.10\end{array}$ & $\begin{array}{r}-3.58 \\
-3.57 \\
-3.67\end{array}$ & $\begin{array}{l}6.81 \\
6.65 \\
5.62\end{array}$ & $\begin{array}{l}.993^{*} \\
1.00\end{array}$ & $\begin{array}{l}1.00 \\
.959^{* *} \\
.872^{* *}\end{array}$ & $\begin{array}{l}1.00 \\
.959 *\end{array}$ \\
\hline
\end{tabular}

Pearson correlations are reported; two-tailed significance: $\nmid p<10,{ }^{*} \mathrm{p}<.05,{ }^{* *} \mathrm{p}<01 . \mathrm{n} \cdot \mathrm{a} .=$ not applicable.

\section{Table 8.2 \\ Descriptives}

Teams' change rates in stable and dynamic environments

\begin{tabular}{|c|c|c|c|c|}
\hline \multirow{2}{*}{$\begin{array}{l}\text { Dependent vari- } \\
\text { able }\end{array}$} & \multirow[t]{2}{*}{ Team type } & \multicolumn{3}{|c|}{ Environmental condition } \\
\hline & & Stable industries & Dynamic industries & All industries \\
\hline $\begin{array}{l}\text { 1. Relative change } \\
\text { rate }\end{array}$ & $\begin{array}{l}\text { Internal } \\
\text { Mixed } \\
\text { External }\end{array}$ & $\begin{array}{c}-.73 \\
(1.64 ; 65) \\
-.22 \\
(2.32 ; 55) \\
.84 \\
(2.21 ; 30)\end{array}$ & $\begin{array}{c}-.03 \\
(2.08 ; 50) \\
-.27 \\
(2.52 ; 35) \\
.83 \\
(2.09 ; 55)\end{array}$ & $\begin{array}{c}-.43 \\
(1.87 ; 115) \\
-.24 \\
(2.39 ; 90) \\
.83 \\
(2.12 ; 85)\end{array}$ \\
\hline $\begin{array}{l}\text { 2. Weighted rella- } \\
\text { the change rate }\end{array}$ & $\begin{array}{l}\text { Internal } \\
\text { Mixed } \\
\text { External }\end{array}$ & $\begin{array}{c}-.75 \\
(1.63 ; 65) \\
-.24 \\
(2.28 ; 55) \\
.85 \\
(2.43 ; 30)\end{array}$ & $\begin{array}{c}-.03 \\
(2.10 ; 50) \\
-.29 \\
(2.40 ; 35) \\
.87 \\
(2.05 ; 55) \\
\end{array}$ & $\begin{array}{c}-.44 \\
(1.88 ; 115) \\
-.26 \\
(2.32 ; 90) \\
.86 \\
(2.18 ; 85)\end{array}$ \\
\hline
\end{tabular}

Means are reported. Standard deviations and number of observations in parentheses.

ging behavior between stable and dynamic environments. Note that we do detect a very strong main effect of team type on the rate of change. This main effect is caused by external teans' consistently higher change rate in either environment, as shown in Table 8.2. In fact, a period-by-period analysis revealed that externals carry out more changes than the other team types in any period of the game. We will return to this interesting point in the discussion.

To test hypothesis 8.2 , correlations were calculated between change activity and operating results (both profits and losses) in previous periods. Table 8.4 reports the correlations between operating results in $t-1$ and the relative (weighted) amount of change carried through in $t$. As the last column indicates, there is no strong general con- 
Table 8.3

ANOVA results on hypothesis 8.1

\begin{tabular}{|c|c|c|}
\hline & \multicolumn{2}{|c|}{ Dependent variable } \\
\hline & $\begin{array}{l}\text { Relative change } \\
\text { rate }\end{array}$ & $\begin{array}{l}\text { Weigluted relintive } \\
\text { charge rate }\end{array}$ \\
\hline Factors: & & \\
\hline Teant type & $\begin{array}{r}847 \\
(.0000)\end{array}$ & $\begin{array}{r}9.05 \\
(.000)\end{array}$ \\
\hline Dynamism & $\begin{array}{c}.707 \\
(.401)\end{array}$ & $\begin{array}{c}.12 \\
(368)\end{array}$ \\
\hline $\begin{array}{l}\text { Team type by dyna. } \\
\text { mism }\end{array}$ & $\begin{array}{c}.996 \\
(.371)\end{array}$ & $\begin{array}{l}1.008 \\
(.366)\end{array}$ \\
\hline $\mathrm{R}^{2}$ & .07 & .08 \\
\hline
\end{tabular}

F walues are reported. Probability of in parentheses. Significant $F$ wallues printed in bold.

Table 8.4

Correlations ${ }^{1}$ : operating results

Previous period result (either profit or loss) and subsequent relative change

\begin{tabular}{|c|c|c|c|c|c|c|c|}
\hline \multirow{2}{*}{$\begin{array}{l}\text { Teama } \\
\text { type }\end{array}$} & \multirow{2}{*}{$\begin{array}{l}\text { Change: } \\
\text { measure }\end{array}$} & \multicolumn{6}{|c|}{ Period } \\
\hline & & 2 & 3 & 4 & 5 & 6 & $\begin{array}{l}\text { all perio } \\
\text { ods }\end{array}$ \\
\hline Incernal & $\begin{array}{l}\text { Unweighted } \\
\text { Werghted }\end{array}$ & $\begin{array}{c}-386+ \\
-406 t \\
(23)\end{array}$ & $\begin{array}{l}336 \\
314 \\
(23)\end{array}$ & $\begin{array}{l}-.257 \\
-.256 \\
(23)\end{array}$ & $\begin{array}{l}.263 \\
.275 \\
(23)\end{array}$ & $\begin{array}{l}156 \\
.185 \\
(23)\end{array}$ & $\begin{array}{l}.006 \\
.003 \\
(115)\end{array}$ \\
\hline Mixed & $\begin{array}{l}\text { Wnweighted } \\
\text { Weigluted }\end{array}$ & $\begin{array}{r}-390 \\
-.392 \\
(18)\end{array}$ & $\begin{array}{c}-.377 \\
-.403 i \\
(18)\end{array}$ & $\begin{array}{l}.100 \\
.089 \\
(1.8)\end{array}$ & $\begin{array}{l}.225 \\
241 \\
(18)\end{array}$ & $\begin{array}{l}.208 \\
217 \\
(18)\end{array}$ & $\begin{array}{l}.047 \\
.047 \\
(90)\end{array}$ \\
\hline External & $\begin{array}{l}\text { Whwaghted } \\
\text { Weighted }\end{array}$ & $\begin{array}{c}-.456 \mathrm{j} \\
\times .457 \\
(17)\end{array}$ & $\begin{array}{l}321 \\
308 \\
(17)\end{array}$ & $\begin{array}{r}-050 \\
-.072 \\
(17)\end{array}$ & $\begin{array}{r}-112 \\
-.99 \\
(17)\end{array}$ & $\begin{array}{l}242 \\
254 \\
(17)\end{array}$ & $\begin{array}{l}.000 \\
.010 \\
(85)\end{array}$ \\
\hline all teams & $\begin{array}{l}\text { Unwerghted } \\
\text { Weighted }\end{array}$ & $\begin{array}{c}-456 \\
-463 \\
(58) \\
\end{array}$ & $\begin{array}{l}183 \\
169 \\
(58) \\
\end{array}$ & $\begin{array}{r}-.053 \\
-.066 \\
(58) \\
\end{array}$ & $\begin{array}{l}119 \\
128 \\
(58) \\
\end{array}$ & $\begin{array}{l}130 \\
.44 \\
(58) \\
\end{array}$ & $\begin{array}{r}.008 \\
.008 \\
2901 \\
\end{array}$ \\
\hline
\end{tabular}

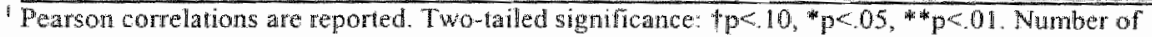
observations in parentheses.

nection between results and the amount of change in the following period. If we look at the correlations in the last row for separate periods, it turns out, that only in period 2 teans react in the expected direction, i.e., they changed more when period I results are lower. However, internal teams' correlation is not significantly different or higher (at 
$p=10)$ than that of extermals? This contradicts hypothesis 8.2 . After period 2, no significant association between action change and previous period performance exists.

It seems logical to assume that one is more likely to change policies after a clear negative feedback signal like a loss than after positive feedback, i.e, a profit. Therefore, we split up Table 8.4 to explore separately the reaction to positive and negative operating results in the previous period. Correlations were recalculated for teams earning a profit and those making a loss. These are reported in Table $8.5 \mathrm{a}$ and $8.5 \mathrm{~b}$.

Table $8.5 \mathrm{a}$

Correlations: positive results

Previous period size of profit and subsequent relative change

\begin{tabular}{|c|c|c|c|c|c|c|c|}
\hline \multirow{2}{*}{$\begin{array}{l}\text { Team } \\
\text { type }\end{array}$} & \multirow{2}{*}{$\begin{array}{l}\text { Change } \\
\text { measure }\end{array}$} & \multicolumn{6}{|c|}{ Period } \\
\hline & & 2 & 3 & 4 & 5 & 6 & $\begin{array}{l}\text { all peri- } \\
\text { ods }\end{array}$ \\
\hline Internal & $\begin{array}{l}\text { Unweighted } \\
\text { Weighted }\end{array}$ & $\begin{array}{l}.052 \\
.026 \\
(9)\end{array}$ & $\begin{array}{c}960^{* * *} \\
966^{* * *} \\
16 \%\end{array}$ & $\begin{array}{l}.097 \\
.114 \\
(20)\end{array}$ & $\begin{array}{l}.3651 \\
.3831 \\
(22)\end{array}$ & $\begin{array}{l}243 \\
.275 \\
(20)\end{array}$ & $\begin{array}{l}.153 \\
.173 \\
(77)\end{array}$ \\
\hline Mixed & $\begin{array}{l}\text { Unweighted } \\
\text { Weighted }\end{array}$ & $\begin{array}{c}-.275 \\
-.306 \\
60\end{array}$ & (1) & $\begin{array}{l}-.090 \\
-.116 \\
(13)\end{array}$ & $\begin{array}{r}. .296 \\
-.265 \\
(13)\end{array}$ & $\begin{array}{r}-.277 \\
-.265 \\
(12)\end{array}$ & $\begin{array}{r}-.088 \\
-.087 \\
(4.5)\end{array}$ \\
\hline Exiermal & $\begin{array}{l}\text { Unweighted } \\
\text { Weighted }\end{array}$ & $\begin{array}{l}1.00 \\
1.00 \\
(2)\end{array}$ & $\begin{array}{l}.072 \\
.133 \\
(7)\end{array}$ & $\begin{array}{l}.307 \\
.408 \\
(10)\end{array}$ & $\begin{array}{l}.107 \\
.136 \\
(14)\end{array}$ & $\begin{array}{c}.658^{*} \\
.676^{* *} \\
(14)\end{array}$ & $\begin{array}{l}.232 \\
.2747 \\
(47)\end{array}$ \\
\hline $\begin{array}{l}\text { all } \\
\text { tearns }\end{array}$ & $\begin{array}{l}\text { Unweighted } \\
\text { Weighted }\end{array}$ & $\begin{array}{c}-.004 \\
-.025 \\
(17)\end{array}$ & $\begin{array}{l}.524 \dagger \\
.545^{*} \\
(14)\end{array}$ & $\begin{array}{l}.053 \\
.066 \\
(43)\end{array}$ & $\begin{array}{l}.188 \\
.211 \\
(49)\end{array}$ & $\begin{array}{l}.112 \\
.152 \\
(46)\end{array}$ & $\begin{array}{r}.104 \\
126 \\
(169)\end{array}$ \\
\hline
\end{tabular}

Pearson correlations are reponted" two-tailed significamee: $\uparrow p<.10,{ }^{*} p<05, * 0<01$. Number of observations in parentheses.

Table 8.5 a shows the correlations between positive results (i.e., profits) and subsequent change, whereas Table $8.5 b$ shows the correlations of losses with subsequent change ${ }^{2}$. Although the correlations remain typically low and insignificant, they tend to indicate a stronger relationship with losses than with profits. In fact, the overall correlation (in the lower right corner of Tables $8.5 \mathrm{a}$ and $8.5 \mathrm{~b}$ ) for losses is significant, whereas that for profits is not. The former is twice as high as the latter and the difference between them approaches significance $(\mathrm{p}=12)$. If we have a look at the strong association between results and change in period 2 (as found in Table 8.4), we can now see that this is in fact brought about by strong correlations with the period 1 lossess of 41 teams. Only a minor-

\footnotetext{
"All companisons of correlations are based on Fishers $r$ to $z^{\prime}$ transformation. See Cohen and Cohen (1983) pp. 53-55.

Note that in this case we took the size of a loss as a positive value. So, positive correlations with the anourt of subsequent change in Table 5 b indicate that higher losses concide with higher change activity. The same goes for all other tables where the size of loss or the size of decline is used.
} 
ity of 17 teams managed to make a profit in period 1 and these profits appear to be unrelated to subsequent change. Nevertheless, again no evidence was found for stronger correlations among internal teams than among other team types. If anything, extenal teams tend to show strongest relationships between losses and change, but the differences do not reach significance.

\section{Table $8.5 \mathrm{~b}$ \\ Correlations': negative results}

Previous period size of loss and subsequent relative change

\begin{tabular}{|c|c|c|c|c|c|c|c|}
\hline \multirow{2}{*}{$\begin{array}{l}\text { Tream } \\
\text { type }\end{array}$} & \multirow{2}{*}{$\begin{array}{l}\text { Change } \\
\text { measure }\end{array}$} & \multicolumn{6}{|c|}{ Periad } \\
\hline & & 2 & 3 & 4 & 5 & 6 & $\begin{array}{l}\text { all peri- } \\
\text { ods }\end{array}$ \\
\hline Internal & $\begin{array}{l}\text { Unweighted } \\
\text { Weighted }\end{array}$ & $\begin{array}{l}.519 \dagger \\
.527 \dagger \\
(14)\end{array}$ & $\begin{array}{l}.226 \\
.275 \\
(17)\end{array}$ & $\begin{array}{l}.429 \\
318 \\
(3)\end{array}$ & 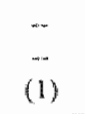 & $\begin{array}{c}-.230 \\
-.108 \\
(3)\end{array}$ & $\begin{array}{l}.244 \\
.266 \\
(38)\end{array}$ \\
\hline Mixed & $\begin{array}{l}\text { Unweighted } \\
\text { Weighted }\end{array}$ & $\begin{array}{l}.546+ \\
.568^{*} \\
(12)\end{array}$ & $\begin{array}{l}332 \\
358 \\
(17)\end{array}$ & $\begin{array}{c}-.575 \\
-.543 \\
(5)\end{array}$ & $\begin{array}{c}-.171 \\
-.155 \\
(5)\end{array}$ & $\begin{array}{l}495 \\
.482 \\
(6) \\
\end{array}$ & $\begin{array}{l}.134 \\
.152 \\
45)\end{array}$ \\
\hline Extemal & $\begin{array}{l}\text { Unweighted } \\
\text { Weighted }\end{array}$ & $\begin{array}{c}.689^{* *} \\
.670^{* * *} \\
(15)\end{array}$ & $\begin{array}{l}.141 \\
.086 \\
(10)\end{array}$ & $\begin{array}{c}-162 \\
-180 \\
(7)\end{array}$ & $\begin{array}{c}.148 \\
.153 \\
(3)\end{array}$ & $\begin{array}{c}-.083 \\
-.119 \\
(3)\end{array}$ & $\begin{array}{l}377^{*} \\
.331^{*} \\
(38)\end{array}$ \\
\hline $\begin{array}{l}\text { all } \\
\text { teans }\end{array}$ & $\begin{array}{l}\text { Unweighted } \\
\text { Weighted }\end{array}$ & $\begin{array}{l}.611^{* *} \\
.608^{* * *} \\
(41)\end{array}$ & $\begin{array}{l}.167 \\
.182 \\
(44)\end{array}$ & $\begin{array}{r}-.442 \\
-.438 \\
(15)\end{array}$ & $\begin{array}{c}-.055 \\
-.078 \\
(9) \\
\end{array}$ & $\begin{array}{l}.120 \\
.118 \\
(12) \\
\end{array}$ & $\begin{array}{l}238^{*} \\
235^{*} \\
(121) \\
\end{array}$ \\
\hline
\end{tabular}

Pearson correlations are reported; two-tailed significance: $t \mathrm{p}<.10, * \mathrm{p}<.05,{ }^{*}{ }^{\mathrm{p}} \mathrm{p}<01$. Number of observations in parentheses.

Possibly teams based their decision to adapt more on the changes they experience in their results, rather than on the absolute performance levels. Thus, a somewhat stronger (negative feedback) signal that current policies are not performing very well and that change may be necessary is a dectining rather than a low result. Conversely, an improving result may be a stronger indication that things are going well than a mere positive result. We therefore recalculated the above correlations to explore the relationship between teams" change activity and the changes in results. Thus, we relate action change from $t-1$ to to the change in results from $t-2$ to $t-1$. First, Table 8.6 lists the correlations between action change and results change. Again, we do not generally sce significant correlations between results change and subsequent action change. Moreover, none of these differ significantly between team types. Only reacti pons to results changes from period 0 to period 1, i.e., the first column are significant. Note, however, that these correlations are by definition exactly the same as those in the first column of Table $8.4^{4}$.

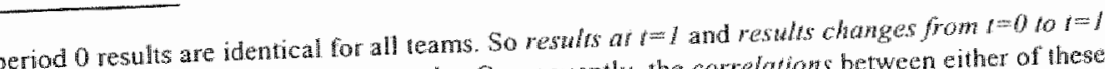
by a constant, namely period 0 results. Consequently, the comralahos between either of lliese 
Table 8.6

Correlations": Results changes

Previous period results change and subsequent relative action change

\begin{tabular}{|c|c|c|c|c|c|c|c|}
\hline \multirow{2}{*}{$\begin{array}{l}\text { Team } \\
\text { type }\end{array}$} & \multirow{2}{*}{$\begin{array}{l}\text { Change } \\
\text { measure }\end{array}$} & \multicolumn{6}{|c|}{ Period } \\
\hline & & 2 & 3 & 4 & 5 & 6 & $\begin{array}{l}\text { all peri- } \\
\text { ods }\end{array}$ \\
\hline Internal & $\begin{array}{l}\text { Unweighted } \\
\text { Weighted }\end{array}$ & $\begin{array}{c}-.386 \uparrow \\
-.406 t \\
(23)\end{array}$ & $\begin{array}{l}.244 \\
.277 \\
(23)\end{array}$ & $\begin{array}{l}-.326 \\
\times .337 \\
(23)\end{array}$ & $\begin{array}{l}.164 \\
.185 \\
(23)\end{array}$ & $\begin{array}{c}-.130 \\
-.160 \\
(23)\end{array}$ & $\begin{array}{r}-.015 \\
-.025 \\
(115)\end{array}$ \\
\hline Mixed & $\begin{array}{l}\text { Unweighted } \\
\text { Weighted }\end{array}$ & $\begin{array}{r}-390 \\
-.392 \\
(18)\end{array}$ & $\begin{array}{r}-.183 \\
-.193 \\
(18)\end{array}$ & $\begin{array}{l}.138 \\
.132 \\
(18)\end{array}$ & $\begin{array}{c}-.291 \\
-303 \\
(18)\end{array}$ & $\begin{array}{r}.084 \\
.079 \\
(18)\end{array}$ & $\begin{array}{r}-.015 \\
-.024 \\
(90)\end{array}$ \\
\hline Externa: & $\begin{array}{l}\text { Unweighted } \\
\text { Weighted }\end{array}$ & $\begin{array}{c}-.456 \hbar \\
-.447 \dagger \\
(17)\end{array}$ & $\begin{array}{l}.248 \\
.244 \\
(17)\end{array}$ & $\begin{array}{r}-.123 \\
-.135 \\
(17)\end{array}$ & $\begin{array}{l}-.098 \\
-.075 \\
(17)\end{array}$ & $\begin{array}{l}.457 \dagger \\
415 t \\
(17)\end{array}$ & $\begin{array}{l}.011 \\
.014 \\
(85)\end{array}$ \\
\hline $\begin{array}{l}\text { all } \\
\text { teams }\end{array}$ & $\begin{array}{l}\text { Unweighted } \\
\text { Weighted }\end{array}$ & $\begin{array}{c}.456^{* *} \\
-463^{* *} \\
(58) \\
\end{array}$ & $\begin{array}{l}.164 \\
.161 \\
(58) \\
\end{array}$ & $\begin{array}{l}-.120 \\
-.136 \\
(58) \\
\end{array}$ & $\begin{array}{l}.010 \\
.023 \\
(58) \\
\end{array}$ & $\begin{array}{r}.151 \\
.139 \\
(58) \\
\end{array}$ & $\begin{array}{r}-.010 \\
-.015 \\
(290) \\
\end{array}$ \\
\hline
\end{tabular}

Pearson correlations are reported; two-tailed significance: $\uparrow p<.10,{ }^{*} p<05, * * p<.01$. Number of observations in parentheses.

In Tables $8.7 \mathrm{a}$ and $8.7 \mathrm{~b}$ separate correlations for improved and worsened results are shown respectively. Note that the period 2 column in Table $8.7 \mathrm{a}$ is empty, indicating that none of the sampled teams realized an improvement of profits over their common starting point (a 4.3 million ECU profit in 'period $0^{\circ}$ ) after the first decision period ${ }^{10}$. Consequently, all 58 teams are present in the period 2 column of Table $8.7 \mathrm{~b}$. If we compare the overall correlations in the lower right corners of Tables $8.7 \mathrm{a}$ and $8.7 \mathrm{~b}$, we see that only very weak associations exist and that only worsened results have (marginally) significant correlations with subsequent change. As with profit levels, the result is mainly attributable to period 2, where truly sizeable correlations in the expected direction appear. Thus, only declining results from the starting period to the first period have a strong connection to the amount of change subsequently carried through from period $\Downarrow$ to period 2 . But even here, we do not find support for our hypothesis that internal teams show stronger relationships between results and change activity than other team types as the correlations do not differ significantly between team types.

Until now we have been looking for quite immediate reactions of action change following either a low or a declining profit. Possibly, this time window is too narrow and changes or reorientations are planned and carried out over more time periods in response to an unsatisfactory cumulative result. To explore this, we related the cumulative results

two measures and period 2 action change are identical.

${ }^{10}$ Mind that a declining profit does not always produce a loss! As Table 5 a shows, 17 teams were still making a profit after period 1, but these profits were all lower than the "period 0 " profit of 4.3 million ECU. 
Table 8.7a

Correlations': improved results

Previous period profit increase and subsequent relative change

\begin{tabular}{|c|c|c|c|c|c|c|c|}
\hline \multirow{2}{*}{$\begin{array}{l}\text { Tem } \\
\text { type }\end{array}$} & \multirow{2}{*}{$\begin{array}{l}\text { Change } \\
\text { meastare }\end{array}$} & \multicolumn{6}{|c|}{ Period } \\
\hline & & 2 & 3 & 4 & 5 & 6 & $\begin{array}{l}\text { all pert- } \\
\text { ods }\end{array}$ \\
\hline Internal & $\begin{array}{l}\text { Unweighted } \\
\text { Weighted }\end{array}$ & $(0)$ & $\begin{array}{c}.046 \\
.056 \\
(8)\end{array}$ & $\begin{array}{r}-.086 \\
-.087 \\
(20)\end{array}$ & $\begin{array}{l}246 \\
277 \\
(12)\end{array}$ & $\begin{array}{l}.108 \\
.074 \\
(10)\end{array}$ & $\begin{array}{l}013 \\
018 \\
(50)\end{array}$ \\
\hline Mixed & $\begin{array}{l}\text { Unweighted } \\
\text { Weighted }\end{array}$ & $\begin{array}{c}- \\
-- \\
(0)\end{array}$ & $\begin{array}{l}.172 \\
.192 \\
(9)\end{array}$ & $\begin{array}{c}-.233 \\
-.241 \\
(16)\end{array}$ & $\begin{array}{r}-.061 \\
-.064 \\
(10)\end{array}$ & $\begin{array}{r}-.373 \\
-.439 \\
(12)\end{array}$ & $\begin{array}{r}-.082 \\
.091 \\
(47)\end{array}$ \\
\hline External & $\begin{array}{l}\text { Unweighted } \\
\text { Weighted }\end{array}$ & $\begin{array}{c}\cdots \\
\cdots \\
(0)\end{array}$ & $\begin{array}{c}531 \\
.508 \\
(8)\end{array}$ & $\begin{array}{r}-318 \\
-282 \\
(13)\end{array}$ & $\begin{array}{c}-131 \\
-.156 \\
(9)\end{array}$ & $\begin{array}{c}948 * \\
875+ \\
(5)\end{array}$ & $\begin{array}{l}319+ \\
291+ \\
(35)\end{array}$ \\
\hline $\begin{array}{l}\text { all } \\
\text { teams }\end{array}$ & $\begin{array}{l}\text { Unweighted } \\
\text { Weighted }\end{array}$ & (0) & $\begin{array}{l}300 \\
.316 \\
(25)\end{array}$ & $\begin{array}{r}-.220 \\
-.221 \\
(49) \\
\end{array}$ & $\begin{array}{l}.188 \\
.192 \\
(31)\end{array}$ & $\begin{array}{l}.3261 \\
.321+ \\
(27)\end{array}$ & $\begin{array}{r}.092 \\
.090 \\
(132)\end{array}$ \\
\hline
\end{tabular}

'Pearson correlations are reported; two-tailed significance: $\nmid \mathrm{p}<.10, * 0<05, * * 0<01$. Number of observations in parentheses.

Table $8.7 \mathrm{~b}$

Correlations ${ }^{1}$ : worsened results

Previous period profit decrease and subsequent relative change

\begin{tabular}{|c|c|c|c|c|c|c|c|}
\hline \multirow{2}{*}{$\begin{array}{l}\text { Team } \\
\text { type }\end{array}$} & \multirow{2}{*}{$\begin{array}{l}\text { Change } \\
\text { measure }\end{array}$} & \multicolumn{6}{|c|}{ Period } \\
\hline & & 2 & 3 & 4 & 5 & 6 & $\begin{array}{l}\text { all peri- } \\
\text { ods }\end{array}$ \\
\hline Internal & $\begin{array}{l}\text { Unweighted } \\
\text { Weighted }\end{array}$ & $\begin{array}{l}.386 \\
.406 \% \\
(23)\end{array}$ & $\begin{array}{l}.215 \\
312 \\
(15)\end{array}$ & $\begin{array}{c}-.664 \\
-.570 \\
(3)\end{array}$ & $\begin{array}{r}-.032 \\
-.042 \\
(1)\end{array}$ & $\begin{array}{l}464 \\
431 \\
(13)\end{array}$ & $\begin{array}{l}189 \\
.200 \\
(65)\end{array}$ \\
\hline Mixed & $\begin{array}{l}\text { Uniweighed } \\
\text { Weighted }\end{array}$ & $\begin{array}{l}390 \\
392 \\
(18)\end{array}$ & $\begin{array}{c}.26 y \\
.296 \\
(9)\end{array}$ & $\begin{array}{c}-1.00 \\
-1.00 \\
(2)\end{array}$ & $\begin{array}{c}-339 \\
-3 \| 1 \\
(8)\end{array}$ & $\begin{array}{l}.222 \\
.267 \\
(6)\end{array}$ & $\begin{array}{l}.124 \\
.143 \\
(43)\end{array}$ \\
\hline Extemal & $\begin{array}{l}\text { Unweighted } \\
\text { Weiglted }\end{array}$ & $\begin{array}{l}456 \dagger \\
457 t \\
(17)\end{array}$ & $\begin{array}{c}-183 \\
-.329 \\
(9)\end{array}$ & $\begin{array}{l}.767 \\
.785 \\
(4)\end{array}$ & $\begin{array}{r}.123 \\
-.079 \\
(8)\end{array}$ & $\begin{array}{l}.02 \% \\
.022 \\
(12)\end{array}$ & $\begin{array}{l}.170 \\
.168 \\
(50)\end{array}$ \\
\hline $\begin{array}{l}\text { all } \\
\text { teams }\end{array}$ & $\begin{array}{l}\text { Unwelghted } \\
\text { Weighted }\end{array}$ & $\begin{array}{c}.456 * \\
.463 * * \\
(58)\end{array}$ & $\begin{array}{l}.030 \\
.041 \\
(33)\end{array}$ & $\begin{array}{c}-260 \\
-.248 \\
(9)\end{array}$ & $\begin{array}{r}-.173 \\
-.154 \\
(27)\end{array}$ & $\begin{array}{l}.092 \\
.089 \\
(31)\end{array}$ & $\begin{array}{l}154 \% \\
.162^{*} \\
(158)\end{array}$ \\
\hline
\end{tabular}

"Pearson correlations are reported; two-tailed significance: $t p<10, * 0,05, " p<01$. Nuntser of observations in parentheses. 
in the early part of the game (period 1 and 2) to changes made from early to the later periods $(3,4,5$ and 6$)$. The correlations of these changes with the cumulative profit in the early period are shown in Table 8.8 .

\section{Table 8.8 \\ Correlations}

Early (period $1 \& 2$ ) cumulative results and change over different time spans ${ }^{3}$

\begin{tabular}{|c|c|c|c|c|c|c|c|c|c|}
\hline \multirow{3}{*}{$\begin{array}{l}\text { Tamm } \\
\text { lype }\end{array}$} & \multicolumn{9}{|c|}{ Change measure } \\
\hline & \multicolumn{3}{|c|}{$\begin{array}{l}\text { Period } \\
1-2 \text { พ5.3-4 }\end{array}$} & \multicolumn{3}{|c|}{$\begin{array}{l}\text { Period } \\
1-2 \text { vs. 3-5 }\end{array}$} & \multicolumn{3}{|c|}{$\begin{array}{l}\text { Period } \\
1-2 \text { vs, } 3-6\end{array}$} \\
\hline & $\begin{array}{l}\text { Cum. } \\
\text { results } \\
\text { (1a) }\end{array}$ & $\begin{array}{l}\text { Cum. } \\
\text { profit } \\
(1 \mathrm{~b})\end{array}$ & $\begin{array}{l}\text { Cum. } \\
\text { loss } \\
(1 \mathrm{c})\end{array}$ & $\begin{array}{l}\text { Curn. } \\
\text { results } \\
\text { (2a) }\end{array}$ & $\begin{array}{l}\text { Cum. } \\
\text { profit } \\
(2 b)\end{array}$ & $\begin{array}{l}\text { Cum. } \\
\text { loss } \\
(2 \mathrm{c})\end{array}$ & $\begin{array}{l}\text { Cum. } \\
\text { results } \\
\text { (3a) }\end{array}$ & $\begin{array}{l}\text { Cum. } \\
\text { profit } \\
\text { (3b) }\end{array}$ & $\begin{array}{l}\text { Cum. } \\
\text { loss } \\
\text { (3c) }\end{array}$ \\
\hline Interna! & $\begin{array}{l}.07 \| \\
(23)\end{array}$ & $\begin{array}{l}.43+ \\
(17)\end{array}$ & $\begin{array}{c}.7431 \\
(6)\end{array}$ & $\begin{array}{l}.001 \\
(23)\end{array}$ & $\begin{array}{l}.374 \\
(17)\end{array}$ & $\begin{array}{l}.554 \\
16)\end{array}$ & $\begin{array}{l}-.005 \\
(23)\end{array}$ & $\begin{array}{l}.326 \\
(17)\end{array}$ & $\begin{array}{l}310 \\
(6)\end{array}$ \\
\hline Mixed & $\begin{array}{c}-.464 \dagger \\
(18)\end{array}$ & $\begin{array}{c}-.622 t \\
(10)\end{array}$ & $\begin{array}{l}.724^{*} \\
(8)\end{array}$ & $\begin{array}{c}-.4181 \\
(18)\end{array}$ & $\begin{array}{l}-.533 \\
(10)\end{array}$ & $\begin{array}{c}.664 \uparrow \\
(8)\end{array}$ & $\begin{array}{r}-299 \\
(18)\end{array}$ & $\begin{array}{r}-.347 \\
(10)\end{array}$ & $\begin{array}{l}573 \\
(8)\end{array}$ \\
\hline External & $\begin{array}{r}-165 \\
(17)\end{array}$ & $\begin{array}{l}.161 \\
\text { (11) }\end{array}$ & $\begin{array}{l}.191 \\
(6)\end{array}$ & $\begin{array}{l}-165 \\
(17)\end{array}$ & $\begin{array}{l}.089 \\
(11)\end{array}$ & $\begin{array}{l}.213 \\
(6)\end{array}$ & $\begin{array}{l}-.150 \\
(17)\end{array}$ & $\begin{array}{l}.092 \\
(11)\end{array}$ & $\begin{array}{l}.198 \\
161\end{array}$ \\
\hline all & $\begin{array}{l}-160 \\
(58)\end{array}$ & $\begin{array}{l}.127 \\
(38)\end{array}$ & $\begin{array}{l}.360 \\
(20)\end{array}$ & $\begin{array}{r}-.170 \\
158)\end{array}$ & $\begin{array}{l}.071 \\
(38)\end{array}$ & $\begin{array}{l}.300 \\
(20) \\
\end{array}$ & $\begin{array}{r}-139 \\
(58) \\
\end{array}$ & $\begin{array}{l}.074 \\
(38) \\
\end{array}$ & $\begin{array}{l}.232 \\
.20 \\
\end{array}$ \\
\hline
\end{tabular}

Pearson correlations are reported; wo-tailed level of significance: $t p<10, * p<05$; number of observations in parentheses.

Columns $1 \mathrm{a}, 2 \mathrm{a}$ and $3 \mathrm{a}$ show the overall correlations with operating results; the following $\mathrm{b}$ and $\mathrm{c}$ columns are again split-ups for teams experiencing early cumulative loss and early cumulative profit. As the bottom row indicates, no significant correlations exist between cumulative results, profits or losses and subsequent change. Again, internals do not have significantly stronger overall correlations (" $a$ " columns), nor profit or loss correlations (' $b$ ' and ' $c$ ' columns) than other teams. Quite surprisingly, however, mixed teans in the first two ' $a$ ' columns have stronger correlations between late changes and early profits than either internal $(p<.01)$ or external teams $(p<.05)$ who both show no significant association. The correlations with early losses appear to be stronger than those with early profits, but the differences do not reach significance either, probably due to small sample size. We may conclude from the results of these various similar analyses. that the generall relationships between performance and adaptive activity is not stronger among internals than it is among other team types. We therefore reject hypothesis 8.2 as well.

If we summarize the results so far, they seem to point in the same direction. We have seen that team types do not in general differ in their change reactions to environmental circumstances or results, although a main effect of team type was found. The simple adaptive model of change following results that we postulated, does not seem to work in the present context, except for the beginning of the game. Typically, we only 
observe a relationship with change activity following a first period loss. Thus, instead of a general change reaction to results (i.e., to both profits and losses). loss aversion seems to be more important to trigger change, but only after the first period. Hereafter, teams generally showed inert behavion in relation to their results development. We will come back to these important findings in the discussion.

Hypothesis 8.3 stated that externals after negative feedback will show greater variation in their adaptive responses than internals or mixed teams. Table 8.9 shows the variance of action changes from early to later periods following either the positive or the negative feedback from early periods.

Table 8.9

Descriptives': Variance of change reactions between early and late periods after positive and negative feedback

\begin{tabular}{|c|c|c|c|c|}
\hline \multirow{2}{*}{$\begin{array}{l}\text { Team } \\
\text { type }\end{array}$} & \multirow{2}{*}{$\begin{array}{l}\text { Feedback } \\
\text { type }\end{array}$} & \multicolumn{3}{|c|}{ Change measure } \\
\hline & & $\begin{array}{l}\text { Period } \\
1-2 \text { vs. } 3-4\end{array}$ & $\begin{array}{l}\text { Period } \\
1-2 \text { vs. 3-5 }\end{array}$ & $\begin{array}{l}\text { Period } \\
1-2 \text { *s. } 3.6\end{array}$ \\
\hline Internal & $\begin{array}{l}\text { Posintue } \\
\text { Negative }\end{array}$ & $\begin{array}{c}5.81 \\
(28 ; 8) \\
2.02 \\
(-87 ; 15)\end{array}$ & $\begin{array}{c}4.71 \\
(.11 ; 8) \\
1.99 \\
(-.94 ; 15)\end{array}$ & $\begin{array}{c}5.15 \\
(.20 ; 8) \\
1.61 \\
(-97 ; 15)\end{array}$ \\
\hline Mixed & $\begin{array}{l}\text { Positive } \\
\text { Negative }\end{array}$ & $\begin{array}{c}4.37 \\
(.29 ; 9) \\
4.00 \\
(-.19 ; 9)\end{array}$ & $\begin{array}{c}3.65 \\
(.36 ; 9) \\
4.24 \\
(-.33 ; 9)\end{array}$ & $\begin{array}{c}2.99 \\
(36 ; 9) \\
5.62 \\
(-16 ; 9)\end{array}$ \\
\hline External & $\begin{array}{l}\text { Positive } \\
\text { Negative }\end{array}$ & $\begin{array}{c}7.90 \\
(1.33 ; 8) \\
5.111 \\
(-.08 ; 9)\end{array}$ & $\begin{array}{c}7.13 \\
(1.32 ; 8) \\
7.08 \\
(.26 ; 9)\end{array}$ & $\begin{array}{c}5.20 \\
(1.20 ; 8) \\
7.45 \\
(.18 ; 9)\end{array}$ \\
\hline all & $\begin{array}{l}\text { Positive } \\
\text { Negative }\end{array}$ & $\begin{array}{c}5.71 \\
(.62 ; 25) \\
3.31 \\
(-.47 ; 33)\end{array}$ & $\begin{array}{c}4.93 \\
(59 ; 25) \\
3.96 \\
(-45 ; 33) \\
\end{array}$ & $\begin{array}{c}4.20 \\
(.58 ; 25) \\
4.24 \\
(-.44 ; 33) \\
\end{array}$ \\
\hline
\end{tabular}

"Mean relative change and number of observations in parentheses.

As shown, we again used three time spans after the early period to evaluate change. To see whether the differences in variance between team types are significant, we calculated pairwise quotients of the reported variances in each cell to obtain $F$ statistics with the number of observations -1 as degrees of freedom in the numerator and denominator. Focusing on the differences between internal and external teams in case of negative feedback, the F-values for the three time spans are $2.52(p<.10), 3.56(p<.05)$ and 4.63 $(p<01)$, respectively. Mixed teams behave like externals, but the difference between their variation and that of internals reaches significance only in the last time span $(\mathrm{F}=3.49 ; \mathrm{p}<.05)$. To visualize our results, Figure $8.1 \mathrm{a}$ and $\mathrm{b}$ show the mean reactions of different team types to negative or positive feedback and their respective $95 \%$ confidence intervals. 
Figure 8.1a

Change reactions following negative feedback

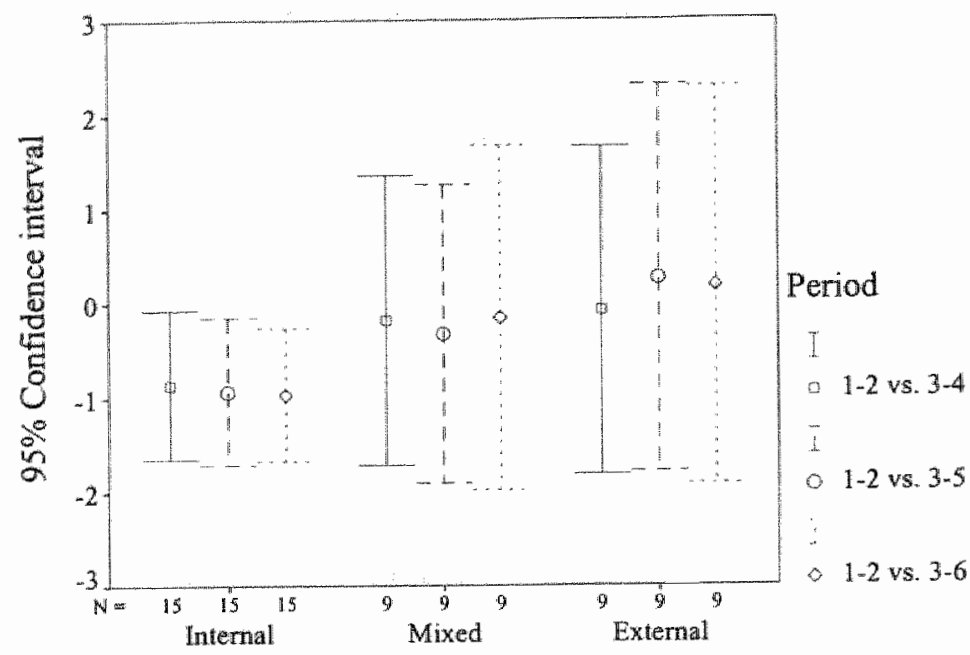

Team type

Figure $8.1 \mathrm{~b}$

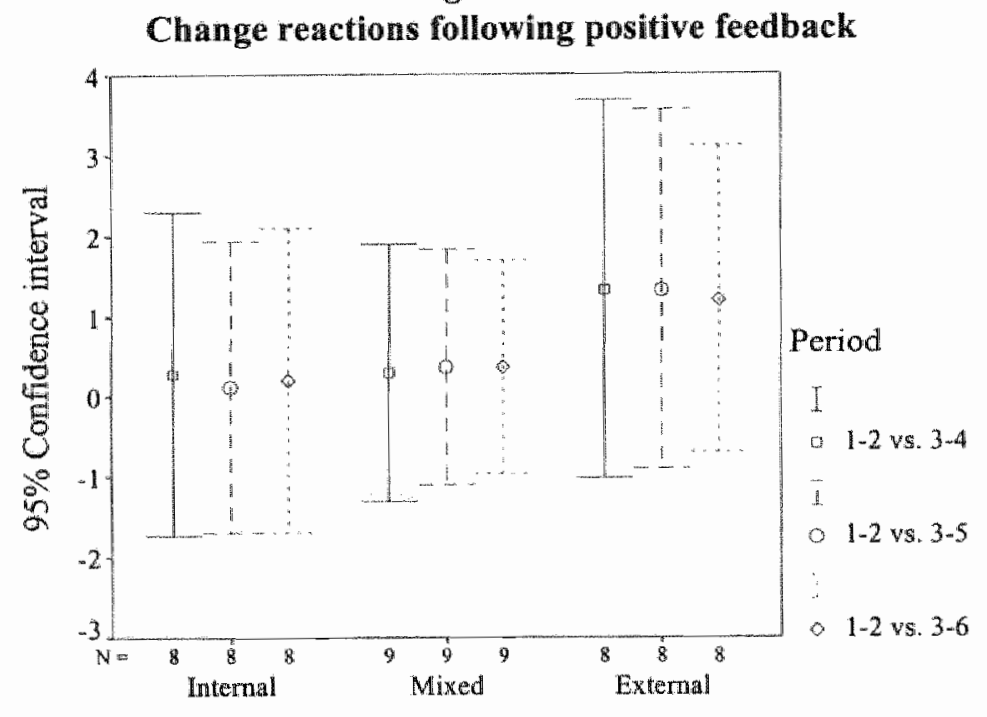

Tearn type

Note that differences clearly become more pronounced as longer time spans are considered. This can be attributed to the fact that comparing longer time periods provides more robust measurement. When the same comparisons are made for the positive feedback condition (depicted in Figure 8.1b), no significant differences between team types are found. We conclude that hypothesis 8.3 is supported: externals do indeed show greater variation in change reactions to negative feedback, and the effect is most pronounced 
when longer time periods are examined. Note that, similarly to the results on immediate period-by-period change (see Table 8.2), external teams appear to change most between early and late periods (under each feedback condition) as well (see mean changes in Table 8.9).

\section{Discussion}

In the present chapter we explored the general expectation that internal teams show more adaptive behavior than mixed and external teams, something previous chapters already indirectly indicated. Two aspects of adaptive behavior were examined. First we looked at adaptation to ongoing environmental circumstances. Second, adaptation in relation to (negative) performance feedback was studied.

Contrary to hypothesis 8.1 , we did not find an interaction between team type and dynamism on the amount of change carried through. Instead, a remarkable and very significant main effect of team type was detected, indicating that externals change more than any other team type, regardless of environmental circumstances" ${ }^{11}$. As mentioned before, in each period external teams appeared to rank highest in (period-by-period) change activity. Both Table 8.2 (period-by-period change) and Table 8.9 (early-late periods change) show a substantive higher average rate of change for external teans. Post-hoc comparisons on the differences in Table 8.2 reveal that external teams change significantly more than internal $(p<.001)$ and mixed teams $(p<.01)$; the latter two do not differ significantly. An ANOVA analysis of the 58 mean changes between early and late periods in Table 8.9, does not show a significant effect of team type (nor a feedback or interaction effect) on any of the three time spans. Although the results point in the same direction, this non-finding is probably due to the number of observations which is only one-fifth of that in the period-by-period analysis. A possible explanation of the higher overall change activity of external teams was already mentioned in the theoretical section and relates to the higher "arousability" of external individuals (De Brabander, Boone and Gerits, 1992). In other words: as externals are more sensitive to weak environmental signals, they may experience a kind of continuous unrest, which leads them to change strategies again and again. Another interpretation of the phenomenon may be found in the difficulty extemals experience in choosing a course of action and holding on to it, i.e., in persisting. This explanation seems at odds with our finding in the previous chapter that externals are equally persistent in their occupation of relative strategic positions as other team types. Note, however, that action persistence in the previous chapter was measured as the stability of positions relatively to competitors, whereas now we look more directly at the absolute amount of change between periods. The present findings provide an important qualification to the result on persistence, in that we find that inter-

\footnotetext{
11 Note that this finding of higher overall change actwity among extermal teams should be interpreted with caution, because among extemal teams the variation in change rexctions is higher than among other team types as well (sec figures $8.1 \mathrm{a}$ and b). Thus, although extemal teams on average sem to be more hyperactive, there are also external teams that show an opposite tendency: they show rather hypo- or inactive behavior.
} 
nals are indeed more persistent in their actions over time (i.e., they change less), although this does not show up in their relative positions vis-à-vis their competitors.

Next, we looked at the relationship between performance feedback teams received and the amount of change they subsequently undertook. Teams did not generally show strong connections between change activity and results. As might be expected, the relationship is more pronounced when results (i.e., profits) are negative or declining. Only in period 2 of the game a strong relationship existed between low or declining profits in the previous (first) period and the amount of change carried through, but these relationships were equally strong for all team types. After period two the relationship vanishes altogether. It seems as though the kind of immediate reactions to performance feedback occur only in the very beginning of the game. To see whether change reactions were perhaps spread over more periods of time, we also studied broader time windows than two successive periods. In particular, we related results in early periods (i.e., periods 1 and 2) to change in later periods, but again we did not find the hypothesized result. What may account for these non-findings is that teams do not steer on immediate results but rather on cumulative results, i.e. they may only change after cumulative results (i.e., losses) have reached a certain point. To explore this possibility, we also related cumulative results until t to changes made at $t+1$ and we constructed a table similar to Table 8.4. The resulting correlations are, however, not significant either ${ }^{12}$, so that we must come to the same conclusion with regard to cumulative profits: they are not related to (immediate) subsequent change. Nevertheless, the significant correlations of changes with losses that we found in the first period are intriguing. As changing course is more risky than simply continuing your chosen policy, teams' behavior after the first period may be interpreted as risk-taking action in case of losses or declining profits and risk aversion (i.e., averting change) in case of profits or increasing results. Interestingly, this finding is in concordance with prospect theory as developed by Kahneman and Tversky (1979). In a series of experiments, they showed that people are in fact risk taking in the domain of losses, but risk averse in the domain of gains (i.e., profits). Empirical studies in business contexts (Bowman, 1980, 1982; Fiegenbaum and Thomas, 1988) underscore prospect theory's assertions on the relationship between risk taking and refurns. For instance, Jegers (1991) in a large sample of Belgian accounting firms, found that firms with ueturns above a certain target level (in his case the industry median) were risk-averse, whereas those below the target level were risk-seeking. Our results indicate that teams display a similar reaction after the first results are received, but after this initial reaction they stay rather inert in response to results feedback. Possibly there is a strong first reaction to initial results, whereas later changes take longer to implement and are carried out through different aspects successively instead of all at once. In fact, our change measure may be too demanding in this respect through its adding of four change aspects. That is: by the method we used, a planned successive adaptation of prices, sales groups,

${ }^{12}$ Except, again, for the correlations with changes made in period 2 . Note that cumulative profits until period 2 (i.e., period 0 - period I) correlate identically with period 2 change as period 1 profits only, because period 0 profits are identical for all teams. 
peomotion and quality is not properly registered as an important change. We can only conclude that strong reorientation only follows after early results.

Finally, we explored the hypothesis that extemal teams show more extreme reactions than other team types when confronted with negative feedback. Analyzing strategic change from early to later periods, we did indeed find that extemals have greater variation in their reactions than other team types in response to negative but not to positive feedback. Externals showed greater variation in changes from early to late periods if their performance kept declining in the first two periods (i.e., in the negative feedback condition). Other, especially internal team types showed more similar responses among each other. Therefore, our findings support the theoretical expectation, that extemal teams exhibit a broader array of responses to negative feedback than do other team types: they range from very strong to very weak. It is important to note, that an inspection of the distribution of external teams" reactions reveals that it is not bimodal ${ }^{! 3}$, that is: externals' reactions are not restricted to the extremes, but it rather varies over a broader range including the extremes. Internals show a more restricted repertoire of reactions to negative feedback. Our treatment of negative feedback was, admittedly, somewhat crude. Perhaps externals showed more extreme reactions than internals because their negative feedback (two profit declines) was actually much stronger than that of internals. To see whether this was so, we compared the cumulative results of the first two periods between team types. This revealed no difference $(\mathrm{F}=513$, $p=.604$ ) in the "strength" of the negative feedback received, so the greater reaction variation was not inspired by stronger negative results by external teams. It is interesting to note that results of the variation tests were more pronounced the longer the observed ("late") time period. Note that this reinforces the possibility raised above, that in fact our time window for studying change is really too narrow and that more pronounced effects may only be traced when longer periods (beyond 6) can be compared.

If we compare the variations following negative and positive feedback (see Table 8.9 and Figures $8.1 \mathrm{a} / \mathrm{b}$ ), internal teams show significantly less variation in change reactions after negative than after positive feedback (two-sided $p<10$ ), whereas mixed and extemals do not differ significantly between feedback types. We could not think of a reasonable explanation of this effect. The effects on mean changes (in parentheses in Table 8.9) are, however, more in line with our previous results: again we see that internal teams were more persistent, i.e., they changed less than other team types both under positive and negative feedback conditions. Moreover, all teams seemed to have changed more after positive than after negative feedback. This is rather counterintuitive as well. However, as mentioned in our discussion of hypothesis 8.1 above, these effects appeared to be insignificant in an ANOVA with team type and feedback condition as factors.

To see how adaptive activity affects the performance differences between team types in dynamic environments we refer to Table 8.10

I3 Inct, reactions to negative feedback were normally distributed for all team rypes according to KolomogorovSinimov tests. 
Table 8.10

Performance implications of adaptive action variables ${ }^{1}$

\begin{tabular}{|c|c|c|c|c|c|c|}
\hline Model number & 1 & 2 & 3 & 4 & 5 & 6 \\
\hline \multicolumn{7}{|l|}{ Independent variables } \\
\hline Constant & $1.36^{*}$ & 95 & .93 & $1.15 \$$ & 1.21 : & $1.26 *$ \\
\hline Team type & & & & & & \\
\hline Internal (dumiry) & $2.09 *$ & $2.53 * *$ & $2.54 *$ & $2.38 * *$ & $2.32^{*}$ & $2.26^{*}$ \\
\hline Mixed (dummy) & -1.48 & -.92 & -91 & -1.31 & -1.39 & -1.48 \\
\hline \multicolumn{7}{|l|}{$\begin{array}{l}\text { General poolad period-by period } \\
\text { change (ct Table } 8.2 \text { ) }\end{array}$} \\
\hline Mean relative change & & $.50 \dagger$ & & & & \\
\hline Mean weighted relative change & & & $.49 \pi$ & & & \\
\hline \multicolumn{7}{|l|}{$\begin{array}{l}\text { Early versus later time periods } \\
\text { charge }\end{array}$} \\
\hline Period 1-2 vs. $3-4$ & & & & .25 & & \\
\hline Period 1-2 vs. 3-5 & & & & & .23 & \\
\hline Period 1-2 vs. $3-6$ & & & & & & .22 \\
\hline Model F & $7.19^{\text {**** }}$ & $6.64 * *$ & $6.47 * *$ & $5.94 * *$ & $5.62 * *$ & $5.51 *$ \\
\hline $\mathbb{R}^{2}$ atifi. & .31 & 39 & .38 & 35 & .34 & .33 \\
\hline \multicolumn{7}{|l|}{ Analysis of cowariance (ANCOVA) } \\
\hline F(Team type) & $7.19 * *$ & $8.30^{* * *}$ & $8.20 * *$ & $8.33^{* * *}$ & $8.08^{* * *}$ & $8.01 * *$ \\
\hline F(Covariate) & & $3.89^{\circ}$ & $3.55 t$ & 2.55 & 1.93 & 1.73 \\
\hline
\end{tabular}

${ }^{1} n=28$. Dependemt variable is the average return on equity in dynamic environments. Unstandardized regression coefticients are reported. Significance of model $F$ and wo-tailed significance levels of coefficients: tp< $10 ;{ }^{*} p<05 ; * 0<01$.

The same two-step regression analysis with team type dummy coding was used as in the previous empirical chapters. Only the general pooled change measures (column 2 and 3 ) indicate that more change leads to a marginally higher return on equity. The changes from early to late periods (columns 4 to 6 ) do not. The relative ordering of teams as expressed in the size of the team dummy variables is not affected by the main effect of change. In fact, the difference between internal and external teams (as expressed in the internal team dummy) gets larger if we control for change. This implies, that change serves as a suppressor of the actually even stronger difference between internal and external teams. This can be explained by the fact that externals change significantly more than internal teams which apparently improves performance in dynamic environments. Indeed the correlations between mean relative change and mean relative weighted change on the one hand and mean profitability on the other amount to $.28(p<10$, one- 
tailed test) and .26 ( $\mathrm{p}<.10$, one-tailed test), respectively in dynamic enviromments ${ }^{\text {i4. }}$. Therefore, extemal teams compensated somewhat for their bad performance because their generally higher change activity payed off. Conversely, internals" performance is somewhat impeded because they do not change so much. Externals" (small) gain through change is however unlikely to be the result of a conscious policy on their part, as they did not differ in change behavior between stable and dynamic enviromments. Rather, it looks like a fortunate but unintended consequence of externals hyperactive behavior in dynamic circumstances: you can"t be wrong all of the time by changing ways. The backdrop of extemal teams after controlling for change activity can also be seen from their higher proximity to mixed teams in columns 2 and 3 of Table 8.10. The bottom line, however, is that change or adaptation is not an important variable to explain the differences in performance between teams, at least not in the way it was treated in this chapter. The indirect evidence in the other chapters is more convincing. That is, adaptive behavlor is an underlying rumning thread in many analyses of the previous chapters.

We may conclude that internal and external teams differ importantly in their adaptive behavior. External teams exhibit a kind of restless behavior which is rather unfocussed or unrelated to environmental circumstances. Internal teams, on the other hand tend to be much more persistent in the courses of actions they choose. Moreover, their reactions to signals that their current policies are unsuccessful (i.e., negative feedback) tend to be more controlled or well-balanced in comparison to the wider variation in change teactions that externals exhibit. This may be taken as an indication that internal teams are better able to strike the subtle balance between persisting (i.e., inertia) and adapting their behavior (i.e., flexibility). In fact, in the economic literature (Spencer and Brander, 1992; van Witteloostuijn, 1994, Boone and van Witteloostuijn, 1994) finding such an optimal level of change has repeatedly been proposed as a crucial factor in surviving turbulent environments. A normative implication of our findings may therefore be, that internal management teams will be better able to find the optimal level of change than other management team types.

Some limitations to our conclusions can be mentioned. First, we chose to operationalise adaptation as changes in a set of variables that were relatively easy to change in direct response to for instance bad performance. This implies that they are almost by definition more tactical than strategic in nature. Genuine strategic changes, as they are studied in real world samples by, for instance, Hambrick, Seung-Cho and Chen (1996: 665) "involve large outlays, long time-horizons, great departures from the statusquo and are difficult to reverse". Our game-environment is not very suitable for siudying these kinds of large-scale changes in response to performance. For instance, one such truly strategic move, executing a planned capacity-increase, takes three game periods before it takes effect (expansion decision (period 0), expanded production (period 1), sales of expanded production (period 2), revenue of expanded production (period 3 )). Consequently, it is unlikely that teams have reacted to immediate performance declines

In stable enwironments the correlations are -13 and -.15 , both insignificant. 
with these kinds of massive decisions. At best, these kinds of strategic decisions are undertaken as part of an overall strategic course that is set out well in advance. In our operationalization we rather followed the methods used in the more recent literature on competitive action repertoires (Miller and Chen, 1994, 1996; Chen and Hambrick, 1995). In this approach sets of decisions are conceived of as a repertoire of actions companies use to compete. These repertoires are studied for their scope, simplicity or indeed stability in reaction to environmental disturbances. This is exactly what we tried to do in the current chapter. Our conclusions must therefore be seen as pertaining most to changes in competitive repertoires instead of strategic changes in the conventional sense.

Second, being exploratory, our statistical methodology was rather bold. Periodby-period correlations within subgroups were often based on low numbers of observations, which necessarily lowers statistical power. These methods are therefore quite conservative and "demanding' of the clata. The real subtleties of adaptation over time would probably be better brought out by less restrictive methods that make use of all data simultaneously. A possible candidate is event history analysis using the complete pool of data at once. A related sophistication of method may involve the analysis of the various (four) decision categories separately. This may reveal decision categories that are in fact much more amenable to change than others, a subtlety that is lost in the currently used method.

In future research, various extensions to the analyses applied in our study can be made. We list some possibilities. First, it must be recognized that our conception of adaptation in response to results is actually only one out of many. Consequently, adaptation can be studied in many more ways (see e.g. Haveman 1992, 1993). For instance, the underlying logic of adaptation patterns may involve mimicking behavior. That is: teams" action change may depend less on their own results, but rather on the actions of other participants. Thus, teams may simply copy what the best performing competitor does, or they may try to follow some kind of industry average. Another possibility to study adaptation is to look at teams' reactions to external shocks. One might be interested how a rather homogeneous (i.e., equal for all) instant change in the environment differentially affects the strategic choices of different team types. Second, in the current study the impact of decreasing results on adaptation are analyzed regardless of their starting point. Therefore, an obvious extension of our analyses might be to investigate whether change reactions to decreasing results differ (i) if the decrease takes place entirely in the positive results (i.e., profits) domain, (ii) if results switch from positive to negative (i.e., from a profit to a loss), or (iii) if a negative result (i.e. a loss) gets worse. This is an important point again from the viewpoint of Kahneman and Tvesky's (1979) prospect theory stating that people are generally more risk taking in the domain of losses than in the domain of gains. This would imply that change may be expected to be higher as one moves from situation (i) to (iii). Similarly, the 'panicking reaction' of externals is likely to be more prominent in the 'turnaround situation'(ii) as compared to situation (i) and (iii). 
Summary, conclusions and outlook 

In this final chapter we will first (in section 2) provide an overview of our main arguments and findings in this study. We will then broaden our scope by identifying the main contributions we feel our research makes to the existing body of knowledge in a number of areas (section 3). Finally, in section 4 , we conclude by identifying limitations and possible future extensions to our work.

\section{Summary of study setup and findings}

Over the past 20 years a host of books and articles were devoted to managers/ owners of (commercial) businesses. The (often implicit) idea behind this interest is, that in many companies the manager's influence is so big, that the decisions taken carry a distinct mark of their originator's character. In other words: the personal background of the manager is thought to be reflected in the company's actions. If this line of reasoning is extended to managing teams, being small collectives of powerful individuals, we may expect comparable influences of the particular composition of teams on their company's decisions, actions and results. Hambrick and Mason (1984) captured the latter idea in a theoretical framework that came to be known as the upper echelons model or theory. In this model the focus is on the impact of team composition variables (e.g., average and spread of age, tenure, functional and educational backgrounds) on dependent variables like profitability, growth, innovativeness and strategic direction. The upper echelons model spawned a multitude of empirical studies testing its hypotheses in the following decades.

In Chapter 2 we critically reviewed a number of these studies and concluded that the empirical field is still very fragmented and methodologically flawed. Moreover, no attempt has been made as yet to include team member personality variety as an explanatory variable of strategic firm behavior. Because of its proven validity in the study of individual managers, as shown in Chapter 3 , we chose to research the impact of a team's composition with regard to its members' control perceptions on a team's actions and results in a simulated business setting. Of 252 individuals forming 58 participating teams, the locus of control was measured using a validated personality inventory. These individuals could then be classified as holding either more internal or more external perceptions of control. In order to classify teams according to their members' locus of control, we designated teams consisting of more than two-third internal members as an internal team and teams with more than two-third external members as an external team. Teams with relatively balanced numbers of internals and externals were designated 'mixed teams'. These procedures and our data are described in detail in Chapter 4.

After the Chapter 3 review of individual psychological research using the locus of control concept, we developed a conceptual framework in order to explain performance differences between differently composed teams. This framework was based on the stylized fact that internals are better managers than externals. Assuming that these tendencies would translate to the team level, we expressed the metahypothesis that the superiority of internal teams over external teams may be caused by either superior strategic choices (Chapter 6) and/or by superior strategy making (Chapters 7 and 8). Strategy making in our view consists 
of three interrelated processes. First is environmental scanning through relevant information gathering (Chapter 7); second is the taking of consistent and planned action (also in Chapter 7) and third is the adaptation of action patterns if necessary (treated in Chapter 8). Thus, internal teams are expected to be generally better at these strategy making skills than mixed and external teams. It is important to note that the impact of personality differences are generally more pronounced in relatively uncertain and ambiguous situations than in more secure and clearly structured situations. In our set-up this ambiguity relates to the amount of dynamism in the industry in which a team competes. We therefor expected the differences between team types to be generally greater in dynamic than in stable industries.

In the empirical chapters 5 to 8 we formally tested our hypotheses. The following serves as a review of our main findings.

In chapter 5 we started by looking whether internal teams, because of their skills, did indeed perform better (in terms of profits and market shares) than did mixed and external teams. This appeared to be the case and the difference was strongest in dynamic environments where team type explained almost $40 \%$ of all variation in profitability! It was, however, not external but mixed teams that did worst. The idea that mixing personality types would be beneficial in dynamic environments was strongly rejected, indicating to the contrary, that in these circumstances it is better to be alike than to be different. This implies that simply adding internals to a team can lead to lower performance if the result is a mixed team! The bad record of mixed teams may have something to do with their difficulty in reaching social team integration because of their personality differences. This handicap may have proved to be especially crucial in dynamic environments. Possibly, if we had witnessed these teams over a longer period of time, they might have overcome their difficulties and realized their potential.

In a first attempt at explaining the performance differences between team types, we looked at the specific content of their strategic choices in Chapter 6 . Possibly, internal teams were better because they engaged in the more profitable actions. The existing literature indicated three types of strategic preferences on which intemal and external people may differ: internals should be more innovative, risk-taking and cooperative. "These general differences were not found. Instead, internal teams innovated and cooperated more only in dynamic environments where a strong association exists between these choices and profitability, but not in stable environments where these associations do not exist. This indicates, that internal teams do not systematically make different decisions, but hat they tailor their choices to ensuing circumstances. This will prove to be a recurrent finding.

With regard to differences in strategy making, i.e. the way in which strategies are shaped, the following was found in chapter 7 and 8 . First we focussed on the scanning of the environment, i.e., on the extent of informed action. Contrary to our expectations, team types did not appear to differ in the amount of money they spent to buy information. However, when we look at the degree to which specilic actions were preceded by a relevant (for that decision) information request, important differences did appear. Internal teams turned out to be belter informed than external teams on matters that indicated the effectiveness of their own behavior. This points at a certain pragmatism from the side of internal teams: they are 
most interested in what their own actions can accomplish. Not that this fits perfectly with their internal control perceptions. External teams, on the other hand, appeared most keen on all kinds of information regarding the actions of competitors, that is: outward bound information. Our analysis showed, as common sense would dictate, that gathering information is stronger associated with profitability in dynamic than in stable environments. Internal teams seem to have grasped this point very well: they are more active at information gathering in dynamic than in stable environments. External teams again appear to be bad adaptors: they do exactly the opposite.

The second strategy making variable studied in chapter 7 , was the amount to which concerted action was taken. This should be reflected in planned, coherent and persistent action patterns. Concerning plaming, internal teams reached the highest overail quality of planning. It is, however, not external but mixed teams who do worst in this respect. As careful simultaneous fitting of various company processes is crucial in reaching good overall planning, mixed teams' integration weakness may have been a particularly serious drawback in this task. When we look at differences between stable and dynamic environments, we see that external teams plan better in stable environments, whereas internal teams plan better in dynamic environments. Planning quality was found to be stronger associated with financial success in dynamic than in stable industries, something which makes inturitive sense: bad planning is probably more costly in a fast changing environment than in the case of a predicable environment. Internal teams seem to have appreciated this idea: they plan more when planning is more important and (consequently) more profitable. In other words: they show more adapted behavior.

The coherence of strategies did not differ between teams. However, internal teams showed less internal coherence in dynamic than in stable environments. The opposite is true for external teams. This indicates, that internal teams defined 'looser' strategies in case of a changing environment than in case of a stable environment. Although this may be interpreted as an attempt to retain some strategic leeway in a changing context, this did not prove to be more profitable in our case. If we look at the persistence of strategic positions over time, no team type differences are found: all teams were equally persistent in their (not) holding on to a chosen strategic profile. Still, the by now familiar qualitative pattern surfaces again: internal teams are more persistent than other team types in stable environments (few reasons to change if the current course is satisfactory), but the team type differences vanish in dynamic contexts.

In the results reported it was shown that the superiority of internal teams is not due to what they do, but to what they do under what circumstances. It seems as though internal teams simply have a better 'feeling' for what behavior is most appropriate given the ensuing conditions: they adapt their behavior to fit the environmental contingencies. In chapter 8 we attempt to observe this 'adaptation effect' (i.e., the third aspect of strategy making) more directly by looking at strategic change activity and change reactions following the feedback teams received concerning their past performance. It turned out, that external teams were generally most restless: they changed course most regardless of their performance. Some kind of continuous unrest characterizes their behavior no matter what the circumstances. Negative performance feedback appeared to positively influence the amount of change of 
all teams only at the beginning of the game and not thereafter. We did find, as hypothesized, that external teams have more difficulty in making controlled reactions to negative feedback. That is: they either change a lot or only very little. Internal teams show more controlled change reactions to negative performance feedback.

Taken together, we may conclude that the crucial difference between internal and external teams appears to be their ability to find responses that suit the environmental demands of the moment. Internal teams are generally better at doing that than are external teams. Compared to both homogeneous internal and external teams, mixed teams appear to suffer from a handicap of poor social integration which may, however, diminish over time. We may infer from all this, that in fast changing and uncertain task environments it is best to form a team consisting of internal members, as they have great capabilities of confidently steering themselves through the vagaries of such contexts. In relatively stable and predictable task environments, personality effects are generally much weaker if clear behavioral guidelines exist. Still, external teams seem especially well suited in these types of environments. In fact they may be especially motivated for and good at scrupulous tasks of planning and coordinating, i.e., in bureaucratic work. Given that such stable contexts provide little opportunities for personal control, it is likely to bore and undermine the motivation of internal teams. Making internal teams perform these kinds of work is therefor a waste of resources. On the other hand putting external teams in complex and dynamic situations is likely to overburden their coping mechanisms leading to confusion and strategic drift. Contrary to the often acclaimed benefits of team variety, we are inclined to recommend no mixing of extremes of this particular personality trait within teams. This recommendation against mixed teams is, however, provisional as their social dynamics and behavior in the long run are not yet fully understood. Apart from these recommendations of matching team types to (task) environments, it is important to stress that payoff of teamwork can only occur when teams have great latitude of action. In other words: they need authority and ample resources ("empowerment") in order to realize their potential. This will lead to empowered teans functioning in environments that have greatest reinforcing power on the things they are good at.

\section{Main scientific contributions}

We think this study has contributed to our understanding in three related areas of inquiry, i.e., team studies in the upper echelons tradition, individual differences at a team level and organizational economics. We will discuss these three below.

First, regarding the upper echelons tradition, we answered a repeated call for the inclusion of psychological variables in the study of team composition. Our effort in this respect was rather successful, as in the end we were able to explain about one third of all performance variation in dynamic contexts by the teams' locus of control make up. Furthermore, we were able to indicate and test several mechanisms through which this influence is brought about. It is important to note, however, that our success was critically dependent on the extensive theoretical and empirical past research that exists in relation to locus of control. Psychological studies have produced many findings on individual 
differences regarding, for instance, attention, information handling, risk taking and adjustment. Past locus of control research already showed its relevance in management settings, although the richness of the construct was not yet fully exploited, especially with regard to the process of strategy making. The point we want to make is, that in isolating psychological variables for upper echelons studies it is very important that they have a strong face validity in relation to the management task under study, plus preferably an extensive background of empirical and theoretical research. This is necessary not only to predict effects, but also to interpret and test explanations of why the effects occur. The latter is a general weakness in most upper echelons studies to date which we tried to overcome in the present study by explicitly testing the intermediate mechanisms that are expected to produce the performance differences. Furthermore, a strong theoretical background also enables to predict interactions with situational variables. Moderating effects are not yet very often tested in upper echelons studies, possibly because their specification would involve more precision than available theory and research findings allow for. In our study, environmental dynamism tumed out to be an extremely important moderator variable as many effects predictably differed between dynamic and stable circumstances. Finally, we followed the call to broaden upper echelons studies through experimental methods. Our research underscores the potential fruitfulness of using the experimental method to deepen our knowledge of management team composition effects. For instance, a classic problem in upper echelons studies has been the identification of the top group of people that really take the important decisions. Usually very bold and imprecise methods were used to identify the main players at the top, e.g., formal positions stated in standard corporate reference books. We narrowed down the group of decision makers by asking team members to rate each other's relative participation. This enabled us to prevent the diluting effect of "bystanders" characteristics on team composition variables and define a 'cone team' of influential decision makers. In doing so, our measurement precision was enhanced. Other important benefits of experimental (team) studies which we exploited, was the complete control over game-related information input for decisions, a complete transparency of actions/decisions and a highly comparable decision environment. All three are much more difficult to obtain in teal company samples.

Second, we also tried to contribute to the study of individual differences at a group level. We showed that individual differences in control perceptions can have predictable effects on the level of the group as well. Specifically, we were able to show that behavioral tendencies of individuals tend to show up in group actions and results as well if a majority of its members carry internall or external characteristics. However, it is obvious, that the group adds a layer of complexity to the effects of individual properties as the interaction among members enters the picture. This is why we included the mixing hypotheses in Chapter 5 . Although not observed directly, the bad results of mixed teams and their planning difficulties indirectly hint at social and/or cognitive integration difficulties in heterogeneous groups. The main question to be answered then, is: to what extent are group actions and outcomes determined by individual tendencies on the one hand and social forces on the other? In other words: under which circumstances (or when) do certain social factors outweigh individual differences in determining group actions and outcomes? In this respect it should be noted, that we have trodden on dangerous ground between social science 
disciplines. Historically, a heated debate exists as to the proper level of analysis in group research. Social psychology, its prime discipline, is divided in a number of factions that have, over time, shown an increasing isolation vis-à-vis each other (House, 1977). Broadly speaking there is a clash between bottom up approaches, describing group behavior from the perspective of the individual and top-down approaches looking at the impact of group phenomena (especially group structure) on individuals. The first approach emanates from psychology, the second from sociology. Various writers on social psychology have identified this divide, even calling it a 'crisis' in the advancement of social psychology and plead for a reconciliation of the two'. In essence, it boils down to a very old problem in social science centering around the exact interplay between the individual and the collective (Allport, 1962). Our own research stumbled upon this issue as we could explain group outcomes by reference to the accumulation of certain individual characteristics (in case of the internal and external teams), but were only partly and indirectly able to explain the actions and outcomes of teams with heterogeneous compositions (mixed teams). To get out of the crisis, Steiner (1986: 285) contends that "(...) it is not my contention that individualistic social psychology should somehow be suppressed and replaced by a more "groupy" variety. But individualistic social psychology should be combined and coordinated with an almost nonexistent social psychology of collective behavior, without which it often provides a distorted picture of the individual's functioning". We think that the same holds for the functioning, behavior and outcomes of the group: individualistic and social factors should be studied concomitantly in order to do justice to their intricate interplay in determining outcomes.

Third, we tried to contribute to the field of organizational economics by showing the potentials for explaining economic behavior when the assumption of homogeneous decision makers is abandoned. When confronted with similar economic problems and trade-offs, we showed that people's behavior is importantly affected by their assessment of the environment and of their possibilities to influence the outcomes of their actions. In short: economic decision making, both individually and in groups is predictably influenced by aspects of personality, in our case control perceptions.

\section{$4 \quad$ Limitations and future research}

Below we will discuss five areas in which our work can be extended in future.

The external validity of the current study critically depends on the realism of the simulation that was offered. We think that the game, the population of subjects and the incentives, provided a realistic mirror of business decision making and competition in a market of monopolistic competition between five firms. We already elaborated on that point in Chapter 4 . However, in the end a simulation always remains a simplification of reality ${ }^{2}$

\footnotetext{
'For elaborate treatments on the laborious relationship between psychology and sociology regarding this issue see Alport (1962), Steiner (1974), Archibald (1976), House (1977), Stryker (1977), Backman (1983) and Steiner (1986)

${ }^{2}$ Note that in order to be externally valid with regard to complexity, the game does not need to be as complex as a real business environment. Given people $=s$ cognitive limits on processirg information (Simon 1955; 1957 ), it only needs
} 
where the ultimate test should take place. An obvious next step therefore, is to test the stated hypotheses in samples of real management teams in business. In order to do this, careful selection of the research population is warranted not to fall victim to the weaknesses of past upper echelons research. In particular, it is important, first, to select industries that clearly differ in terms of relevant research variables, like in our case envirommental or industry dynamism. This enables the testing of (interaction-) hypotheses between environmental settings. Second, it is important that firm management within the industry has considerable (preferably high) managerial discretion, that is: management's impact on firm decisions to be studied must be strong. Thind, a precise delmeation of the dominant coalition to observe must be established. This rules out corporate reference books and calls for more intensive methods like interviews, sociometry (Moreno, 1960) or, very promising, network analysis (Collin, 1998). We think that only this kind of measurement precision and research set up can deepen our insights into the effects of (psychological) team composition.

A second area that needs attention in future research is the social process by which team composition affects organizational outcomes. This has hardly been investigated in upper echelons studies at large. Our own research only indirectly hinted at the importance of social interaction between (mixed) team members in determining outcomes and it is perfectly conceivable that much of the relative success of internal teams is also explainable by the way they dealt with each other. Our review in Chapter 3 hinted at many possible theoretical and empirical starting points for studying internals' and externals' group behavior. Of course a wealth of more general studies into group interaction, functioning or structuring already exists in the group dynamics literature (see, for instance, Shaw (1981) or Forsyth (1990)). When pursued, this future line of research requires methods of close and structured observation of group processes using, for instance, interaction process analysis (Bales, 1950; 1980). Close observation of real management teams may, however, run into practical difficulties as the teams should grant the researcher repeated access to their meetings. If this problem is encountered, the only ways to resolve it will be to study either more easily accessible groups with comparably difficult tasks or to start off with in-depth case studies and comparisons of only a few top teams that are willing to lend full cooperation. More experimentally-oriented methods may also be used to investigate how control perceptions in a group affect its internal functioning.

Third, research should be aimed at studying team composition effects using longer time-windows. Most TMT research to date ${ }^{3}$ employs cross-sectional data which make it impossible to infer the causality of various effects. Moreover, many important issues in strategy making, for instance adaptation research, can only be studied in a longitudinal fashion. Especially strategic reorientation procesess often (but not always) take many years to be designed and implemented. But top management teams themselves also change over time and the changing or replacement of top managers has in fact been proposed and studied as a conscious adaptation method of itself (Schreuder et al., 1991; Hambrick and D'Aveni,

to have a complexity beyond man $=$ s cognivive processing limits in order to be realistic from the player=s viewpoint. That is: it should be complex enough, which we think the current game is.

${ }^{3}$ The swdies by Hambrick and $\mathrm{D}=\mathrm{A}$ ven $(1988,1992)$ are important exceptions. 


\section{8; 1992).}

Fourth, interesting avenues for future research in upper echelons exist in the area of top management team formation, i.e., in the question as to what individual characteristics are important to get to the top. In taking an evolutionary point of view, it may be very worthwhile to study the selection and attraction of managers into organizations and top positions. As we already indicated, these selection criteria may differ substantially between industries as well as between individual organizations. What are these (implicit) selection criteria? How are profiles of suitable manager characteristics in organizations or industries formed and how does selection based on individual characteristics into higher echelons take place? Do management teams simply 'reproduce' themselves or do suitable management profiles change over time? If so: what are the circumstances that trigger adaptations in the selection processes? On the other hand, different individuals may be attracted to careers in different types of organizations and industries. What are the differences between these individuals? Do they screen organizations for a match with their personal characteristics and if so: how? Does this match have an effect on their carcer advancement?

A final proposal for future research is in the broadening of upper echelons studies to a higher level of analysis, like for instance economic sectors, industries, business groups or managerial elites that connect various organizations or industries. It is still an open question whether and how psychological characteristics of teams of economic decision makers affect (larger parts of) the economy. In industries with unconstrained and influential management teams, these teams are more likely to have their personality make-up reflected in their policies than lame teams that have their hands tied to their backs. Consequently, economic business behavior is more likely to be 'personalized' in the former than in the latter industries. Note however, that personality effects on the level of economies will only be traceable if between-sector variation in the personality of management teams is higher than within-sector variation. This is not at all implausible. Personalities in different subsections of the economy may well differ because the composition of the economy's managerial elite is ruled by social and economic attraction and selection forces determining who gets to the top and who does not (Schneider, 1987). The basis on which people are selected and attracted (in)to jobs may vary between different subsections of the economy, thus creating differentiation of types of people in different subsections. For instance, stable or bureaucratic environments may provide an attractive and motivating employment setting for persons that like a clear, secure and directing environment (i.e., externals), whereas it is boring and frustrating for people who want to mould their own environment and like to feel in control (i.e., internals). A good match between job environment and personality is likely to lead to more motivation and upward mobility. Thus, externals may be attracted to and promoted in different industries or environments than internals. This will in turn influence and/or strengthen the social and economic behaviorall properties of these industries. Likewise, the economic and legal circumstances under which entrepreneurs are to start new businesses co-determines the (psychological) composition of the pool of successful entrepreneurial talent through a similar attraction and selection process. This will in turn affect the extent and mix of new economic initiatives and the structure of the economy. Technical industries (steel, chemicals) are also likely to attract different people than 'social' industries (advertising, marketing, consultancy). These are just a few examples of 
mechanisms that warrant future research at higher levels of analysis. This kind of research adds an interesting (macro-)sociological flavor to the study of very powerful upper echelons with far-reaching influence on entire business systems or economies. Again, this type of research is not easy, but its potentials seem worth the effort. 



\section{References}

Abrahamson, N. (1992), Factors influencing the entry of Canadian software manufacturers into the United States market, Unpubished doctoral dissertation, The University of Western Ontario.

Aczel, A.D. (1993), Complete business statistics, second edition, Hornewood, II: Irwin.

Alchian, A.A. and Demsetz, H. (1972), Production, infornation costs and economic organization, American Economic Review, 62: 777.795.

Allison, P.D. (1978), Measures of inequality, American Sociological Review, 43: 865-880.

Allport, F.H. (1962), A structuronomic conception of behavior: individual and collective. I. Structural theory and the master problem of social psychology, Journal of Abnormal and Social Psychology, 64: 3-30.

Alutro, J.A. and Hrebiniak, L.G (1975), Research on commitment to employing organizations" preliminary findings on a study of managers graduating from engineering and MBA programs, Paper presented at the Academy of Management meetings $s_{2}$ New Orleans.

Ancona, D.G. and Caldwell, D.F. (1992), Demography and design: predictors of new product team performance, Organization Science, $3: 321-341$

Anderson, C.R. (1977), Locus of control, coping behaviors and perfornance in a stress setting: a longitudinal study, Journal of Applied Psychology, 62: 446-451.

Anderson, C.R. and Schneier, C.E. (1978), Locus of control, leader behavior and leader performance among management students, Academy of Management Journal, 21:690-698.

A.ndrisani, P.J. and Nestel, G. (1976), Internal-external control as contributor to and outcome of work experience, Journal of Applied Psychology, 61: 156-165.

Archibald, W.P. (1976), Psychology, sociology and sacial psychology: bad fences make bad neighbours, British. Journal of Sociology, 27: 115-129.

Asch, S.E., (1956), Studies of independence and a minority of one against a unanimous majority, Psychological Monographs, 70, whole issue no. 416.

Aspinwall, L.G. and Taylor, S.E. (1992), Modeling cognitive adaptation: a longitudinat investigation in the impact of individual differences and coping on college adjustment and perfornance, Journal of Personality ant Social Psychology, 63: 989-1003.

Backman, C.W. (1983), Toward an interdisciplinary social psychology, Advances in Experimental Social Psychology, 16: 219-261.

Bales, R.F. (1950), Interaction process analysis: a method for the study of small groups, Reading, MA: Addison Wesley.

Bales, RF. (1980), SYMLOG case study kät, New York: The Free Press.

Bantel, K.A. and Jackson, S.E. (1989), Top management and innovations in banking: does the composition of the top team make a difference?, Strategic Management Journal, 10: 107-124.

Bar-Tal, D. and Bar-Zohar, Y. (1977), The relationship between perception of locus of control and academic achievement, Contemporary Educational Psychology, 2: $181-199$.

Bass, B.M. (1990), Bass and Stogdill"s handbook of leadership: theory, research and managerial applications, third edition, New York: The Free Press.

Batlis, N.C. (1978), Relationship between locus of control and instrumentality theory predictors of academic performance, Psychological Reports, 43: 239-245.

Becker, M. (1970), Sociometric location and innovativeness, American Sociological Review, 35: 267-304.

Begley, $\mathbb{T}$.M. and Boyd, D.P. (1987), Psychological characteristics associated with perfornance in entrepreneurial firms and smaller businesses, Journal of Business Veniuring, 2:79-93.

Belbin, R.M. (1981), Mamagement teams: why they succeed or fall, London: Heinemann.
Benassi, V.A., Sweeney, P.D. and Dufour, C.L. (1988), Is there a relation between locus of control and depression?, Journal of Abnormal Psychology, 97:357-367.

Bialer, 1. (1961), Conceptualization of suecess and failure in mentally retarded and nomal children, Journal of Personality, 29: 303-320.

Bildersee, J.S. (1975), The association befween a marketdetemined measure of risk and alternative measures of risk, The Accounting Rewiew, 50:81-98.

Blaylock, B.K. (1983), Teamwork in a simulated production environment, Research in Psychological Type, 6 : 58 67.

Bollen, K.A. (1989), Structural Equations with Latent Variables, New York: John Wiley \& Sons.

Boone, C. (1992), Research into the relationship between managers' perception of control and strategy and performance of companies in the furniture findustry, Antwerp: State Uniwersity Center. 
Boone, C. and De Brabander, B. (1993), Generalized versus specific locus of control expectancies of chief executive officers, Strategic Management Journal, 14:619-626.

Boone, C., De Brabander, B. and Geris, P. (1991), Perception of control and information-search strategy in an investment decision game, Perceptual and Motor Skills, 72: $39 /-398$.

Boone, C., De Brabander, B., Gerits, P. and Willeme, P. (1990), Relation of scores on Rotter's L-E scale to shorrteam control expectancies and fatalism, Psychological Reports, 66: $1107-1111$

Boone, C., De Brabander, B. and van Witteloostuijn, A. (1995), Het adaptievermogen van organisaties, Maandblad woor Accountancy en Bedrififseconomie, 69:690-705.

Boone, C. De Brabander, B. and wan Witteloostuin, A. (1996), CEO locus of control and small firm performance an integrative framework and empirical test, Journal of Management Studies, 33: 667 -699.

Boonc, $C_{r}$ De Brabander, B. and van Witteloostujin, A. (1998), The impact of personality on behavior in the prisoner's dilemma ganes, Research Memorandum, Maastricht University: NRBOR

Boone, C. and wan Wifteloostuin, A. (1994), Hypercompetitive rivalry: flexibility, inertia and performance, Research Memorandum, Mastricht University: NIBOR.

Boone, C. and van Witteloostuign, A. (1996), Industry competition and firm human capital: the cases of the Flemish furniture and Dutch andit industries, Small Business Economics, 8: 1-18.

Botwilick, J. (1977), Aging and behavior, New York: Spanger.

Bowman, E.H. (1980), A risk/return paradox for strategic management, Sloan Management Review, $21: 17-31$.

Bownan, E.H. (1982), Risk seeking by troubled furms, Sloan Management Review, 23: 33-42.

Brockhaus, R.S. (1975), I-E locus of control scores as predictors of entrepreneurial intentions, Academy of Management Proceedings.

Brockner, J. (1992), The escalation of commitment to a faling course of action: toward theoretical progress, Acaderny of Management Review, 17: 39-61.

Burgelman, R.A. (1991), Intraorganizational ecology of strategy making and organizational adaptation: theory and field research, Organization Science, 2: 239-262.

Burke, D. and Light, L.L. (1981), Mernory and aging: the role of retrieving processes, Psychological Bulletin, 90: $513-546$.

Burke, R.L. and Bennis, W. (1961), Changes in perception of self and others during human relations training, Fuman Relations, 14: 165-182.

Byrne, D. (1969), Attifudes and attraction, New York: Academic Press.

Byme, D., Clore, J.L., and Worchel, P. (1966), Erfect of economic similarity dissimilarity on interpersonal attraction, Journal of Personality and Social Psychology, 4: 220-224.

Carlsson, $G$. and Karisson, $K_{\text {. }}(1970)$, Age, coltorts and the generation of generations, American Sociological Review, 35: 710-718.

Chaganti, R. and Sarnbharya, R. (1987), Strategic orientation and characteristics of upper management, Strategic Management Journal, $8: 393-401$.

Chen, M-J. and Hambrick, D.C. (1995), Speed, stealth and selective atrack: how small fims differ from large firms in competitive behavior, Acadeny of Management Journal, 38:453-482,

Child, I. (1972), Organizational structure, environment and performance: the role of strategic choice, Sociology, $6:$ 1.22.

Chidd, J. (1974), Managerial and organizational factors associated with company performance - Part I, Journal of Management Studies, $11: 175-189$.

Ciborra, C.U. (1993), Teams, markets and systems. Business innovation and information technology, Cambridge: Cambridge University Press.

Cohen, J. and Cohen, P. (1983), Applied multiple regression/correlation analysis for the behavioral sciences, second edition, Hillsdale, New Jersey: Lawrence Erbaum publishers.

Collin, 5.-O. (1998), Turnover and heterogeneity in networks. A demographic analysis of two Swedish business groups, Paper presented at the 14 th EGOS Colloquium at Maastricht, The Netherlands.

Cook, H, and Chi, C. (1984), Cooperative behavior and locus of control among American and Chinese-American boys, Journal of Psychology, 118:169-177.

Cook, H. and Sloane, J. (1985), Locus of control and cooperative behavior in 10-year old children, Journal of Social Psychology, 125: 619-630.

Cozzarelli, C. (1993), Personality and self-efficacy as predictors of coping with abortion, Journall of Personality and Social Psychology, 65: 1224-1236.

Crowne, D.P. and Liverant, S. (1963), Conformity under various conditions of personal conmiment, Journal of Abnormal and Social Psychology, 66:547-555.

Cyert, R.M. and March, J.G. (1963), A behavioral theory of the firm, Englewood Cliffs, NJ: Prenticen-Hall. 
Davis, W.L. and Davis, D.E. (1972), Intemal-extemal control and attribution of responsibility for success and failure, Journal of Personality, 40: 123-136.

Davis, W.L. and Phares, E.J. (1967), Internal-external control as a determinani of information seeking in a social influence situation, Journal of Personality, 35: $547-561$.

De Brabander, B. and Boone, C. (1990), Sex differences in perceived locus of control Journal of Social Psychalogy, 130: 271-272.

De Brabander, B., Boone, C. and Gerits, P. (1992), Locus of control and cerebral asymmetry, Perceptual and Motor Skills, 75: 131-143.

Dearborn, D.C. and Simon, H.A. (1958), Selective perception: a note on the deparmental identification of executives, Saciometry, $21: 140-144$.

Delacroix, J. and Swanninathan, A. (1991), Cosmetic, speculative and adaptive organizational change in the wine industru: a longitudinal study, Administrative Science Quarterly, 36: 631-661.

Dollinger, M. (1984), Environmental boundary spanning and information processing effects on organizational performance, Academy of Managenent Journal, $27: 351-368$.

DuCette, J. and Wolk, S. (1973), Cognitive and motivational cortelates of generalized expectancies for control, Journal of Personality and Socüal Psychology, 26:420-426.

Durand, D.E. and Shea, D. (1974), Entrepreneurial actiwities a function of achievenent motivation and reinforcement control, Journal of Psychology, 88:57-63.

Eisenhardi, K.M. and Schoonhoven, C.B. (1990), Organizational growth: linking founding tean, strategy, environment, and growth anong U.S. semiconductor ventures, 1978-1988. Administrative Science Quarterly, 35: 504-529.

Eisenstadi, SN. (1956), From Generation to Generation: Age Groups and Social Structure, Glencoe, LL: Free Press.

Fiegenbaum, A. and Thomas, H. (1988), Attitudes toward risk and the risk-return paradox: prospect theory explanations, Academy of Management Journal, 31: 85-106.

Filley, A.C., House, R.J. and Kerr, S. (1976), Managerial process and organizational behavior, Glenview, IL: Scott Foresman.

Finkelstein, S. and Hambrick, D.C. (1990), Top-managementweam tenure and organizational outcomes: the moderating role of managerial discretion, Administrative Science Quarterly, 35:484-503.

Finkelstein, S. and Hambrick, D.C. (1996), Strategic leadership. Top executives and their effects on organizations, St. Paul, MN: West Publishing Company.

Forsyth, D.R. (1990), Group Dynanics, second edition, Brooks/Cole Publishing Company, Pacific Grove: Califormia.

Foster, G. (1986), Financial statement analysis, second edition, New York: Prentice-Hall International

Frederickson, J.W. and Mitchell, T.R. (1984), Strategic decision processes: comprehensiveness and performance in an industry with an unstable enwironment, Academy of Management Journal, 27: 399-423.

Ganelten, R.J. and Blaney, P.H. (1984a), Hardiness and social support as moderators of the effect of life siress, Journal of Personality and Social Psychology, 47: 156-163.

Ganellen, R.J. and Blaney, P.H. (1984b). Stress, externality and depression, Journal of Personality, 52: 326-337.

Gemmill, G.R. and Heisler, W.J. (1972), Fatalism as a factor in managerial fob satisfaction, job strain and mobility, Personinel Psychology, 25: 241-250.

Glass, D.C., Sirger, J.E. and Friedman, L.M. (1969), Psychic cost of adaptation to an environmental stressor, Journal of Personality and Social Psychology, $12: 200-210$.

Good, L.R. and Nelson, D.A. (1971), Effects of person-group and intra-group attitude similarify on perceived group attractiveness and cohesiveness, Psychonomic Science, 25: 215-217.

Goodstadt, B.E. and Hjelle, L.A. (1973), Power to the powerless: locus of control and the use of power, Journal of Personality and Social Psychology, 27: 180-196.

Gore, P.S. (1962), Individual differences in the predliction of subject compliance to experimenter bias, Ohio: State University.

Govindarajan, V. (1989), Implementing competitive strategies at the business tunit level: implicutions of matching managers to strategies, Strategic Management Journal, 10:25:-270.

Gregory, W.L. (1978), Locus of control for positive and negative outcomes, Journal of Personality and Social Psychology, 36: 840-849.

Gujarati, D.N. (1988), Basis econometrics, second edition, McGraw-Hill International Edition.

Gupta, A.K. (1984), Contingency linkages between strategy and general manager characteristics: a conceptual examination, Academy of Management Review, 9: 399-412. 
Gupta, A.K. and Govindarajan, W. (1984), Business wnit strategy, managerial characteristics, and business unit effectiveness at strategy implementation, Academy of Management Journal, 27:25-41.

Haleblian, I. and Finkelstein, S. (1993), Top management team size, CEO dominance, and firm performance: the moderating roles of enwironmental turbulence and discretion, Academy of Management Journal, 36: $844-863$.

Halfens, R.J.G. (1985), Locus of control: beheersingsoriëntatie in relatie tot ziekte- en gezondheidsgedrag (Locus of control: control orientation in relation to iliness and health behawior), Unpublished doctoral dissertation, Mastricht University.

Hambrick, D.C. (1987), The top mamagement team: key to strategic success, Californa Management Review, Fall: 89-108.

Hambrick, D.C. and D'Aveni, R.A. (1988), Large corporate failures as downward spirals, Administrative Science Quarterly, 33: 1-23.

Hambrick, D.C. and D'Aveni, R.A. (1992), Top team deterioration as part of the downward spiral of large corporate bankruptcies, Management Science, 38: 1445-1466.

Hambrick, D.C. and Finkelstein, S. (1987), Managerial discretion. a bridge between polar views of organizational outcomes, Research in Organizational Behavior, 9: 369-406.

Hambrick, D.C, Geletkanycz, M.A. and Fredrickson, J.W. (1993), Top management commitment to the status quo: some tests of its determinants, Strategic Management Journal, 14: 401-418.

Hambrick, D.C. and Mason, P.A. (1984), Upper echelons: the organization as a refection of its top managers, Academy of Management Review, 9: 193-206.

Hambrick, D.C., Seung Cho, T'. and Chen, M-J. (1996), The influence of top management team heterogeneity on firms' competitive moves, Administrative Science Quarterly, 41: 659-684.

Hannan, M.T and Freeman, J. (1977), The population ecology of organizations, American Jlournal of Sociollogy, 82: 929.964 .

Hannan, M.T. and Freeman, J. (1984), Struchural inertia and organizational change, American Sociological Review, 49: 149-164.

Hart, P. and Mellons, J. (1970), Management youth and company growth: a correlation?, Management Decision, 4: $50-53$.

Haveman, H.A. (1992), Between a rock and a hard place: organizational change and performance under conditions of fundamental environmental transformation, Administrative Sclience Quarterly, 37: 48-75.

Haveman, H.A. (1993), Organizational size and change: diversification in the savings and loan industry after deregulation, Administrative Science Quarterly, 38: $20-50$.

Hayes, R.H. and Abernathy, W.J. (1980), Managing our way to economic decline, Harvard Business Review, July-August: $67-77$.

Hitt, M.A., Ireland, R.D. and Palia, K.A. (1982), Industrial firm's grand strategy and functional importance: Moderating effects of technology and unceriainty, Academy of Management Journal, 25: 265-298.

Holland, J,L. (1985), Malking vocational choices: a theory of vocational personalities and work environments. second edition, Englewood Cliffs, NJ: Prentice-Hall.

Holmstrom, B.R. and Tirole, J. (1989), The theory of the firm, North Holland: Elsevier Science.

House, J.s. (1977), The three faces of social psychology, Sociometry, 40: 161-177.

Hurst, D.K., Rush, J.C. and White, R.E. (1989), Top management teams and organizational renewal, Strategic Maragement Journal, 10:87-105.

James, W.H. and Rotter, J.B. (1958), Partial and 100 percent reinforcement under chance and skill conditions, Journal of Experimental Psychology, 55: 397-403.

Janis, I.L. (1972), Victims of groupthink, Boston: Houghton Mifflin.

Jegers, M. (1991), Prospect theory and the risk-retum relation: some Belgian evidence, Academy of Management Journal, $34: 215-225$.

Jensen, M.P. and Karoly, P. (1991), Control beliefs, coping efforts and adjustments to chronic pain, Journal of Consulting and Clinical Psychology, 59:431-438.

Johnson, A.L., Luthans, F, and Hennessey, H.W. (1984), The rale of locus of control in leader influence behavior. Personnel Psychology, 37: 61-75.

Johnson, J.H. and Sarason, I.G. (1978), Life stress, depression and anxicty: internal-external control as a moderator variable, Journal of Psychosomatic Research, 22: 205-208.

Jöreskog, K.G. and Sörbom, D. (1993), LISREL (r) 8: Structural Equation Modeling with the SIMPLIS Command Language. Hillsdale: Scientific Software International, Chicago/Lawrence Erlbaum Associates. 
Jullan, J.W. and Katz, S.B. (1968), Internal vercus external control and the value of the reinforoment, Journal of Personality and Social Psychology, $76: 43-48$.

Katmeman, D and Twersky, A. (1979), Prospect theory: an antlysis of decisions under risk, Econometriea, 47: $263-291$

Karabonick, S.A. and Srull, T.K. (1978), Effects of personality and situational wariation in locus of control on cheating: Determinants of the "congruence effect", Journal of Personality. 46: $72-95$.

Katz, R. (1982), The effects of group longevity on project communication and performance, Admanistrative Scisnce Quarterly, 27:81-104.

Kelly, D. and Amburgey, T.L. (1991), Organzational inertia and momentum: a dymamic nodel of strateguc change, Acadeny of Management Journal, 34:591-612.

Kets de Vries, M.F.R. (1977), The entrepreneurial personality: a person at the crosscosds, Journal of Management Studies, $14: 34-57$.

Kets de Vries, M.F.R. (1980), Stress and entrepreneur, New Kork: Wiley.

Khan, A.M. and Manopichewattana, $V$. (1989). Innovative and nonimovative small finms: types and characteristics, Management Sciemce, 35: $597-606$.

Kimberly, J. and Evanisko, M. (1981), Organizational innovation: the infuence of the individual, organizational and contextual factors on hospital adoption of technological and administrative innovations, Academy of Management Journal, $24: 689-713$.

Kobasa, S.C. (1979), Stressful life events, personality and health: an inquiry anto handiness, Journal of Personality and Soicial Psychology, 37: $1-11$.

Krause, N. and Stryker, S. (1984), Stress and well-being: the buffering role of locus of control beliefs, Social Science and Meticine $18: 783-790$.

Lant, T.K., Milliken, F.J. and Batra, B. (1992), The role of managerial learning and interpretation in strategic persistence and reorientation: an empirical exploration, Strategic Managenat Journal, 13:585.608.

Lant, TH, and Montgonery, D.B. (1987), Leaming from strategic success and failure, Journal of Business research, $15: 503-518$.

Lefconti, H.M. (1982), Locus of control: current trends in theory and research, Hillsdale, NJ: Lawrence Erlbaum

Lefcourt, H.M., Lewis, L.E. and Silverman, I.W. (1968), Internal versus extemal control of reinforcement and attention in decision making tasks, Journal of Personality, 36: 663-682.

Lefout, H.M., Miller, R.S., Ware, E.E. and Sherk, D. (1981), Locus of control as a moditier of the relationship bewween stressors and moods, Journal of Personality and Social psyehology, 41: $357-369$.

Lefcourt, H.M. and Wine, J. (1969), Intenal versus external control of reinforcentent and the deployment of attention in experimental situations, Canadian fournal of Relhavional Science, 1: 167-181.

Lewin, A.Y. and Stephens, C.U. (1994), CEO attitudes as deterninants of organization design: an integrate model, Organization Studies, $15: 183-212$.

Lewin, K. (1948), Resolwing Social Conflicts, New York: Harper \& Row.

Lewin, $\mathbb{K}$. (1951), Field Theory in the Social Sciences, New York: Harper \& Row.

1. ot. A.J. and Lot, B.E. (1961), Group cohesiveness, communication level and conformify, Journal of Abnormal and Socilal P'sychollogy, 62: $408-412$.

March, 1. (19. (191), Exploration and exploitation in organizational leaming, Organization Schence, 2:71.87.

Warch, J.G. and Simon, H.A. (1958), Organizations, New York: Wiley.

Maznewsk, M.L. (1994), Understanding our differences: performance in decision making groups with diwerse members, Human Relations, $47: 531-549$

MCC (1994), Management Game Manual, Amsterdam: MCC lndemational b..$_{.}$

McCan. B.E, OReilly II, C.A. and Pfeffer, J (1983), The effect of departmental denography on turnover: the case of a university, Academy of Management Journal, 26: 626-641

Michel, J.G. and Hambrick, D.C. (1992), Divetsification posture and top management characteristics, Academy of Management Journal, 26:9-37.

Miller, D. (1983), The correlates of entrepreneurship th threv types of firms, Management sctenct, $29: 770-791$.

Miller. D. and Chen. M.-J. (1994), Sources and consequences of comperitive inertia: a study of the US arline industry, Administrative Science Quartery, $39: 1-23$

Millar. D. and Chen, M.-J. (1996), The simplicity of competitive repertoires, Strategic Management Journal, 17: 419.439.

Miller, D. and Friesen, F.H. 1980), Archetypes of organizational transition, Administrative Science Quarterly, $25: 268-299$. 
Miller, D., Kets de Vries, M.R. and Toulouse, J.M. (1982), Top executive locus of contral and its relationship to strategy-making, structure and environment, Academy of Management Journal, 25: 237-253.

Miller, D., Lant, T.K., Milliken, F.J. and Kon, H.J. (1996), The evolution of strategic simplicity: Exploring two models of organizational adaptation, Journal of Management, $22: 863-887$.

Miller, D. and Toulouse, J.M. (1986a), Chief executive personality and corporate strategy and structure in small firms, Managemeat Selence, 32: 1389-1.409.

Miller, D. and Toulouse, JM. (1986b), Strategy, structure, CEO personality and performance in small firms, American Journall of Small Business, $10: 47-62$.

Miller, J.Z. and Rose, R.J. (1982), Familial resemblance in locus of control a twin-family study of the internalexternal scale, Journal of Personality and Social Psychology, 42: 535-540.

Milliker, F.). and Martins, L.L. (1996), Searching for common threads: understanding the multiple effects of diversity in organizational groups, Academy of Management Review, 21: 402-433.

Mitchell, T.R., Smyser, C.M. and Weed, S.E. (1975), Locus of control: supervision and work satisfaction, Academy of Management Jourmal, 18:623-631.

Moreno, J.L. (1960) (ed), The Sociometry Reader, Glencoe, New York: The Free Press.

Mowrer, O.H. and Viek, P. (1948), An experimental analogue of fear from a sense of helplessness, Journal of Abnormal and Social Psychology, 43: 193-200.

Mullen, B. and Copper, C. (1994), The relation between group cohesiveness and performance: An integration, Psychological Bulletin。 11.5:210-227.

Murray, A.I. (1989), Top management group heterogeneity and firm performance, Strategic Management Journal, 10:125-141.

Norburn, D. and Birley, S. (1988), The top management team and corporate performance, Strategic Management Journal, 9:225-237.

Nunnally, J.C. (1978), Psychometric theory, second edition, New York: McGraw-Hill.

OBBien, G.E. (1984), Reciprocal effects between locus of control and job attributes, Australiam Journal of Psychology: 36: 57-74.

OReilly III, C.A., Caldwell, D.F. and Bamett, W.P. (1989), Work group demography, social integration and turnover, Administrative Science Quarterly, 34: 21-37.

Parker, L.E. (1993), When to fix it and when to leave it: relationships among perceived control, self-efficacy, dissent and exit, Journal of Applied Psychology, 78: 949-959.

Parkes, K.R. (1984), Locus of control, cognitive appraisal and coping appraisal and coping in stressful episodes, Journal of Personality and Social Psychology, 46:655-668.

Patrick, B.C., Skinner, E.A. and Connell, J.P. (1993), What motivates children"s behawior and emotion? Joint effects of perceived control and autonomy in the academic domain, Journal of Personality and Social Psychology, 65: 781-791.

Pelz, D. and Andrews, F.M. (1966), Scientists in Organizations, New York: Willey.

Pfeffer, J. (1983), Organizational demography, Research in Organization Behawior, 5: 299-357.

Phares, EJ. (1957), Expectancy changes in skill and chance situations, Journal of Abnormal and Social Psychology, 54: 339-3.42.

Platres, E.J. (1968), Differential, watilization of infonmation as a function of intemal-external control, Journal of Personality, 36: 649-662.

Ifhares, E.J. (1971), Intermal-external control and the reduction of reinforcement value after failure, Journal of Consulting and Clinical Psychology, 37: 3:86-390.

Phares, E J. (1976), Locus of controll in personality, Morristown, NJ: General Learning Press.

Phares, E.J. (1991), Introduction to personality, third edition, New York: HarperCollins.

Phares, E.J., Ritchie, D.E. and Davis, W.L. (1968), Internal-external controll and reaction to threat, Jaurnal of Personality and Sociall Psychology, 10: 402-405.

Phares, E.J., Wilson, K. G. and Klyver, N., W. (1971), Internal-external control and the attribution of blame under neutral and distractive conditions, Journal of Personality and Social Psychology. 10: 285-28.8.

Porter, L.W., Lawler, E.E and Hackman, J.R. (1975), Dehavior in Organizations, New York: McGraw-Hill.

Porter, $M_{1}$ (1980), Competitive strategy: techniques for andlyzing industries and companies, New York: The Free Press.

Pribram, K.H. and McGuimess, D. (1975), Arousal, activation and effort in the control of attention, Psychological Review, 82: 116-149

Pruitt, D. and Kimmel, M. (1977), Twenty years of experimental gaming: critique, synthesis and suggestions for the future, Annual Review of Psychology, 28: 363-392. 
Reeve, J., Olson, B.C. and Cole, S.G. (1987), Intrinsic motivation in competition: the intervening role of four individual differences following objective competence information, Journal of Research in Personality, 21: $148-170$.

Reitz, H.J. and Jewell, L.N. (1979), Sex, locus of control and job involvement: a six-county investigation, Academy of Management Journal, 22: 72-80.

Ritchie, $\mathbb{E}$. and Phares, E.J. (1969), Attitude change as a function of internal-external control and communicator status, Journal of Personality, 37: $429-443$.

Robinson, J.P. and Shaver, P.R. (1973), Measures of social psychological attitudes, Survey research center: Imstitute for Social Research.

Rogers, E.M. and Shoemaker, F.F. (1971), Communications of Innovations: a Cross-Cultural Approach, New York: Free Press.

Ronter J.B. (1954), Social learning and clinical psychology, Englewood Clifrs, NJ: Prentice Hall.

Rotter J.B. (1966), Generalized expectancies for internal versus external control of reinforcenent, Psychological Monographs, entire nr. 609

Rotter, J.B. (1975), Some problems and misconceptions related to the construct of internal versus external controt of reinforcement, Journal of Consulting and Clinical Psychology, 43: 56-67.

Rotter, J.B. (1982), Social learning theory, Hillsdale: NJ:

Rotter, J.B., Chance, J.E. and Phares, E.J. (1972), Applications of a social learning theory of personality, New York: Holt, Rinehart \& Winston.

Ratter, J.B., Liwerant, S. and Crowne, D.P. (1961), The growth and extinction of expectancies in chance cantrolled and skilled tasks, Journall of Psychology, 52: 161-177,

Ryckman, R.M., Rodda, W.C. and Sherman, M.F. (1972), Locus of control and expertise ralevance as determinanis of changes in opinion about student activism, The Journal of Social Psychology, 88: 107114.

Ryder, N.B. (1965), The cohort as at concept in the study of social change, American Sociological Review, 30 $843-861$.

Salancik, G.R. (1977), Commitnent and the control of organizational behavior and belief, in: Staw, B.M. and Salancik, G.R. (eds.), New directions in organizational behavior, Chicago: St. Clair Press, $1-54$

Salancik, G.R. and Pfeffer, J. (1978). A social information processing approach to job attitudes and task design, Administrative Science Quarterly, 23: 224-253.

Schmidt, W. and Posner, B.Z. (1983), Managerial Values in Perspective, New York: American Managenuent Association.

Schmitz, B. and Skinner, E. (1993), Perceived control, effort and academic performance: interindividual and multivariate time-series analyses, Journall of Personality and Social Psychology, 64: 1010-1028.

Schneider, B. (1987), The people make the place, Personnel Psychology, 40:437-453.

Schreuder, H., Van Cayseele, $P_{-,}$Jaspers, $P$, and De Graaff, $\mathbb{B}_{\text {., }}(199 \mathrm{l})$. Successful bear-fighting strategies, Strategic Management Journal, 12: 523-534.

Schröder. H.M., Driver, M.J. and Steufert, S. (1967), Human Information Processing, New York: Holt Rineham \& Winston.

Seeman, M. and Evans, J.W. (1962), Allenation and learning in a hospital setting, American Sociologiteal Review, 27: $772-783$.

Shapiro, A.C. and Titman, S. (1989), An integrated approach to corporate risk management, Bhackwell

Shaw ME. (1981), Group Dynanics: the Psychology of Small Group Behawhor, third ed., New York: McGraw-Hill.

Sherrod, D.R. (1974), Crowding, perceived control and behavioral aftereffects, Journal of Applied Social Psychology, 4: 171-186.

Simon, HA. (1955). A behavioral model of rational choice, Quarterly Journal of Economics, 69: 99-118.

Simon, HA (1957), Models of Man, New York: Wiley.

Singh, J.V.. House, R.J. and Tucker, D.I. (1986), Organizational change and organizational mortality, Administrative Science Quarterly, $31: 587-611$

Smith, C.G. (1970), Age of R\&D groups: a reconsideration, Human Relations, 23: 81-93.

Smith, H.L. and Dechter, A. (1991). No shift in locus of control among women during the 1970 s, Journal of Personality and Social Psychology, 60: 638-640.

Smith, K.G., Smith, K.A., Olian, J.D., Sims jr, H.P., OBBanon, D.P. and Scully, J.A. (1994), Top managentent team demograply and process: the role of social integration and communication, Administrative Science Quarterly, 39: $412-438$. 
Snow, C.C. and Huebiniak, L.G. (1980), Strategy, distinctive compettence and organizational performance, Administrative Seience Quarterly, 25:317-336.

Song, J.H. (1982), Diversification strategies and the experience of top executives of large firms, Strategic Management Journal, $3: 377-380$.

Sousa De Vasconcellos, J.A. and Hambrick, D.C. (1989), Key success factors: tesi of a general theory in a mature industrial product sector, Strategle Management Journal, 10:367-382

Spector, P.E. (1982), Behavior in organizations as a function of employee's locus of control, Psychological Bulletín, 91: 482 4997

Spencer, B.J. and Brander, J.A. (1992), Pre-commitment and flexibility: applications to oligopoly theory, European Economic Review, 36:1601-1626.

Spender, J.C. (1989), Industry Recipes: The Nature and Sources of Managerial Judgement, Oxford: Basil Blackwell.

Srull, T.K. and Karabenick, S.A. (1975), Effects of personality-situation locus of control congruence, Journall of Personally and Sociall Psychology, 32: 617-628.

Staw. B.M. (1976), Kneewdeep in the big muddy. A study of escalating contmitment to a chosen course of action, Organizational Behavior and Human Performance, 16: $27-44$.

Staw, B.M. (1981), The escalation of commitment to a course of action, Academy of Management Review, 6 : 577.587 .

Steiner, I.D. (1974). Whatever happened to the group in social psychology?, Journal of Experimental Social Psychology, 10: 94-108.

Steiner, 1.D. (1986), Paradigms and groups, Advances in Experimental Social Psychology, 19: 251-289.

Stevens, J.M., Beyer, J.M. and Trice, H.M. (1978), Assessing personal, role and organizational predictors of managerial commitment, Academy of Management Journal, 21:380-396.

Stryker, S. (1977), Devellopments in "two social psychologies": toward an appreciation of mutual relevance, Sociometry, 40: 145-160.

Tabachnick, B.G. and Fidell, L.S. (1989), Using multivariate statistics, second edition, Harper Collins.

Thompson, S.C., Sobolew-Shubin, A., Galbraith, M.E., Schwankovsky, L. and Cruzen, D. (1993), Maintainimg perceptions of control: finding perceived control in low-control circumstances, Journal of Personality and Social Psycliology, 64: 293-304.

Tirole, J. (1988), The theory of industrial organization, Cambridge MA: MTr Press.

Tjosvold, D. (1991), Team organization: an enduring competitive advantage, Chichester: Wiley.

Trist, E. and Bamforth, K.W. (1951), Some social and psychological consequences of the longwall method of coal getting, Human Relations, 4: 3-38.

Tucker, D.M. and Williamson, P.A. (1984), Asymmetric neural control systems in human selfregulation, Psychological Review, 91: 185-215.

Tushmen, M.L. and Romanelli, E. (1985), Organizational evolution; A metamorphosis model of convergence and reorientation, in: Cummings, L.L and Staw, B.M. (eds.), Research in organizational beliavior. 7 : $171-222$.

Tushman, M. Newman, W. and Romanelli, E. (1988), Convergence and upheaval: managing the unsteady pace of organizational exolution, in: Cameron K.S., Sutton, R.I. and Whetten, D.A. (eds.), Readings in organizattonal decline, Cambridge, MA: Ballinger.

Valecha, G.K. (1972), Construct validation of intermal-external locus of reinforcement related to work- related variables, Proceedings of the 80th annual Convention of the American Psychological Association, $7: 455-456$.

Vroom, $V$, and Pahl, B. (1971), Relationship between age and risk-taking anong mamagers, Journal of Applied Psychology, 55: 399-405.

Wagner, W.G. Pfeffer $\mathrm{J}$, and O'Reilly III, C.A. (1984), Organizational demography and turnover in top managencent groups, Administrative Science Quarterly, 29: 74-92.

Walsh, JP. (1988), Selectivity and selective perception: an investigation of managers belief structures and information processing, Academy of Management Journal, 31:873-896.

Wanous, J.P. (1980), Organizational entry: recruitment, selection and socialization of newcomers, Reading, MA: Addison-Wesley.

Wanous, J.P. and Youtz, M.A. (1986), Solution diversity and the quality of group decisions, Academy of Management Journal, 29:149-158.

Weick, K.E. (1979), The social psychology of organizing, Reading MA: Addison-Wesley.

Weiner, $N$ and Mahoney, T.A. (1981). A model of corporate performance as a funcrion of environmental, organizational en leadership influences, Academy of Management Journal, 24:453-470. 
Welsch, H.P. and Young, E.C. (1982), The information source selection decision: the role of entrepreneurial personality characteristics, Journal of Small Business Management, 20:49-57.

Wheeler, R.W. and Davis, J.M. (1978), Decision making as a function of locus of control and cognitive dissonance, Psychological Reports, 44: 499-502.

Whimey, J. and Smith, R. (1983), Effects of group colnesiveness on attitude polarization and the acquisition of knowledge in a strategic planuing context, Journal of Marketing Restearch, 20:16\%-176.

Wriebe, D.J. (1991), Hardiness and stress moderation: a test of proposed mechanisms, Journal of Personality and Social Psychology, 60: 89-99.

Wiersena, M.F. and Bantel, K.A. (1992), Top managenent team demography and corporate strategic change, Academy of Management Jourmal, 35:91-121.

Wiersema, M.F and Bantel, K.A. (1993), Top management team turnover as an adaptation mechanism the role of the erwiromment, Strategic Management Journal, 14:485-504.

Wiersema, M.F. and Bird, A. (1993), Organizational demography in Japanese firms: group heterogeneity, individual dissimilarity, and top management team tumover, Academy of Management Journal, 36 : 996-1025.

Witteloostuijn, A.w. (1994), Laat duizend bloemen blocien - tolerantie in en rond organisaties (in Dutch), Schoonhoven: Academic Serwice.

Wittelloostuijn, A.v. (1995), Market evolution: competition and cooperation. Boston: Kluwer Academic Publishers.

Wolk, S. and DuCette, J. (1974), Intentional performance and incidental learning as a function of personality and task dimensions, Journal of Personality and Social Psychology, 29: 90-101.

Zenger, T.D. and Lawrence, B.S. (1989), Organizational demography: the differential effects of age and tenure distributions on technical communication, Academy of Management Journal, 32:353-376. 



\title{
Controle Percepties op Team Niveau en Concurrentiegedrag
}

\author{
Een Experimentele Studie
}

\section{Inleiding: het belang van psychologische variabelen in team studies}

Over de laatste 20 jaar zijn talrijke artikelen en boeken gewijd aan de persoon van de ondememer of bedrijfsleider. De achterliggende idee hierbij is, dat in veel ondememingen deze bedrijfsleider een dermate grote invloed heeft op de beslissingen die genomen worden, dat veel wan die beslissingen een typisch stempel van hun bedenker zullen dragen. Met andere woorden: de persoonlijke achtergrond van de manager 'weegt door' in zijn ondernemingsgedrag en daarmee in de aand en resultaten van de onderneming. Deze gedachte heeft geleid tot een stortwloed aan empirische studies die een verband trachten te ontdekken tussen eigenschappen wan de bedrijfsleider enerzijds en tal van ondememings- en strategiekenmerken anderzijds.

In het verlengde hiervan mag worden verwacht dat kemmerken van teams, als collectief wan individuen, vergelijkbare invloeden zullen witoefenen op ondernemingsvariabelen. Deze gedachte werd in 1984 door Hambrick en Mason van de Amerikanse Columbia Universiteit in een theoretisch raamwerk gevat onder de naam "upper echelons theory". Hierbij gaat het dus om de invloed van teamsamenstellingskenmerken (bij voorbeeld gemiddelde en spreiding van leeftijd, ambtstermijn, functionele en opleidingsachtergronden) op zaken als winstgevendheid, groei, innovativiteit en strategische koers.

Deze theoretische voorzet heeft geleid tot een indrukwekkend aantal empirische studics (zie hoofdstuk 2), die echter een grote versnippering van aandacht en onsamenhangende (non)resultaten te zien geef. Een fundamenteler bezwaar kan worden aangetekend tegen de grove behandeling die het individuele keuzeproces in de 'upper echelons' benadering ten deel walt door middel van demografische variabelen. In essentie wordt er vanuit gegaan dat mensen met een bepaald demografisch kenmerk zoals leeftijd een homogene groep vomen met vergelijkbare karakters, attitudes en waarden die hen daarom tot vergelijkbaar gedrag anizetten. Deze attitudes en waarden zelf, noch hun (veronderstelde) relatie met de demografische variabelen, worden echter zelden vastgesteld. Hierdoor bliff de manier waarop demografie gedrag beinvloedt onduidelijk, hetgeen tot wilde speculaties leidt wanneer een verband niet empirisch kan worden vastgesteld. Een illustratie. Hambrick en Mason (1984) citeren onderzoek dat erop wijst dat managers met een lage sociaal-economische achtergrond meer ovemames en diversificaties plegen. Zij doen dit "verwoedelyk met het doel erkenning en wardering te ontwangen" (pag. 201; onze vertaling en cursivering). Echter, wanneer Hambrick en Mason hieruit een hypothese op team niveau afleiden houden ze eenvoudig vast aam het simpele yerband tussen achtergrond en diversificatie. of hogere 'behoefte an waardering' inderclaad tot diversificatie leidt bliff hierdoor onduidelijk, evenzo de relatio tussen sociale achtergrond en "behoefte aan waardering". In plaats hiervarn wordi een zwakker (verondersteld) correlaat van "behoefte aan waardering", namelijk sociale achtergrond gebruikt on de mate van diversilicatie te voorspellen. Kortom: alle effecten zijn eigenlijk zwakke afgeleiden van dieper liggende persoonskenmerken die zelden of nooit rechtstreeks worden gemeten. Hier komt nog bij dat de afgeleide gedragsconsequenties van demografische variabelen zeer divers en soms zelfs 
conflicterend kunnen zijn. Zo wordt een hoge gemiddelde leeftijd van het team gewoonlik opgevat als een indicatie van meer ervaring en routine, die positief uitwerkt op laakprestaties. Aan de andere kant kan die leeftijd ook tot conservatisme of zelfs fysieke (i.h.b. geheugen ) achtenitgang leiden, hetgeen een negatiewe uitwerking kan hebben. Wij menen dat het gebruik wan "afstandelijke" demografische variabelen veel van de teleurstellende resultaten in het empirisch onderzoek tot op heden zou kunnen verklaren.

Een onderzoeksgebied dat zoveel non-resultaten heef opgeleverd ( $52 \%$ in ons overicht; zie Appendix A) doet er goed aan een stap terug te zetten in de causale keten door de onderliggende (pre)disposities zêlf rechtstreeks te meten en deze vervolgens aan gedrag, keuzes en uiteindelijk prestaties te relateren. Een focus op meer fundamentele gedragstendensen zoals die in de persoonlijkheid zijn geworteld lijkt op zijn plaats aangezien zij directer aan het gedrag zijn gekoppeld en een meer valide meting van waarden en attitudes opleveren dan demografische variabelen. Dit punt werd, vreemd genoeg, wel door Hambrick en Mason erkend toen zij stelden dat "het twijfelachtig is, of deze onderzoeksstroom verder vooruit kan komen zonder een grotere aandacht voor de relevante literatuur in verwante onderzoeksvelden, zoals psychologie en sociale psychologie" (Hambrick and Mason, 1984, p. 203, onze vertaling). Hun nadruk op 'observeerbare' kenmerken, zoals zij het uitdrukten, werd ingegeven door pragmatische redenen van meetbaarheid en databeschikbaaheid, maar de toenemende behoefte aan meer psychologische variabelen in 'upper echelons' studies werd daarna herhaaldeljik gemeld door onderzoekers. Bijna tien jaar later, bijwoorbeeld, stellen Hambrick, Geletkanycz en Frederickson dat "(...) hoewel psychollogische factoren van centraal belang zijn in de upper echelons theorie, worden dergelijke fenomenen zelden direct bestudeerd of gemeten in cmpirisch onderzoek naar top managers" (onze vertaling). Zelfs tot op heden blijft onderzoek naar de invloed van psychologische diversiteit op management-gerelateerd gedrag een lacune in de 'upper echelons' traditie. Onze studie tracht een aanzet te geven om deze lacune te dichten.

Hieronder geven we een overzicht van de uitkomsten verkregen uit het voorlÿggende dissartatieonderzoek nar de invloed die de psychologische samenstelling van een groep beslissers heeft op hun keuzes en gedrag in een management simulatie. Daartoe zullen we eerst kort ingaan op het persoonlijkheidskenmerk dat centraal stond in deze studie, namelijk de zogenaande "perceptie van controle" ('locus of control' in het Engels). Verwolgens bespreken we ons algemene onderzoeksmodel en de resultaten. We sluiten af met een conclusie.

\section{Locus van controle en het gedrag van managers}

Eon uitgebreid overicht var het perceptie van controle onderzoek werd gegeven in hoofdstuk 3 . Het begrip 'perceptie van controle' stamt uit de sociale leertheorie van Julian Rotter (1966) en verwijst naar de mate warin individuen menen ('percipièren') dat hetgeen hen overkomt te wijten of te danken is an henzelf (dit noemen we een interne perceptie van controle) of aan factoren buiten henzelf (een externe perceptie van controle). Mensen met een interne perceptie van controle (kortweg intemen genoemd), zoeken de oorzaak van wat hen overkomt in hun eigen gedrag, waardigheden of tekorkomingen. Mensen met een meer externe perceptie wan controle (oftewel extemen) wanen zich passieve agenten in hun leven; zij wijten of danken wat er gebeurt aan zaken als geluk, toeval of machtige personen. Dit algemene verschil in ingesteldheid heeft verregaande consequenties voor (ondermeer) taakgericht gedrag van mensen, 
zoals op school en op het werk! Het empirisch onderzoek tot op heden laat zien dat internen in het algemeen beter presteren in prestatiegericht gedrag, zoals management dan extemen (Lefcourt, 1982; Boone, 1992). Dit stemt overeen met de intuitie, inmers: wanneer men het gevoel heeft geen invloed te hebben op de uitkomsten van het bedrijfsproces (zoals externem), is het nogal zinloos om een actieve, gemotiveerde houding aan de dag te leggen; je acties doen er toch weinig toe Aan de andere kant, als je wel het gevolel hebt dat je de zaken in de hand hebt en de resultaten kunt beinvloeden (zoals internen), levert dit een krachtige motivatie om de omgeving en het werk actief tegemoet te treden en hard te werken². Op het vlak van management blijken bedrijven geleid door inteme bedrijfsleiders ook inderdaad beter te presteren dan bedrijwen met exteme managers aan het roer, en dit zowel op korte als op lange termijn (Miller and Toulouse, 1986; Boone et al., 1996). De grote vraag bliff echter: waarom precies? In ons onderzoek trachten we die vraag te beantwoorden aansluitend op zowel verklaringen wit het verleden als nieuwe inzichten. Bovendien verleggen we voor het eersi de aandacht van individuele managers naar (kleine) groepjes van beslissers. Per slot van rekening worden belangrijke beslissingen in het hedendaagse bedrijfsleven in meerderheid in teamverband genomen. De centrale vraag in het onderhavige onderzoek is dan ook: Zijn er verschillen in bedrijfsprestaties tussen teams die en verschillende mix van interne en externe individuen hebben? En zo ja: waarom?

Het is nog van belang te vermelden dat de effecten van persoonlijkheid op beslissingen in het algemeen het sterkst zijn in retatief onzekere, ambigue situaties (ook wel aangeduid ats 'weak situations') in tegenstelling tot stabiele, duidelijk gestructureerde situaties ('strong situations'). De reden hiervoor is, dat men in de eerste situatie veel minder kan wertrouwen op gevestigde methodes en zienswijzen, waardoor ieders persoonlijke benadering meer to uitdrukking komt in thet gedrag. Zo valt dus te verwachten dat de effecten van psychologische variatie bimmen teams in een bedrijfssetting sterker zullen zijn in meer dynamische bedrijfsomgevingen dan in relatief stabiele en voorspelbare omgevingen. We komen hier nog op terug.

\section{Theoretische achtergrond: een model}

In beginsel menen wij, dat verschillen in bedrijfsprestaties aan een tweetal zaken toe te schrijven zouden kunnen zijn. Ten eerste kan het te maken hebben met de inhoud van de gevoerde strategieën, $\mathbb{d}$. W.Z. het ene team neemt andere en/of betere strategische beslissingen dan het andere. Zo bestaan er aanwijzingen dat inteme managers meer innovatieve en proactieve keuzes maken of meer risico nemen, met andere woorden: ondernemender zijn (Miller et al, 1982; Miller, 1983, Miller and Toulouse, 1986). Een tweede mogelijkheid heeft echter in het verleden nauwelijks aandacht gekregen. Deze houdt in dat controle percepties een belangrijke invloed uitoefenen op de manier warop strategieën worden gevormd, in de Angelsaksische literaturur aangeduid met het moeiljk vertaalbare "strategy making'. Wij zijn van mening dat de superioriteit van inteme over exteme managers (mede) gelegen zou kunnen zijn in zaken als

I Voor een uitgebreid overzicht van de implicaties van verschillende controle percepties zie Lefcourt (1982)

2 We geven hier uiteraard yoor de duidelijkheid even de extreme posities van (zeer) interne en externe managers weer. In de praktijk komt het neer op verschillen in een meer of minder uitgesproken geneigdheid tot externe dan wel interne percepties van controle. 
betere informatie-inwinning, bedrijfsplanning, interne consistentie van strategieën (los van hun inhoud) alsmede en goed doordachte en tijdige aanpassing ervan.

Deze verwachtingen hangen allen samen met het feit dat intemen ons inziens beter gemotiveerd on in staat zijn lot doelgevicht gedrag (opnieuw: los van de inhoud van dat gedrag). Doelgericht gedrag, veronderstelt de volgende componenten, die zijn weergegeven in figuur 1.

Figuur 1: Conceptueel ramwerk van doelgerichte strategievorming

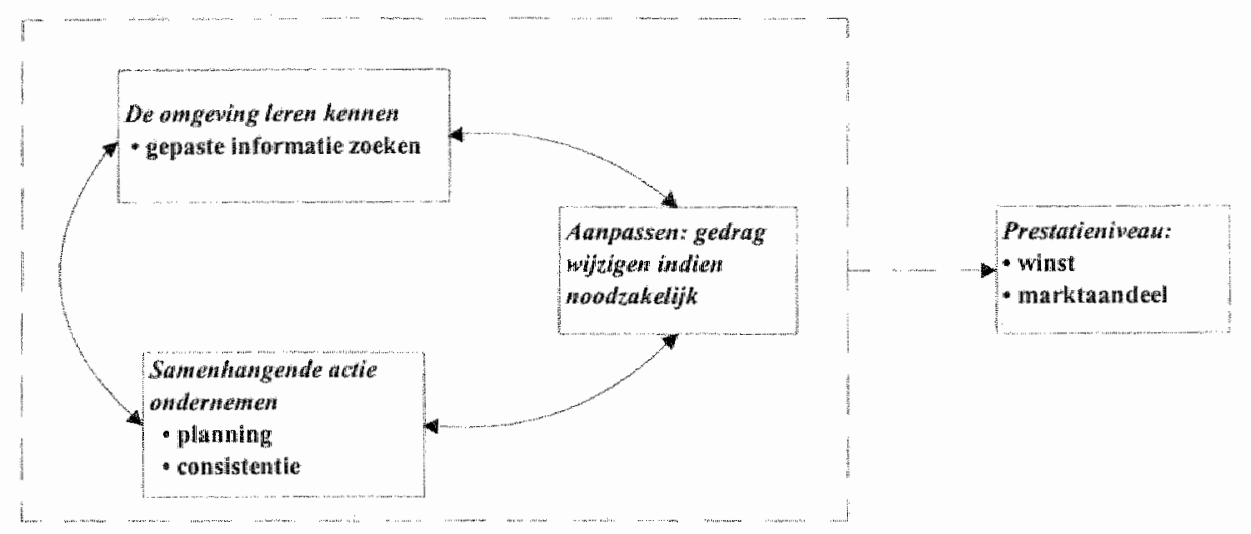

Op de eerste plaats dient men zijn omgeving in kaart te brengen middels het zoeken van relevante informatie over de interne en exteme omgeving. Experimenten en veldstudies (Phares, 1976,1991 ) hebben overtuigend aangetoond dat intemen actievere informatiezoekers zijn dan externen. Dit stemt overeen met de intuitie: de eigen effectiviteit waarin intenen geloven wordt namelijk aanzienlijk verhoogd als men weet onder welke omstandigheden men moet opereren. Voor extemen voegt informatie weinig toe.

De tweede component behelst het ondermemen van samenhangende acties door middel van nawkeurige planning en het ontwikkelen van een intem consistent beleid. Planning als methode on de toekomst voorspelbaarder te maken is een typisch kenmerk van intem georienteende individuen (Miller and Toulouse, $1986 \mathrm{a}$; Miller, Kets de Vries and Toulouse, 1982; Miller, 1983); externen zullen er de zin moeiljk van in kunnen zien. Iets dergelijks geldt ook voor de beleidsconsistentie. Het hele idee van strategie als een bewust geconfigureerd actiepatroon on een bepald doel te bereiken, is iets wat op basis van het voorgaande sterker onder intemen dan onder extemen zall leven. Wo verwachten dan ook dat intemen zich meer moëte zullen getroosten om een goede samenhang in hun beslissingen aan te brengen dan. extemen.

Het laatste element in figum $\mathbb{l}$ is thet anpassingsgedrag. De effectiviteit van de strategle is er uiteraard bij gebaat dat zij wordt aangepast indien daar reden toe bestaat, bijvoorbeeld naar aanleiding van legenvallende resultaten. Dit laatste element voegt dus een dynamische component aan het model toe. Het ligt woor de hand te veronderstellen dat iemand die meent een zekere beheersing te hebben over wat hem (of zijn organisatie) overkomt (d.w.z. een interne) zich moeilijker aan de verantwoordelijkheid voor slechte resultaten zal kunnen onttrekken. Hij zal in het algemeen ook meer het gevoel hebben en de motivatie hebben om er eventueel wat aan te kunnen doen. Onderzoek blijkt deze algemene verwachting te bevestigen: zij wijst duidelijk in de richting van een hoger aanpassingsvemogen en aanpassingseffectiviteit onder internen 
(Phares, Wilson and Klyver, 1971; Srull and Karabenick, 1975; Anderson, 1977; Aspinwall and Taylor, 1992). Tezamen valt te verwachten dat de genoemde drie elementen bijdragen aan de, reeds vastgestelde, betere bedrijfsprestaties van inteme managers dan van exteme managers.

\section{Onderzoeksopzet}

Hoofdstuk 4 besprak de gevolgde methode van het proefschrift. Een belangrijke tekortkoming van 'upper echelons' onderzoek in het verleden is de heterogenteit van de steekproeven. Bowendien werden persoonlijkheidskenmerken veelal niet gemeten om redenen van practische aard: managers werken hier niet graag aar mee. Wij hebben geprobeerd om deze bezwaren te ondervangen door onze hypotheses eerst eens in een relatief gecontroleerde ongeving van een 'management game' te toetsen. Middels medewerking van de organisatoren van dit game konden we alle deelnemers persoonlijk benaderen voor deelname aan ons onderzoek. Onze studie is dus uitgevoend in de experimentele setting van een grootschalige internationale management competitie (IMC) die jaarlijks georganiseerd wordt door MCC International b.v. in Amsterdam. Deelnemers zijn teams van veelal jonge managers van bedrijven uit gelkeel Europa Deze bedrijven schrijven hun teams meestal in als onderdeel van een "management development" of trainings programma. In de door ons onderzochte editie 1994 van het spel deden teams van 167 bedrijven mee. Elk team leidt een fictief productiebedriff, opererend op drie verschillende markten. Onze steekproef bestond uit 58 volledige teams, variërend in grootte van 2 to 7 teamleden met een grote meerderheid van 4 leden. De gemiddelde leeftijd was ongeveer 33 jaar, $88 \%$ was Nederlands en eenzelfde percentage was man. Voor ons onderzock analyseerden we een reeks van beslissingen die door teams werden gemaakt in zes opeenvolgende zogenaande spelperiodes. In elke periode moeten de teams een beslissingsformulier invullen met 37 beslissingscategorieèn variërend van (investeringen in) productie (capaciteit en kwaliteit), marketing (prijszetting, reclame, verkoopbevordering), financiering (lenen-aflossen), personeel (aanname, training, ontslag, verloop) tot informatieverzameling ('business intelligence') en $\mathrm{R} \& D$. Groepen van vijf teams vormen telkens een bedrijfstak waarin zij moeten concurreren tegen vier anderen: een 'pentapolie' dus. Als onderzoekers hadden we hierdoor de beschikking over alle beslissingen die genomen werden, alle resultaten van de bedrijven en, midels enquêtes, persoonlijkheidsdata en andere achtergrondgegevens van de deelnemers uit de steekproef.

Locus van controle werd gemeten met een gevalideerde vagenlijst ontleend aan Ratter (1966). Respondenten werd gevraagd om telkens een keuze te maken welk wan twee statements het meest hun overtuiging weergaf. (forced choice format'). Elk paar altematieven bestond uit een externe variant (bijv. "succes in het leven is een kwestie van geluk') en een inteme variant (bijv. 'succes kan worden bereikt door hard te werken'). De eindscore wordt berekend door het aantal exteme alternatieven dat gekozen werd op te tellen. Aan de hand van de mediaanscores op de persoonlijheidsvragenlijst werden alle respondenten als intern of extern geclassificeerd. Teams met meer dan $2 / 3$ intemen werden als "interne teams aangemerkt, zij met meer dan $2 / 3$ externen als 'externe teams' en de rest als 'gemengde teams'.

De bedrijistak waarin de teams opereerden werd als stabiel of dynamisch aangemerkt aan de hand van de omvang wan de prijsschommelingen en de grootte van de verschuivingen in de marktaandelen die tussentijds optraden. 


\section{Resultaten}

We zullen ons in het navolgende vanwege de ruimte beperken tot de hoofdlignen van onze bevindingen.

Als cerste werd in Hoofdstuk 5 gekeken of interne teams grosso modo inderdaad beter presteerden (qua winst en behaald marktaandeel) dan exteme en gemengde teams. Dit bleek inderdaad het geval te zijn, an wel het sterkst in dynamische ongevingen. Opvallend was de slechte prestatie van gemengde teams: zij deden het veruit het slechtst van de drie. Mogelijk komt dit door het feit dat gemengde teams (zoals alle heterogeen samengestelde teams) nog een extra probleem hadden, namelijk een gebrek aan goede sociale integratie. Blikbaar is dit in dynamische omgevingen van extra groot belang. Het belang van psychologische varialie in de verklaring wan prestatieverschillen moge blijken uit het feit dat deze verschillen in dynamische bedrijfstakken maar liefst $37 \%$ van de variatie in de rentabiliteit van het eigen vermogen kumnen verklaren!

Ter verklaring van deze prestatieverschilten werd in Hoofdstuk 6 eerst gekeken of ze ts maken hadden met de imhoud van de strategische keuzes die gemaakt waren. Dit bleek in het algemeen niet het geval te zijn. Interne teams waren gemiddeld niet innovatiever, coöperatiever of meer risico nemend dan externe teams. Echter: een interessante interactie bleek te bestaan met de mate van omgevingsdynamiek. Dat wil zeggen; interne teams investeerden alleen meer in innovatie of samenwerking wanneer dat in het spel profijtelijk was, namelijk in dynamische omgevingen. Dit wijst erop dat interne teams niet noodzakelijk andere beslissingen nemen, maar dat ze hum beslissingen beter campassen aan de situatie: ze lijken een betere neus te hebben voor welk gedrag meer gepast is onder bepaalde omstandigheden. Dit zal een terugkerende bevinding blijken te zijn.

Ten axnzien van de verschillen in strategievorming, d.w.z. de manier waarop strategieèn tot stand komen (zie figuur 1), werd in Hoofdstuk 7 het volgende gevonden. In tegenstelling toi onze verwachting bleken de teams niet te verschilen in de totale hoeveelheid geld die zij uitgaven aan het kopen van informatie. Wanneer we echter kijken naar de mate waarin specifieke acties door teams ondernomen voorafgegaan werden door een voor die beslissing relevant informatieverzoek, werden wel belangrijke verschillen gevonden. Inteme teams blijken zich voorafgaand aan een beslissing beter dan externe teams te informeren over zaken die te maken thebben met de effectiviteit wa hum eigen handelen. Dit wijst op een zeker pragmatisme van de zijde van interne teams: ze zijn geinteresseerd in wat hun acties kunnen betekenen. Externe teams daanentegen bleken meer geïnteresseerd in allerlei zaken aangaande de acties van concurrenten; naar buiten gerichte informatie dus. Uit analyse blijkt, dat het verzamelen van informatie in het spel een belangrijkere bijdrage aan de prestaties levert in dymanische dan in stabiele omgevingen. Interne teams blijken dit goed te hebben aangevoetd: ze zijn actievere informatieverzamelaars in dynamische dan in stabiele omgewingen. Extene teams betonen zich opnicuw slechte aampassers: $z$ in doen precies het omgekeerde.

Een soortgejijk resultat werd verkregen ten aanzien van de kwaliteit van de plamingsinspanningen. Internen blijken in het algemeen het best te plannen, maar het zijn niet de externen maar de gemengde teams die het hier het slechtst doen. Aangezien een goede afstemming tussen bedrijfsonderdelen hier crucial is, hebben de integratie en/of communicatiemoellijkheden van gemengde teams zich hier mogelijk het zwaarst laten gevoelen. Wanneer we de verschillen tussen stabiele en dynamische omgevingen beschouwen, zien we dat externen het beste plannen in stabiele omgevingen en internen het beste plannen in dymamische omgevingen. Planningskwaliteit blijkt sterker geassocieerd met financieel succes in dynamische omgevingen; iets wat intuitief te begrijpen valt: een slechte bedrijfsplanning is waarschijnlijk 
kostbaarder in een snel veranderende omgeving dan ingeval alles redelik voorspelbaar verloopt. Intemen lijken deze gedachte op waarde geschat te hebben: ze plannen beter naarmate planning noodzakelijker en (bijgevolg) profijtelijker is. Met andere woorden: ze vertonen aangepaster gedrag.

De interne samenhang van de strategieën die de teams ontwikkelden bleek niet te verschillen. Echter, inteme teams bleken minder inteme coherentie in hun strategieën te vertonen in dynamische dan in stabiele omgevingen. Het omgekeerde geldt voor externe teams. Dit wijst erop dat interne teams hun strategieën 'losser' definiëerden als de omgeving veranderlijker was dan in geval zij relatief stabiel was. Hoewel dit te begrijpen vallt als een poging om meer strategische 'armslag' te houden in dynamische bedrijfstakken, bleek het in dit geval niet profijtelijker te zijn. Als we kijken naar de vasthoudendheid aan bepaalde strategische profielen over de tijd zien we geen verschillen tussen team types: allen zijn ongeveer even persistent in hun keuzes voor een bepaald profiel. Toch duikt ook hier het inmiddels vertrouwde kwalitatieve patroon op: intemen zijn persistenter dan andere teamtypes in stablele omgevingen (weing reden om te veranderen als het werkt), maar het verschil verdwijnt in een dynamische bedrijfscontext.

In de hierboven genoemde resultaten werd aangetoond dat de superioriteit van intene teams mogelijk niet gelegen is in wat ze doen maar onder welke omstandigheden ze wat doen. Het lijkt erop alsof inteme teams eenvoudig een beter gevoel hebben voor passend gedrag ahankelijk van de omstandigheden. In een poging om dit aanpassingseffect (zie liguur 1) directer te observeren werd in Hoofdstuk 8 gekeken naar strategische veranderingsreacties op resultatenfeedback, m.a.w. hoeveel verandert men naar aanleiding van slechte prestaties? Externen bleken in het algeneen het meest onnustig te zijn: ongeacht hun prestaties waren zij het meeste aan het veranderen. Een soort continue onrust lijkt hun gedrag te typeren, ongeacht de omstandigheden. De reacties op negatieve prestatie-feedback bleek alleen in het begin van het spel een rol te spelen; daarna waren de team resultaten niel meer van invloed op de hoeveelleid verandering. Wel is het zo, dat exteme teams meer moeite leken te hebben om een gepaste reactie op negatiewe feedback te geven. Om precies te zijn: ze veranderden ofwel heel sterk ofwel heel weinig, m.a.w. de variatie in hun veranderingen was hoger dan die van andere teams.

\section{Besluitt}

Tezamen genomen mogen we concluderen dat de aanpassing van gedrag cruciaal is in de verklaring van prestatieverschillen tussen verschillende teamtypes. Locus van controle is een belangrijk psychologisch kenmerk om het gedrag van managers te verklaren. Onze analyse toont aan dat dit zeer zeker ook geldt op het team niveau. Maat zoals zo vaak in de organisatiewelenschappen is de rol van de omgeving van prominent belang. Psychologische kenmerken, en dus ook het onderhawige, hebben de sterkste verklaringskracht in omgevingen die ambigue en onzeker zijn. Dáar is het dat managers teruggeworpen worden op hun meest fundamentele eigenschappen en gedragstendenties. 



\section{Appendix A}

Overview of empirical top management team studies 


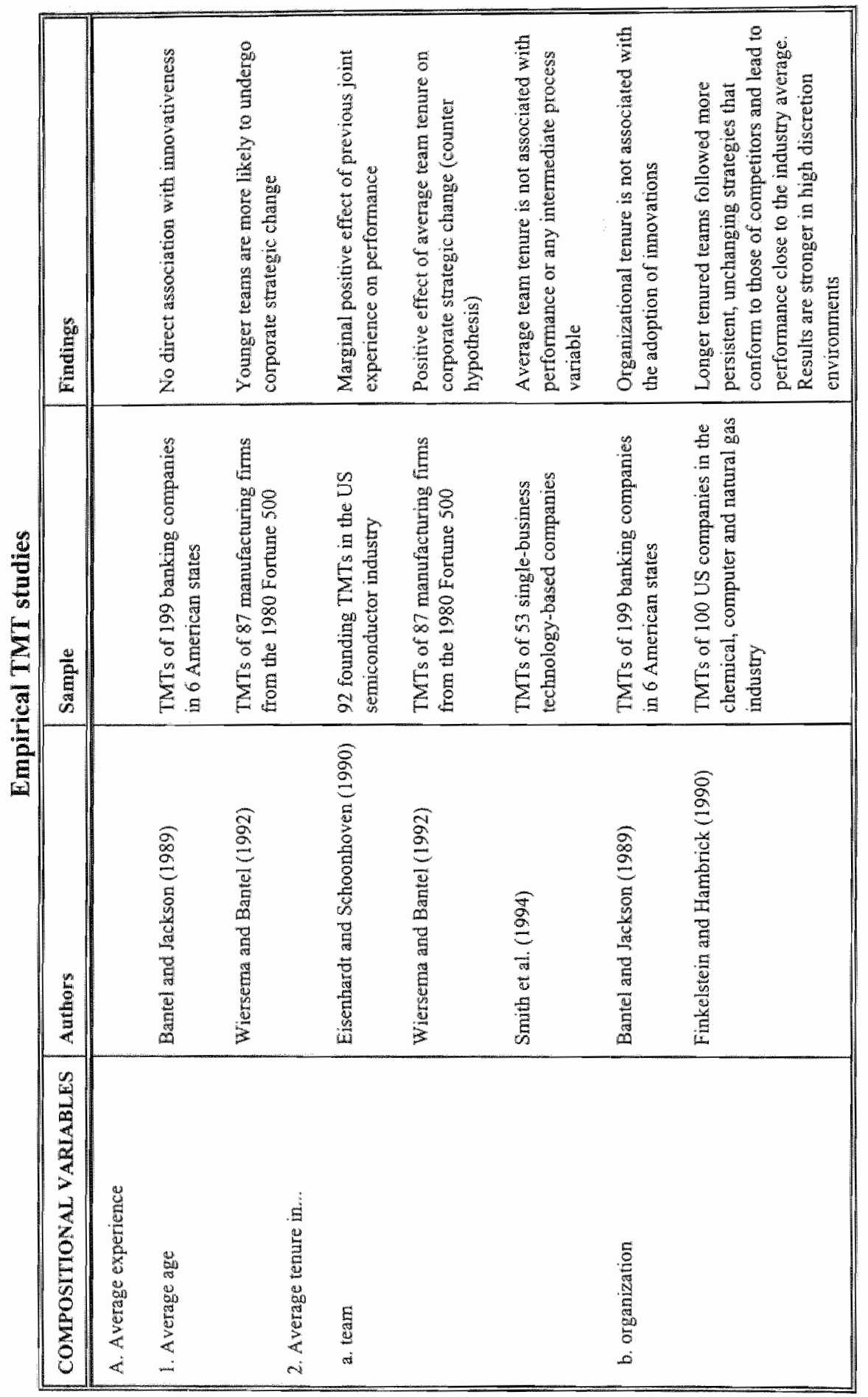




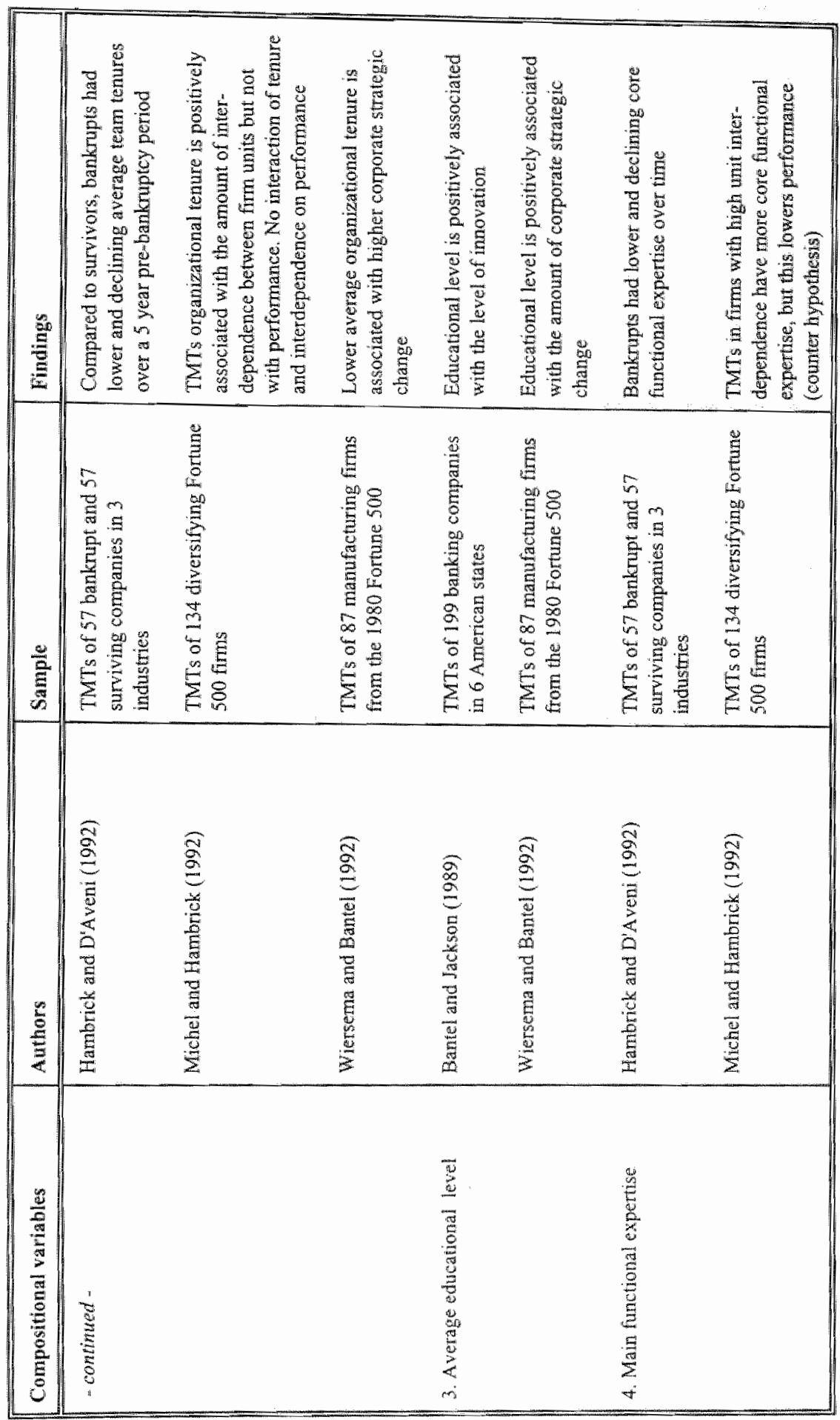




\begin{tabular}{|c|c|c|c|c|c|c|c|c|c|c|c|}
\hline 总 & & 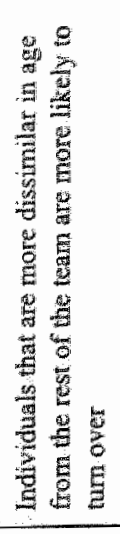 & 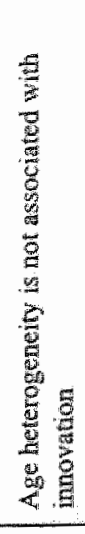 & 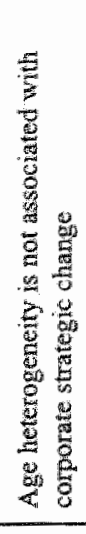 & 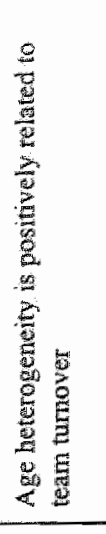 & & 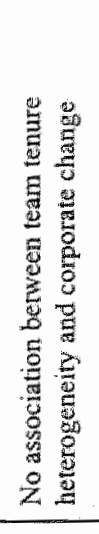 & 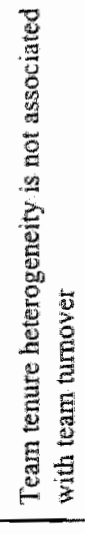 & 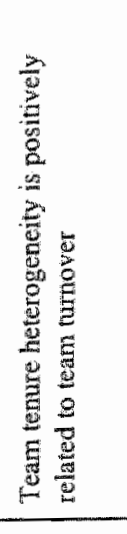 & 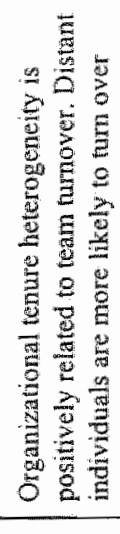 & 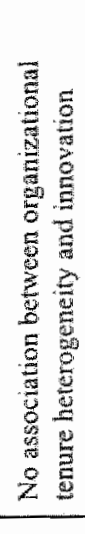 \\
\hline 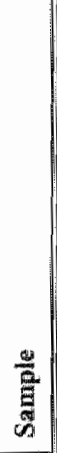 & & 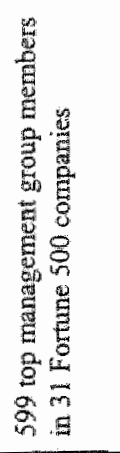 & 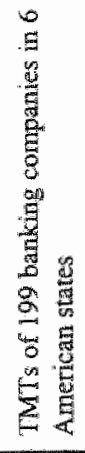 & 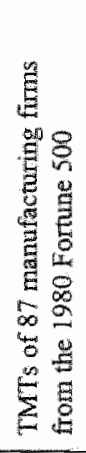 & 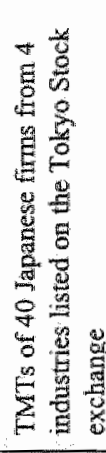 & & 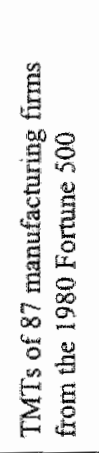 & 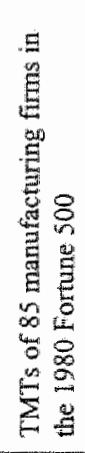 & 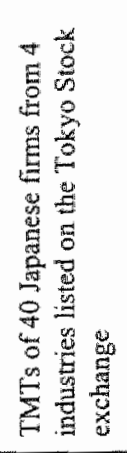 & 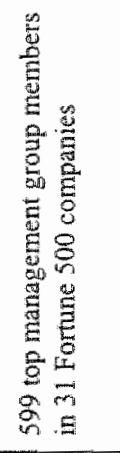 & 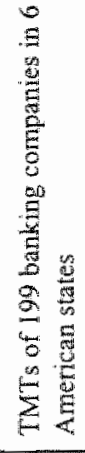 \\
\hline$\stackrel{5}{g}$ & & 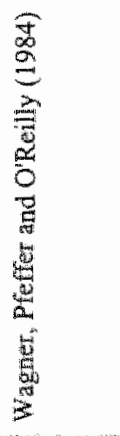 & 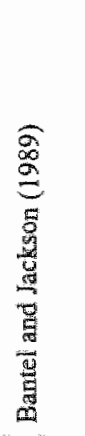 & 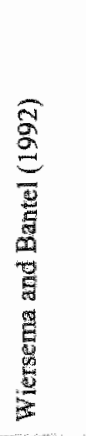 & 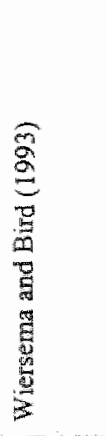 & & 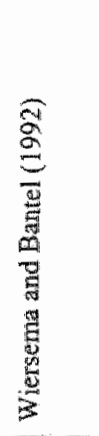 & 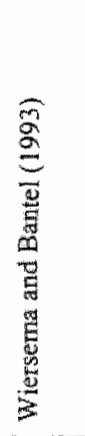 & 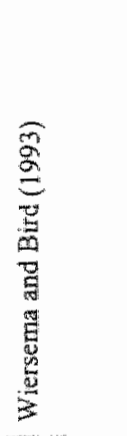 & 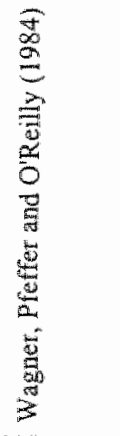 & 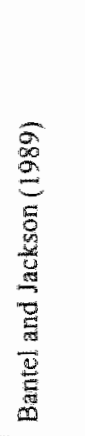 \\
\hline 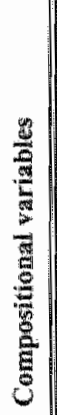 & 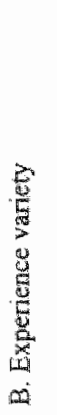 & 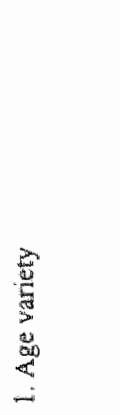 & & & & 4 & 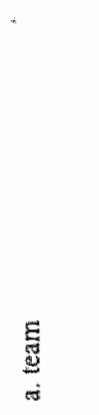 & & & 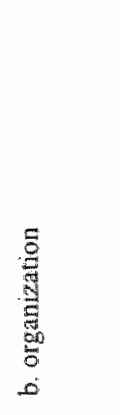 & \\
\hline
\end{tabular}


221

\begin{tabular}{|c|c|c|c|c|c|c|c|c|}
\hline 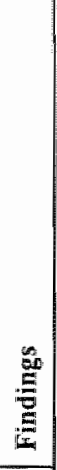 & 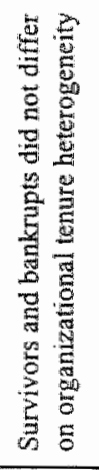 & 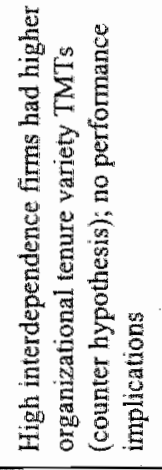 & 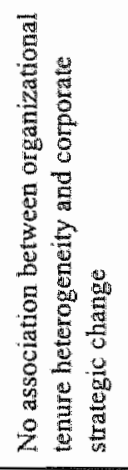 & 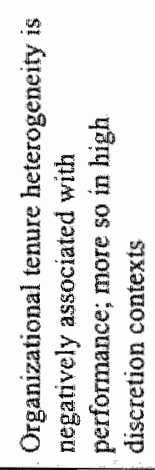 & 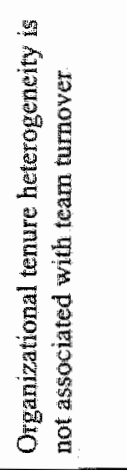 & 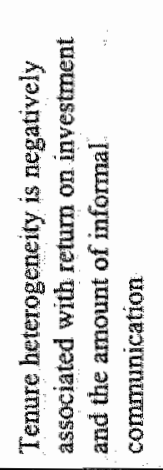 & 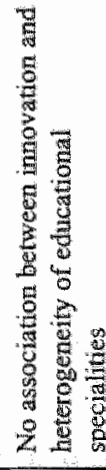 & 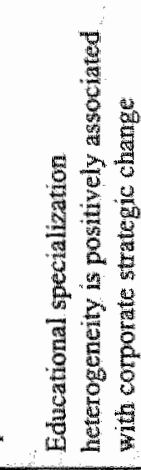 \\
\hline 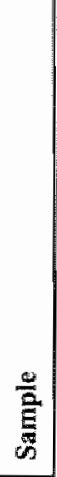 & 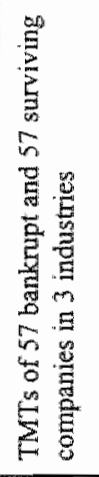 & 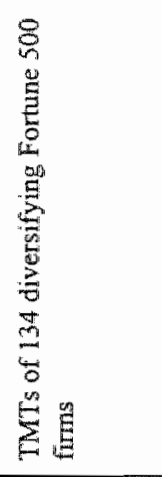 & 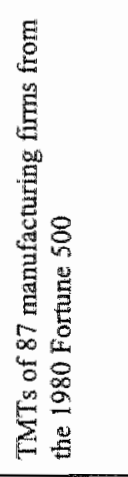 & 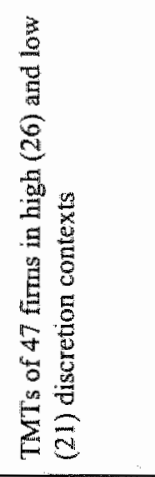 & 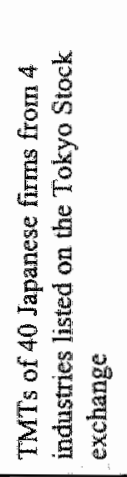 & 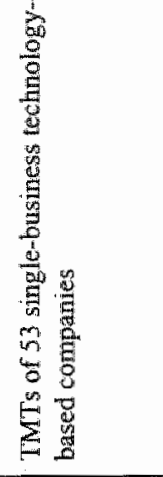 & 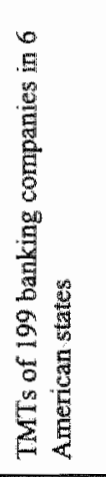 & 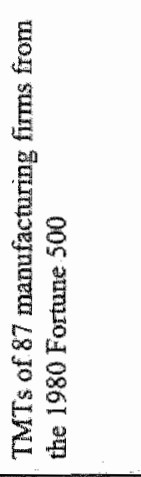 \\
\hline 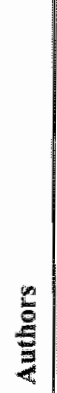 & 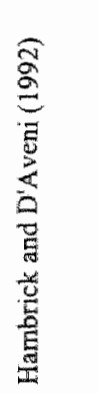 & 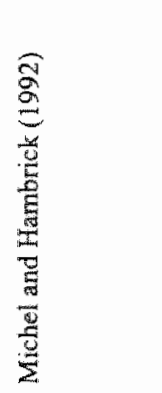 & 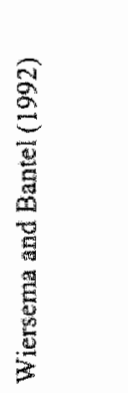 & 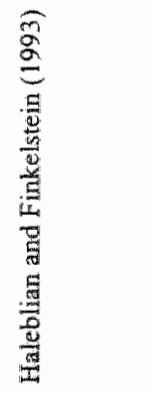 & 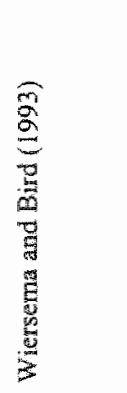 & 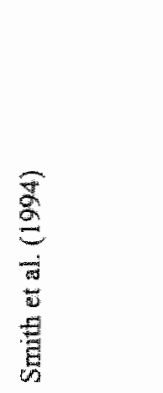 & 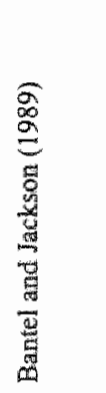 & 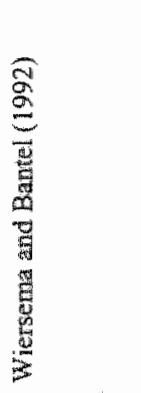 \\
\hline 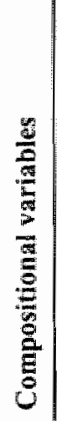 & & & & & & & 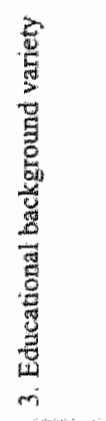 & \\
\hline
\end{tabular}




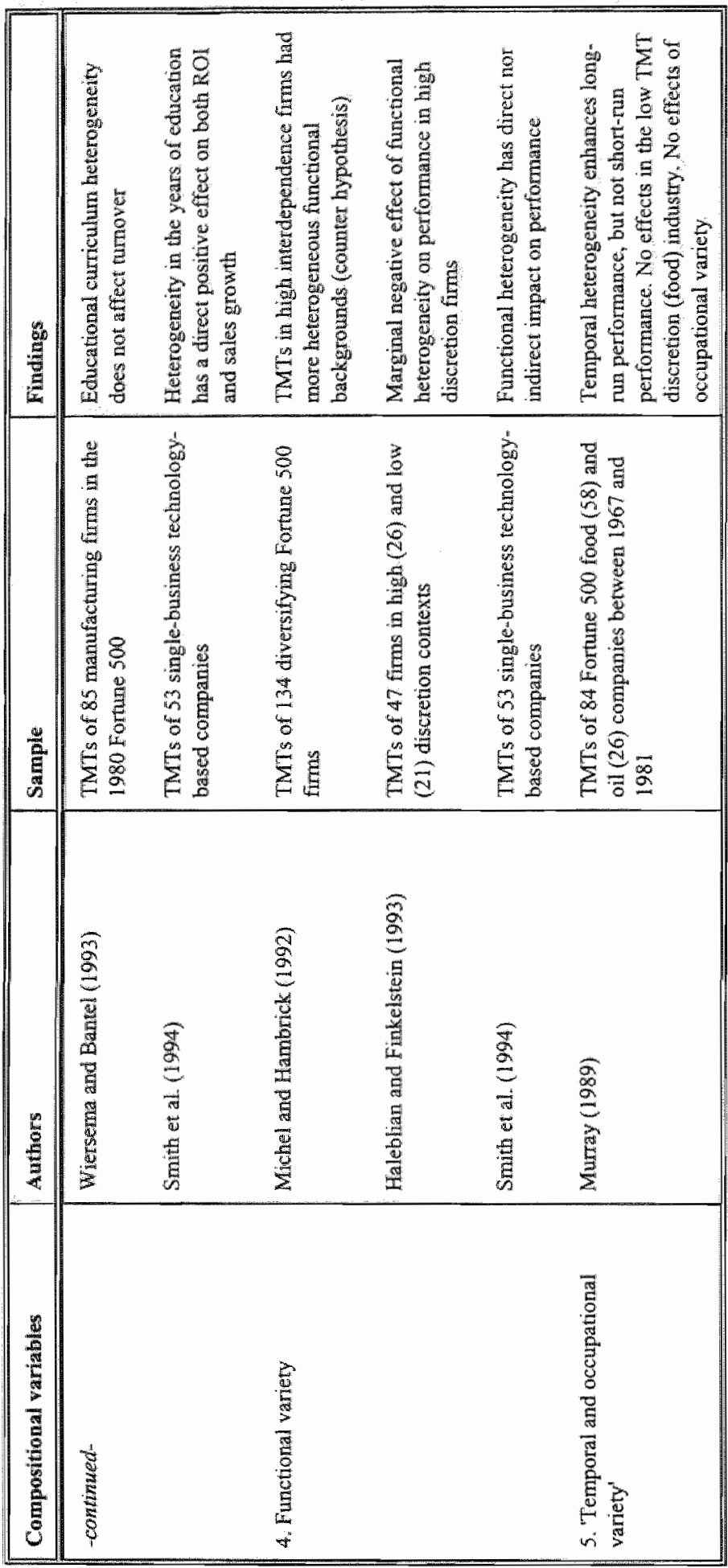




\section{Appendix B}

Decisions form 



\section{General}

1. mistarase Clis A-regular

I. Ancrezse Cus Anired

3. irtcrease CU/s B-bought

4. Herease CUs B-teased

3. bonrowings

d. redempzions

7. orders for product 2

a. code suppliers credit

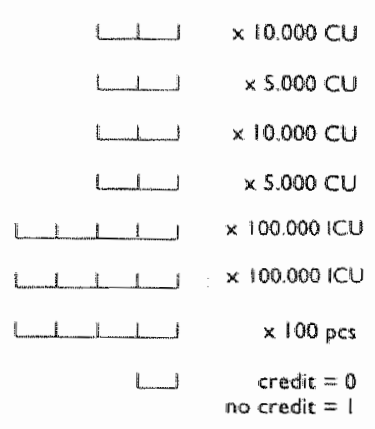

9. shorthrye working

10. pend work condimpr.

11. expe of sales groups

12. dividend payment

13. wage increase

14. onders for raw mat. I

15. ordars lor raw mat 2

16. orders for raw mat 3

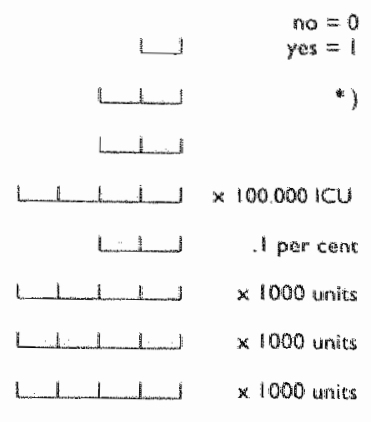

product 3

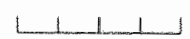

K 100 pes

$\times 100$ pes

in
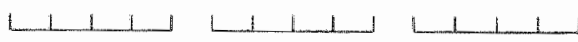

L L L I I

$\because \quad 1 \quad H$

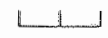

$1+1$

*)

1.

$+1$

L. 1

)

")

*)

23. tredis facilley

\section{Information}

24. competitors prices

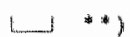

25. competitors mall strock

26 competitors production capacity

27. e⿶凵thect product improvement expenditures:

lev. 1:

19: 2

23. effect effictiency improvement expenditures

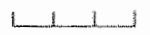

$1+1$

29. fixed costs at a cercain

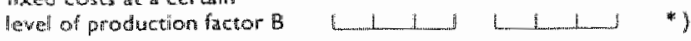

31. affece of promotional experdicures

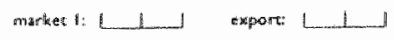

3. compecitorst shate in promiction

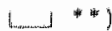

32. comperitors" product quality lewels

$[\ldots \ldots * j *$

33. campecitors" sales groups

亿 $甘 * *)$

34. estmate of rnarktet demands

35. competicors' share in working conditlons improvernent.

Lrencing

36. compet tors marker shares

37. compecitors' wage cosits

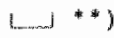

L...

L i i i * ) 


\section{Appendix C}

Results feedback example 

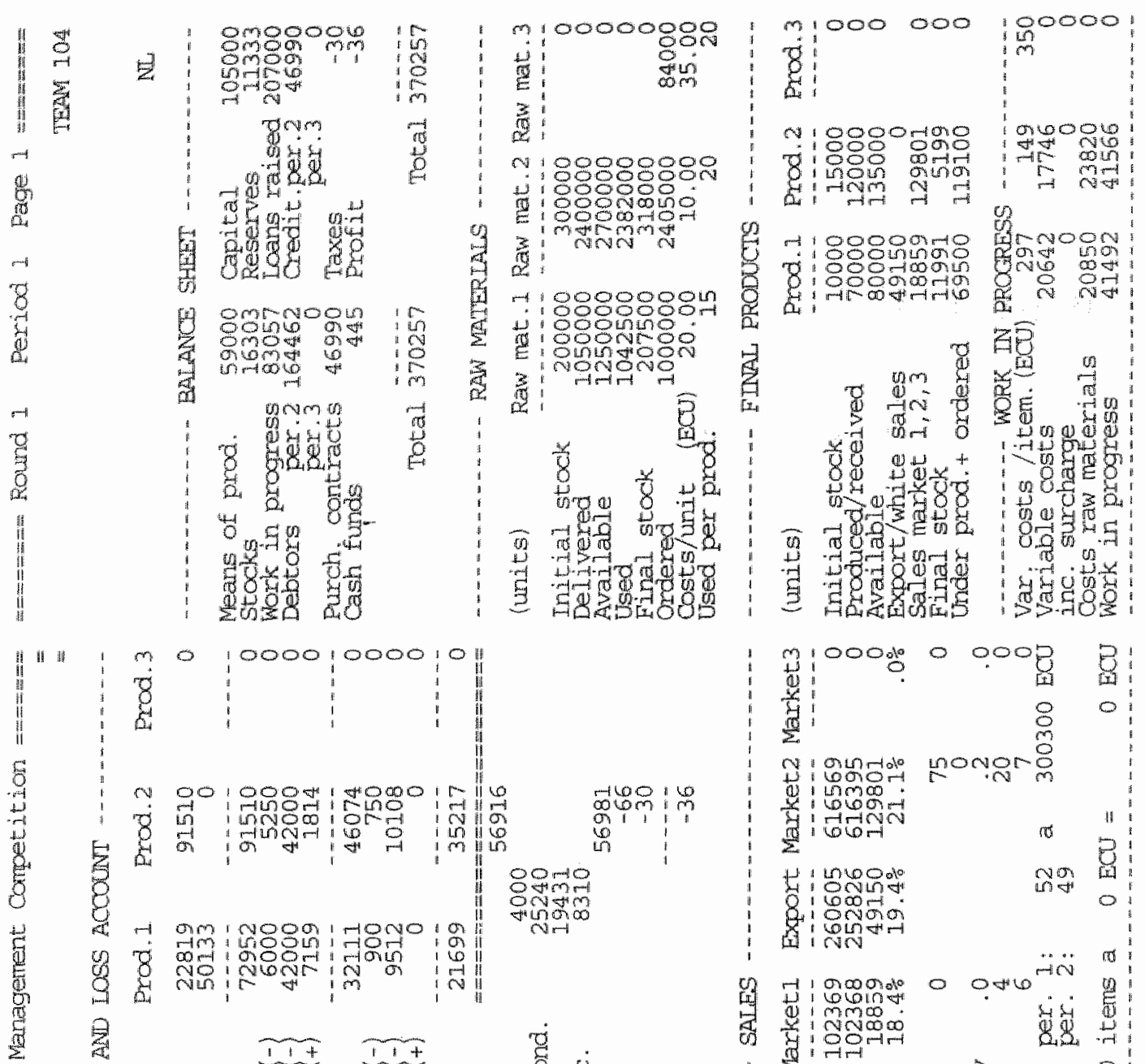

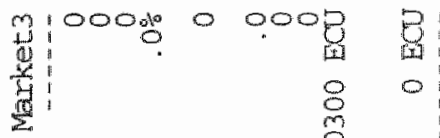

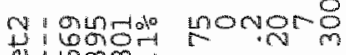
a 1000

मे $\rightarrow$ rin

1060

H' now

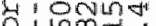

\&. 1000 का

a i 60004

g

a

in: $\mathrm{SON}_{-\rightarrow 1}$

要
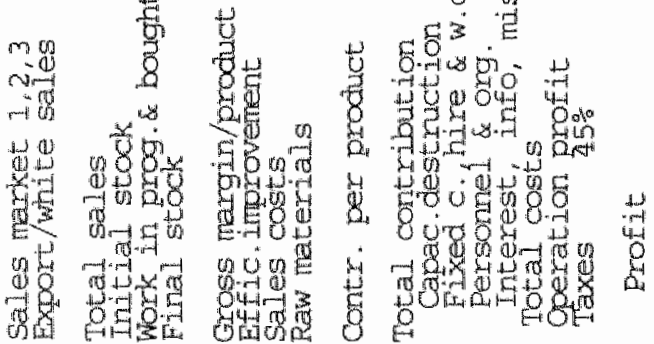

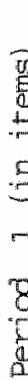
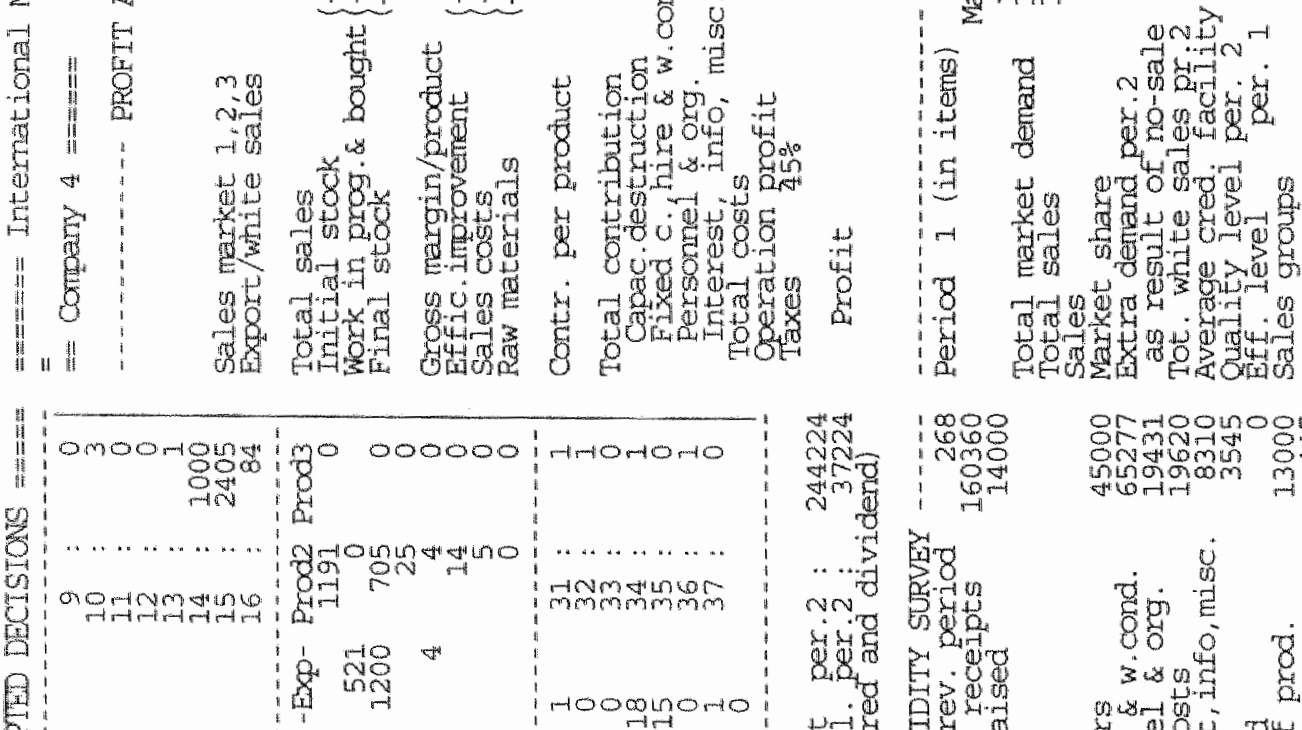

बํㅔ

츄:

1000

舟的:

8Nmonomon

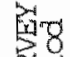

nrod 3.40

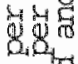

and

o

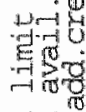

is

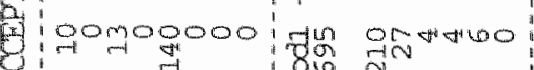

ounontin

B.

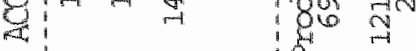

sis

y.

$\rightarrow$ is

800

, 38

Hon

is:

ठलखำ 8 ungorom m

更

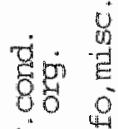

800

का क⿺⿻一⿰冫⿰亅⿱丿丶丶⿱⿰㇒一乂

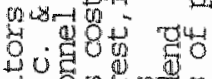

8890 ars

Unom

HNm 


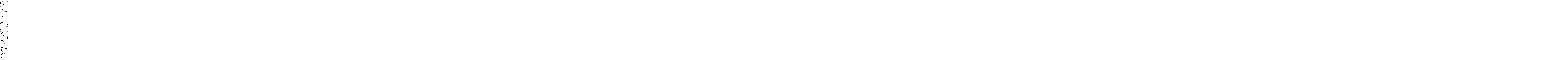


Appendix D

Rotter scale questionnaire 

Below we reproduce the Rotter scale questionnaire that the subjects in our study were requested to fill out. We indicated locus of control items by the capital $R$ and filler items by the capital $F$. The external alternatives on locus of control items are denoted with a capital $\mathrm{E}$. In case of a filler item, the socially desirable altemative carries a capital $\mathrm{S}$.

The total locus of control score (the so-called Rotter score) is obtained by summing the total number of external alternatives chosen. To obtain the total social desirability score, the number of socially desirable alternatives chosen are added.

\section{Ingtructions}

The following questionnaire consists of a mumber of statements that are used for finding out how some important social phenomena influence people. Every question consists of two possible responses : a or b. Please choose one alternative by encircling either $a$ or $b$.

In some cases you may find that both or neither of the statements reflect your opinion. Please make a choice anyway. Choose the statement that fits in with your opinion most, no matter how litule.

1. (F) a. Children get into trouble because their parents punish them too much.

b. The problem with most chitdren nowadays is that their parents are too easy with them. (S)

2. (R) Many of the unhappy things in people's lives are partly due to bad luck. (E)

b. People's misfortunes result from the mistakes they make.

3. (1) a. Heredity plays the major role in determining one's personality.

b. It is one's experiences in life which determine what they're like. (S)

4. (F) a. One showld always be willing to admit mistakes. (S)

b. It is usually best to cover up one's mistakes.

5. (F) There are certain people who are just no good.

b. There is some good in everybody. (S)

6. (R)
One of the major reasons why we have wars is because people don't lake chough interest in politics.

There will always be wars, no matter how hard people try to prevent them. (E)

a. In the long run people get the respect they deserwe in this wotd.

b. Unfortunately, an individual's worth of ten passes unrecognized no natter liow hard he tries. (E)

a. The idea that superiors are tnfair in assessing young managers is monsense.

b. Most young managers don't realize the extent to which their assessment is anfluenced by accidental happerings. (E)

Without the right breaks one cannot be an effective leader. (E)

b. Capable people who fail to become leaders have not laken advanage of their opportumities.

a. No matter how hard you try some people just dont like you. (E)

b. People who cant get others to like them don't understand how to gett along with others 
11. (F) a. People pay too much aftention to body culture

b. Sports ara an excellent way to build character. (S)

12. (R) a. I have often found that what is going to happen will happen. (E)

b. Trusting to fate has never turned out as well for me as making a decision to take a definite course of action.

13. (F) Women don't get to the top as easy as men because they have always been discriminated. (S)

b. Women are not as able as men to hold leadership positions.

14. (R) A. A hard wotking young manager can hardly ever receive an unsatisfactory assessment.

b. Most of the time there is hardly any connection between a young manager's performance and his assessment, which implies that working hard is relatively useless. (E)

15. (F) a. Children get too much homework, there isn't enough time to play and relax. (S)

b. Mosit children only want to play so that it is wnlikely that they shall have a successful carreer.

16. (1) a. Sports is no good, you only get injured.

b. Sports is good for health. (S)

17. (R) a. Becoming a success is a matter of hard work, luck has little or nothing to do with it.

b. Getting a good job depends mainly on being in the right place at the right time. (E)

18. (R) a. The average citizen can have influence in government decisions.

b. This world is run by the few people in power, and there is not much the little guy can do about it. (E)

19. (F) al people can't look out for themselves. They should be placed in a home.

b. Aged persons should have the possibility to live on their own as long as possible. (S)

20. (R) a. When I make plans, I am almost certain that I can make them work.

b. It is not always wise to plan too far ahead because many things turn out to be a matter of good or bad fortune any how. (E)

21. (1) a. Violence on TV gives rise to aggressive behavior of children. (S)

b. Violence on TV gives children the opportunity to work of their aggressive feelings.

22. (R) a. In my case getting what I want has little or nothing to do with luck.

b. Many times we night as well decide what to do by flipping a coin. $(\mathbb{E})$

23. (R) Who gets to be the boss often depends on who was lucky enough to be in the right place first. (E)

b. Getting people to do the right thing depends upon ability, luck has little or nothing to do with it.

24. (R) As far as world affairs are concerned, most of us are the victims of forces we can neither understand, nor control. (E)

b. By taking an active part in political and social affairs the people can controll world eventsi.

25. (R) a. Most people don't realize the extent to which their lives are controlled by accidental happenings. (E)

b. There really is no such thing as "fuck". 
26. (R) a. It is hard to know whether or not anerson teally likes you. (E)

b. How many friends you have depends upon how nice a person you are.

27. (17) a. One should not boast when thang abilities that others do not have (S)

b. If an indidual has certan abilities, he has the right to mention it so that he gets the respect he deserves.

28. (R) In the long run the bad things that happen to us are balanced by whe good ones. (E)

b. Most misfortunes are the result of lack of ability, ignorance, laziness, or all thee.

29. (R) a. With enougheffort we can wipe out political corruption.

b. It is difficult for people to have much control over things politicins do in wftice. (E)

30. (RR) a. Sometimes If can't understand how my superiors arrive at their assessments of my work performance. (H)

b. There is a direct connection between how hard I work and how well I an assessed by my superiors.

31. (F) a. Nowadays, most people pay too nuch atiention to material things ant the expense of their mental well being. (S)

b. Striving for material wellfare makes life more pleasant.

32. F) a. Environmental pollution is the price society has to pay for achieving wellfare.

b. Nature can not be protected enough, even if it costs a lot of money. (S)

33. (F) The conditions of life in certain prisons are degrading. (S)

b. Many prisoners do not deserve a human treatmemt.

34. (R)

35. (R)

a. Many thmes I feel that I have little influence over the things that happen to me. (E)

b. It is impossible for me to believe that chance or luck plays an important role in my life.

a. People are lonely because they don't try to be friendly.

b. There's not much use in trying too hard to please peaple, if uhey like you, they like you (E)

36. (R) What happens to me is my own doing.

b. Sometimes I feel that I don't have enough control over the direction nuy life is taking. (E)

Most of the time 1 cant understand why politicians behave the way dhey do. ( $\mathrm{E}$ )

b. In the long nin the people are responsible for bad gowernment on a national as well as on a locallevel. 



\section{Appendix E}

Game planning scheme 


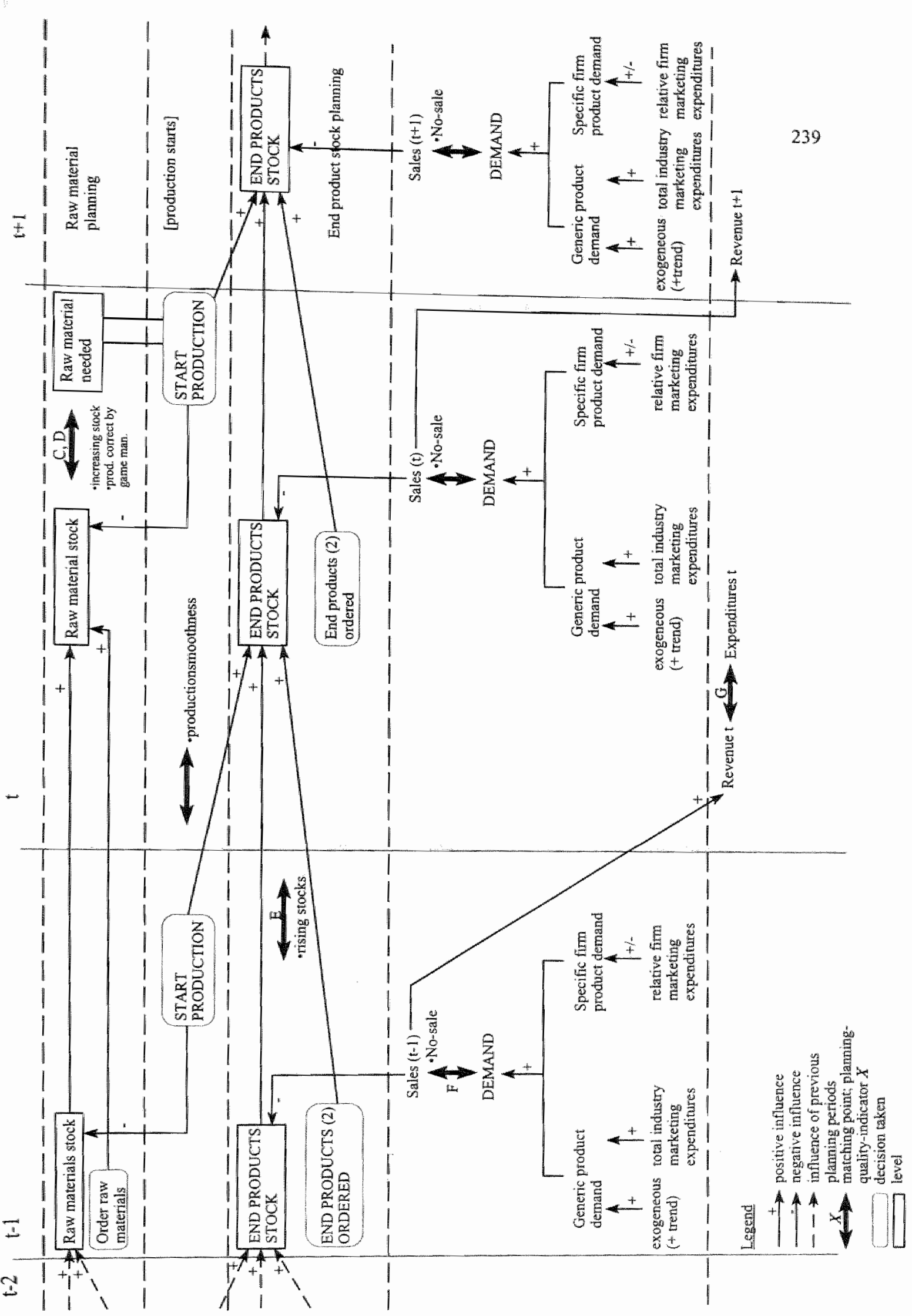




\section{Explanation of Appendix $\mathbf{E}$}

Appendix E provides an overview of the inter relationships between the different parts of the game and the influencing decisions. Square boxes indicate levels of certain variables; round boxes indicate a decision taken. In the remainder of this explanation each decision we mention will be followed by a bold figure in brackets, indicating its number on the decision form in Appendix B. Across the top we see a time line with vertical lines distinguishing different time periods over which the planning takes place. The time dimension is necessary as several lagged effects take place in the game (see the various lines and arrows crossing vertical time lines).

There are two broad and connected categories of planning issues in the game. First is the planning of production volumes through inputs (upper half of figure including "production starts'), second is the planming of outputs to the market (lower half of the figure including "production starts"). Productions starts function as a kind of linking pin between the two planning categories. We will describe both below.

\section{Production planning}

Central to this planning problem is the matching of available production factors (staff, raw materials and machine capacity) to the levels that are needed in order to reach the production objective in each period. This basic problem is depicted in the double vertical lines connecting staff needed, machine capacity needed and raw materials needed to the decision variable START PRODUCTION (17). The former three are confronted with their actual availability through the symbolic double arrow, indicating a planning 'moment of truth'. The capitals above arrows indicate these various planning points as they are explained in the main text. We will describe the three planning issues consecutively.

\section{i) Personnel planwing}

The change in total amount of staff is mainly influenced by the balance of staff bought (1) and hired (2) on the one hand and the turnover rate in the previous period on the other. Hiring contracts last two periods. The turnover rate has some base level ( $7 \%$ per period), which is, however, importantly affected by working conditions (10) and wage level (13). Bad firm performance and especially suspension of payments increase the turnover rate. To fire personnel, teams have to contact game management; it is not an option on the decision form. Firings are generally rare as they are very disturbing: they increase turnover and lower staff effectiveness, possibly via strikes. Staff effectiveness (i.e., the percentage of staff that is available for production) is further influenced by the wage level (13) and the working conditions (10). The occurrence of exogenous disturbances of effective staff capacity (industrywide strikes) are identical for all teams.

\section{ii) Machine capacity planning}

Analogous to personnel, machines can be either bought (3) or leased (4) (for two periods). Machines depreciate at a $5 \%$ rate per period. To scrap machine capacity, teams must contact game management; it is not an option on the decision form. Scrapping machines is very expensive: only $15 \%$ of their original value is received as compensation. 
iii) Raw maierials planning

Changes in raw materials stock is a resultant of raw materials orderings (14-16) in the previous. period and the use of raw materials in the production (17) of the current period.

\section{Output planning}

End products are sold to satisfy market demand. This demand shows a positive but different trend for all products. The general demand trend is (mildly) influenced by the total marketing expenditures of the industry. The demand for the products of a single firm within the industry depends on its relative marketing expenditures (19-23) vis-à-vis its competitors (see for instance effect curves in Figure 6.1).

\section{i) End products planning}

Changes in end products stock occur because of sales and new production (17). Additionally, with regard to product 2 , teams could choose to directly buy products externally $(7)$, i,e, not to produce them themselves.

\section{ii) Financial planning}

Sales lead to revenues one period later. Teams may decide to allow customers to pay a certain amount in a later period (8). In order to balance their revenues with their current expenditures, teams may borrow (5) and pay redemptions (6). 